ÂNGELO PARISE PINTO

Análise cladística de Sympetrinae Tillyard, 1917 com ênfase no grupo de armadura femoral especializada: os gêneros de 'Erythemismorpha' (Insecta: Odonata: Libellulidae)

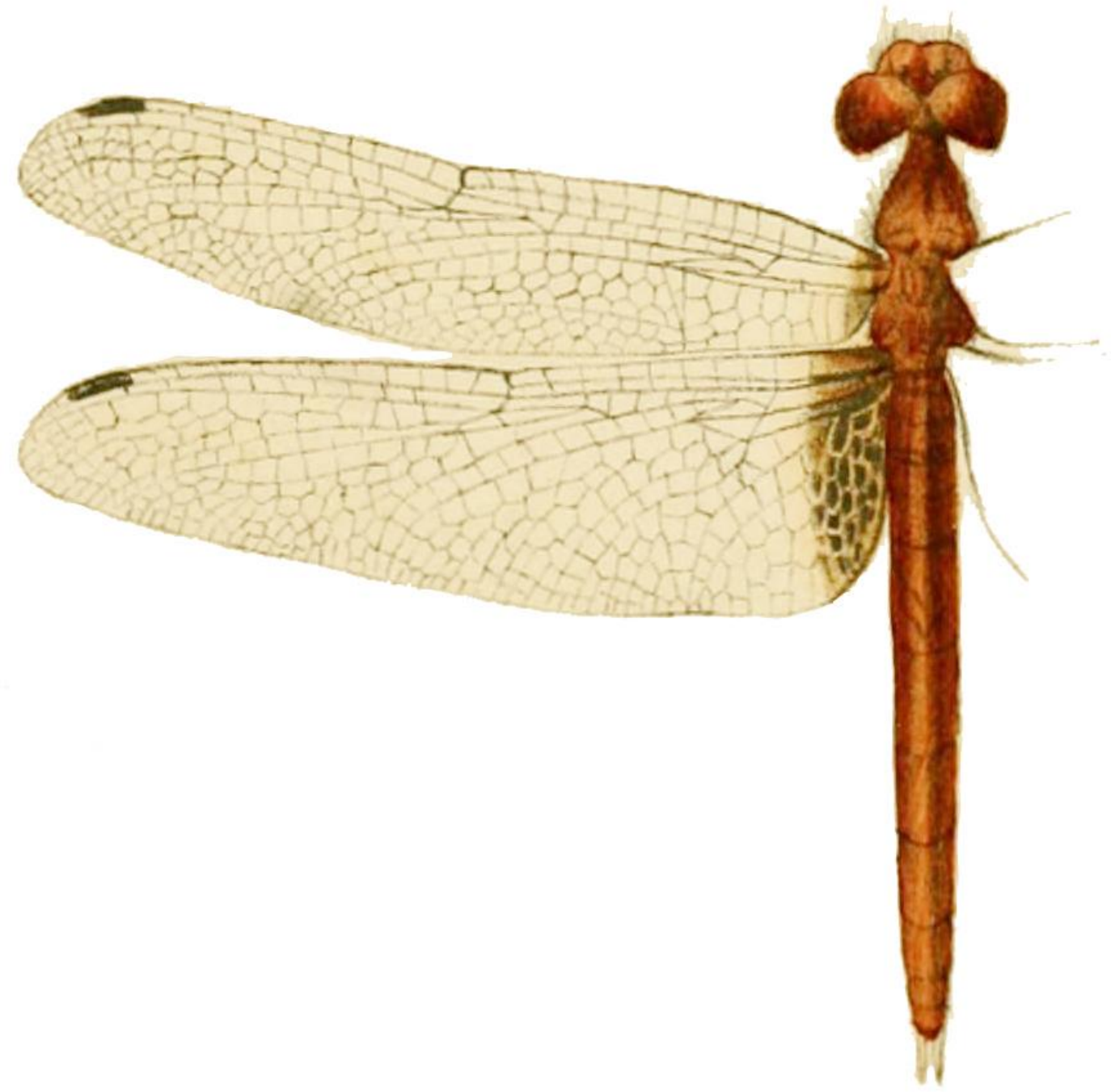

São Paulo 


\section{Análise cladística de Sympetrinae Tillyard, 1917 com ênfase no grupo de armadura femoral especializada: os gêneros de 'Erythemismorpha' (Insecta: Odonata: Libellulidae)}

A cladistics analysis of Sympetrinae Tillyard, 1917 with an emphasis in the group of specialized femoral armature: the genera of 'Erythemismorpha' (Insecta: Odonata: Libellulidae)

\footnotetext{
**Exemplar corrigido, original encontra-se depositado na biblioteca do Instituto de Biociências da USP**
}

Tese apresentada ao Instituto de Biociências da Universidade de São Paulo, para a obtenção de Título de Doutor em Ciências Biológicas, na Área de Zoologia.

Orientador: prof. Dr. Carlos José Einicker Lamas

Coorientador: prof. Dr. Alcimar do Lago Carvalho

São Paulo 
Pinto, Ângelo Parise

Análise cladística de Sympetrinae Tillyard, 1917 com

ênfase no grupo de armadura femoral especializada: os gêneros de 'Erythemismorpha' (Insecta: Odonata: Libellulidae)

$187 \mathrm{p}$.

Tese (Doutorado) - Instituto de Biociências da

Universidade de São Paulo. Departamento de Zoologia.

1. Erythemismorpha 2. Cladística 3. Homoplasia I.

Universidade de São Paulo. Instituto de Biociências.

Departamento de Zoologia.

**Exemplar corrigido, original encontra-se depositado na biblioteca do Instituto de Biociências da USP**

Comissão Julgadora:

Prof. Dr. Mário César Cardoso de Pinna

Prof. Dr. Pablo Pessacq
Prof. Dr. Marcelo Duarte da Silva

Prof. Dr. Carlos José Einicker Lamas

Prof. Dr. Taran Grant

Orientador

Capa: Erythemis mithroides (Brauer in Therese, 1900). Therese, Prinzessin von Bayern. (1900). Von Ihrer königl. hoheit der Prinzessin Therese von Bayer auf einer reise in SüdAmerika gesammelte insekten. II. Orthopteren. Berliner Entomologische Zeitschrift, 45, 253-268, prancha III. 


\begin{abstract}
Aviso
A presente tese é parte dos requisitos necessários para obtenção do título de Doutor na área de Zoologia, e como tal, não deve ser vista como uma publicação no senso do Código Internacional de Nomenclatura Zoológica (apesar de disponível publicamente sem restrições). Dessa forma, quaisquer das opiniões e hipóteses apresentadas, assim como novos nomes, não estão disponíveis na literatura Zoológica. Pessoas interessadas devem estar cientes de que referências públicas ao conteúdo deste estudo, na sua presente forma, devem somente ser feitas com aprovação prévia do autor.
\end{abstract}

\title{
NOTICE
}

This thesis is a partial requirement for PH. D. degree in Zoology and, as such, it should not be considered as a publication in the sense of International Code of Zoological Nomenclature (although is available without restrictions). Therefore, any new information, opinions and hypotheses, as well as new names, are not available is the zoological literature. Interested people are advised that any public references to this study, in its current form, should only be done after previous acceptance of the author. 
Aos meus avós paternos Arthur (in memoriam) e Maria, À minha mulher Janaína 
Nas pegadas das minhas botas, trago as ruas de Porto Alegre

E na cidade dos meus versos, o sonho dos meus amigos

Caminhando pelas ruas de uma cidade Americana

Eu percebo que não quero migalhas nem tampouco medalhas isso tudo é ilusão Vendo as mesmas mentiras num país desenvolvido armado até os dentes para a guerra me dói o coração Perceber a situação em que estamos envolvidos sem perspectivas de qualquer solução

É quando penso na razão que nos leva a acreditar Que estamos mudando um país uma voz vem lá de dentro que me diz

Que o sistema no fundo é o mesmo e em nós se perpetua E não cabe mais aqui e agora essa máquina que nos fez aprendiz de um poder vagabundo

E não podemos mais desperdiçar energia Com uma vazia retórica estética amordaçando o grito de um coração Que luta contra toda falta de perspectiva e informação do pensamento Abatido pelos mísseis imperialistas dentro de sua própria nação Com toda falta de cultura, sensibilidade, amor, respeito e educação

E fico puto ao constatar que desperdiçamos tempo parados em segredo Bebendo num bar que nos feriu a memória e nos tirou a força humana O único sentido de revolução de um ser, o objetivo intrínseco de um homem novo de qualquer geração Para toda e qualquer falta de possibilidade tem que haver reação

E agora eu sei que o que nos ensinou a esperar inutilmente Foi a burocracia, o misticismo e a religião, esperar por Deus, por alimento, pão Esperar que as coisas mudem num próximo momento E eu atento contra a culpa e o sofrimento judaico-cristão

Contra toda dúvida e medo com muita insatisfação

Caminhando pelas ruas de uma cidade Americana Eu lembro o poeta Duclós que disse "estar a salvo não é se salvar" E eu complementaria hoje em dia se sentir salvo é esperar pela salvação E nada nos salvará Um dia, ainda, nos aniquilarão parodiando Russians do Tting eu também diria Então espero que os brasileiros amem muito seus filhos, de coração

Nas pegadas das minhas botas, trago as ruas de Porto Alegre E na cidade dos meus versos, o sonho dos meus amigos 
Essa seção é uma das mais curiosas de um trabalho de tese, considerando que o autor mescla sentimentos dos mais variados no momento em que é escrita, como o de alívio, frustação por não ter alcançado parte dos objetivos e de certo modo (mas pouco) o sentimento de dever cumprido. Obviamente, gostaria de agradecer a todos que de forma direta ou indireta contribuíram para a realização desta tese; para a minha formação pessoal e profissional e em especial as seguintes pessoas e instituições listadas abaixo. Reservo o direito de não fazer referência direta a pessoas em alguns casos para poupar espaço, portanto peço desculpas por algumas pequenas omissões, saibam que vocês colaboram significantemente durante esta jornada.

A CAPES e ao programa de Pós-graduação em Zoologia pela concessão da bolsa de estudos, sem a qual este trabalho não seria possível.

Aos meus orientadores Profs. Carlos J. E. Lamas e Alcimar L. Carvalho pela confiança, respeito, compreensão das dificuldades enfrentadas, assim como paciência durante os momentos mais difíceis nessa etapa final um pouco "turbulenta" da realização deste trabalho, recebam meus sinceros agradecimentos.

Aos curadores e odonatólogos que gentilmente cederam material de suas coleções: J. M. Costa (MNRJ), N. Ferreira-Jr. e J. L. Nessimian (DZRJ), D. R. Paulson, (DRP), O. S. Flint (USNM), W. Mauffray (FSCA), P. Tirenella (INHS), P. de Marco Jr. e L. Juen (UFG), M. O’Brien (UMMZ), A. Rafael (INPA), S. Casari (MZSP) e J. Muzón (ILPLA) em especial aos amigos Angelo B. M. Machado (ABMM) e Rosser W. Garrison (RWG), por não terem medido esforços para que eu tivesse acesso ao material importante, em grade parte raro, sem o qual esse trabalho não seria possível.

Aos odonatólogos, não mencionados acima, T. W. Donnelly, N. von Ellenrieder, M. L. May, H. K. Pfau, K-.D. Dijkstra, J. van Tol, G. Theischinger, J. Daigle e G. Fleck pela troca de informação sobre as mais diversas questões referentes à odonatologia.

A todos do Laboratório de Hemiptera do Museu Nacional (UFRJ) chefiado pelo Prof. Gabriel Mejdalani, pelo companheirismo, discussões acaloradas sobre cladística e descontração na hora do almoço, em especial a Raquel Carvalho pela "via de mão dupla".

Aos amigos dipteristas (termo horrível!) do MZUSP pelo auxílio durante minha passagem pela instituição, pela amizade e troca de informações em especial ao Ramon, Julia e 
Lucas. Ao Carlos que permitiu que eu tivesse livre acesso ao rico material depositado na coleção de Odonata.

Aos professores Marcelo Duarte e Sônia Casari (MZUSP) pelo auxílio durante a realização da etapa de monitoria do programa de aperfeiçoamento de ensino (PAE, não tem nada a ver com endemismo!) em sua disciplina.

A profa. C. A. Mello-Patiu, A. P. L Giupponi e J. S. Silva pelo auxílio nas duas expedições à Reserva Ecológica de Guapiaçu em busca das larvas de Erythemismorpha.

Aos cladistas M. C. C. de Pinna (MZUSP) e L. C. S. Assis (UFMG) pelas discussões sobre homologia (ou homoplasia?).

Aos bromeliólogos do Museu Nacional e laboratórios agregados, Ricardo, Adriana, etc. pela companhia nas coletas e mesas de bar (alguns apenas em mesas de bar).

Aos fotógrafos que gentilmente cederam suas belíssimas imagens oriundas dos mais variados cantos do planeta, C. Cohen; D. Nys, O. Kosterin, H. Leinsinger, N. Mézière, em especial ao T. Kompier, meus sinceros agradecimentos.

Aos meus familiares e amigos, meus pais Ângela e Júlio, minha irmã Paula "Neatherslands", minha avó Maria, assim como minha madrasta Eunice, Thayana "Hobbit Lulu" e a meu sogro Abílio por todo carinho e incentivo, pela dedicação despendida na minha educação, por sempre estarem dispostos a "contribuir" quando preciso, pela amizade, "patrocínio", confiança etc.

Finalmente à minha mulher, companheira e cúmplice Janaína, por estar ao meu lado todo esse tempo, pela imensa (nem tanto) paciência com meu modo de encarar a vida, em minha insistência com discussões sobre libélulas e cladística, saiba que grande parte desse trabalho é dedicada a você. 
Libellulidae compreende a maior família de Anisoptera com mais de mil espécies, sendo uma das mais abundantes de Odonata. As investigações do padrão de relacionamento filogenético entre os gêneros dessa família têm sido demonstradas complexas, com hipóteses largamente divergentes, sendo as análises consideradas complicadas. Nesse trabalho é apresentada pela primeira vez uma análise cladística de uma de suas maiores subfamílias 'Sympetrinae' baseada em 171 caracteres morfológicos de adultos com ênfase no grupo com a armadura femoral especializada (Erythemismorpha) que contém os gêneros Acisoma, Carajathemis, Cyanothemis, Erythemis, Porpax, Rhodopygia, Rhodothemis e Viridithemis. Representantes de quase todas as subfamílias de Libellulidae, assim como de todos os gêneros de 'Sympetrinae' foram incluídos, totalizando 69 táxons terminais. Essa ampla amostragem objetivou testar de modo robusto o monofiletismo de Erythemismorpha e identificar grupos monofiléticos em 'Sympetrinae'. Duas análises diferentes foram executadas uma com a parcimônia de Fitch e outra a de Sankoff, ambas com diferentes esquemas de ponderação de caracteres. A parcimônia de Sankoff foi utilizada para minimizar a influência dos "gaps" e demonstrou ser inapropriada para cálculos de índices de estabilidade com técnicas de reamostragem devido às exigências computacionais. Erythemismorpha foi demonstrado monofilético e além dos gêneros previamente citados inclui pelo menos Erythrodiplax castanea. Os gêneros Rhodothemis, Rhodopygia e Acisoma também tiveram suas hipóteses de monofiletismo suportas, enquanto Erythemis demonstrou ser parafilético em quase todas as árvores contrariando resultados anteriores. A maior parte dos nós internos de Eyrthemismorpha é inconclusiva, no entanto Cyanothemis + Porpax, assim como Carajathemis + Rhodopygia apresentaram suporte alto. A composição completa de Erythemismorpha permanece em aberto e dados de outras fontes devem ser incorporados. Também são discutidos extensivamente alguns conceitos equivocados sobre homoplasia e suas implicações em relação aos caracteres da venação alar em Anisoptera, advogando em favor da prevalência do padrão sobre o processo no paradigma da cladística. Defende-se homoplasia como um erro, um erro no estabelecimento da homologia primária, portanto, convergência reversão e conceitos similares, ligados ao processo e fortemente dependes de hipótese ad hoc não são concretos e tampouco observados no mudo real.

Palavras-Chave. Libélulas, filogenia, Erythemismorpha, Homologia, Libellulidae. 
Libellulidae comprises the largest family of Anisoptera with more than a thousand of species and one of the most abundant among dragonflies' families. The investigations of its phylogenetic pattern of relationships, especially among their genera have been shown complex, with widely divergent hypotheses, and considered tricky. A first cladistic analysis of 'Sympetrinae' based on 171 characters from adults morphology, with an emphasis on the 'armed leg group' (Erythemismorpha) including the genera Acisoma, Carajathemis, Cyanothemis, Erythemis, Porpax, Rhodopygia, Rhodothemis and Viridithemis is presented here. Representatives of almost all Libellulidae subfamilies, as well as all genera of 'Sympetrinae' were also included, summing up a total of 69 terminal taxa. This broad sampling aimed to provide a strong test to hypothesis of monophyly of Erythemismorpha and identify monophyletic groups in 'Sympetrinae'. Two different analyzes were performed, each Fitch and Sankoff parsimony, both with distinct weighting schemes. The Sankoff parsimony was adopted to minimize the influence of 'gaps' on the results, but proved be inappropriate for to obtain stability indexes with resampling techniques, due to the high cost of computational requirements. Erythemismorpha was shown be monophyletic and further than to those genera previously cited, also includes, at least Erythrodiplax castanea. The genera Acisoma, Rhodothemis, and Rhodopygia were has each their hypotheses of monophyly also supported by the analyses performed here, however Erythemis showed be paraphyletic in almost all trees contradicting previous results. Almost all of the internal nodes of Erythemismorpha are inconclusive, however Cyanothemis + Porpax, as well as Carajathemis + Rhodopygia presents both high support. The entire composition of Erythemismorpha still open, pending the inclusion of other data sources. Also was discussed the misconceptions about homoplasy and its implications on venational characters of Anisoptera dragonflies. Is advocated the already discussed prevalence of pattern over process in cladistics paradigm. Homoplasy in cladistics is an error, more precisely an error of establishment of homologues (primary homology), thus convergence, reversal and similar terms are process tied ad hoc hypotheses over a pattern of inclusive hierarchy and not is concrete neither observable in real world.

Keywords. Dragonflies, phylogeny, Erythemismorpha, Homology, Libellulidae. 


\section{SUMÁRIO}

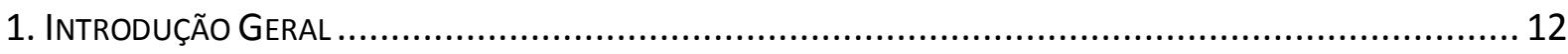

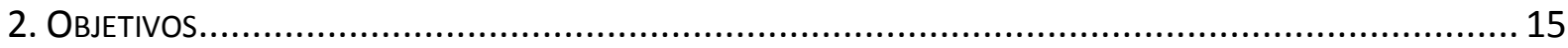

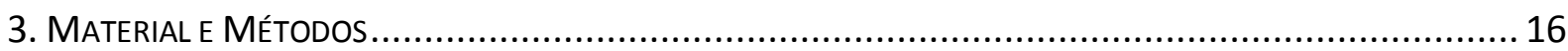

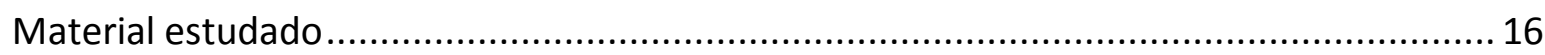

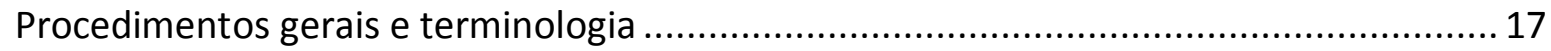

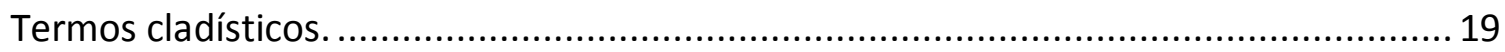

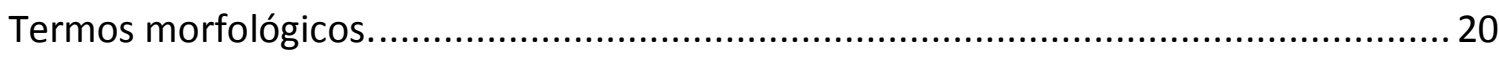

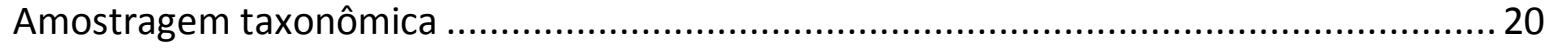

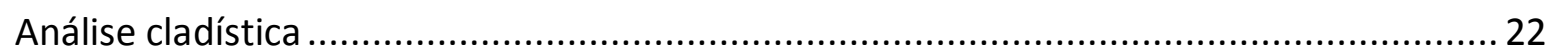

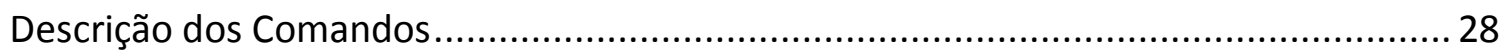

4. BREVE HISTÓRICO DA FILOGENIA E CLASSIFICAÇÃO DE OdONATA COM ÊNFASE EM 'ERYTHEMISMORPHA' ..... 34

5. NOMENCLATURA DOS GÊNEROS ERYTHEMIS, LEPTHEMIS E MESOTHEMIS ....................................... 44

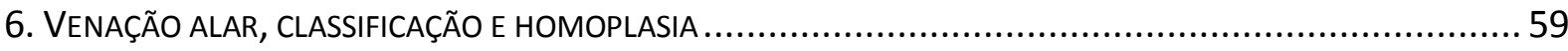

Existem verdadeiros sistemas de classificações para Odonata? .................................... 61

A "Natureza" homoplástica dos caracteres da venação alar ........................................ 63

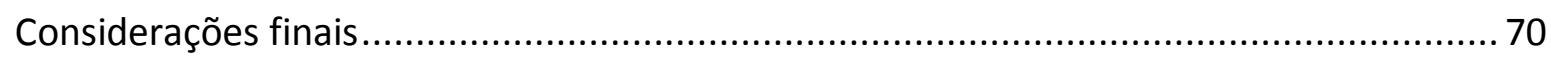

7. ANÁLISE CLADÍSTICA DE SYMPETRINAE S. L.COM ÊNFASE EM ERYTHEMISMORPHA................................. 73

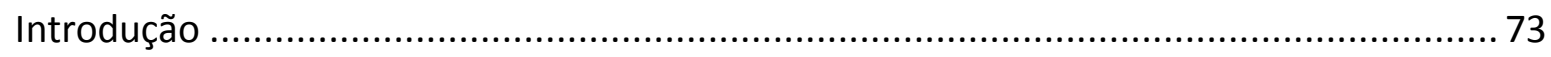

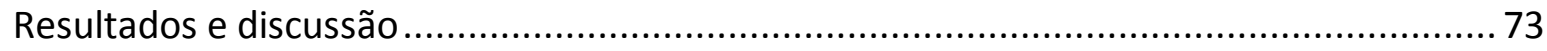

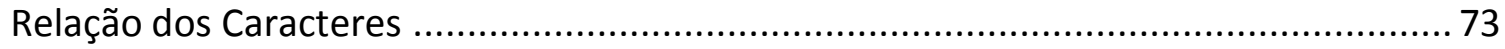

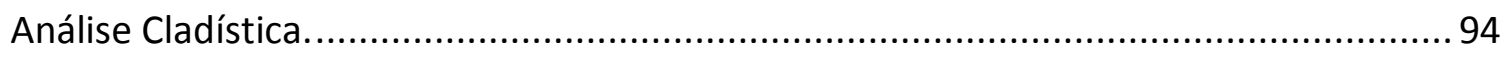

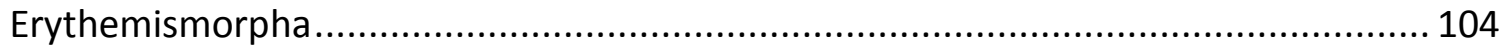

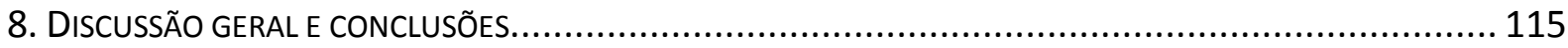

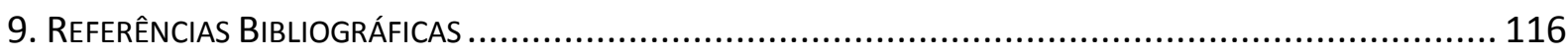

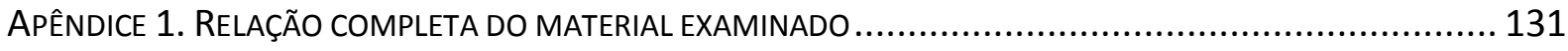

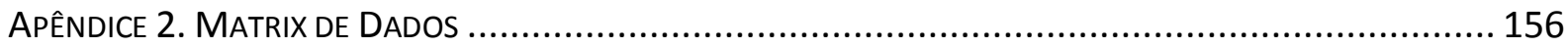

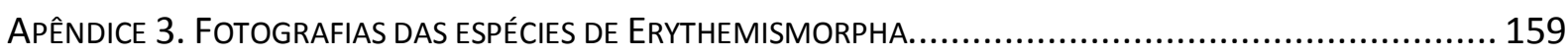

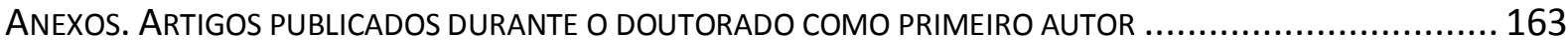




\section{INTRODUÇÃO GERAL}

Odonata reúne os insetos popularmente conhecidos como libélulas, são importantes predadores em uma grande variedade de ambientes de água doce e devido à facilidade de observação no campo se tornaram organismos modelos para pesquisas comportamentais, ecológicas e evolutivas (Corbet 1999; Córdoba-Aguilar 2008). Suas espécies, as quais exibem voo elegante e cores vistosas, possuem grande apelo popular principalmente no hemisfério norte onde guias de campo e manuais são relativamente comuns e de interesse do público leigo em geral (e.g. Needham et al. 2000).

São insetos hemimetabólicos com a fase juvenil aquática e a adulta terrestre (Corbet 1999). Os imaturos passam por oito a dezoito estádios até a emergência (Corbet 2002). Desenvolvem-se predominantemente em ambientes dulçaquícola típicos, lóticos e lênticos, desde pequenos locais com acúmulo de água pluvial, como em reservatórios nas bainhas de Bromeliaceae até grandes rios ( $c f$. Corbet 1999; Clausnitzer \& Lindeboom 2002). Algumas espécies desenvolvem-se em áreas de água salobra (Dunson 1980) ou mesmo em ambiente terrestre, vivendo sob a camada de serapilheira no interior de florestas úmidas (Watson 1982). O número de gerações por ano, i.e. voltinismo, é variável e considerado inversamente proporcional à latitude de ocorrência das espécies podendo ser bi ou multivoltinas nos trópicos, enquanto univoltinas, semivoltinas e partivoltinas nas regiões temperadas do globo (Corbet et al. 2005).

Os adultos são predominantemente heliófilos, comumente encontrados em áreas abertas com alta incidência solar (Corbet 1999). Algumas espécies são crepusculares (Garrison et al. 2006) ou até mesmo noturnas (Corbet 1999). Tanto as larvas como os adultos são predadores vorazes, generalistas, e devido eventualmente se alimentarem de insetos prejudiciais aos seres humanos, são considerados de modo geral benéficos. São reconhecidos como exímios voadores, geralmente capturam suas presas em voo com auxílio de suas pernas raptoriais providas de espinhos especializados (Corbet 1999).

Estima-se que existam 5600 espécies atuais, distribuídas em todas as regiões biogeográficas, sendo as regiões Neoguineana, Neotropical e Oriental com o maior número de espécies (Kalkman et al. 2008). Apesar de comparativamente possuir um menor número de espécies que as ordens megadiversas de Holometabola, sua posição singular na filogenia de Pterygota torna o estudo dessa ordem chave para compreensão da evolução dos insetos (Ogden \& Whiting 2003; Simon et al. 2009; Ballare \& Ware 2011), já que pertence a uma das 
primeiras linhagens a divergir do ramo principal dos insetos alados, sendo o fóssil mais antigo datado entre o Permiano Superior e Jurássico Inferior, há cerca de 250 e 208 milhões de anos (Ma) (Grimaldi 2001).

A presente tese se refere em sua maior extensão à análise cladística da subfamília 'Sympetrinae' incluída em Libellulidae, a mais rica da subordem Anisoptera. Está dividida em Capítulos que correspondem a documentos integrais ou parciais, os quais se referem a artigos publicados, submetidos e ou em preparação. A leitura dos Capítulos 2-3 é obrigatória, pois detalham os objetivos, assim como os métodos e procedimentos gerais adotados nos capítulos subsequentes. No Capítulo 4 é apresentado um breve histórico dos estudos taxonômicos e filogenéticos do grupo aqui estudados, contextualizando o estudo, em seguida no Capítulo 5 um artigo em sua forma completa sobre a nomenclatura de um dos gêneros analisados é também apresentado. No Capítulo 6 é realizada uma ampla discussão de aspectos teóricos envolvendo os conceitos de homoplasia e classificação, sendo destacado que muitos dos conceitos têm sido aplicados de modo equivocado.

O Capítulo 7 se refere ao conteúdo principal da tese em que uma análise cladística de 'Sympetrinae' com ênfase em Erythemismorpha é apresentada e discutida. Seguido pelas conclusões e referências de todos os capítulos exceto desse.

\section{Referências}

Ballare, E. F. \& Ware, J. L. (2011). Dragons fly, biologists classify: an overview of molecular odonate studies, and our evolutionary understanding of dragonfly and damselfly (Insecta: Odonata) behavior. International Journal of Odonatology, 14, 137-147.

Clausnitzer, V. \& Lindeboom, M. (2002). Natural history and description of the dendrolimnetic larva of Coryphagrion grandis (Odonata). International Journal of Odonatology, 5, 29-44.

Corbet, P. S. (1999). Dragonflies: Behavior and Ecology of Odonata. Ithaca: Cornell University Press.

Corbet, P. S. (2002). Stadia and growth ratios of Odonata: a review. International Journal of Odonatology, 5, 45-73.

Corbet, P. S., Suhling, F. \& Soendgerth, D. (2005). Voltinism of Odonata: a review. International Journal of Odonatology, 9, 1-44.

Córdoba-Aguilar, A. (2008). Dragonflies and Damselflies: Model organisms for ecological and evolutionary research. Oxford: Oxford University Press. 
Dunson, W. A. (1980). Adaptations of nymphs of a marine dragonfly, Erythrodiplax berenice, to wide variations in salinity. Physiological Zoology, 53, 445-452.

Grimaldi, D. (2001). Insect evolutionary history from Handlirsch to Hennig, and beyond. Journal of Paleontology, 75, 1152-1160.

Garrison, R.W., von Ellenrieder, N. \& Louton, J. A. (2006). Dragonfly genera of the New World: an illustrated and annotated key to the Anisoptera. Baltimore: The John Hopkins University Press.

Kalkman, V. J., Clausnitzer, V., Dijkstra, K.-D.B., Orr, A. G., Paulson, D. R. \& van Tol, J. (2008). Global diversity of dragonflies (Odonata) in freshwater. Hydrobiologia, 595, 351363.

Needham, J. G., Westfall Jr., M. J. \& May, M. L. (2000). Dragonflies of North America. Gainesville: Scientific Publishers.

Ogden, H. T. \& Whiting, M. F. (2003). The problem with “'the Paleoptera Problem:'” sense and sensitivity. Cladistics, 19, 432-442.

Simon, S., Strauss, S., von Haeseler, A. \& Hadrys, H. (2009). A Phylogenomic Approach to Resolve the Basal Pterygote Divergence. Molecular Biology and Evolution, 26, 27192730.

Watson, J. A. L. (1982). A truly terrestrial dragonfly larva from Australia (Odonata: Corduliidae). Journal of the Australian Entomological Society, 21, 309-311. 


\section{OBJetivos}

O objetivo principal desse trabalho é contribuir para a compreensão do padrão evolutivo em Libellulidae por meio da realização de análises filogenéticas da subfamília 'Sympetrinae', os objetivos listados abaixo correspondem aos específicos:

1. Estudar a nomenclatura dos gêneros de Erythemismorpha;

2. Realizar um estudo comparativo da morfologia externa de Sympetrinae para incluir em uma análise cladística;

3. Testar o monofiletismo da 'Sympetrinae' com a inclusão de pelo menos um representante de cada gênero da subfamília e assim identificar grupos monofiléticos;

4. Testar o monofiletismo dos gêneros Acisoma Rambur, 1842, Erythemis Hagen, 1861, Rhodopygia Kirby, 1889 e Rhodothemis Ris, 1909;

5. Propor hipóteses de relacionamento entre as espécies dos gêneros de Libellulidae com armadura femoral especializada, o grupo Erythemismorpha sensu Pinto \& Carvalho (em prep.), mais os gêneros monotípicos Cyanothemis Ris, 1915, Carajathemis Machado, 2012 e Viridithemis Fraser, 1960;

6. Avaliar o nível de relacionamento do gênero Porpax Karsch, 1896 ('Brachydiplacinae') com o grupo estudado (Erythemismorpha); 


\section{Material e Métodos}

Os métodos, procedimentos e termos descritos nesta seção se referem a todos os capítulos subsequentes. A partir desse as referências serão relacionadas separadamente no final da tese, com exceção do Capítulo 5, com a nomenclatura do gênero Erythemis Hagen, 1861 em que segue o formato original como publicado.

\section{MATERial estudado}

Os espécimes examinados (total de 1205) estão depositados nas instituições relacionadas abaixo, com seus respectivos acrônimos, curadores e, quando disponível, também são fornecidos os endereços eletrônicos permanentes no formato Life Science Identifier (LSID) utilizado na base de dados digital Biodiverity Collections Index (BCI). Um resumo dos espécimes utilizados no estudo morfológico, com suas respectivas coleções de depósito, dados de procedência são fornecidos na Tabela 1, a lista completa com maior detalhamento pode ser consultada no Apêndice 1.

ABMM - Coleção particular Angelo B. M. Machado, Belo Horizonte, MG, Brasil (Angelo B. M. Machado registro Universidade Federal de Minas Gerais, http://biocol.org/urn:1sid:biocol.org:col:35287);

DRP - Coleção particular Dennis R. Paulson, Seattle, WA, E.U.A. (Dennis R. Paulson, http://biocol.org/urn:1sid:biocol.org:col:33253);

DZRJ - Coleção Entomológica Prof. José Alfredo Pinheiro Dutra, Departamento de Zoologia, Instituto de Biologia, Universidade Federal do Rio do Janeiro, Rio de Janeiro, RJ, Brasil (Jorge L. Nessimian e Nelson Ferreira-Jr., http://biocol.org/urn:lsid:biocol.org:col:35135);

FSCA - Florida State Collection of Arthropods/International Odonata Research Institute, Gainesville, FL, E.U.A. (William Mauffray, http://biocol.org/urn:1sid:biocol.org:col:1021);

INHS - Illinois Natural History Survey, Champaign, IL, E.U.A. (Paul Tirenella, http://biocol.org/urn:lsid:biocol.org:col:33527);

INPA - Instituto Nacional de pesquisas Amazônicas, Manaus, AM, Brasil (J. A. Rafael, http://biocol.org/urn:lsid:biocol.org:col:33531); 
MNRJ - Departamento de Entomologia, Museu Nacional, Universidade Federal do Rio do Janeiro, Rio de Janeiro, RJ, Brasil (Janira M. Costa, http://biocol.org/urn:1sid:biocol.org:col:33870);

MZSP - Serviço de Invertebrados, Museu de Zoologia, Universidade de São Paulo, SP, Brasil (Sônia Casari, http://biocol.org/urn:lsid:biocol.org:col:33949);

RWG - Coleção particular Rosser W. Garrison, Sacramento, CA, E.U.A. (Rosser W. Garrison, http://biocol.org/urn:lsid:biocol.org:col:34234);

UFG - Universidade Federal de Goiás, Goiânia, GO, Brasil (Paulo de Marco Jr.);

UMMZ - University of Michigan Museum of Zoology, Ann Arbor, MI, E.U.A. (Mark

O'Brien, http://biocol.org/urn:lsid:biocol.org:col:34475);

USNM - National Museum of Natural History, Smithsonian Institute, Washington, D.C., E.U.A. (Oliver S. Flint, http://biocol.org/urn:1sid:biocol.org:col:1019).

\section{Procedimentos gerais e terminologia}

A nomenclatura geral da morfologia foi baseada em Asahina (1954) e Garrison et al. (2006), exceto para os nomes específicos aqui introduzidos. A terminologia da venação alar segue o sistema proposto por Riek \& Kukalová-Peck (1984) incorporando as modificações posteriores as quais estão resumidas em Fleck et al. (2003) exemplificada na Fig. 1. Devido às dificuldades expostas por Pinto \& Lamas (2011) para o estabelecimento de declarações seguras de homologia primária ("homologização") para as estruturas da vesica spermalis em Libellulidae s.s. (excluindo todos os táxons de Corduliidae s.l.) utilizando a terminologia proposta por Pfau $(1971,2005,2011)$, adotamos provisoriamente os termos propostos por Miller (1990, 1991) o qual essencialmente corresponde ao mesmo sistema utilizado por Kennedy $(1922,1923)$ e Borror $(1931,1942)$, apesar dessa terminologia aparentemente não possuir correspondência com as estruturas "homólogas" em outras famílias ( $c f$. Pinto \& Lamas 2011). Os termos aqui empregados estão exemplificados na Fig. 2.

A vesica spermalis é a principal estrutura da genitália secundária a qual está diretamente ligada à cópula. Essa estrutura exclusiva de Odonata é extremamente complexa em Anisoptera, com um intricado sistema hidráulico, o qual permite a inflação e deflação controlada de seus mais variados lobos (Pfau 2011), atuando em uma função similar ao edeago encontrado nas demais ordens de Insecta. Muitas de suas estruturas são apenas observadas quando o órgão está completamente inflado. Para os estudos comparativos realizados nesse trabalho os espécimes foram relaxados com algumas gotas de solução de 


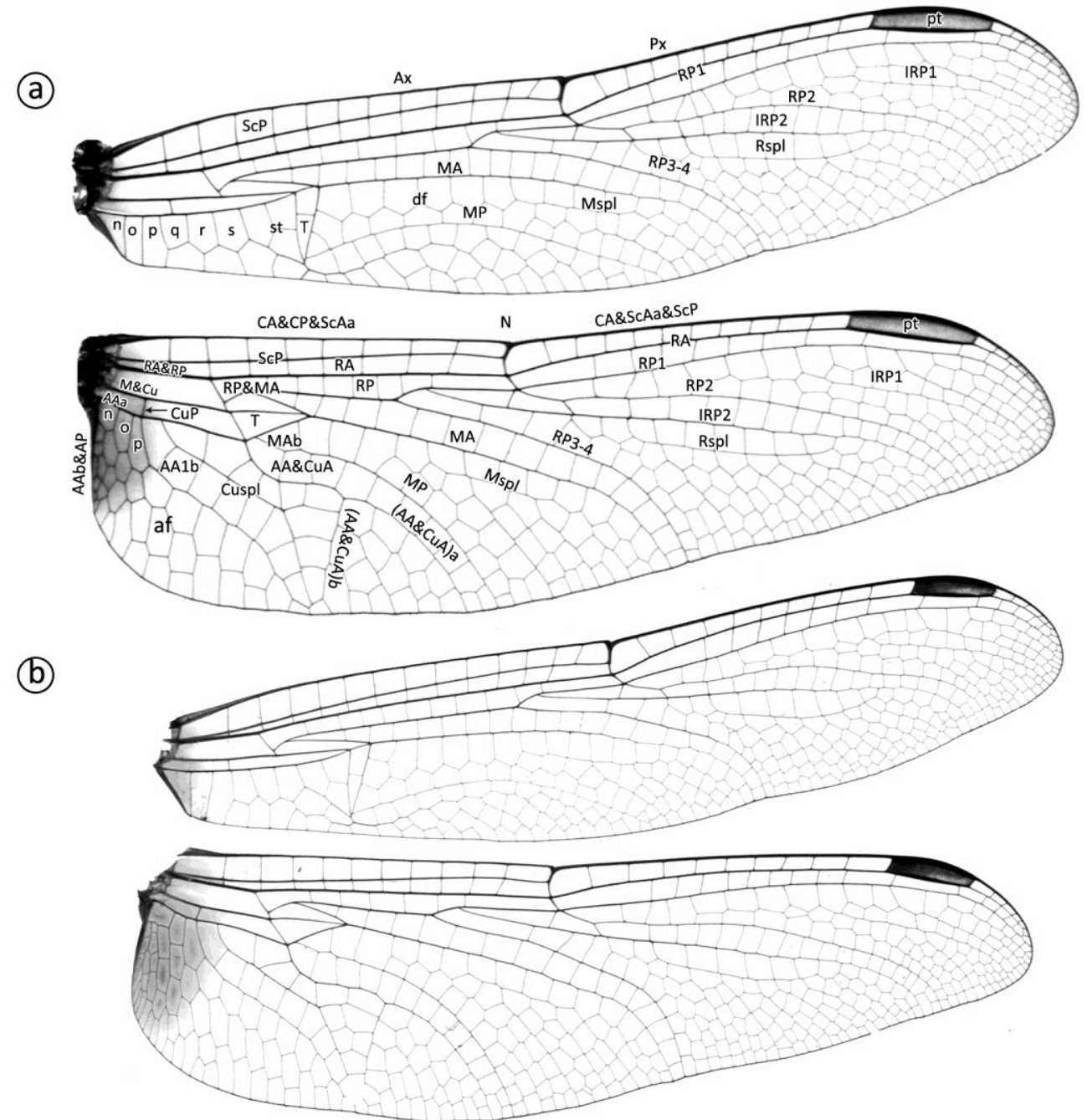

(C)

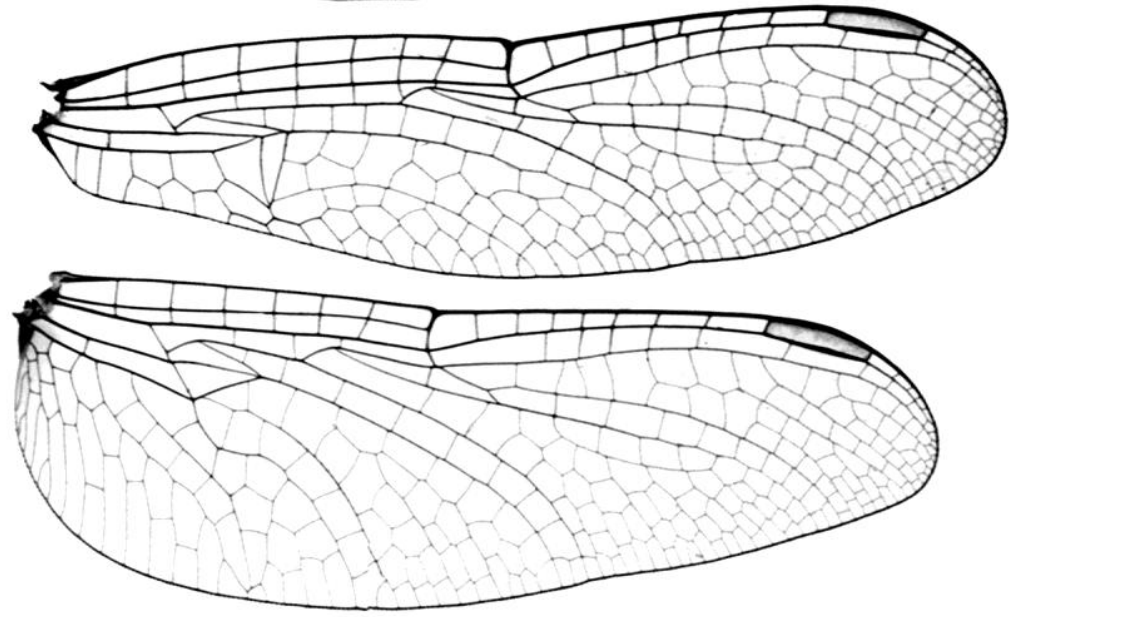

Figura 1. Asas de Erythemismorpha. a, Erythemis credula (Hagen, 1861); b, Rhodothemis rufa (Rambur, 1842); c, Acisoma panorpoides panorpoides Rambur, 1842. Sistema de abreviaturas segue Riek \& Kukalová-Peck (1984) com modificações sensu Fleck et al. (2003). 
amônia a $10 \%$ diretamente sobre o ventre do S2-3, sendo extraída juntamente com o esternito do S3 com o auxílio de agulhas histológicas, após foi macerada em solução de hidróxido de potássio $(\mathrm{KOH}$ a $10 \%)$ a temperatura ambiente por 12-72 horas. Posteriormente imersa em água por alguns minutos, seguida por uma solução contendo algumas gotas de ácido acético glacial para o tamponamento do processo. Geralmente a vesica spermalis infla após esse procedimento provavelmente devido à pressão osmótica ( $c f$. Santos 1945). Após o exame, as estruturas foram armazenadas em pequenos frascos cilíndricos de vidro contendo glicerol $\left(\mathrm{C}_{3} \mathrm{H}_{8} \mathrm{O}_{3}\right)$ e mantidas no interior do envelope de seu respectivo exemplar.

Caracteres estabelecidos com base nas estruturas da vesica spermalis têm sido amplamente utilizados em diversos estudos taxonômicos, muitas vezes como decisivos para a definição do status taxonômico de populações (e.g. Borror, 1942), além disso, mais recentemente, foram utilizados em análises filogenéticas em detrimento a outras fontes de dados como da venação alar (e.g. Pilgrim \& von Dohlen 2012). No entanto, possui grande plasticidade dificultando significativamente a correspondência entre suas estruturas ( $c f$. Miller 1991; Pfau 2011; Pinto \& Lamas 2011). Embora seja útil e apresente sinal filogenético em diferentes níveis, devido a essa plasticidade Miller (1991, p. 69) considerou como "poor guide to phylogenetics relationships". Portanto, algumas das estruturas aqui descritas podem ter sido erroneamente interpretadas, já que a maioria dos exemplares foi observada apenas em seu estado de repouso o que impede a visualização de algumas articulações e consequentemente dos respectivos lobos. Como destacado anteriormente por Pinto \& Lamas (2011) estudos mais abrangentes devem ser realizados em Libellulidae para que hipóteses de homologia com base nas estruturas da vesica spermalis sejam propostas com maior segurança.

Todas as medidas e as ilustrações foram elaboradas com o auxílio de um estereomicroscópio Zeiss V6 aumento de 80x, equipado com uma câmara clara, artefinalizadas em nanquim sobre papel vegetal e posteriormente digitalizadas e organizadas em pranchas. As abreviaturas abaixo mencionadas foram utilizadas ao longo do texto.

\section{TERMOS CLADÍSTICOS.}

Os termos foram preferencialmente utilizados em língua portuguesa conforme Amorim (2002), quando isso não foi possível se manteve no idioma original. No entanto as abreviaturas seguem as formas já consagradas em revistas especializadas. Uma exceção é o termo monofilia que é utilizado de modo inconsistente ao longo do livro de Amorim (2002, p. 46) e se optou pelo conceito do glossário em que é defendido o emprego do termo monofiletismo (p. 149). BSG = reamostragem Poisson (bootstrap) demonstrada em frequência relativa GC (grupo presente e contraditório); ch = caráter; $\mathrm{CI}=$ índice de 
consistência total; $\mathrm{ci}$ = índice de consistência específico do caráter; EW = peso igual; IW = peso implicado; $\mathrm{RB}=$ suporte de Bremer relativo; $\mathrm{MPT}(\mathrm{s})=$ para árvore(s) mais parcimoniosa(s); PF = parcimônia de Fitch; PS = parcimônia de Sankoff; SR = reamostragem simétrica (jackknife) demonstrada em frequência absoluta; SRG = reamostragem simétrica (jackknife) demonstrada em frequência relativa GC (grupo presente e contraditório); $\mathrm{K}=$ constante de concavidade; RI = índice de retenção total; ri = índice de retenção específico de um caráter.

TERMOS MORFOLÓGICOS.

$\mathrm{Ax}=$ veias transversais antenodais $\mathrm{Fw}=$ asa anterior; $\mathrm{Hw}=$ asa posterior $; \mathrm{LC}=$ carena lateral abdominal; $\mathrm{Px}=$ veias pós-nodais transversais; $\mathrm{pt}=$ pterostigma; $\mathrm{S} 1-10=$ segmentos abdominais $1-10 ; \mathrm{TC}=$ carena transversa abdominal; $\mathrm{VC}=$ carena ventral; $\mathrm{VS}=$ vesica spermalis; $\mathrm{V} 1-4=$ segmentos da vesica spermalis.

\section{AMOSTRAGEM TAXONÔMICA}

A lista completa das espécies selecionadas, com a respectiva indicação dos táxons do grupo-externo e grupo-interno é apresentada na Tabela 1. Assim, como será mencionado no capítulo seguinte, não há uma classificação, seja ela filogenética ou não, confiável para Libellulidae e, dessa forma, a disposição sistemática em subfamílias foi baseada no catálogo de Bridges (1994), embora diversas análises demonstrem a maioria como agrupamentos não monofiléticos (Ware et al. 2007; Fleck 2008; Pilgrim \& von Dohlen 2008). O status dos nomes específicos segue preferencialmente Garrison (2009) para as espécies com ocorrência para o Novo Mundo e para as demais regiões a base de dados digital "Taxonomy [Odonata]" (http://www.odonata.info/get?alias=odonata) mantida por Dr. Jan van Tol ao invés do catálogo do Bridges (1994) que se encontra desatualizado. A exceção do status dos nomes subespecíficos que refletem o julgamento taxonômico do próprio autor, sendo mencionados apenas quando há clara distinção entre as subespécies descritas ou para destacar que os espécimes utilizados se referem à espécie nominal.

Um total de 69 táxons terminais foi incluído neste estudo, representando todos os 23 gêneros atualmente incluídos em 'Sympetrinae' (Fraser 1957; Davies \& Tobin 1985; Bridges 1994). Apenas para os gêneros monotípicos Viridithemis Fraser, 1960 e Nothodiplax Belle, 1984 unicamente dados disponíveis na bibliografia e algumas fotografias foram utilizadas, já que os poucos exemplares conhecidos pertencem as suas respectivas série-tipo, estando indisponíveis para o presente estudo. 
(a)

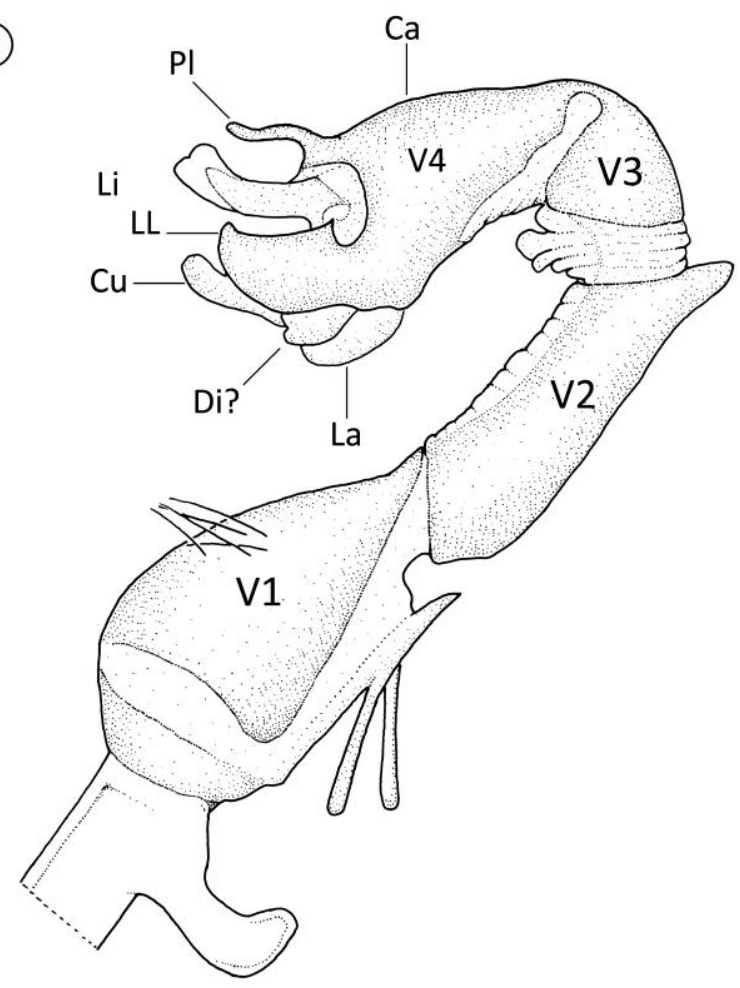

(b)

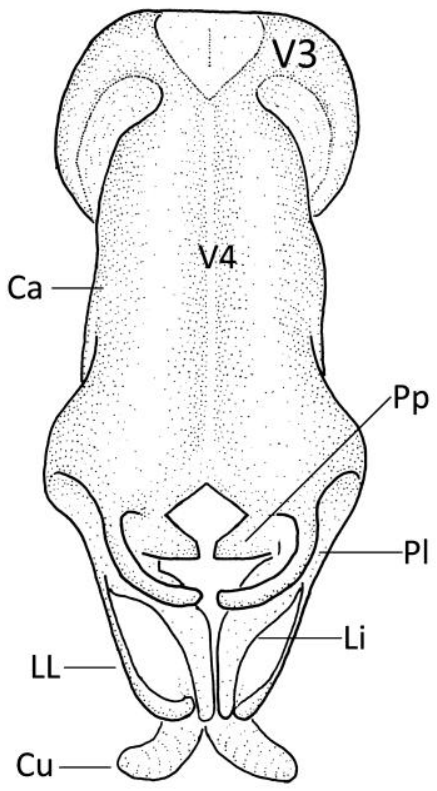

(c)

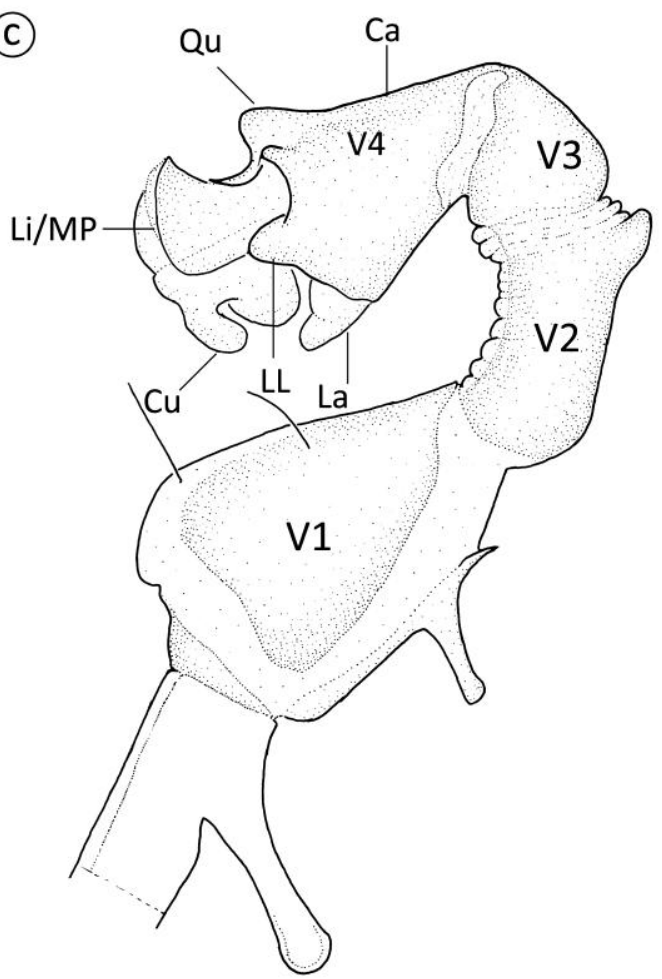

(d)

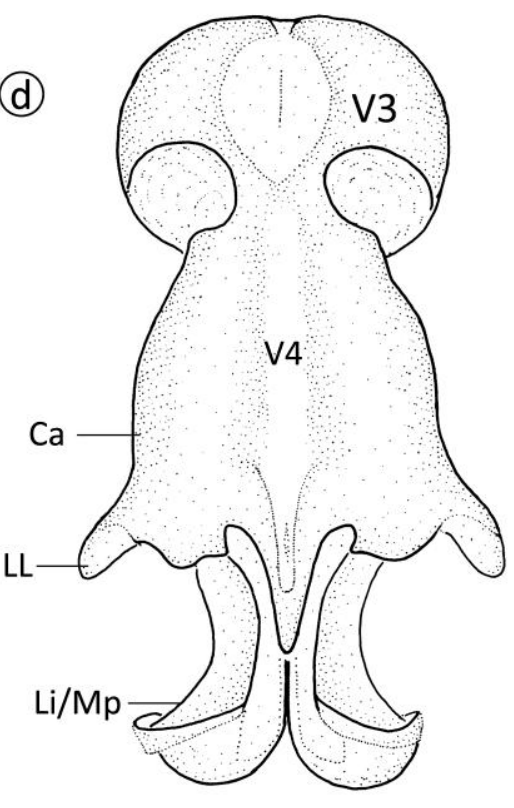

Figura 2. Vesica spermalis de Erythemismorpha, em vista lateral (a, c) e dorsal (b, d). a-b. Erythemis peruviana (Rambur, 1842); c-d. Rhodothemis lieftincki Fraser, 1954. Ca, capuz; Cu, cornua; Di, dobra interna do lobo lateral; La, lobo apical; Li, lobo interno; LL, lobo lateral; MP, processo mediano; Pl, processo lateral; $\mathrm{Pp}$, processo paramediano; Qu, quilha do capuz; V1-V4 segmentos da vesica. 
Devido a grande incerteza sobre o relacionamento filogenético entre os gêneros de Libellulidae, adicionalmente, espécies pertencentes às demais 11 subfamílias foram também amostradas, exceto Onychothemistinae que incluí apenas o gênero-tipo, o qual aparentemente é relacionado aos gêneros Zygonyx Selys in Hagen, 1867 (trópicos do Velho Mundo), Elasmothemis Westfall, 1988 e Orionothemis Fleck, Hamada \& Carvalho, 2009 (Neotropical) (cf. Fleck et al. 2009) uma linhagem aqui representada por duas espécies, i.e. Zygonyx ida Selys, 1860 e Elasmothemis cannacrioides (Calvert, 1906). A composição dos táxons terminais foi configurada para permitir um teste robusto ao monofiletismo de Erythemismorpha bem como permitir uma avaliação preliminar de suas relações com outros gêneros, assim, representantes dos gêneros Porpax Karsch, 1896, Nannothemis Brauer, 1868 e Nannophya Rambur, 1842 de 'Brachydiplacinae', foram também selecionados com base na possível relação filogenética próxima a 'Erythemismorpha' (Ris 1911; Lohmann 1984; Fleck 2004; Pilgrim \& von Dohlen 2007; Ware et al. 2007), bem como devido a sua semelhança morfológica. Sempre que possível foram incluídas pelo menos duas espécies de cada gênero de 'Sympetrinae'. Para os gêneros de Erythemismorpha tentou-se incluir o maior número de espécies possível, sendo que a totalidade das espécies de Erythemis Hagen, 1861 (10 spp.), Rhodopygia Kirby, 1889 (5 spp.) e os monotípicos Carajathemis Machado, 2012 e Cyanothemis Ris, 1915, assim como quatro das cinco espécies de Acisoma Rambur, 1842 e três das quatro espécies de Rhodothemis Ris, 1909 foram amostradas. A raiz foi inserida no ramo de Miathyria marcella (Selys in Sagra, 1857) desde que espécies deste gênero são consideradas distantes filogeneticamente aos gêneros aqui analisados (Pilgrim \& von Dohlen 2007; Ware et al. 2007) e, portanto, uma posição confiável para o posicionamento da raiz. O grupo-externo, que inicialmente poderia incluir todos os terminais os quais potencialmente não pertencem a Erythemismorpha, foi alterado para permitir a discussão de alguns dos relacionamentos aqui obtidos, assim, além de M. marcella também foram consideradas como grupos-externos as duas espécies de Macrodiplax Brauer, 1868, gênero o qual Fraser (1957) considerou como uma família, i.e. Macrodiplactidae (sic.), a parte de Libellulidae.

\section{ANÁLISE CLADÍSTICA}

As declarações (proposição de caracteres) iniciais de homologia (homologia primária sensu De Pinna 1991) foram estabelecidas seguindo o referencial teórico detalhadamente discutido por Fitzhugh (2006), em que um caráter é considerado inseparável de seus estados. No entanto, com a intenção de reduzir o comprimento das descrições dos caracteres optou-se 
por separar o "caráter" de seu "estado". Portanto o caráter "Margem posterior do epiprocto da fêmea em vista dorsal" e o estado "com uma concavidade central, dividindo-a em dois lobos" devem originalmente ser compreendidos como pertencentes à mesma sentença, da seguinte forma "Margem posterior do epiprocto da fêmea em vista dorsal com uma concavidade central, dividindo em dois lobos". Os dados morfológicos foram codificados em uma matriz de táxons por caracteres com auxílio do programa NEXUS Data Editor 0.5.0 (Page 2001) e exportados como arquivos do no formato NONA/Piwe e manualmente editados para serem lidos de modo adequado no programa TNT referido abaixo. A matriz de dados será futuramente depositada na base digital TreeBASE (http://treebase.org/), assim que o artigo referente for aceito para a publicação.

As análises foram realizadas utilizando o programa TNT versão 1.1 (novembro de 2012, Goloboff et al. 2008a) com algumas buscas complementares no PAUP* versão 4.0 beta 10 (Swofford 1998), especialmente para comparar as reconstruções mais parcimoniosas. Uma análise "simultânea" irrestrita aplicando a parcimônia cladística (sensu Farris 1983) foi realizada, com a polarização dos carácteres determinada após o enraizamento ( $c f$. Nixon \& Carpenter 1993a). Durante todas as estratégias de busca apenas árvores estritamente suportadas pelos dados foram investigadas, assim nós espúrios com comprimento mínimo igual a zero foram colapsados em todas as árvores (Nixon \& Carpenter 1996a). Os dados ausentes, seja devido à falta, inadequação do material, ou mesmo dúvida quanto sua correspondência, foram representados com “?”e aqueles não comparáveis com “-"na matriz de conjunto de dados (Apêndice 2). Embora não tenha sido feito nenhum esforço para detectar todas as autapomorfias, as mesmas foram incluídas na matriz de dados quando observadas como resultado da investigação cladística (Yeates 1992), porém, não computados para o cálculo do valor total do índice de consistência como discutido por Bryant (1995).

Os caracteres foram tratados como não ordenados (parcimônia de Fitch 1971) e com pesos iguais numa primeira aproximação, e os resultados comparados através do consenso estrito (Sokal \& Rohlf 1981). A ponderação implicada (IW, Goloboff 1993) aplicando diferentes valores para a constante de concavidade $(\mathrm{K})$ agindo como uma 'análise de sensibilidade' (Wheeler 1995; Goloboff et al. 2008b; porém veja Grant \& Kluge 2005 para um ponto de vista distinto) foi executada para determinar a hipótese primária de relacionamento discutida aqui. A decisão de qual valor de $\mathrm{K}$ a ser utilizado deve ser baseada na matriz de dados ( $c f$. Goloboff 1993; Goloboff et al. 2008b; Mirande 2009), mesmo que 
(a)

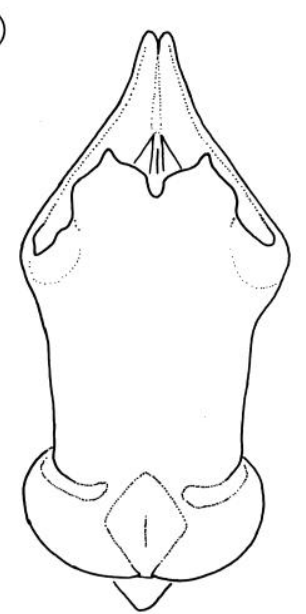

(d)

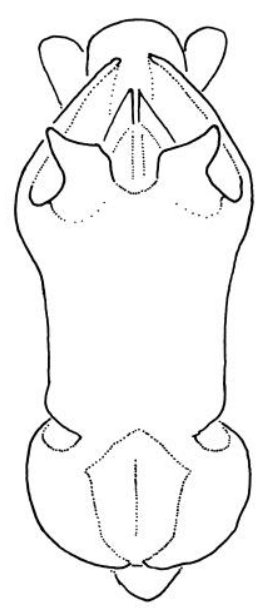

(g)

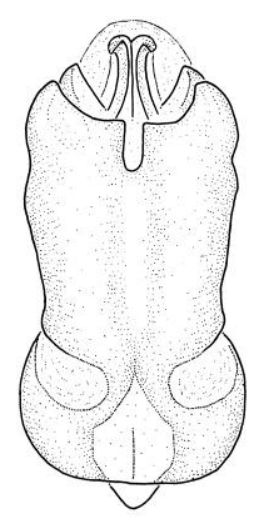

(b)

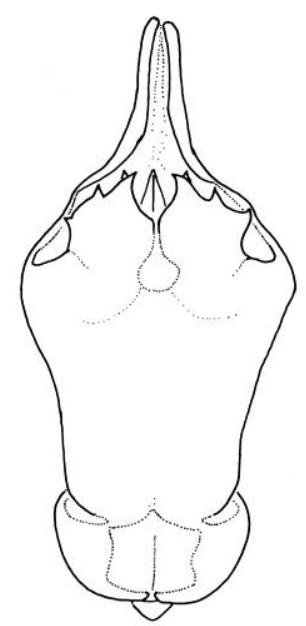

(e)

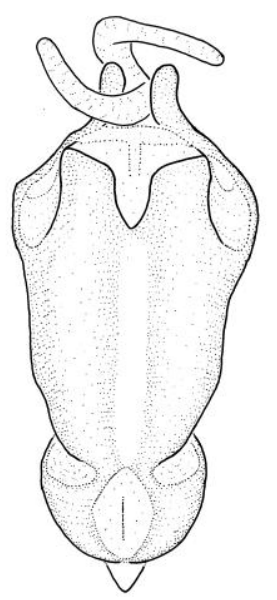

(h)

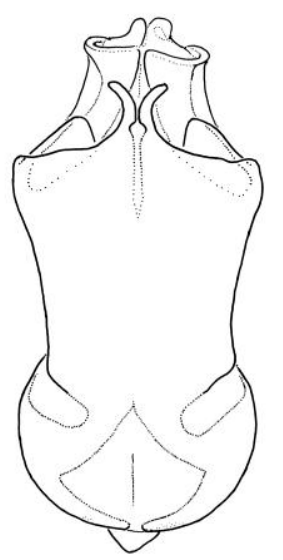

(c)

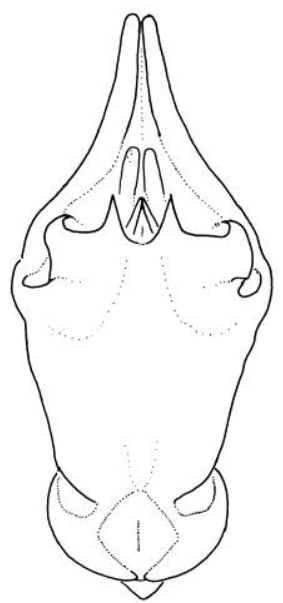

(f)

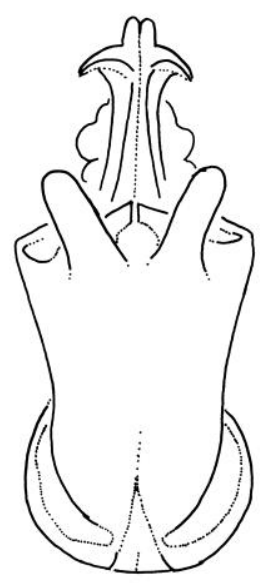

(i)

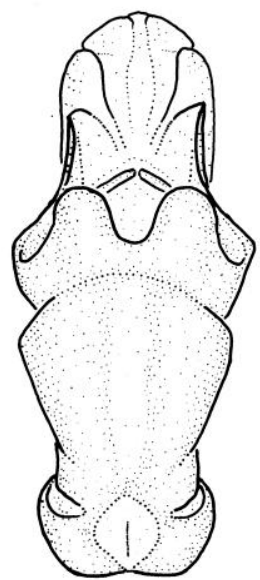

Figura 3. Vesica spermalis (V3-V4) de Erythemismorpha em vista dorsal. a, Carajathemis simone Machado, 2012; b, Rhodopygia cardinalis Erichson, 1848; c, Rhodopygia hollandi Calvert, 1907; d, Erythrodiplax castanea (Burmeister, 1839); e, Erythemis attala (Selys in Sagra, 1857); f, Acisoma trifidum Kirby, 1889; g, Rhodothemis rufa (Rambur, 1842); h, Cyanothemis simpsoni Ris, 1915; i, Erythemis simplicicollis (Say, 1840). 
para isso um método adequado ainda não tenha sido largamente utilizado. Porém, Goloboff et al. (2008b, p. 767) sugerem uma fórmula ${ }^{1}$ em que esse valor pode ser calculado e destacam um valor de $\mathrm{K}$ entre 5 e 16, aqui se optou por $\mathrm{K}=15$ como a principal hipótese de relacionamento.

A utilização de pesos distintos têm sido controversa na literatura cladística sendo os oponentes a adoção desse critério tão eloquente quanto seus defensores (e.g. Carpenter 1988; Bryant 1989; Goloboff 1993, 1995; Turner \& Zandee 1995, Farris 2001; Grant \& Kluge 2005, Goloboff et al. 2008b). Não há intenção alguma de discutir novamente estes argumentos aqui, mas apenas justificar a preferência pela hipótese obtida usando IW. De um modo simples, a ponderação diferencial baseia-se na premissa de que alguns caracteres fornecem evidência de maior confiabilidade à hierarquia (árvore binária) que outros e que a parcimônia (teste de congruência com outros caracteres) deve ser utilizada como critério de escolha para aplicação dos pesos. Farris (1983, grifo adicionado) discutiu que a(s) árvore(s) preferida(s) deve ser aquela com maior poder explanatório, "those that minimize the (possibly weighted) total of required independent origins [hipóteses ad hoc] of known features". Esse argumento foi adotado por Goloboff (1993) que suportou a ideia de que homoplasia deve receber menor peso (downweighted) e que a parcimônia fornece um meio para pesar os caracteres. Farris (1983) também argumentou que nem todos os caracteres "yield equally strong evidence" para a escolha entre as hipóteses concorrentes de relacionamento, neste sentido Goloboff (1993, 1995) e mais recentemente Goloboff et al. (2008b) em um experimento empírico, mostrou que pesando os caracteres baseado em sua self-consistence (em português algo como autoconsistência) melhora a decisão pela(s) MPT(s) resolvendo conflitos produzidos pelas homoplasias, especialmente para caracteres morfológicos. Portanto, a melhor árvore é aquela com maior ajuste total (Goloboff 1993, 1995). Baseado nesta argumentação a(s) árvore(s) resultante(s) da análise com IW foi selecionado como a hipótese mais confiável de hierarquia baseado na base de dados aqui analisada.

Índices de retenção e consistência ( $c f$. Farris 1989) são apresentados para tanto a árvore selecionado, bem como para cada caráter sobre essa mesma árvore. Devido a grande quantidade de caracteres não comparáveis (“-”), os quais, na maioria dos casos são computacionalmente tratados como ausência de dados (“?”) e atuam como estados curingas, assumindo o código de qualquer um dos estados o que pode causar distorções nos resultados

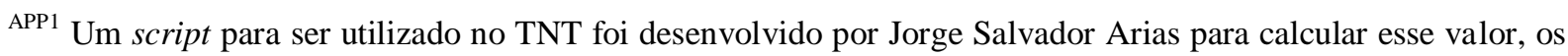
testes utilizando esse script demonstram valores próximos ao de $\mathrm{K}=12$.
} 
da análise ( $c f$. Kitching et al. 1998), um método alternativo foi testado pata lidar com esse tipo de dados. Embora o TNT permita ler os “-” (gaps nas análises moleculares nas quais se refere aos indels) como um estado adicional (quinto estado em análises com nucleotídeos), o que minimizaria seu impacto nos resultados, esse procedimento, independente do padrão resultante, certamente não é adequando para análises morfológicas. Isso se deve ao fato de que na maior parte dos casos em que há dados não comparáveis, eles resultam da ausência de uma determinada estrutura em alguns terminais, a qual simultaneamente apresenta variações (estados distintos) em outros. Os gaps em análises morfológicas representam uma exigência do método, de que todos os terminais apresentem o mesmo número de caracteres, caso contrário são tratados como ausências (qualquer estado). Portanto, tais ausências não deveriam ser otimizadas já que não representam uma observação positiva de um dado caráter. Assim, com o objetivo de minimizar os efeitos dos gaps, duas abordagens distintas foram utilizadas para lidar com os dados não comparáveis, a primeira, do mesmo modo que os caracteres ausentes, considerada tradicional, e uma segunda com o método conhecido como parcimônia de Sankoff ou "generalized parsimony" (cf. Sankoff \& Rousseau 1975; Swofford \& Maddison 1992). De modo simples o método inicia com a especificação de diferentes passos (custos) as transformações em uma matriz de custos que especifica o menor custo da transformação de um estado em outro. Na parcimônia de Fitch todas as transformações são igualmente parcimoniosas já que a passagem de um estado a qualquer outro representa um único passo e a exemplo da parcimônia de Wagner, pode ser compreendida como um caso especial da parcimônia de Sankoff. No entanto, os gaps correspondem à negação de qualquer estado e, portanto a transformação de um estado em gap e vice-versa pode ser limitada ou impedida. Para limitar a transformação de um estado em gap foi atribuído o custo essencialmente proibitivo de 100 passos a qualquer transformação envolvendo o código “-”, como exemplificado na Figura 4 em um grafo de estados de caracteres não direcionado pesado e sua respectiva matriz de custos. Algoritmos para aplicação da parcimônia de Sankoff são detalhadamente descritos por Swofford \& Maddison (1992), porém possivelmente sejam diferentes daqueles utilizados no TNT. Análises preliminares foram realizadas para verificar se o alto custo das transformações com gaps não poderia implicar em um efeito contrário ao desejado e atrair os ramos que contenham o código “-”, o que demonstrou não ser o caso com os dados aqui analisados, excetuando algumas poucas transformações sem impacto no relacionamento resultado final. 

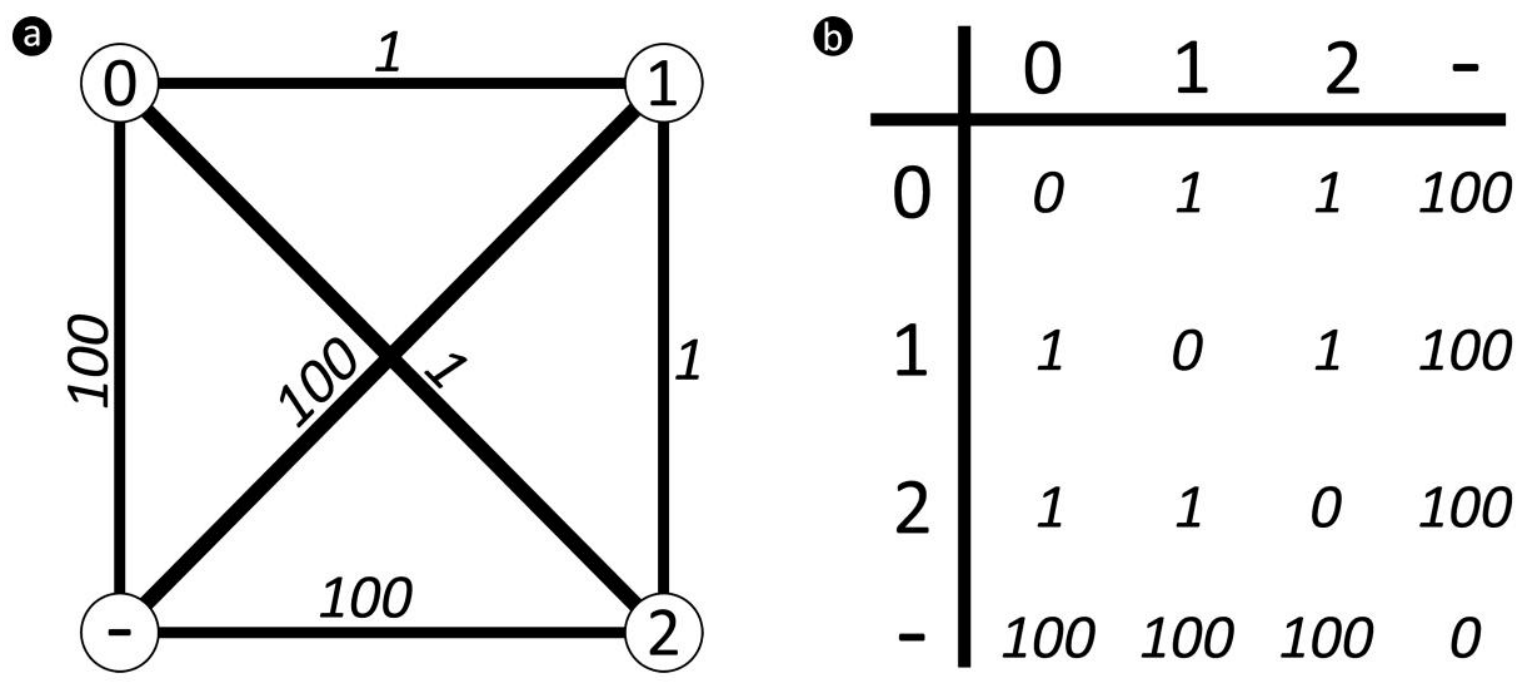

Figura 4. Exemplo dos custos das transformações de caracteres com até três estados utilizados na parcimônia de Sankoff ou "generalized parsimony" (sensu Swofford \& Maddison 1992). a. grafo não direcionado (não ordenado e não polarizado na linguagem cladística) pesado com os estados do caráter; b. matriz de custos correspondente.

A relativa estabilidade dos ramos individuais foi avaliada com três índices: Suporte de Bremer Relativo (Goloboff \& Farris 2001), uma forma modificada do Bootstrap com reamostragem de Poisson (próximo à simetria $\mathrm{p} \approx 37$ ), bem como do Jackknife com reamostragem simétrica $(\mathrm{SR})$ de $\mathrm{p}=33$. Para os valores de Bootstrap foi utilizado apenas usando a frequência GC (grupo presente e contraditório), enquanto para o Jackknife ambas às frequências, absoluta e GC (Goloboff et al. 2003). Todos os índices foram calculados com ponderação implicada com constante de concavidade $K=15$. Além disso, os valores de $K$ de $5,10,20,25$ e 30 foram comparados com o resultado obtido com $K=15$, como uma forma de suporte de ramos verificando os nós presentes em cada análise. Essas abordagens distintas foram utilizadas para acessar a estabilidade dos ramos, como um conceito de exploração de dados (Grant \& Kluge 2003) para avaliar a robustez dos nós na MPT nas hipóteses concorrentes com base no conjunto de dados analisado. Na medida em que cada um dos índices avalia aspectos distintos dos dados, eles podem ser vistos como mutuamente complementares, portanto, os nós que mostram os valores mais elevados são considerados mais robustos (ou estáveis) do que outros que apresentam valores baixos.

O suporte de Bremer absoluto não foi utilizado, pois este avalia quanto menos parcimoniosa deve ser uma hipótese para que um nó seja colapsado, fornecendo uma espécie de medida de força. No entanto, não dá informações sobre dados contraditórios e também não 
é escalonada ${ }^{2}$, impedindo comparações entre conjuntos de dados distintos. Essa insuficiência é superada pelo Suporte de Bremer relativo que avalia a quantidade de evidências favoráveis e contraditórias (Goloboff \& Farris 2001; mas veja Grant \& Kluge 2003 para uma visão distinta sobre evidência contraditória). Além disso, pode ser escalonado em porcentagem tornando possível uma comparação direta entre conjuntos de dados distintos, mesmo com diferentes esquemas de ponderação de caracteres (Goloboff \& Farris 2001). Técnicas de reamostragem sobre dados com pesos assimétricos podem atribuir maior suporte a nós não suportados (Goloboff et al. 2008). Tal influência é minimizada quando a função de reamostragem se aproxima da simetria, o que é alcançado quando um caráter tem a mesma probabilidade de ser excluído (downweighting) ou duplicado (upweighting). Assim, a reamostragem simétrica parece não ser influenciada pelo peso do caráter e, portanto mais adequada para aplicação utilizando pesos implicados ( $c f$. Goloboff et al. 2008). Contudo, resultados expressos como frequências absolutas podem falhar em recuperar todos os grupos suportados que são observados com frequências baixas, portanto, de um modo semelhante ao do suporte relativo de Bremer, valores de frequência descritos como sendo a diferença entre as frequências do nó avaliado e aquelas do nó contraditório mais frequente, observado nas pseudoréplicas (frequência GC), demonstram de forma mais clara a quantidade de evidências contraditórias ao nó.

O programa, WINCLADA versão 1.00 .08 foi usado para otimizar os caracteres (Nixon 2002), por meio da fast optimization (transformação acelerada, ACCTRAN) (Swofford \& Maddison 1987). Embora existam outras reconstruções mais parcimoniosas para alguns caracteres e assim a otimização ACCTRAN é uma decisão arbitrária para um nó específico (Swofford \& Maddison 1992) os conjuntos de estados das reconstruções mais parcimoniosas (MPR-sets) não são fornecidos por ser inviável e pouco informativo, por exemplo, para o caráter 2 na árvore obtida com IW utilizando a parcimônia de Sankoff existem mais de 240 reconstruções mais parcimoniosas. As reconstruções mais parcimoniosas (MPR-sets) foram investigadas também no TNT e PAUP.

DESCRIÇÃo dos Comandos. O número de terminais envolvidos na análise impede a realização de buscas exatas, sendo assim foram realizadas apenas buscas heurísticas. Computadores com processadores Intel ${ }^{\mathrm{tm}}$ com um ou dois núcleos e memória RAM de 1,5 a

\footnotetext{
APP2 Bremer (1994) propôs um cálculo para o reescalonamento baseado no número de passos, o qual apenas pode ser utilizado com a utilização da ponderação sucessiva (Farris 1969, 1989) e não com IW baseado no fit (ajuste a homoplasia). Além disso, o valor resultante depende do número de caracteres e da escala dos valores da ponderação (inteiro ou fracionado) o que torna difícil a comparação entre diferentes bases de dados.
} 
3,0 Gb foram utilizados. Devido às diferentes exigências de cada tipo de busca os parâmetros foram alterados conforme cada uma, para obter o máximo de desempenho no menor tempo computacional possível. Todas as análises foram realizadas duas vezes com variações de "random addition sequences" seguidas de "tree bisection and reconnection" (RAS + TBR) e algoritmos da "new technology" com diferentes níveis. Os parâmetros gerais são descritos abaixo.

Todas as buscas no TNT foram realizadas em um único procedimento usando a linguagem de comandos com as especificações escritas em um arquivo “.txt”, com os seguintes parâmetros básicos e suas respectivas descrições abaixo. As MPT(s) tanto com pesos iguais e pesos implicados foram obtidas utilizando as especificações "mxram 700" (memória RAM ajustada para $700 \mathrm{Mb}$ ); “hold 1000000” (máximo de 1.000.000 de árvores retidas); "collapse 3" (critério para o colapso de ramos especificado para todos os ramos com comprimento mínimo zero); qcollapse = (método de estimativa de consenso rápido como descrito por Goloboff \& Farris 2001, ativo); bbreak: fillonly (troca de ramos apenas até o buffer ficar preenchido); "unique *" (descarte de árvores duplicadas condensando-as antes da comparação com base na regra de colapsamento de ramos); "best*" (descartar árvores subótimas, condensando-as antes da comparação com base na regra de colapsamento de ramos). Para as buscas com RAS + TBR usou-se "mult= tbr replic 10000 hold 100" (executar 10.000 réplicas com adição aleatória de sequências, troca de ramos por bisseção e reconexão de subárvores e no máximo 100 árvores salvas por réplica); “condense” (colapsar os nós com comprimento mínimo zero).

Para os algoritmos da "new technology" de modo geral foram adotados os parâmetros a seguir: drift: numsubs 50 xfactor 5 autoconst 2 giveup 99; tfuse: rounds 5 choose best; sectsch: rss minsize 10 maxsize 20 slack 300 noequals; ratchet: numsubs 50 noequals autoconst 2 upfactor 5 downfact 5 ; xmult= noupdate keepall rss hits 2 replications 100 drift 200 fuse 5 ratchet 200; (fazer múltiplas réplicas usando buscas da "new technology", buscar o melhor comprimento duas vezes por réplica usando sectorial search, tree-drifting com 200 repetições, 50 substituições, fator 2 para rejeição de árvores subótimas e troca de ramos complete $99 \%$ durante a fase de perturbação; tree-fusing com cinco rodadas iniciando da melhor árvore e aceitar apenas trocas que melhorem o comprimento; e finalmente parcimônia ratchet com 200 repetições, 50 substituições e probabilidade de exclusão (down-) e inclusão (up-weighting) de 5\%.

A ponderação implicada foi implementada com valores de constante de concavidade de $1 \leq \mathrm{k} \leq 30$, através do comando "piwe $=k$ " (ponderação implicada ativa com constante de 
concavidade com valores de K). Valores de Bremer foram calculados com a busca heurística tradicional (RAS + TBR) por árvores subótimas obtida gradualmente até 30 passos mais longas $(\mathrm{N})$ e uma diferença relativa de ajuste de até $1(\mathrm{R})$, nesta sequência de NxR: 1x0.0333, $2 \times 0.0667 ; \ldots 30 \times 1.000$. Os comandos utilizados foram: “subopt $N+1 x R+0.0333$ " (definir busca por árvores subótimas com $n+1$ passo e definir o valor de ajuste adicional constante de 0,0333 a partir da análise anterior. Optou-se por buscar usando RAS + TBR ao invés dos algoritmos de busca da "new technology" (Goloboff 1999; Nixon 1999) uma vez que eles foram desenvolvidos para obter resultados ótimos e, portanto, podem não recuperar todas as árvores subótimas. As árvores salvas foram lidas para a memória e os suportes relativos ("bsupport [") calculados. Para buscas de reamostragem foram aplicados apenas os algoritmos da "new technology" (Goloboff 1999; Nixon 1999), os parâmetros foram escolhidos na tentativa de combinar uma estratégia de busca profunda, e um curto de tempo de consumo computacional com os seguintes comandos: "resample sym replications 10000 frequency gc from $0[$ xmult $=N]$ ]" (aplicar 10.000 pseudoréplicas de reamostragem simétrica mostrando os resultados como frequências absoluta e GC sobre a árvore mais parcimoniosa ' 0 '.

As análises usando o PAUP foram executadas tentando simular o desempenho do TNT e os procedimentos básicos são similares a aqueles descritos por Pinto \& Carvalho (2010, Anexo 2). Considerando que foram apenas complementares não serão descritos aqui, contudo os algoritmos heurísticos básicos foram (RAS + TBR). 
Tabela 1. Relação das espécies, coleções de depósito e países de procedência dos exemplares utilizados na análise cladística. Acrônimos das coleções correspondem aqueles listados no material e métodos. GI = táxons do grupo-interno; GE = táxons do grupo-externo. Informações detalhadas sobre o material examinado pode ser consultado no Apêndice 1. Classificação segundo Bridges (1994).

\begin{tabular}{|c|c|c|c|c|c|}
\hline & Espécie & Subfamília & $\begin{array}{c}\text { status } \\
\text { na } \\
\text { Análise }\end{array}$ & $\begin{array}{l}\text { Coleções } \\
\text { acrônimos }\end{array}$ & $\begin{array}{c}\text { País de } \\
\text { procedência }\end{array}$ \\
\hline 1. & Miathyria marcella (Selys in Sagra, 1857) & Trameinae & GE & DZRJ & Brasil \\
\hline 2. & Macrodiplax balteata (Hagen, 1861) & Urothemistinae & GE & MNRJ & EUA \\
\hline 3. & Macrodiplax cora (Brauer, 1867) & Urothemistinae & GE & MNRJ & Indonésia \\
\hline 4 & Brachymesia furcata (Hagen, 1861) & Leucorrhiniinae & GI & $\begin{array}{l}\text { DZRJ, MNRJ, } \\
\text { MZSP }\end{array}$ & $\begin{array}{l}\text { Argentina, } \\
\text { Brasil }\end{array}$ \\
\hline 5. & Zygonyx ida Selys, 1869 & Zygonychinae & GI & MNRJ & Indonésia \\
\hline 6. & Elasmothemis cannacrioides (Calvert, 1906) & Trithemistinae & GI & $\begin{array}{c}\text { ABMM, } \\
\text { DZRJ, MNRJ, } \\
\text { MZSP }\end{array}$ & $\begin{array}{c}\text { Brasil, } \\
\text { Paraguai, Peru }\end{array}$ \\
\hline 7. & Perithemis mooma Kirby, 1889 & Paupopleurinae & GI & DZRJ & Brasil \\
\hline 8. & Libellula herculea Karsch, 1890 & Libellulinae & GI & DZRJ, MZSP & Brasil \\
\hline 9. & Orthemis discolor (Burmeister, 1839) & Libellulinae & GI & DZRJ, MZSP & Brasil \\
\hline 10. & Micrathyria atra (Martin, 1897) & 'Brachydiplacinae' & GI & DZRJ, MNRJ & Brasil \\
\hline 11. & Uracis siemensi Kirby, 1897 & 'Brachydiplacinae' & GI & DZRJ & Brasil \\
\hline 12. & Ypirangathemis sp. & 'Sympetrinae' & GI & MNRJ & Brasil \\
\hline 13. & Pachydiplax longipennis (Burmeister, 1839) & 'Sympetrinae' & GI & MNRJ, RWG & EUA \\
\hline 14. & Sympetrum illotum (Hagen, 1861) & 'Sympetrinae' & GI & RWG & EUA \\
\hline 15. & Sympetrum rubicundulum (Say, 1840) & 'Sympetrinae' & GI & INHS, MNRJ & EUA \\
\hline 16. & Sympetrum risi risi Bartnef, 1915 & 'Sympetrinae' & GI & MNRJ & Japão \\
\hline 17. & Sympetrum vicinum (Hagen, 1861) & 'Sympetrinae' & GI & $\begin{array}{l}\text { INHS, MNRJ } \\
\text { UMMZ }\end{array}$ & EUA \\
\hline 18. & Nesogonia blackburni (McLachlan, 1883) & 'Sympetrinae' & GI & RWG & Havaí \\
\hline 19. & Brachythemis contaminata (Fabricius, 1793) & 'Sympetrinae' & GI & MNRJ & Indonésia \\
\hline 20. & Brachythemis leucosticta (Burmeister, 1839) & 'Sympetrinae' & GI & $\begin{array}{l}\text { FSCA, } \\
\text { USNM }\end{array}$ & $\begin{array}{c}\text { Republica } \\
\text { Democrática } \\
\text { do Congo, } \\
\text { Uganda }\end{array}$ \\
\hline 21. & Deielia phaon (Selys, 1883) & 'Sympetrinae' & GI & $\begin{array}{l}\text { MNRJ, RWG, } \\
\text { USNM }\end{array}$ & China, Japão \\
\hline 22. & Bradinopyga geminata (Rambur, 1842) & 'Sympetrinae' & GI & RWG & Tailândia \\
\hline 23. & $\begin{array}{l}\text { Crocothemis erythraea erythraea (Brullé, } \\
\text { 1832) }\end{array}$ & 'Sympetrinae' & GI & RWG & Namíbia \\
\hline 24. & Crocothemis servilia (Drury, 1773) & 'Sympetrinae' & GI & RWG & $\begin{array}{c}\text { EUA, } \\
\text { Tailândia }\end{array}$ \\
\hline 25. & Crocothemis mariannae Kiauta, 1983 & 'Sympetrinae' & GI & MNRJ & Japão \\
\hline
\end{tabular}

Continua. 
Tabela 1. Continuação.

\begin{tabular}{|c|c|c|c|c|c|}
\hline & Espécie & Subfamília & $\begin{array}{c}\text { status } \\
\text { na } \\
\text { Análise }\end{array}$ & $\begin{array}{c}\text { Coleções } \\
\text { acrônimos }\end{array}$ & $\begin{array}{c}\text { País de } \\
\text { procedência }\end{array}$ \\
\hline 26. & Erythrodiplax nigricans (Rambur, 1842) & 'Sympetrinae' & GI & DZRJ & Brasil \\
\hline 27. & Erythrodiplax umbrata (Linnaeus, 1758) & 'Sympetrinae' & GI & DZRJ & Brasil \\
\hline 28. & Erythrodiplax castanea (Burmeister, 1839) & 'Sympetrinae' & GI & DZRJ & Brasil \\
\hline 29. & Neurothemis fluctuans (Fabricius, 1793) & 'Sympetrinae' & GI & $\begin{array}{l}\text { MNRJ, } \\
\text { UMMZ }\end{array}$ & Indonésia \\
\hline 30. & $\begin{array}{l}\text { Neurothemis terminata terminata (Brauer, } \\
\text { 1866) }\end{array}$ & 'Sympetrinae' & GI & $\begin{array}{l}\text { INHS, MNRJ, } \\
\text { UMMZ }\end{array}$ & $\begin{array}{l}\text { Filipinas, } \\
\text { Indonésia }\end{array}$ \\
\hline 31. & Neurothemis decora (Brauer, 1866) & 'Sympetrinae' & GI & MNRJ & Indonésia \\
\hline 32. & Neurothemis feralis (Burmeister, 1839) & 'Sympetrinae' & GI & MNRJ & Indonésia \\
\hline 33. & Pseudoleon superbus (Hagen, 1861) & 'Sympetrinae' & GI & DZRJ, MNRJ & México \\
\hline 34. & Indothemis carnatica (Fabricius, 1798) & 'Sympetrinae' & GI & RWG & Tailândia \\
\hline 35. & Indothemis limbata limbata (Selys, 1891) & 'Sympetrinae' & GI & RWG & Tailândia \\
\hline 36. & Diplacodes bipunctata (Brauer, 1865) & 'Sympetrinae' & GI & FSCA & Nova Zelândia \\
\hline 37. & Diplacodes luminans (Karsch, 1893) & 'Sympetrinae' & GI & USNM & Zimbábue \\
\hline 38. & Diplacodes trivialis (Rambur, 1842) & 'Sympetrinae' & GI & FSCA & Filipinas, Índia \\
\hline 39. & Nothodiplax dendrophila Belle, 1984 & 'Sympetrinae' & GI & Bibliografia & Suriname \\
\hline 40. & Nannodiplax rubra Brauer, 1868 & 'Sympetrinae' & GI & RWG & Austrália \\
\hline 41. & Microtrigonia gomphoides Lieftinck, 1933 & 'Tetrathemistinae' & GI & MNRJ & Indonésia \\
\hline 42. & Nannothemis bella (Uhler, 1857) & 'Brachydiplacinae' & GI & $\begin{array}{l}\text { DRP, FSCA, } \\
\text { INHS, MNRJ } \\
\text { UMMZ }\end{array}$ & EUA \\
\hline 43. & Nannophya pygmaea Rambur, 1842 & 'Brachydiplacinae' & GI & $\begin{array}{l}\text { DRP, MNRJ, } \\
\text { USNM }\end{array}$ & China, Japão \\
\hline 44. & Acisoma inflatum Selys, 1882 & 'Sympetrinae' & GI & MNRJ & $\begin{array}{l}\text { Costa do } \\
\text { Marfim }\end{array}$ \\
\hline 45. & Acisoma panorpoides Rambur, 1842 & 'Sympetrinae' & GI & MNRJ & Indonésia \\
\hline 46. & Acisoma trifidum Kirby, 1889 & 'Sympetrinae' & GI & $\begin{array}{l}\text { DRP, FSCA, } \\
\text { MNRJ, RWG }\end{array}$ & $\begin{array}{l}\text { Costa do } \\
\text { Marfim, } \\
\text { Gabão, } \\
\text { Uganda }\end{array}$ \\
\hline 47. & Acisoma variegatum Kirby, 1898 & 'Sympetrinae' & GI & FSCA & Uganda \\
\hline 48. & Porpax asperipes Karsch, 1896 & 'Brachydiplacinae' & GI & RWG & $\begin{array}{l}\text { República do } \\
\text { Congo }\end{array}$ \\
\hline 49. & Cyanothemis simpsoni Ris, 1915 & 'Sympetrinae' & GI & RWG & Camarões \\
\hline 50. & Rhodothemis rufa (Rambur, 1842) & 'Sympetrinae' & GI & DRP, RWG & $\begin{array}{l}\text { Tailândia, } \\
\text { Malásia }\end{array}$ \\
\hline 51. & Rhodothemis lieftincki Fraser,1954 & 'Sympetrinae' & GI & $\begin{array}{l}\text { DZRJ, FSCA, } \\
\text { USNM, RWG }\end{array}$ & $\begin{array}{l}\text { Austrália, } \\
\text { Papua-Nova } \\
\text { Guiné }\end{array}$ \\
\hline
\end{tabular}

Continua. 
Tabela 1. Conclusão.

\begin{tabular}{|c|c|c|c|c|c|}
\hline & Espécie & Subfamília & $\begin{array}{l}\text { status na } \\
\text { Análise }\end{array}$ & $\begin{array}{c}\text { Coleções } \\
\text { acrônimos }\end{array}$ & $\begin{array}{c}\text { País de } \\
\text { procedência }\end{array}$ \\
\hline 52. & Rhodothemis mauritsi Lohmann, 1984 & 'Sympetrinae' & GI & MNRJ, & Indonésia \\
\hline 53. & Carajathemis simone Machado, 2012 & 'Sympetrinae' & GI & DZRJ & Brasil \\
\hline 54. & Rhodopygia cardinalis (Erichson, 1848) & 'Sympetrinae' & GI & $\begin{array}{l}\text { ABMM, DZRJ, } \\
\text { INPA, MNRJ, } \\
\text { MZSP, UFG, } \\
\text { USNM, }\end{array}$ & $\begin{array}{l}\text { Brasil, Colômbia, } \\
\text { Equador }\end{array}$ \\
\hline 55. & Rhodopygia geijskesi Belle, 1964 & 'Sympetrinae' & GI & $\begin{array}{c}\text { RWG, MNRJ, } \\
\text { DZRJ }\end{array}$ & Brasil, Suriname \\
\hline 56. & Rhodopygia hinei Calvert, 1907 & 'Sympetrinae' & GI & $\begin{array}{l}\text { DRP, FSCA, } \\
\text { UMMZ, USNM }\end{array}$ & $\begin{array}{c}\text { Colômbia, Costa } \\
\text { Rica, Panamá, } \\
\text { Nicarágua }\end{array}$ \\
\hline 57. & Rhodopygia hollandi (Calvert, 1906) & 'Sympetrinae' & GI & $\begin{array}{c}\text { DZRJ, MNRJ, } \\
\text { MZSP, UFG }\end{array}$ & Brasil \\
\hline 58. & Rhodopygia pruinosa Buchholz, 1953 & 'Sympetrinae' & GI & $\begin{array}{l}\text { MNRJ, RWG, } \\
\text { USNM }\end{array}$ & $\begin{array}{c}\text { Brasil, } \\
\text { Venezuela, } \\
\text { Equador }\end{array}$ \\
\hline 59. & Erythemis attala (Selys in Sagra, 1857) & ‘Sympetrinae’ & GI & $\begin{array}{l}\text { ABMM, DZRJ, } \\
\text { INPA, MNRJ, } \\
\text { MZSP, UFG }\end{array}$ & Brasil, México \\
\hline 60. & Erythemis haematogastra (Burmeister, 1839) & 'Sympetrinae' & GI & $\begin{array}{l}\text { ABMM, DZRJ, } \\
\text { INPA, MNRJ, } \\
\text { MZSP }\end{array}$ & Brasil, Suriname \\
\hline 61. & Erythemis plebeja (Burmeister, 1839) & 'Sympetrinae' & GI & $\begin{array}{l}\text { ABMM, DZRJ, } \\
\text { MNRJ, MZSP }\end{array}$ & $\begin{array}{l}\text { Brasil, Colômbia, } \\
\text { Cuba, Suriname }\end{array}$ \\
\hline 62. & Erythemis credula (Hagen, 1861) & 'Sympetrinae' & GI & $\begin{array}{l}\text { ABMM, DZRJ, } \\
\text { MNRJ, MZSP }\end{array}$ & Brasil, Suriname \\
\hline 63. & Erythemis peruviana (Rambur, 1842) & 'Sympetrinae' & GI & $\begin{array}{l}\text { ABMM, DZRJ, } \\
\text { INHS, INPA, } \\
\text { MNRJ, MZSP }\end{array}$ & $\begin{array}{c}\text { Argentina, } \\
\text { Brasil, Suriname, } \\
\text { Venezuela }\end{array}$ \\
\hline 64. & Erythemis carmelita Williamson, 1923 & 'Sympetrinae' & GI & $\begin{array}{l}\text { ABMM, MNRJ, } \\
\text { UFG, UMMZ }\end{array}$ & $\begin{array}{l}\text { Brasil, Colômbia, } \\
\text { Venezuela }\end{array}$ \\
\hline 65. & $\begin{array}{l}\text { Erythemis mithroides (Brauer in Therese, } \\
\text { 1900) }\end{array}$ & 'Sympetrinae' & GI & $\begin{array}{l}\text { ABMM, DRP, } \\
\text { DZRJ, INHS, } \\
\text { MNRJ, UFG, } \\
\text { UMMZ }\end{array}$ & $\begin{array}{c}\text { Brasil, Costa } \\
\text { Rica, Paraguai, } \\
\text { Peru, Suriname, } \\
\text { Venezuela }\end{array}$ \\
\hline 66. & Erythemis collocata (Hagen, 1861) & 'Sympetrinae' & GI & $\begin{array}{l}\text { FSCA, RWG, } \\
\text { UMMZ }\end{array}$ & EUA \\
\hline 67. & Erythemis simplicicollis (Say, 1840) & 'Sympetrinae' & GI & $\begin{array}{c}\text { ABMM, RWG, } \\
\text { MNRJ }\end{array}$ & EUA \\
\hline 68. & Erythemis vesiculosa (Fabricius, 1775) & 'Sympetrinae’ & GI & $\begin{array}{c}\text { ABMM, DZRJ, } \\
\text { INPA, MNRJ, } \\
\text { UFG }\end{array}$ & $\begin{array}{c}\text { Brasil, Colômbia, } \\
\text { Peru, Suriname }\end{array}$ \\
\hline 69. & Viridithemis viridula Fraser, 1960 & 'Sympetrinae' & GI & Bibliografia & Madagascar \\
\hline
\end{tabular}




\section{Breve histórico da filogenia e classificação de Odonata com ÊNFASE em 'ERYTHEMISMORPHA'}

Tradicionalmente Odonata é divida em três subordens: Zygoptera, Anisozygoptera e Anisoptera (Fraser 1957; Davies \& Tobin 1985). Diversas hipóteses foram apresentadas quanto ao relacionamento filogenético entre as subordens e níveis taxonômicos inferiores, muitas delas com grande incongruência entre si, sem haver consenso sobre o monofiletismo e o relacionamento de cada grupo (e.g. Pfau 1991; Carle 1995; Rehn 2003).

A subordem Zygoptera, com 18 famílias e cerca de 2900 espécies (Pilgrim \& von Dohlen 2008), teve sua condição monofilética questionada por diversas vezes, entretanto, análises filogenéticas atuais têm corroborado o seu monofiletismo (Carle 1982; Bechly 1996; Rehn 2003). Anisozygoptera é constituída principalmente por fósseis do Jurássico, tendo até recentemente como os únicos representantes atuais duas espécies pertencentes à família monotípica Epiophlebiidae, considerados rélitos, porém mais duas novas espécies foram descritas para essa subordem (Li et al. 2011; Carle 2012). Essa subordem foi demonstrada ser parafilética e a família Epiophlebiidae posicionada como grupo-irmão de Anisoptera (Carle 1982; Nel et al. 1993 apud Rehn 2003; Lohmann 1996; Pfau 2002; Rehn 2003). O grupo monofilético formado por 'Anisozygoptera' + Anisoptera é designado de Epiproctophora (Bechly 1996).

Anisoptera é a mais rica em número de espécies, possui um número menor de famílias reconhecidas, entre 9 e 14 (Misof 2002). Dentre todas as famílias de Anisoptera, Libellulidae é a mais diversa, com mais de 1000 espécies atuais, sendo o grupo dominante na fauna de Odonata de qualquer região. O registro fóssil mais antigo atribuído a Libellulidae é o mais recente dos Anisoptera, tendo sido encontrado no Cretáceo Superior Turoniano, a cerca de 90 milhões de anos (Fleck et al. 1999). A maior parte dos autores apresenta Libellulidae sensu Fraser 1957 com o status de família (e.g. Davies \& Tobin 1985). Porém, com a hipótese do não monofiletismo de Corduliidae ( $c f$. Bechly 1996; Jarzembowski \& Nel 1996; Ware et al. 2007), alguns autores tem dividido essas famílias em inúmeras outras (Carle 1995; Bechly, 1996) ou atribuído status de subfamília a elas (e.g. Garrison et al. 2006). Dessa forma, a classificação de Libellulidae permanece instável, já Corduliidae s.l. incluí no mínimo três famílias distintas Macromiidae, Synthemistidae s.l. e Corduliidae s.s. Bybee et al. (2008) propôs todas como subfamílias com distintos arranjos taxonômicos, já que em sua analise ambos Synthemistidae e Macromiidae estão inseridos em Corduliidae s.l., além do status de 
quase todas as famílias propostas por Fraser (1957) e Bechly $(1995,1996)$ permanecem não resolvidas e estudos adicionais devem ser realizados para obter uma hipótese de relacionamento mais estável.

Contudo, o monofiletismo de Libellulidae é suportado principalmente pela redução de algumas estruturas como as quilhas tibiais e triângulo anal nos machos; veias transversais antenodais alinhadas com as primárias indistintas (visíveis em alguns gêneros como Antidythemis Kirby, 1889, Zenithoptera Selys, 1869 e Tramea Hagen, 1861, Bechly et al. 1998) e ausência do músculo 9a do hâmulo anterior (Ware et al. 2007). Muitos dos caracteres citados como sinapomorfias de Libellulidae (e.g. desenvolvimento da alça anal, disposição dos triângulos) são compartilhados em maior ou menor grau com Corduliidae e Macromiidae. Embora seja de difícil delimitação a família tem sido recorrentemente identificada como monofilética (cf. Ware et al. 2007; Fleck et al. 2008).

Apesar do interesse no relacionamento filogenético de Odonata ter surgido praticamente junto com os estudos modernos na sistemática da ordem (e.g. Calvert 1893; Walker 1912; Tillyard 1917; Kennedy 1922, 1923; Needham \& Broughton 1927; veja também Trueman 2007), a maioria não possui métodos formais e objetivos de investigação. Igualmente nas últimas três décadas várias hipóteses de relacionamento filogenético foram propostas usando uma polarização a priori e métodos subjetivos, conhecida em alguns círculos como "Argumentação Hennigiana" ( $c f$. Trueman 2007), mas na verdade eles são desprovidos de procedimentos formais e explícitos o que fazem dessas "análises" irreproduzíveis e certamente menos testáveis ( $c f$. Ogden et al. 2005 para uma discussão sobre repetitividade e testabilidade). Por outro lado, alguns desses trabalhos são verdadeiramente brilhantes sob o ponto de vista da investigação morfológica e apesar das limitações metodológicas as hipóteses filogenéticas são inovadoras e razoáveis, certamente ilumiram as investigações posteriores (e.g. Carle 1982; Pfau 1991, 2002, 2005, 2011; Bechly 1995, 1996; Lohmann 1996a-c, Fleck 2004; Fleck \& Legrand 2006).

Os primeiros estudos verdadeiramente cladísticos, como análise filogenética formal, são datados a partir da década de1980 (e.g. Wighton \& Wilson 1986), e este campo têm aumentado drasticamente nos últimos vinte anos (e.g. Jarzembowski \& Nel 1996; Trueman 1996; Kambhampati \& Charlton 1999; Westman et al. 2000; von Ellenrieder 2002, 2003; May 2002; O’Grady \& May 2003; Rehn 2003; Hovmöller \& Johansson 2004; Dijkstra 2006b; Pessacq 2008; Pinto \& Carvalho 2010). Abordagens probabilísticas para inferência filogenética também ganharam terreno rapidamente e as análises moleculares utilizando esses métodos se tornararam dominantes para quase todos os grupos (Misof et al. 2000, 2001; 
Jordan et al. 2003; Dumont et al. 2005; Ware et al. 2007, 2009; Baskinger et al. 2008; Bybee et al. 2008; Carle et al. 2008; Fleck et al. 2008a,b; Pilgrim \& von Dohlen 2008, 2012; Damm et al. 2010; Ingley et al. 2012).

Algumas das análises filogenéticas de Carle (Carle 1986, 1995; Carle \& Kjer 2002), apesar de estarem enraizadas na teoria cladística, devem ser consideradas a parte dessa escola, uma vez que são baseadas em um método infundado e mal discutido de ponderação a priori, assim como de otimização de caráteres, vários dos conceitos empregados em seus estudos estão em grande parte em desacordo com a literatura cladística, e, além disso, se utilizam de uma terminologia idiossincrática como "exapomorphy". De fato, Carle desenvolveu seu próprio método de análise filogenética, que é em grande parte baseado em Hennig (1965, 1966) de onde também surgiu a cladística em seu senso mais estrito (parcimônia cladística ou cladística numérica de Ebach et al. 2008; Williams \& Ebach 2008).

Revisões recentes listam vários estudos filogenéticos em Odonata (Trueman 2007; Ware et al. 2007; Ballare \& Ware 2011; Dijkstra \& Kalkman 2012), mostrando o estado da arte desse campo, demonstram o rápido aumento do interesse por este tipo de pesquisa. No entanto, um número muito pequeno desses estudos foi empregado na modificação das classificações, somente recentemente tímidas tentativas têm sido feitas para transformar os resultados filogenéticos e atualizar as categorias taxonômicas de Odonata (May 2002; von Ellenrieder 2003; Dijkstra et al. em prep.; Pilgrim \& von Dohlen 2012), podendo se dizer que os odonatólogos têm sido em grande parte conservadores.

Neste cenário, os intrigantes Libellulidae são considerados a família mais rica de Anisoptera com mais de 1000 espécies, sendo muito abundante e praticamente onipresente em quase todos os ambientes (Kalkman et al. 2008). Libellulidae é considerada uma família distinta, dividida em 11 ou 12 subfamílias, no entanto, como foi admitido por Fraser (1957, p.115) estes agrupamentos podem não ser "naturais" ( $c f$. Trueman 2007). Recentemente várias destas subfamílias não foram corroboradas sob uma estrutura filogenética (Ware et al. 2007; Fleck et al. 2008a; Damm et al. 2010), em que se destaca 'Sympetrinae' (Pilgrim \& von Dohlen 2008) uma das mais diversificada e, certamente, um verdadeiro desafio para próximas décadas.

\section{Sympetrinae s.l.}

O atual sistema de classificação de Libellulidae em subfamílias se deve em grande parte a monumental revisão de Ris (1909-1919) que dividiu a família em grupos de gêneros, porém sem atribuir nome algum. $\mathrm{O}$ primeiro autor a se referir coletivamente a grupos de 
gêneros com um nome foi Bartnef (1915) em um trabalho escrito em russo antigo em que praticamente revisou o grupo VI de Ris (1909) ('Sympetrinae') e o considerou uma tribo “Триба Sympetraria”. Porém, em 1915 as regras da Comissão Internacional de Nomenclatura Zoológica já estavam em vigor ( $c f$. ICNZ 1999) e por ele não ter utilizado o sufixo correto, independente da categoria taxonômica, essa designação trata-se apenas de um nome coletivo e não de uma categoria supragenérica. Bartnef (1915) faz uma extensiva comparação entre os gêneros de sua então tribo "Sympetraria", propondo chaves e descrevendo espécies. A formalização de 'Sympetrinae' como categoria do grupo da Família foi estabelecida no nível taxonômico de tribo por Tillyard (1917) baseado nas seguintes características: (1) setores do árculo (RP e MA) fusionados, porém por uma distância menor na asa anterior que na posterior; (2) árculo posicionado entre a primeira e segunda veias transversais antenodais (vta); (3) vta distal na asa anterior restrita ao espaço entre a margem costal e a ScP; (4) veia Suplementar do Rádio (Rspl) bem definida e côncava em relação ao RP3-4; (5) Suplementar da Média (Mspl) geralmente bem definida; ausência de veias transversais acessórias da ponte (vtp) e no espaço cubital; (6) asa posterior com ampla área anal; (7) alça anal variável, mas bem formada; (8) hâmulo genital com ramo interno e externo (bifurcado); (9) placa subgenital da fêmea proeminente; (10) larva geralmente lisa, com a cabeça grande e região anterior triangular, olhos largos e arredondados e corpo e pernas curtos. Tillyard (1917) não menciona Bartnef (1915), talvez por desconhecimento ou mesmo intencionalmente, porém de modo curioso usa Sympetrum Newman, 1833 com o gênero-tipo para o táxon. Nenhuma dessas características propostas por Tillyard (1917) são exclusivas desse grupo, sendo que muitas são compartilhadas com espécies de outras subfamílias (e.g. caracteres de 1 a 7 compartilhados com Trameinae), e espécies de diversos dos gêneros incluídos, não possuem os caracteres relacionados por Tillyard (1917) (e.g. Pachydiplax Brauer, 1868 e Rhodopygia Kirby, 1889).

Atualmente 'Sympetrinae' é uma das maiores subfamílias de Libellulidae, e talvez seja o agrupamento mais artificial. Possui cerca de 200 espécies em 23 gêneros, dos quais 11 são monotípicos (Davies \& Tobin, 1985). Inúmeros agrupamentos foram propostos Tabela 2.

Needham \& Broughton (1927) estudaram extensivamente o padrão da venação de Libellulidae e mantiveram o status de tribo ao grupo de Tillyard (1917), com a consideração de outros caracteres como a ondulação da IR2. Além disso, inúmeros outros gêneros foram adicionados à tribo, atualmente referidos principalmente à Brachydiplacinae e à Tritemistinae (Fig. 5). 

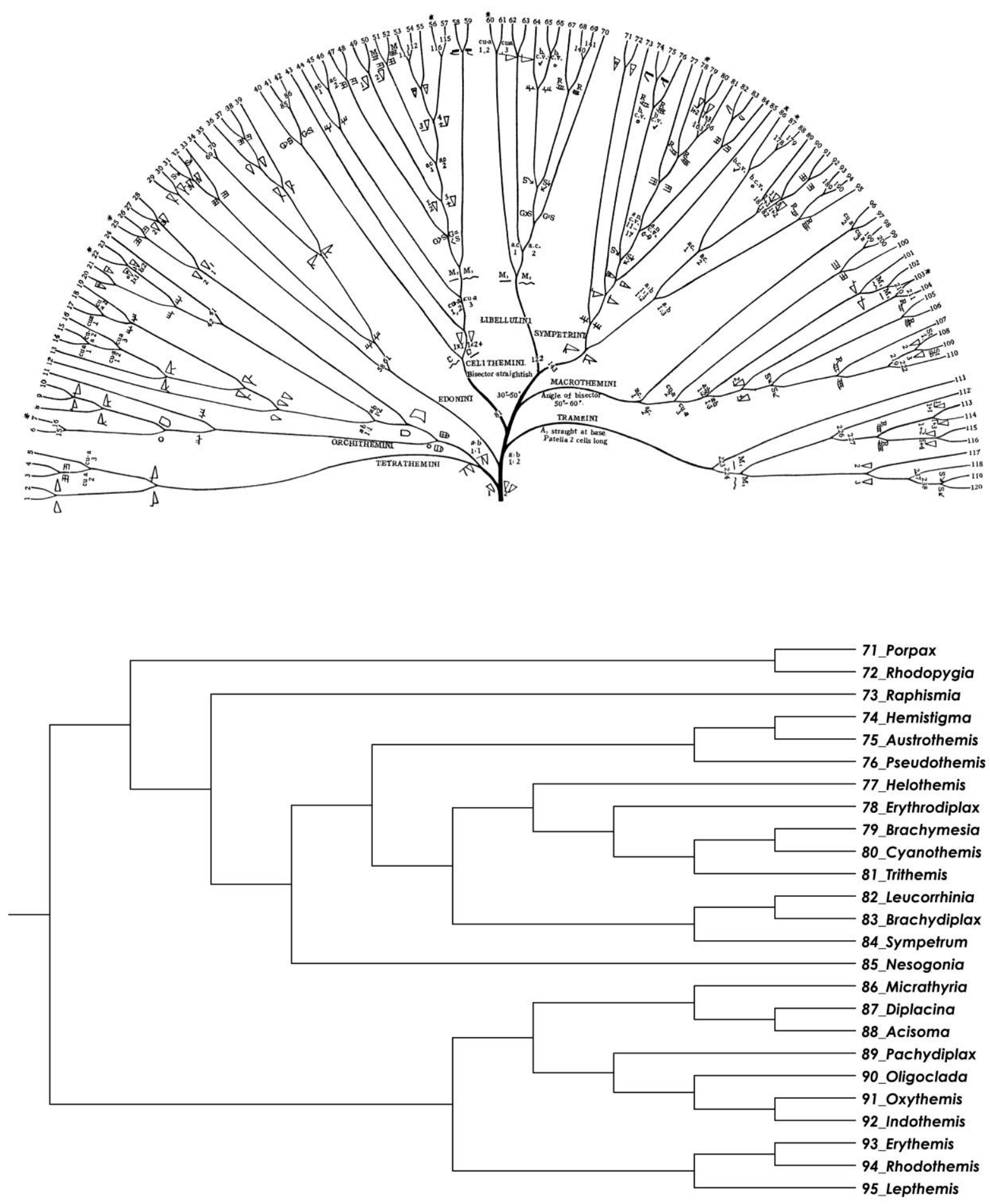

Figura 5. Árvore filogenética das espécies de Libellulidae (Odonata: Libellulidae) retirada de Needham \& Broughton (1927), baseado na venação alar, cladograma abaixo o relacionamento de 'Sympetrinae' em destaque. 
Na classificação proposta por Fraser (1957) o grupo foi então elevado à subfamília e, baseado na grande variação morfológica, o autor admitiu que futuramente fosse necessário dividir Sympetrinae, talvez indicando a condição não monofilética da subfamília. O único estudo que teve como objetivo principal analisar as relações filogenéticas em Sympetrinae foi apresentado por Pilgrim \& von Dohlen (2008). Sua análise foi baseada em dados moleculares com a aplicação de dois métodos de inferência: Parcimônia e Bayesiano. Nos diagramas apresentados a subfamília aparece fragmentada em cinco ou seis ramos, com apenas dois grandes ramos contendo exclusivamente espécies de Sympetrinae.

\section{Os gêneros com a armadura femoral especializada: Erythemismorpha}

Desde a monumental revisão de Libellulidae por Ris $(1909,1911,1919)$ o próximo relacionamento entre o gênero Americano Erythemis Hagen, 1861 com o gênero IndoAustralasiano Rhodothemis Ris, 1909 tem sido sugerida, sendo considerado um intrigante problema Biogeográfico. Ris $(1915,1919)$ incluiu ambos os gêneros em seu grupo "VI. 3" juntamente com outros gêneros de 'Sympetrinae' com pernas fortemente cobertas com espinhos robustos, tais como o Americano Rhodopygia Kirby, 1889 e especialmente o Africano Cyanothemis Ris, 1915, os quais também posicionou no grupo "VI.3.EE" (veja também Fleck 2004). Kennedy (1923) discutiu a proximidade morfológica entre os gêneros Erythemis e Rhodothemis, e propôs dois cenários evolutivos, um africano e outro oriental (i.e. centros de origem). Devido ao desconhecimento de espécies africanas relacionadas, atribuiu maior possibilidade à origem oriental com posterior dispersão ativa ao Novo Mundo via estreito de Bering. Fraser (1960) descreveu o gênero Viridithemis Fraser, 1960 baseado em uma única fêmea proveniente de Madagascar, o qual superficialmente comparou com Rhodothemis.

Mais recentemente Fleck (2004) ao descrever a larva da única espécie do gênero africano Cyanothemis observou grande semelhança com a morfologia daquelas das espécies de Acisoma Rambur, 1842, Erythemis (como Lepthemis, veja capítulo seguinte) e Rhodothemis. Esse fato, o levou a sugerir o grupo monofilético "Rhodothemis-ErythemisCyanothemis-Acisoma" e reavaliar a interpretação da armadura femoral dos machos. Fleck (2004) também sugeriu um próximo relacionamento filogenético com os gêneros Nannophya e Nannothemis que apesar do tamanho reduzido possuem a morfologia dos estádios imaturos semelhantes, além de armadura femoral levemente robusta. Entretanto, o nível hierárquico de relacionamento entre os gêneros não é evidente, sendo que nenhum diagrama ou anotação parentética foi apresentado. Além disso, sua hipótese é baseada em caracteres gerais 
Tabela 2. Relação dos gêneros incluídos em 'Sympetrinae' por diferentes autores e sua posição nos respectivos sistemas, tendo como base a classificação apresentada por Bridges (1994). Os gêneros atualmente considerados em Sympetrinae estão destacados em negrito. $\mathrm{Br}$, Brachydiplacinae; $\mathrm{Ce}$, Celitheminae; Ed, Edoninae; Le, Leucorrhiniinae; Li, Libellulinae; Ma, Macrothemistinae; Sy, Sympetrinae; Tr, Trithemistinae.

\begin{tabular}{|c|c|c|c|c|c|c|c|c|}
\hline Gênero/Sistema & $\begin{array}{c}\text { Ris } \\
(1909- \\
1919)\end{array}$ & $\begin{array}{c}\text { Bartnef } \\
\text { (1915) }\end{array}$ & $\begin{array}{c}\text { Tillyard } \\
(1917)\end{array}$ & $\begin{array}{c}\text { Needham } \\
\& \\
\text { Broughton } \\
(1927) \\
\end{array}$ & $\begin{array}{l}\text { Fraser } \\
(1957)\end{array}$ & $\begin{array}{c}\text { Davies \& } \\
\text { Tobin } \\
(1985)\end{array}$ & $\begin{array}{c}\text { Bridges } \\
(1994)\end{array}$ & $\begin{array}{l}\text { Steinmann } \\
(1997)\end{array}$ \\
\hline Acisoma Rambur, 1842 & VI & Sy & Sy & Sy & Sy & Sy & Sy & Sy \\
\hline Austrothemis Ris, 1912 & VII & - & $\mathrm{Le}$ & Sy & $\operatorname{Tr}$ & $\mathrm{Le}$ & $\mathrm{Le}$ & Le \\
\hline Brachydiplax Brauer, 1868 & IV & Sy & $\mathrm{Br}$ & Sy & $\mathrm{Br}$ & $\mathrm{Br}$ & $\mathrm{Br}$ & $\mathrm{Br}$ \\
\hline Brachymesia Kirby, 1889 & VII & - & $\mathrm{Le}$ & Sy & $\mathrm{Le}$ & $\mathrm{Le}$ & $\mathrm{Le}$ & $\mathrm{Le}$ \\
\hline Brachythemis Brauer, 1868 & VI & - & Sy & $\mathrm{Ce}$ & Sy & Sy & Sy & Sy \\
\hline Bradinopyga Kirby, 1893 & VI & - & Sy & $\mathrm{Ce}$ & Sy & Sy & Sy & Sy \\
\hline Carajathemis Machado, 2012 & - & - & - & - & - & - & - & - \\
\hline Crocothemis Brauer, 1868 & VI & Sy & Sy & $\mathrm{Ce}$ & Sy & Sy & Sy & Sy \\
\hline Cyanothemis Ris, $1915^{1}$ & VI & - & Sy & Sy & $?$ & Sy & Sy & Sy \\
\hline Deielia Kirby, $\mathbf{1 8 8 9}^{2}$ & VI & Sy & Sy & $\mathrm{Ce}$ & Sy & Sy & Sy & Sy \\
\hline Diplacina Brauer, 1868 & II & - & $\mathrm{Li}$ & Sy & $\mathrm{Li}$ & $\mathrm{Li}$ & $\mathrm{Li}$ & $\mathrm{Li}$ \\
\hline Diplacodes Kirby, 1889 & VI & Sy & Sy & $\mathrm{Ed}$ & Sy & Sy & Sy & Sy \\
\hline Erythemis Hagen, 1861 & VI & Sy & Sy & Sy & Sy & Sy & Sy & Sy \\
\hline Erythrodiplax Brauer, 1868 & VI & Sy & Sy & Sy & Sy & Sy & Sy & Sy \\
\hline Helothemis Karsch, $1899^{3}$ & VIII & - & $\operatorname{Tr}$ & Sy & $\operatorname{Tr}$ & $\operatorname{Tr}$ & $\operatorname{Tr}$ & $\operatorname{Tr}$ \\
\hline Hemistigma Kirby, 1889 & IV & - & $\mathrm{Br}$ & Sy & $\mathrm{Br}$ & $\mathrm{Br}$ & $\mathrm{Br}$ & $\mathrm{Br}$ \\
\hline Indothemis Ris, 1909 & VI & Sy & Sy & Sy & $?$ & Sy & Sy & Sy \\
\hline Lepthemis Hagen, $1861^{4}$ & VI & Sy & Sy & Sy & Sy & Sy & Sy & Sy \\
\hline Leucorrhinia Brittinger, 1850 & VII & - & Le & Sy & Le & Le & Le & Le \\
\hline Micrathyria Kirby, 1889 & V & - & $\mathrm{Br}$ & Sy & $\mathrm{Br}$ & $\mathrm{Br}$ & $\mathrm{Br}$ & $\mathrm{Br}$ \\
\hline Nadiplax Navás, $1916^{5}$ & - & - & - & - & - & Sy & Sy & Sy \\
\hline Nannodiplax Brauer, 1869 & VI & Sy & Sy & $\mathrm{Ed}$ & Sy & Sy & Sy & Sy \\
\hline Nesogonia Kirby, $1898^{6}$ & VI & Sy & $\mathrm{Li}$ & Sy & Sy & Sy & Sy & Sy \\
\hline
\end{tabular}

\section{Continua}

\footnotetext{
${ }^{3}$ Referiu-se a Триба Sympetraria.
} 
TABELA 2. Conclusão.

\begin{tabular}{|c|c|c|c|c|c|c|c|c|}
\hline Gênero/Sistema & $\begin{array}{c}\text { Ris } \\
(1909- \\
1919)\end{array}$ & $\begin{array}{l}\text { Bartnef } \\
(1915)\end{array}$ & $\begin{array}{l}\text { Tillyard } \\
(1917)\end{array}$ & $\begin{array}{c}\text { Needham } \\
\& \\
\text { Brougthon } \\
(1927)\end{array}$ & $\begin{array}{l}\text { Fraser } \\
(1957)\end{array}$ & $\begin{array}{c}\text { Davies \& } \\
\text { Tobin } \\
(1985)\end{array}$ & $\begin{array}{c}\text { Bridges } \\
(1994)\end{array}$ & $\begin{array}{l}\text { Steinmann } \\
\text { (1997) }\end{array}$ \\
\hline Neurothemis Brauer, 1867 & VI & Sy & Sy & $\mathrm{Ce}$ & Sy & Sy & Sy & Sy \\
\hline Nothodiplax Belle, 1984 & - & - & - & - & - & Sy & Sy & Sy \\
\hline Oligoclada Karsch, 1890 & $\mathrm{~V}$ & - & $\mathrm{Br}$ & Sy & $\mathrm{Br}$ & $\mathrm{Br}$ & $\mathrm{Br}$ & $\mathrm{Br}$ \\
\hline Ophippus Navás, $1916^{7}$ & - & - & - & - & - & Sy & $\operatorname{Tr}$ & Sy \\
\hline Oxythemis Ris, 1909 & - & - & $\mathrm{Li}$ & Sy & $\mathrm{Li}$ & $\mathrm{Li}$ & $\mathrm{Li}$ & $\mathrm{Li}$ \\
\hline Pachydiplax Brauer, 1868 & VI & Sy & Sy & Sy & Sy & Sy & Sy & Sy \\
\hline Philonomon Föester, $1906^{8}$ & VI & Sy & - & $\mathrm{Ce}$ & Sy & Sy & Sy & Sy \\
\hline Porpax Karsch, 1896 & IV & - & $\mathrm{Br}$ & Sy & $\mathrm{Br}$ & $\mathrm{Br}$ & $\mathrm{Br}$ & $\mathrm{Br}$ \\
\hline Pseudoleon Kirby, 1889 & VI & Sy & Sy & $\mathrm{Ce}$ & Sy & Sy & Sy & Sy \\
\hline Pseudothemis Kirby, 1889 & VIII & - & - & Sy & $\operatorname{Tr}$ & $\operatorname{Tr}$ & $\operatorname{Tr}$ & $\operatorname{Tr}$ \\
\hline Raphismia Kirby, 1889 & IV & - & $\mathrm{Br}$ & Sy & $\mathrm{Br}$ & $\mathrm{Br}$ & $\mathrm{Br}$ & $\mathrm{Br}$ \\
\hline Rhodopygia Kirby, 1889 & VI & Sy & Sy & Sy & Sy & Sy & Sy & Sy \\
\hline Rhodothemis Ris, $1909^{9}$ & VI & Sy & Sy & Sy & Sy & Sy & Sy & Sy \\
\hline Sympetrum Newman, 1833 & VI & Sy & Sy & Sy & Sy & Sy & Sy & Sy \\
\hline $\begin{array}{l}\text { Tarnetrum Needham \& } \\
\text { Fisher, } 1936^{10}\end{array}$ & - & - & - & - & - & - & Sy & Sy \\
\hline Trithemis Brauer, 1868 & VIII & - & $\operatorname{Tr}$ & Sy & $\operatorname{Tr}$ & $\operatorname{Tr}$ & $\operatorname{Tr}$ & $\operatorname{Tr}$ \\
\hline $\begin{array}{l}\text { Trithetrum Dijkstra \& } \\
\text { Pilgrim, 2007 [?] }\end{array}$ & - & - & - & - & - & - & - & - \\
\hline Viridithemis Fraser, 1960 & - & - & - & - & - & Sy & Sy & Sy \\
\hline $\begin{array}{l}\text { Ypirangathemis Santos, } \\
1945\end{array}$ & - & - & - & - & - & Sy & Sy & Sy \\
\hline
\end{tabular}

1. Nome ignorado por Fraser (1957); 2. Sinonimizado com Brachythemis por Dijkstra \& Matushkina 2009; 3. Sinonimizado com Trithemis por Davies \& Tobin (1985); 4. Formalmente sinonimizado com Erythemis por Pinto et al. (2012); 5. Sinônimo de Erythrodiplax (Garrison 1991); 6. Formalmente sinonimizado com Sympetrum por Dijkstra \& Kalkman (2012); 7. Sinonimizado com Macrothemis por Garrison \& Ellenrieder (2006); 8. Sinonimizado com Diplacodes por Dijkstra (2006c); 9. Citado ao longo do texto como Sympetrinae por Fraser (1957), porém não relacionado na lista com os demais gêneros; 10. Sinonimizado com Sympetrum por Garrison et al. (2006).

de cada gênero, sem considerar a variação em cada um deles. Sua análise pode ser considerada subjetiva desde que nenhum teste de congruência de caracteres foi realizado. Uma abordagem similar foi adotada para as larvas de Nesocordulia Mclachlan, 1882 e comentado por Pinto \& Carvalho (2010).

Pilgrim \& von Dohlen (2008) em uma análise molecular compreensiva de toda a 
subfamília 'Sympetrinae' usando dois loci mitocondriais (12S e 16S) e um nuclear (EF1A) mostrou alto suporte ao relacionamento de Erythemis com os gêneros de 'Sympetrinae' Acisoma, Rhodothemis e Rhodopygia, atribuindo maior força a hipótese de Fleck (2004), contudo estranhamente incluiu o gênero africano de 'Brachydiplacinae' Porpax Karsch, 1896. Entretanto, os adultos de Porpax também possuem a armadura femoral modificada com espinhos fortes e especializados (veja Dijkstra 2006a), os quais, possivelmente justificam essa hipótese sob o ponto de vista morfológico. Exceto para o gênero Rhodopygia em duas espécies foram analisadas, Pilgrim \& von Dohlen (2008) amostraram apenas uma espécies de cada um dos gêneros citados.

Pinto (2008) e Pinto \& Carvalho (em prep.) analisaram espécies de Acisoma, Erythemis, Rhodopygia e Rhodothemis e as identificaram como um grupo monofilético sendo proposto o nome Erythemismorpha (Pinto \& Carvalho em prep.). Cinco sinapomorfias putativas para esse grupo de gêneros foram propostas: (1) fileira de espinhos da margem ântero-ventral do fêmur mesotorácico dos machos, divididas em duas seções (proximal e distal); (2) fileira de espinhos da margem póstero-ventral do fêmur metatorácico dos machos com aumento gradual no comprimento em sentido distal; (3) vesica spermalis com a margem póstero-dorsal do capuz projetada em dois processos esclerosados; (4) carena do esternito do S8 restrita a porção basal na fêmea; (5) ápice do epiprocto da fêmea bilobado (Pinto 2008). Esse grupo possui especial interesse biogeográfico devido a grande disjunção espacial entre os gêneros, sendo a identificação de seu padrão filogenético fundamental para qualquer investigação biogeográfica que envolva padrão e processo.

Mais recentemente Machado (2012) descreveu um grande Libellulidae da Serra de Carajás na Amazônia Brasileira com nome de Carajathemis Machado, 2012 o qual possui grande semelhança com as espécies de Erythemismorpha e possivelmente pertença a esse grupo.

Diversas análises filogenéticas incluíram espécies de Erythemismorpha, quase todas usando dados moleculares, nas quais apenas Erythemis simplicicollis (Say, 1840) foi investigada, uma das espécies de Libellulidae mais comuns na América do Norte ( $c f$. Kambhampati \& Charlton 1999; Artiss et al. 2001; Carle \& Kjer 2002; Saux et al. 2003; Ware et al. 2007). Apesar de geralmente esses gêneros terem sido recuperados como monofiléticos, embora com composições bastante distintas, nenhum estudo testou seu monofiletismo ou incluiu um grande número de suas espécies para avaliar o possível relacionamento entre si, bem com os grupos-irmãos. Um resumo pode ser consultado na Fig. 6. 
No presente trabalho é analisado esse grupo de gêneros com distribuição Holotropical em que pela primeira vez é testado seu monofiletismo seguindo a hipótese de sua composição completa proposta por Pinto \& Carvalho (em prep.). Com isso, o maior número de espécies disponíveis dos gêneros Erythemis (10 spp. / 10 incluídas), Rhodopygia (5 spp. / 5 incluídas), Rhodothemis (4 spp. / 3 incluídas); Acisoma (possivelmente 5 spp./ 4 incluídas), Viridithemis (1 sp. / 1 incluída), Carajathemis (1 sp. / 1 incluída) e Cyanothemis (1 sp. / 1 incluída). Além de Nannophya e Nannothemis sugerido como pertencente a esse grupo por Fleck (2004) são investigadas.
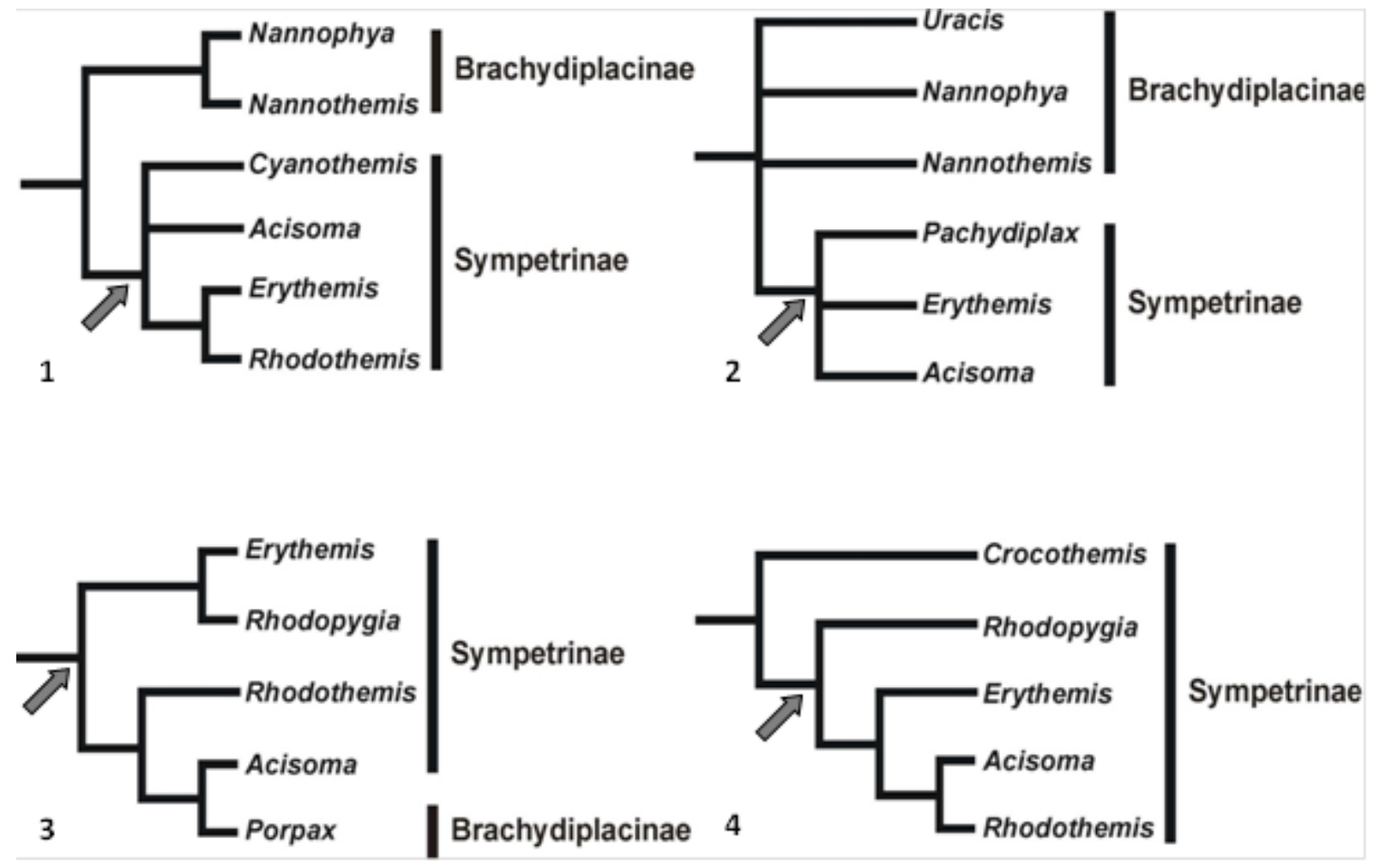

Figura 6. Resumo das hipóteses de relacionamento filogenético em 'Sympetrinae', destacando o grupo de gêneros de Erythemismorpha em que os machos apresentam a armadura femoral especializada (seta). 1. Hipótese sugerida por Fleck (2004) baseada na morfologia larvar; 2. Cladograma de consenso estrito de análises de Parcimônia (cladística) e Bayesiana, com dados moleculares (Ware et al. 2007); 3. Cladograma de consenso estrito de análises de cladística e Bayesiana com dados moleculares (Pilgrim \& von Dohlen 2008); 4. Cladograma de consenso estrito baseada na morfologia dos adultos (Pinto 2008; Pinto \& Carvalho em prep.). 


\section{Nomenclatura dos gêneros ERYTHEMIS, LePtheMIS E MESOTHEMIS ${ }^{4}$}

\section{Case 3584}

Erythemis Hagen, 1861: proposta de precedência sobre Lepthemis Hagen, 1861 (Insecta, Odonata)

Ângelo Parise Pinto

Programa de Pós-Graduação em Ciências Biológicas (Zoologia) IB - USP, Museu de Zoologia da Universidade de São Paulo, Ipiranga 04263-000, Av. Nazaré 481, São Paulo, SP, Brazil

(e-mail: odonata_angelo@hotmail.com)

\section{Rosser W. Garrison}

California Department of Food \& Agriculture, 3294 Meadowview Road, Sacramento, CA 95832-1448, U.S.A. (e-mail: rosser.garrison@cdfa.ca.gov)

Dennis R. Paulson

Slater Museum of Natural History, University of Puget Sound, Tacoma, WA 98416, U.S.A. (e-mail: dennispaulson@comcast.net)

Thomas W. Donnelly

2091 Partridge Lane, Binghamton NY 13903, U.S.A. (e-mail: tdonelly@binghamton.edu)

Michael L. May

Rutgers University, New Brunswick, NJ 08901, U.S.A. (e-mail: mimay@rci.rutgers.edu)

Resumo. O objetivo desse requerimento, nos termos dos Artigos 23.9.3 e 81.1 do Código, é conservar a ampla utilização do nome genérico Erythemis Hagen, 1861 para um grupo de libélulas comuns do Novo Mundo, sobre o gênero nominal simultaneamente publicado

\footnotetext{
${ }^{\text {APP4 }}$ Artigo originalmente publicado em junho de 2012 no Bulletin of Zoological Nomenclature 69(2): 1-9. [ISSN 0007-5167]. A formatação segue a exigida pelo periódico, exceto pelo espaçamento e inclusão de material suplementar como gráficos. A versão original pode ser consultada no Anexo 00.
} 
Lepthemis Hagen, 1861, selecionado para ter prioridade pela ação do Primeiro Revisor (Article 24.2), sempre que esses nomes sejam considerados sinônimos. Esta proposta visa impetrar a menor modificação na nomenclatura envolvendo as espécies atualmente posicionadas nesses dois gêneros em estrita conformidade com o Principio 4 do Código.

Palavras-chave. Nomenclatura; taxonomia; Insecta; Odonata; LIBELLULIDAE; Erythemis; Lepthemis; Erythemis peruviana; Mesothemis; libélulas; Novo Mundo.

1. Hagen (1861), em um trabalho tratando de espécies norte-americanas, estabeleceu três gêneros para acomodar várias espécies de libélulas, novas e previamente descritas, do Novo Mundo. O primeiro, Lepthemis (p. 160), incluiu três espécies, Libellula vesiculosa Fabricius, 1775; Libellula haematogastra Burmeister, 1839; e Libellula verbenata Hagen, 1861. O segundo, Erythemis (p. 168), incluiu Erythemis furcata Hagen, 1861; Libellula bicolor Hoffmannsegg in Erichson, 1848; e Erythemis longipes Hagen, 1861. O terceiro, Mesothemis (p. 170), incluiu Libellula simplicicollis Say, 1840; Mesothemis collocata Hagen, 1861; Mesothemis corrupta Hagen, 1861; Mesothemis illota Hagen, 1861, Libellula attala Selys in Sagra, 1857; Libellula mithra Selys in Sagra, 1857; e Libellula longipennis Burmeister, 1839 como espécies válidas. Ele também listou Libellula acuta Say, 1840 como sinônimo de Lepthemis vesiculosa (p. 161); Libellula caerulans Rambur, 1842 e Libellula maculiventris Rambur, 1842 como sinônimos de Libellula simplicicollis (p.170); Libellula annulata Rambur, 1842 (partim, nec Libellula annulata Palisot de Beauvois, 1807) como sinônimo de Libellula mithra Selys in Sagra, 1857 (p. 172); Libellula socia Rambur, 1842; e Libellula truncatula Rambur, 1842 como sinônimo de Libellula longipennis (p. 173).

2. No mesmo trabalho, Hagen (1861), em sua "List of South American Neuroptera" (pp. 316-318), incluiu mais quinze espécies nestes três gêneros. Sob o gênero nominal Lepthemis (p. 316) mais cinco espécies foram citadas, duas previamente descritas, Libellula cardinalis Erichson, 1848; e Libellula attenuata Erichson, 1848; e introduziu os seguintes novos nomes do grupo da espécie, Lepthemis picta Hagen, 1861; Lepthemis extensa Hagen, 1861; e Lepthemis cultriformis Hagen, 1861 todos eles como nomina nuda, uma vez que não atendem as disposições do Artigo 12 do Código. Para Erythemis (pp. 317-318), ele incluiu mais dois nomes do grupo da espécie Libellula peruviana Rambur, 1842; e Libellula rubriventris Blanchard, 1845, e adicionou Erythemis lavata Hagen, 1861 (um nomen nudum). Finalmente, para Mesothemis (p. 318), ele incluiu mais sete espécies Libellula annulata 
Palisot de Beauvois, 1807; Libellula plebeja Rambur, 1842; Libellula connata Burmeister, 1839; Libellula communis Rambur, 1842; Libellula distinguenda Rambur, 1842; e Libellula abbreviata Rambur, 1842; e novamente introduziu um nomen nudum, Mesothemis gilva Hagen, 1861. Todos estes nomes do grupo da espécie listados por Hagen (1861, pp.160-173, 316-318) representam espécies nominais originalmente incluídas (Article 67.2.1), tornando cada um dos gêneros distintamente grupos heterogêneos. Nenhuma espécie-tipo foi selecionada para qualquer um destes três gêneros.

3. Kirby (1889), por designação subsequente, fixou Libellula vesiculosa Fabricius, 1775 como espécie-tipo para Lepthemis Hagen, 1861 (p. 302); Libellula simplicicollis Say, 1840 como espécie-tipo para Mesothemis Hagen, 1861 (p. 303); e Libellula peruviana Rambur, 1842, como espécie-tipo para Erythemis Hagen, 1861 (p. 305). Embora se possa argumentar que Libellula peruviana não era um dos nomes originalmente incluídos no gênero nominal Erythemis, o que tornaria a fixação do tipo por Kirby um ato inválido sob o Artigo 67.2.5 do Código, Hagen (1861, p. 169) sob Erythemis bicolor (Hoffmannsegg in Erichson, 1848, p. 583), sugeriu a sinonímia com Libellula peruviana Rambur, 1842 ('Is it different of Libellula peruviana Rambur?'), embora ele ( $c f$. Selys, 1850, p. 398) anteriormente houvesse considerado ambos como sinônimos ('Dans le Voyage de Schomburgk au Brésil et à la Guyane, M. Erichson a décrit sous le nom de Lib. bicolor la Lib. peruviana, dit M. Hagen...' [Na viagem de Schomburgk ao Brasil e Guiana, Mr. Erichson descreveu sob o nome de Lib. bicolor, Lib. peruviana, diz Mr. Hagen....]). Além disso, Hagen (1861, p. 318) incluiu em sua "List of South American Neuroptera" Libellula peruviana em Erythemis, uma espécie para a qual ele tinha anteriormente (p. 169) e novamente (p. 318) sugerido a sinonímia com Libellula bicolor Hoffmannsegg in Erichson, 1848 ('Perhaps E. bicolor'). Apesar de Libellula peruviana Rambur, 1842 ter sido apenas provisoriamente citada por Hagen (1861, p. 169) sob o gênero nominal Erythemis, todas as espécies nominais citadas por Hagen (1861, pp. 160173, 316-318) no mesmo trabalho (excluindo nomina nuda e aqueles que não cumprem as disposições do Artigo 67.2), mesmo quando aparecem em páginas diferentes, devem ser consideradas como nomes originalmente incluídos como disposto no Artigo 67.2.1, e, portanto todos são elegíveis para a fixação como espécie-tipo. Isto torna o ato de Kirby (1889, p. 305) fixando Libellula peruviana Rambur, 1842 como espécie-tipo do gênero nominal Erythemis Hagen, 1861 válido. Kirby muito provavelmente seguiu o alerta de Hagen que Libellula peruviana era a mesma espécie que L. bicolor Hoffmannsegg in Erichson, 1848, e escolheu-a como espécie-tipo. 
4. Kirby (1890, p. 40), seguido por Calvert (1906, p. 30), considerou Libellula bicolor um sinônimo júnior de Libellula peruviana. Calvert (1906, p. 30-31) estabeleceu o sinônimo entre Erythemis e Mesothemis e escolheu Erythemis como sinônimo sênior, baseado na prioridade de página. A partir de Calvert (1906), Mesothemis como um nome do grupo do gênero foi raramente utilizado, com a maioria das citações até 1940 referindo-se a sua espécie-tipo, Libellula simplicicollis (e.g. Needham \& Heywood, 1929, pp. 246-248; Hinman, 1933, p. 50; Ahrens, 1938, p. 14; Ferguson, 1942, p. 148). Depois de 1940, Mesothemis tem sido listado como sinônimo júnior exceto em dois estudos ecológicos onde foram citados com gênero (Polcyn, 1994, p. 443) e como subgênero (Harrison \& Lighton, 1998, p. 1739), respectivamente.

5. O número de nomes incluídos em Lepthemis flutuou do original oito (Hagen, 1861, pp. 160-162, 316), cinco (Hagen, 1877, pp. 73-74), até onze (Brauer, 1868, p. 724), mas estas duas últimas obras simplesmente listam nomes do grupo da espécie. Calvert (1907, p. 339), seguido por Ris (1911, pp. 594-608) em sua monografia para a família inteira, reduziu este número para um, sua espécie-tipo $L$. vesiculosa, e este foi o único nome associado ao gênero de 1907 até 1957.

6. O número de nomes incluídos em Erythemis flutuou do original seis (Hagen, 1861, pp. 168-169, 317-318), para onze (Brauer, 1868, p. 723), mas o último trabalho novamente simplesmente listou nomes do grupo da espécie. Williamson (1923, pp. 8-10) em sua revisão do gênero, reduziu este número para nove, um número que permaneceu estável até 1957.

7. Lepthemis Hagen, 1861 e Erythemis Hagen, 1861 foram considerados gêneros válidos até a avaliação de Kennedy (1923, p. 20) dos membros destes dois gêneros. Ele sugeriu que Erythemis e Lepthemis (também Rhodothemis Ris, 1909 do Velho Mundo) poderiam ser congenéricos baseado na morfologia da vesica spermalis (pênis), porém não formalizou a sinonímia entre eles ('...The writer would be inclined to call the whole series of five or six groups Lepthemis and would consider the individual groups as subgenera...' and '...The comprehensive genus would have to be Lepthemis because of the [page] priority in the use of that name by Hagen...').

8. Rácenis (1958, p. 217 [footnote]) seguindo a opinião informal de Kennedy acima citada, e como Primeiro Revisor formalmente sinonimizou Erythemis e Lepthemis e optou por Lepthemis, baseado aparentemente na prioridade de página ('Según mi opinión, Lepthemis Hagen, 1861 y Erythemis Hagen, 1861 son congenéricos y merecen solamente el status de subgéneros. Para emplear el nombre Lepthemis para este género, véase también las opiniones de Kennedy (1923)' [Em minha opinião, Lepthemis Hagen 1861 e Erythemis Hagen 1861 são 
congenéricos e merecem apenas status de subgêneros. Para usar o nome Lepthemis para este gênero, veja também a opinião de Kennedy (1923)].

9. Gloyd (1980, p. 104) discutiu a dupla utilização de nomes genéricos Lepthemis (com uma espécie) e Erythemis (com 11 [sic!] espécies), nada que '...page priority is not longer considered adamant in the choice of a name.' e 'If the species in these two genera are eventually proven to be congeneric, then retaining the name Erythemis would evoke less change.' ['...prioridade de página já não é considerado inflexível na escolha do nome.' e 'Se as espécies neste dois gêneros forem eventualmente provadas ser congenéricas, então reter o nome Erythemis poderia acarretar menor alteração.']. Ela advertiu contra uma sinonímia na pendência de uma revisão completa do grupo, uma opinião similar também expressada por Belle (1978, p. 5).

10. O uso de um ou outro nome durante os últimos 50 anos (1960-2011) mostra uma inconsistência para as dez espécies que hoje constituem estes dois gêneros. Somente seis citações, Lutz \& Pittman (1970, pp. 280-281, 283), Paulson (1977, p. 180; 1982, p. 266), Sherk (1977, p. 394; 1978, p. 62), e Fleck (2004, pp. 53-54) seguiram Rácenis $(1958,1959)$ na utilização de Lepthemis como sinônimo sênior para todas as dez espécies; 25 citações consideram Erythemis e Lepthemis como gêneros válidos; mais de 120 citações de pelo menos 65 diferentes autores consideram Erythemis sinônimo sênior (Fig. 7-9), lista completa de citações disponíveis a partir dos autores). Uso atual de Erythemis como sinônimo sênior é predominante na literatura (Fig. 7-9). Uma espécie comum do Leste dos Estados Unidos, Erythemis simplicicollis, tem sido objeto de estudos sobre idade de maturação (McVey, 1985), comportamento (Belle \& Whitcomb, 1961; Currie, 1963; Edwards; 1987; Sanborn, 1996), seleção sexual e competição de esperma (McVey \& Smittle, 1984; Waage, 1986; McVey, 1988), fisiologia e parasitologia (May, 1976, 1979; McVey, 1984; Harrison et al., 1994; Painter et al., 1996; Locklin \& Vodopich, 2010), taxonomia (Donnelly, 2004a); ela aparece em numerosos guias de campo ilustrados e listas faunísticas (Dunkle, 1989; Abbott, 2001, 2005, 2006; Curry, 2001; Nikula et al., 2002; 2003; Legler et al., 2003; Manolis, 2003; Mead, 2003; Biggs, 2004; Beaton, 2007; Behrstock, 2008), e trabalhos gerais sobre Odonata (Arnett, 2000; Silsby, 2001; Corbet, 2004; Triplehorn \& Johnson, 2005; Evans, 2007). Existem também numerosas referências taxonômicas, checklists, manuais e livros-texto onde espécies posicionadas em Erythemis, Lepthemis e Mesothemis têm sido incluídas todas juntas em Erythemis na América do Sul (Costa \& Pujol-Luz, 1992; Rodrigues-Capitulo, 1992; Carvalho \& Nessimian, 1998; Costa et al., 2000; Heckman, 2006; von Ellenrieder \& Muzón, 2008); América Central (Measey, 1994; Boomsma \& Dunkle, 1996; Ramírez, Paulson \& 
Esquivel, 2000; Förster, 2001); América do Norte (González-Soriano \& Novelo-Gutiérrez, 1996; Dunkle, 2000; Needham et al., 2000; Donnelly, 2004b; Paulson, 2009), ou todas as espécies do Novo Mundo (Davies \& Tobin, 1985; Garrison, 1991; Bridges, 1994; Steinmann, 1997; Garrison et al., 2006).

11. Uma dissertação de mestrado não publicada (Pinto, 2008), atualmente em fase final de preparação para publicação (Pinto \& Carvalho, in prep.) mostra que todas as 10 espécies compreendendo Erythemis e Lepthemis são congenéricas, necessitando a escolha entre Lepthemis e Erythemis como sinônimo sênior. Desconsiderando Lepthemis como sinônimo sênior, em favor do quase universalmente utilizado Erythemis causaria o mínimo de mudanças na nomenclatura e promoveria estabilidade para este grupo de libélulas, especialmente considerando que vários membros do último gênero são espécies comuns e bem distribuídas, algumas das quais têm sido objeto de estudos de comportamento e de seleção sexual. Aplicando a regra do Primeiro Revisor (Artigo 24.2.1 do Código) poderia não promover estabilidade da nomenclatura (Princípios 4 do Código).

12. A Comissão Internacional de Nomenclatura Zoológica é solicitada:

(1) usar seu poder de plenário para determinar que o nome genérico Erythemis Hagen, 1861 ganhe precedência sobre Lepthemis Hagen, 1861, sempre que eles sejam considerados como sinônimos;

(2) colocar na lista oficial de nomes genéricos em Zoologia o nome Erythemis Hagen, 1861 (gênero: feminino), espécie-tipo por designação subsequente por Kirby (1889) Libellula peruviana Rambur, 1842, com o aval de ser dada precedência sobre Lepthemis Hagen, 1861, sempre que estes dois nomes sejam considerados sinônimos;

(3) colocar na lista oficial de nomes genéricos em Zoologia o nome Lepthemis Hagen, 1861 (gênero: feminino), espécie-tipo por subsequente designação por Kirby (1889) Libellula vesiculosa Fabricius, 1775, com o aval para que não seja dada prioridade sobre Erythemis Hagen, 1861, sempre que estes dois nomes sejam considerados sinônimos.

(4) colocar na lista oficial de nomes específicos em Zoologia os seguintes nomes:

(a) peruviana Rambur, 1842, tal como publicado no binômio Libellula peruviana, sinônimo sênior subjetivo de Libellula bicolor Hoffmannsegg in Erichson, 1848, nome específico da espécie-tipo de Erythemis Hagen, 1861;

(b) vesiculosa Fabricius, 1775, tal como publicado no binômio Libellula vesiculosa, nome especifico da espécie-tipo de Lepthemis Hagen, 1861. 


\section{Agradecimentos:}

Agradecemos a Alcimar L. Carvalho (Museu Nacional, Rio de Janeiro), Jürg De Marmels (Universidad Central de Venezuela, Maracay), Jan van Tol (Naturalis, Leiden), e Natalia Von Ellenrieder (California Department of Food \& Agriculture, Sacramento) pelas opiniões e ajuda com este requerimento, bem como aos dois Comissários pela revisão.

\section{Referências}

Abbott, J.C. 2001. Distribution of dragonflies and damselflies (Odonata) in Texas. Transactions of the American Entomological Society, 127(2): 199-228.

Abbott, J.C. 2005. Dragonflies and damselflies of Texas and the south-central United States: Texas, Louisiana, Arkansas, Oklahoma, and New Mexico. vii, 344 pp. Princeton University Press, Princeton.

Abbott, J.C. 2006. Dragonflies and damselflies (Odonata) of Texas, vol. 1. vii, 320 pp. Odonata Survey of Texas, Austin.

Ahrens, C. 1938. A list of dragonflies (Odonata) taken in southern Alaska. Entomological News, 49: 225-227.

Arnett, R.H. 2000. American insects. A handbook of the insects of America north of Mexico. Ed. 2. xvii, 1003 pp. CRC Press, Boca Raton.

Beaton, G. 2007. Dragonflies \& damselflies of Georgia and the Southeast. ix, 355 pp. The University of Georgia Press, Athens.

Bell, R. \& Whitcomb, W.H. 1961. Erythemis simplicicollis (Say), a dragonfly predator of the Bollworm Moth. The Florida Entomologist, 44(2): 95-97.

Belle, J. 1978. Dragonfly records from Highlands County, Florida, United States. Notulae Odonatologicae, 1(1): 4-5.

Behrstock, R.A. 2008. Dragonflies \& damselflies of the Southwest. 80 pp. Rio Nuevo Publishers, Tucson.

Biggs, K. 2004. Dragonflies of California and common dragonflies of the Southwest. 160 pp. Azalea Creek Publishing Co., Sebastopol.

Boomsma, T. \& Dunkle, S.W. 1996. Odonata of Belize. Odonatologica, 25(1): 17-29.

Brauer, F. 1868. Verzeichniß der bis jetzt bekannten Neuropteren im Sinne Linne's. Verhandlungen Zoologisch-botanishen Gesellschaft in Wien, 18: 359-416, 711-742. 
Burmeister, H. 1839. Handbuch der Entomologie, v. 2, part 2. Pp. 757-1050. Enslin, Berlin.

Bridges, C.A. 1994. Catalogue of the family-group, genus-group and species-group names of the Odonata of the world (Third Edition). xxi, 905 pp. Privately published, Urbana, Illinois.

Calvert, P.P. 1906. Nomenclature of certain North American Odonata. Entomological News, 17: $30-31$.

Calvert, P.P. 1907. Odonata. Pp. 17-420. In: Godman, F.D. \& Salvin, O. (Eds.), Biologia Centrali-Americana: Neuroptera. v.50, 1892-1908. xxx, 420 pp. Porter \& Dulaü Co., London.

Corbet, P. 2004. Dragonflies. Behavior and ecology of Odonata (Third printing). xxxii, 829 pp. Comstock Publishing Associates, Ithaca.

Carvalho, A.L. \& Pujol-Luz, J.R. 1992. On the odonate fauna of Ilha Grande and some other coastal islands of the State of Rio de Janeiro, Brazil. Notulae Odonatologicae, 3(10): 157-159.

Carvalho, A.L. \& Nessimian, J.L. 1998. Odonata do Estado do Rio de Janeiro, Brasil: hábitats e hábitos das larvas. Pp. 3-28. In: Nessimian, J. L. \& Carvalho, A. L. (Eds.), Ecologia de Insetos Aquáticos. xiv, 1-161 pp. Series Oecologia Brasiliensis, vol. V. PPGE-UFRJ. Rio de Janeiro, Brasil.

Costa, J.M., Machado, A.B.M., Lencioni, F.A.A. \& Santos, T.C. 2000. Diversidade e distribuição dos Odonata (Insecta) no estado de São Paulo, Brasil: Parte I - Lista das espécies e registros bibliográficos. Publicações Avulsas do Museu Nacional, 80: 1-27.

Costa, J.M. \& Pujol-Luz, J.R. 1993. Descrição da larva de Erythemis mithroides (Brauer) e notas sobre as larvas conhecidas do gênero (Odonata, Libellulidae). Revista Brasileira de Zoologia, 10(3): 443-448.

Currie, N. 1963. Mating behavior and local dispersal in Erythemis simplicicollis. Proceedings North Central Branch, Entomological Society of America, 18: 112-115.

Curry, J.R. 2001. Dragonflies of Indiana. xiv, 303 pp. Indiana Academy of Science, Indianapolis.

Davies, D.A.L. \& Tobin, P. 1985. The dragonflies of the world: a systematic list of the extant species of Odonata. Vol. 2. Anisoptera. Societas Internationalis Odonatologica, Rapid Communications, Supplement, 5: 1-151.

Donnelly, T.W. 2004a. Erythemis simplicicollis and collocata - subspecies? Argia, 15(4): $11-13$. 
Donnelly, T.W. 2004b. Distribution of North American Odonata. Part II: Macromiidae, Corduliidae and Libellulidae. Bulletin of American Odonatology, 8(1): 11-32.

Dunkle, S.W. 1989. Dragonflies of the Florida Peninsula, Bermuda, and the Bahamas. 154 pp. Scientific Publishers, Gainesville.

Dunkle, S.W. 2000. Dragonflies through binoculars. viii, 266 pp. Oxford University Press, Oxford.

Edwards, G.B. 1987. Predation by adult Erythemis simplicicollis (Say) on spiders (Anisoptera: Libellulidae). Notulae odonatologicae, 2(9): 153-154.

Erichson, W.F. 1848. Insecten. Pp. 553-617. In: Schomburgk, R. Reisen in British Guiana in den Jahren 1840-1844, versuch einer fauna und flora von British Guiana. v.3, viii, Pp. 533-1261. Verlagsbuchhandlung von J.J. Weber, Leipzig.

Evans, A.E. 2007. Field guide to insects and spiders of North America. 497 pp. Sterling Publishing Co., Inc., New York.

Fabricius, J.C. 1775. Systema Entomologiae, Sistens Insectorum Classes, Ordines, Genera, Species, Adiectis, Synonymis, Locis, Descriptionibus, Observationibus. xxx, 832 pp. Flensburgi et Lipsiae in Officina Libraria, Kortii.

Fleck, G. 2004. Le larve du genre Cyanothemis Ris, 1915 (Odonata: Anisoptera: Libellulidae). Conséquences phylogénétiques. Annals de la Société Entomologique de France, 39(4): 51-58.

Ferguson, A. 1942. Scattered records of Texas and Louisiana Odonata with additional notes on the Odonata of Dallas County. Field and Laboratory, 10(2): 145-149.

Förster, S. 2001. The Dragonfly of the Central America exclusive of Mexico and West Indies. A guide to their identification. Second Edition. x, 141 pp. Gunnar Rehfeldt, Wolfenbüttel, Germany.

Garrison, R.W. 1991. Synonymic list of New World Odonata. Argia, 3(2): 1-30.

Garrison, R.W., von Ellenrieder, N. \& Louton, J.A. 2006. Dragonfly genera of the New World: an illustrated and annotated key to Anisoptera. xiv, 368 pp. The Johns Hopkins University Press, Baltimore.

Gloyd, L.K. 1980. The status of the generic names Erythemis, Lepthemis, and Mesothemis (Anisoptera: Libellulidae). Notulae odonatologicae, 1(6): 103-104.

González-Soriano, \& Novelo-Gutiérrez, R. 1996. Odonata. Pp. 147-167. In: LlorenteBousquets, J., Garcia-Aldrete, A.N. \& Gonzalez-Soriano, E. (Eds.), Biodiversidad, taxonomía y biogeografía de artrópodos de México: Hacia una sintesis de su conocimiento. 660 pp. Universidad Autonoma de Mexico, Mexico D.F. 
Hagen, H.A. 1861. A synopsis of the Neuroptera of North America with a list of the South American species. Smithsonian Institution Miscellaneous Collections, 4: xx, 1-347.

Hagen, H.A. ' 1875 ' [1877]. Synopsis of the Odonata of America. Proceedings of the Boston Society of Natural History, 18: 20-96.

Harrison, J.F. \& Lighton, J.R.B. 1998. Oxygen-sensitive flight metabolism in the dragonfly Erythemis simplicicollis. The Journal of Experimental Biology, 201: 1739-1744.

Harrison, S.J., Platt, A.P. \& Sanders S.P. 1994. An electrophoretic comparison of enzymes from Anax junius (Drury) and Erythemis simplicicollis (Say) (Anisoptera: Aeshnidae, Libellulidae). Odonatologica, 23(4): 421-429.

Hinman, E.H. 1933. Dragon-flies predacious on Tabanus spp. Entomological News, 44: 4950.

Heckman, C.W. 2006. Encyclopedia of South American aquatic insects: Odonata Anisoptera. Illustrated keys to known families, genera, and species in South America. viii, 705 pp. Springer, Dordrecht.

Kennedy, C.H. 1923. The phylogeny and the distribution of the genus Erythemis (Odonata). Miscellaneous Publications of the Museum of Zoology University of Michigan, 11: 1921.

Kirby, W.F. 1889. A revision of the subfamily Libellulinae, with descriptions of new genera and species. Transactions of the Zoological Society of London, 12(9): 249-348.

Kirby, W.F. 1890. A synonymic catalogue of Neuroptera Odonata, or dragonflies, with an appendix of fossil species. ix, 202 pp. Gurney \& Jackson, London.

Legler, K., Legler, D. \& Westover, D. 2003. Color guide to dragonflies of Wisconsin. Ed. 4.0. 68 pp. Amberwing publishing, Sauk City.

Locklin, J.L. \& Vodopich, D.S. 2010. Eugregarine parasitism of Erythemis simplicicollis (Say) at a constructed wetland: a fitness cost for females? (Anisoptera: Libellulidae). Odonatologica, 39(4): 319-331.

Lutz, P.E. \& Pittman, A.R. 1970. Some ecological factors influencing a community of adult Odonata. Ecology, 51(2): 279-284.

May, M. L. 1976. Thermoregulation and adaptation to temperature in dragonflies (Odonata: Anisoptera). Ecological Monographs, 46(1):1-32.

May, M.L. 1979. Energy metabolism of dragonflies (Odonata: Anisoptera) at rest and during endothermic warm-up. Journal of Experimental Biology, 83: 79-94.

Manolis, T. 2003. Dragonflies and damselflies of California. x, 201pp.University of California Press, Berkeley. 
Mead, K. 2003. Dragonflies of the North Woods. x, 203 pp. Kollath-Stensaas Publishing, Duluth.

Measey, G.J. 1994. Some Odonata from Belize, Central America. Notulae Odonatologicae, 4(3): 40-46.

McVey, M.E. 1984. Egg release rates with temperature and body size in libellulid dragonflies (Anisoptera). Odonatologica, 13(3): 377-385.

McVey, M.E. 1985. Rates of color maturation in relation to age, diet, and temperature in male Erythemis simplicicollis (Say) (Anisoptera: Libellulidae). Odonatologica, 14(2): $101-114$.

McVey, M.E. 1988. The opportunity for sexual selection in a territorial dragonfly, Erythemis simplicicollis, Pp. 44-58. In Clutton-Brock, T.H. (Ed.), Reproductive success: studies of individual variation in contrasting breeding systems. ix, 548 pp. University Chicago Press, Chicago.

McVey, M.E. \& Smittle, B.E. 1984. Sperm precedence in the dragonfly Erythemis simplicicollis. Journal of Insect Physiology, 30(8): 619-628.

Needham, J.G. \& Heywood, H.B. 1929. A handbook of dragonflies of North America (Anisoptera). viii, 615 pp. Berkeley, University of California Press.

Needham, J.G., Westfall Jr., M.J. \& May, M.L. 2000. Dragonflies of North America. Revised Edition. xv, 939 pp. Scientific Publishers, Inc., Gainesville.

Nikula, B., Sones, J., Stokes, D. \& Stokes, L. 2002. Stokes beginner's guide to dragonflies and damselflies. 159 pp. Little, Brown \& Company, Boston.

Nikula, B., Loose, J. L. \& Burne, M. R. 2003. A field guide to the Dragonflies and Damselflies of Massachusetts. vii, 197 pp. Massachusetts Division of Fisherires \& Wildlife, Natural Heritage \& Endangered Species Program, Boston.

Painter, M.K., Tennessen, K.J. \& Richardson, T.D. 1996. Effects of repeated applications of Bacillus thuringiensis israelensis on the mosquito predator Erythemis simplicicollis (Odonata: Libellulidae) from hatching to final instar. Environmental Entomology, 25(1): $184-191$.

Paulson, D.R. 1977. Odonata. Pp. 170-184. In: Hurlbert, S.H. (Ed.), Biota Acuatica de Sudamerica Austral. San Diego State University, San Diego.

Paulson, D.R. 1982. Odonata. Pp. 249-277. In: Hurlbert, S.H. \& Villalobos-Figueroa, A. (Eds.), Aquatic biota of Mexico, Central America and the West Indies. San Diego State University, San Diego.

Paulson, D.R. 2009. Dragonflies of the West. 535 pp. Princeton University Press, Princeton. 
Pinto, A.P. 2008. Análise cladística de Erythemis Hagen, 1861 com avaliação de seu posicionamento filogenético em Sympetrinae (Insecta, Odonata, Libellulidae) [Cladistic Analysis of Erythemis Hagen, 1861 with assessment of its phylogenetic placement in Sympetrinae]. xiv, 144 pp. UFRJ / MN, Rio de Janeiro. [Dissertation presented in the post-graduate program in Biological Sciences (Zoology)/UFRJ, as requirement for degree of Master of Science].

Pinto, A.P. \& Carvalho, A.L. [in preparation]. A morphological cladistic analysis of Erythemis Hagen, 1861 and the significance of congruence test of characters for homology statements of wing venation in Anisoptera (Odonata).

Polcyn, D.M. 1994. Thermoregulation during summer activity in Mojave Desert dragonflies (Odonata: Anisoptera). Functional Ecology, 8: 441-449.

Rácenis, J. 1958. Los Odonatos Neotropicales en la coleccion de la Facultad de Agronomia de la Universidad Central de Venezuela. Acta Biologia Venezuelica, 2(19): 179-226.

Rácenis, J. 1959. Lista de los Odonata del Peru. Acta Biologia Venezuelica, 2(34): 467-522.

Rambur, P. 1842. Histoire naturelle des insectes. Néuroptères. i-xviii, 534 pp. Libraire Encyclopédique de Roret, Paris.

Ramírez, A., Paulson, D.R. \& Esquivel, C. 2000. Odonata of Costa Rica: diversity and checklist of species. Revista de Biología Tropical, 48(1): 247-254.

Rodrigues Capitulo, A. 1992. Los Odonata de la republica Argentina. Fauna de agua dulce de la República Argentina, 34(1): 1-91.

Ris, F. 1911. Libellulines 2, Libellulinen 5. In: Catalogue Systematique et Descriptif des Collections Zoologique Du Baron Edmond Selys de Longchamps, 13: 529-700.

Sanborn, A.F. 1996. The cicada Diceroprocta delicata (Homoptera: Cicadidae) as prey for the dragonfly Erythemis simplicicollis (Anisoptera: Libellulidae). Florida Entomologist, 79(1): 69-70.

Say, T. '1839' [1840]. Descriptions of new North American neuropterous insects, and observations on some already described. Journal of the Academy of Natural Sciences of Philadelphia, 8(1): 9-46.

Selys-Longchamps, Edm. de. 1850. Revue des Odonates ou Libellules d'Europe. Mémoires de la Société Royale des Sciences de Liége, 6: i-xxii, 1-408.

Selys-Longchamps, Edm. de. 1857. Odonates de Cuba. Pp. 436-472. In: Sagra, R. de La (Ed.). Histoire Physique, Politique et Naturelle de I'Ile de Cuba. Animaux articules, tomo 7: 35-473. Arthus Bertrand Editeur, Paris. 
Sherk, T.E. 1977. Development of the compound eyes of dragonflies (Odonata). I. Larval compound eyes. Journal of Experimental Zoology, 201(3): 391-416.

Sherk, T.E. 1978. Development of the compound eyes of dragonflies (odonata). III. Adult compound eyes. Journal of Experimental Zoology, 203(1): 61-79.

Silsby, J.D. 2001. Dragonflies of the World. vii, 216 pp. CSIRO Publishing, Collingwood.

Steinmann, H. 1997. World catalogue of Odonata, Volume II Anisoptera. xiv, 636 pp. Walter de Gruyter, Berlin.

Triplehorn, C.A. \& Johnson, N.F. 2005. Borror and Delong's introduction to the study of insects. Ed. 7. x, 864pp. Thomson Brooks/Cole, Belmont.

von Ellenrieder, N. \& Muzón, J. 2008. An updated checklist of the Odonata from Argentina. Odonatologica, 37(1): 55-68.

Waage, J.K. 1986. Sperm displacement by two libellulid dragonflies with disparate copulation durations (Ansisoptera). Odonatologica, 15(4): 429-444.

Williamson, E.B. 1923. Notes on the genus Erythemis with a description of a new species (Odonata). Miscellaneous Publications of the Museum of Zoology University of Michigan, 11: 1-18.

Aviso do recebimento deste requerimento foi publicado no BZN 69: 83.

Comentários sobre esse caso são convidados para publicação (sujeitos a edição) no Bulletin; eles devem ser enviados ao Secretário Executivo, I.C.Z.N., a/c Natural History Museum, Cromwell Road, London SW7 5BD, U.K. (e-mail: iczn@nhm.ac.uk). 


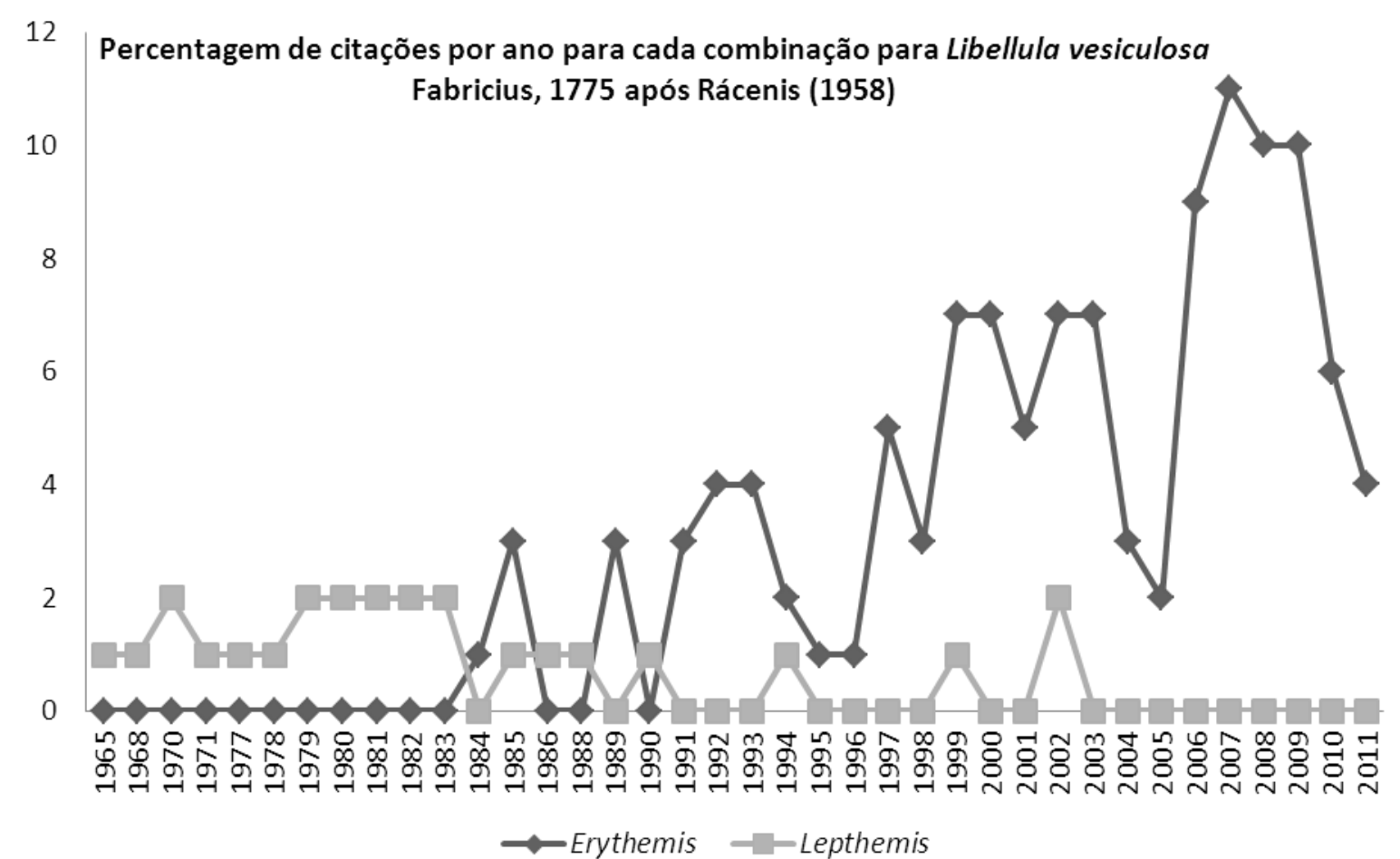

Figura 7. Número de citações anuais de 1958 a 2011 da espécie-tipo de Lepthemis após a ação do Primeiro Revisor (Rácenis 1958) em diferentes combinações.

Combinações para Libellula vesiculosa Fabricius, 1775 após Rácenis (1958)

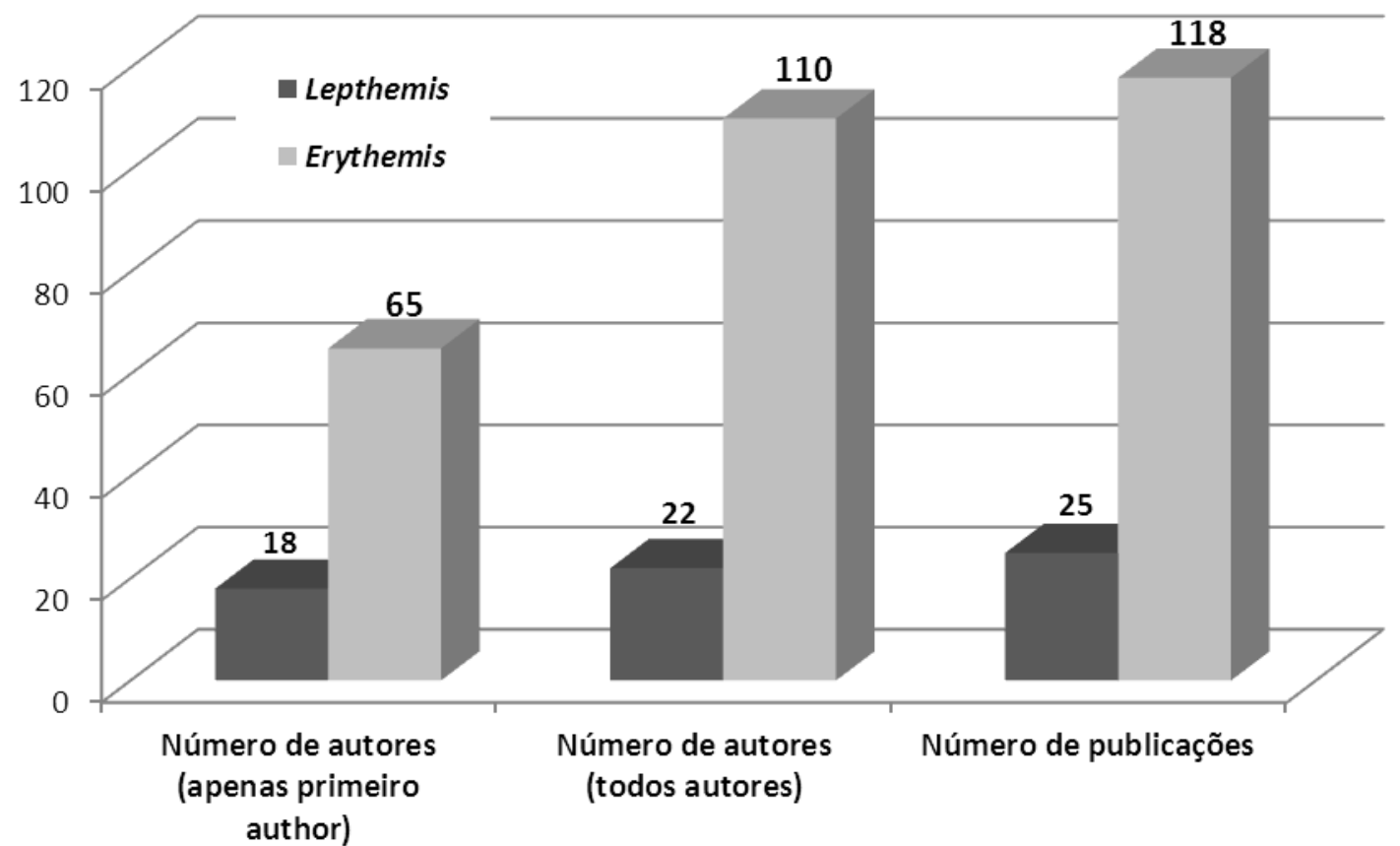

Figura 8. Número de autores e publicações de 1958 a 2011 que citam a espécie-tipo de Lepthemis após a ação do Primeiro Revisor (Rácenis 1958) em diferentes combinações. 
Percentagem de citações por ano para cada combinação para Libellula vesiculosa Fabricius, 1775 após Rácenis (1958)

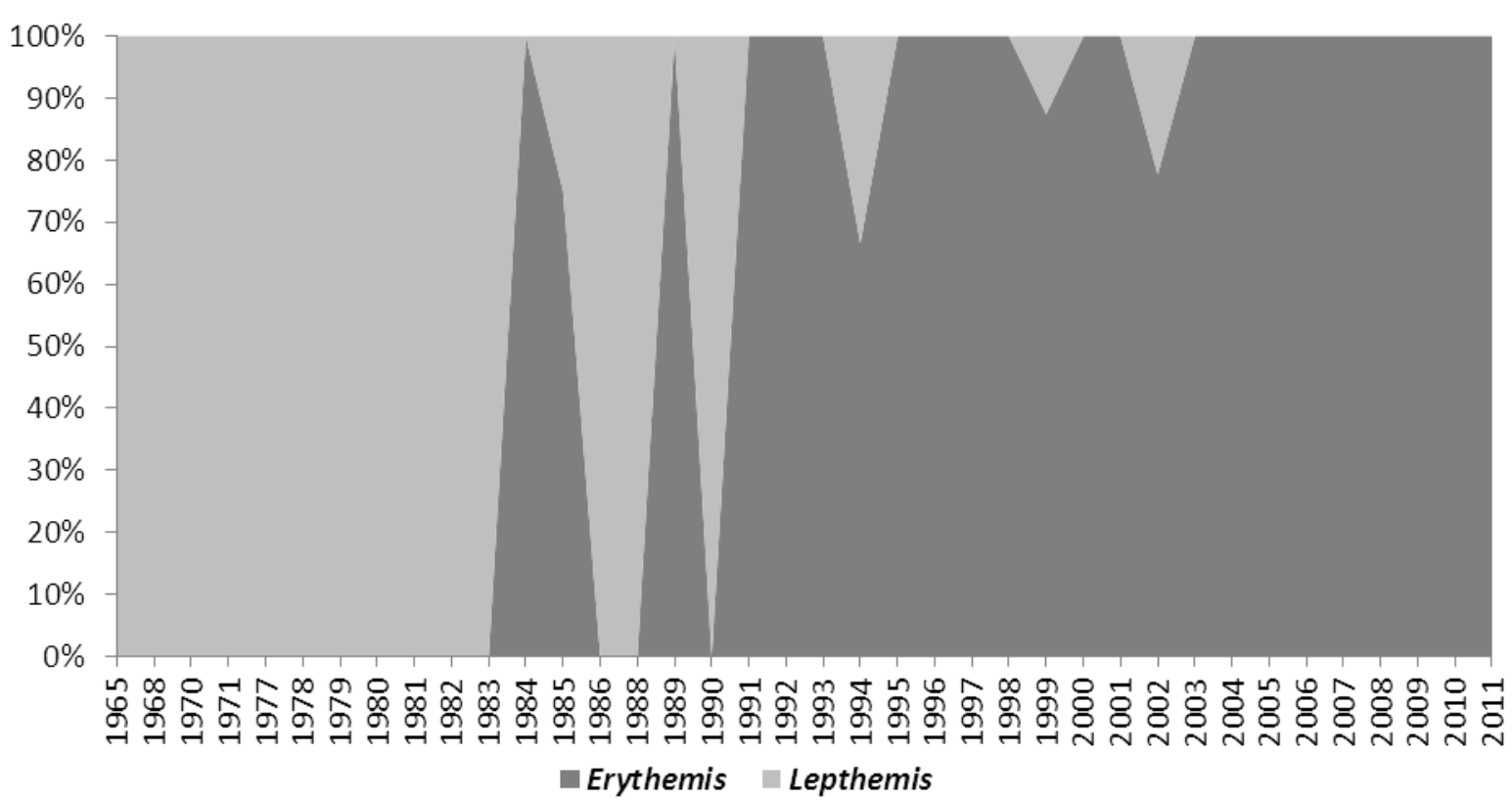

Figura 9. Número de citações anuais em percentagem de 1958 a 2011 da espécie-tipo de Lepthemis após a ação do Primeiro Revisor (Rácenis 1958) em diferentes combinações. 


\section{VENAÇÃO ALAR, CLASSIFICAÇÃO E HOMOPLASIA ${ }^{5}$}

"That, however, appears to be based wholly on the untenable assumption that because a form is an ancient fossil it is therefore primitive." (Needham \& Broughton 1927, p. 164).

"Apparently it is often forgotten that the impossibility of determining directly the essential criterion of homologous characters [...] (p. 93) [n]aturally, in determining homologies we are limited to erecting hypotheses [...] (p. 94)”. (Hennig 1966).

"A character is thus a theory, a theory that two attributes which appear different in some way are nonetheless the same (or homologous). As such, a character is not empirically observable; hence any (misguided) hope to reduce taxonomy to mere empirical observation seems futile." (Platnick 1979, p. 542).

As passagens acima sintetizam a "natureza" hipotética das declarações sobre caracteres largamente aceitas sob as bases conceituais da teoria cladística e que se tornaram gradualmente nebulosas pelas práticas atualmente empregadas nas análises filogenéticas. $\mathrm{Na}$ última década muitos odonatólogos direcionaram suas ofensivas contra os "sistemas", ou hipóteses de classificação, com base em caracteres morfológicos, principalmente naqueles fortemente centrados em caracteres da venação alar (e.g. Dijkstra \& Vick 2006; Ware et al. 2007; Pilgrim \& von Dohlen 2008; Ballare \& Ware 2011). Tais autores difundiram a ideia de que caracteres da venação apresentam níveis elevados de homoplasia, ou pelo menos, maior que outras fontes de dados, na maioria dos casos quando comparados com dados moleculares e que, portanto, deveriam ser excluídos das análises filogenéticas. Apesar de sermos simpatizantes com alguns dos argumentos expostos por esses autores, especialmente relativos à objeção ao uso de uma única fonte de dados, suas conclusões tendenciosas sobre a adoção de caracteres da venação estão profundamente baseadas em conceitos equivocados, e iremos demonstrar que são extremamente reducionistas e quase desprovidos de base empírica.

\footnotetext{
${ }^{5}$ Texto originalmente escrito inglês como parte integrante de um dos artigos escritos durante o doutorado (Pinto \& Carvalho, Zoologica Scripta, in prep.).
} 
Caracteres da venação alar tem sido a espinha dorsal das classificações em Odonata, desde suas fundações com o Barão Michel Edmond de Sélys-Longchamps (e.g. Selys 1850), largamente reconhecido como o criador da odonatologia moderna ( $c f$. Donnelly 1997), passando por Needham (1903), Tillyard (1917) e Fraser (1957), até mais recentemente com Carle (1982), e Bechly (1995, 1996), estes dois últimos sob um enfoque filogenético mais contemporâneo (para uma visão geral veja Trueman 2007 e Bybee et al. 2008). Em parte, a preferência por caracteres da venação pode ser explicada por eles tornarem possível a comparação de fósseis com táxons atuais, desde que estruturas das asas são facilmente observáveis e geralmente são as únicas partes corporais preservadas de linhagens fósseis extintas de libélulas. Deve-se concordar que, em casos nos quais, há uma superestimação de características da venação sobre outras fontes de dados, isso pode levar a hipóteses errôneas de relacionamento ou, pelo menos, com menor suporte, mas tais resultados não podem ser atribuídos unicamente aos caracteres da venação.

Um dos mais fortes e diretos ataques ao emprego de caracteres da venação foi perpetrado por Dijkstra \& Vick (2006, p. 51), com o assertivo título "Inflation by venation and the bankruptcy of traditional genera [...]", já que, superficialmente, caracteres da venação adotados de modo isolado não permitem um posicionamento adequado das espécies em distintos gêneros de um determinado grupo de Libellulidae. Apesar da classificação revista apresentada pelos autores com base em outros caracteres aparentemente estar correta, deve-se considerar que uma hipótese enganosa não é uma propriedade defectiva exclusiva aos caracteres da venação. De fato, suas críticas devem ser direcionadas para as análises extremamente polarizadas, em que se utiliza uma única fonte de dados, ou mesmo da inadequação dos métodos de inferência empregados. Esse problema assemelha-se ao da dualidade de árvores de genes versus árvores de espécies (Nichols 2001; Degnan \& Rosenberg 2006) quanto à fonte de dados, assim como da distância fenética baseada em similaridade global versus análises filogenéticas (Farris 2011) em relação aos métodos de inferência. "Erros" no posicionamento de espécies, caso possa ser interpretado desse modo, em diferentes táxons não é um resultado exclusivo dos caracteres da venação, mas também de outras fontes de dados, desde nucleotídeos a macroestruturas, todas podem conduzir a hipóteses de agrupamento equivocadas, assim como, diferentes métodos de análise também podem potencialmente produzir diferentes resultados, embora não necessariamente errados, já que são baseados em distintas suposições.

As críticas em relação à venação, como fonte de dados inútil para a análise filogenética, falham em não reconhecer que quase todos os "sistemas de classificação", os 
quais, em grande parte estão baseados nessa fonte de dados, não aplicam qualquer método formal para a reconstrução filogenética, ou mesmo propuseram seus arranjos classificatórios como filogenéticos, pelo menos não em um sentido estrito. Algumas dessas críticas são difíceis de compreender quais são suas reais propostas devido à ausência de uma base empírica, por exemplo, alguns argumentos são profundamente atrelados à classificação defeituosa de Tillyard-Fraser (Tillyard \& Fraser 1938-1940; Fraser 1957), mas sua fragilidade é prontamente reconhecida, já que foi proposta anterior à revolução Hennigiana e adota amplamente a noção de uma relação direta, real, de ancestral-descendente, muito distinta do corrente tratamento hipotético dos ancestrais e do reconhecimento da impossibilidade de representar relacionamentos ancestral-descendente em uma árvore filogenética (para discussão sobre a representação de relacionamento ancestral-descendente veja Goldstein \& DeSalle 2000). Além disso, a maioria das classificações após Hennig apresenta inúmeros problemas metodológicos ( $c f$. Bybee et al. 2008). Certamente um dos maiores problemas nesse caso é tratar cada nova hipótese como absoluta, como realmente inovadora e melhor que as anteriores, uma vez que estão sob a luz da "moderna" sistemática filogenética. Esse fato é agravado quando é negligenciado a quase inexistência de sistemas adequados de classificação para realizar comparações precisas.

\section{Existem verdadeiros sistemas de classificações para Odonata?}

Um dos objetivos da sistemática é classificar os táxons com base em algum tipo de critério. Nesse sentido, após Darwin, a classificação objetiva refletir o padrão de ancestralidade comum entre as espécies ( $c f$. Reif 2007). Assim, a então denominada "Árvore da Vida", corresponde nada mais que um sistema de classificação descrito em um grafo acíclico aninhado (uma árvore binária), representando uma hipótese de relacionamento filogenético da vida.

Nesse contexto, Ware et al. (2007) ofereceram uma revisão completa sobre a classificação sistemática de Libelluloidea na qual foi adotada uma intrigante categorização baseada no método de inferência denominado de 'análise' em sua tabela 1 (p. 291-292). Infelizmente, o sistema dos autores falha em não reconhecer abordagens distintas, tanto sob o ponto de vista filosófico quanto metodológico. Muitos dos sistemas categorizados como "parcimônia manual", na verdade são simplesmente listas de nomes, sem qualquer método de agrupamento de táxons, sendo que nos melhores dos casos, alguns conceitos da sistemática filogenética foram adotados nessas proposições classificatórias. Este raciocínio não é trivial, 
possui profundas consequências e pode levar o leitor a equacionar de modo impreciso hipóteses de classificação baseadas em premissas subjetivas, as quais são quase inteiramente desprovidas de procedimentos claros e de base teórica, daquelas formais, objetivas, com procedimentos claros e reproduzíveis, largamente utilizados na parcimônia cladística ou outros métodos baseados em modelos como a máxima verossimilhança. Modificando uma sentença de Sober (2004, p. 644), embora utilizada em outro contexto, servirá aqui para ilustrar a fragilidade dessa crença "Which is better - using a [classification] that explicitly makes unrealistic assumptions or a [classification] whose assumptions are unknown?". Para demonstrar o abismo entre os pressupostos da verdadeira análise cladística e dos métodos subjetivos, incluindo aqueles às vezes referidos como "Critério Hennigiano", primeiro devese esclarecer os procedimentos da parcimônia, ou em outras palavras, o programa da parcimônia (sensu Brady 1983, 1985).

Parcimônia, sob um senso amplo, é adotada em diversas etapas da investigação científica ( $c f$. Sober 1988), no entanto, na sistemática filogenética parcimônia corresponde a um procedimento formal, largamente baseado na teoria, no qual se refere à escolha de uma hipótese hierárquica inclusiva de relacionamento entre táxons (ou outros elementos), em que, idealmente é expresso em uma árvore binária na qual se se minimiza hipóteses ad hoc (Farris 1983). Atualmente esse programa é realizado com a aplicação de algoritmos específicos, geralmente os de Wagner (Farris 1970) e Fitch (Fitch 1971), no entanto, outros procedimentos como Dollo ou Sankoff possam também ser aplicados ( $c f$. Swofford \& Maddison 1992). Portanto, a equivalência de "sistemas de classificação" desprovidos de metodologia com parcimônia, como o catálogo de nomes organizados em categorias taxonômicas de Davies \& Tobin (1985), ou os comentários sobre a classificação de Corduliidae de Lieftinck (1977), mesmo considerando como não intencional, é fortemente depreciativa aos estudos cladísticos e a toda investigação filogenética como disciplina. Tal como previamente demonstrado nos capítulos introdutórios, o primeiro estudo cladístico verdadeiro com Anisoptera, apesar de sua metodologia mal aplicada, deve ser considerado aquele de Wighton \& Wilson (1986) envolvendo linhagens de Aeshnidae.

Entre todos os trabalhos enumerados como "parcimônia manual" por Ware et al. (2007), aqueles que correspondem a lista de nomes ou a propostas de classificação descompromissadas não devem ser considerados como parcimônia, mesmo manual. Assim, de modo geral, apenas duas abordagens de "parcimônia" podem ser identificadas, uma baseada nos defeituosos métodos apriorísticos e obscuros de análise, conhecidos como "Critério Hennigiano" (denominado algo como parcimônia manual em alguns círculos, possivelmente 
possa também incluir a análise de três itens), e outro objetivo largamente testável, com um claro estabelecimento de caracteres, geralmente analisados usando programas computacionais de parcimônia. A divisão entre parcimônia manual e "computer assisted parsimony" utilizada por Ware et al. (2007), como já demonstrada em outros trabalhos é uma divisão fútil, já que não se refere a aspectos metodológicos, mas sim ao uso de uma ferramenta indispensável (o computador) para a análise filogenética. Divisões muito mais aprimoradas, organizadas em diferentes escolas cladistas, ainda que informalmente, têm sido propostas ( $c f$. Carpenter 1987; Ebach et al. 2008). Consequentemente, o único método verdadeiramente cladístico é o derivado do estabelecimento objetivo e da congruência entre caracteres, o que exige um processo de descoberta para a seleção de uma hipótese de hierarquia (Farris 1983; Nelson 1989, mas veja Williams \& Ebach 2009; Williams et al. 2010 para distintos pontos de vista).

A parte da caracterização da parcimônia em sistemática, na verdade, existem poucos sistemas verdadeiros de classificação. Após Tillyard-Fraser (Fraser 1957), talvez apenas os propostos por Bechly $(1995,1996)$ e Lohmann (1996a-c) possam ser considerados sistemas de classificação em um sentido estrito, no entanto, eles são incompletos para vários níveis. Por outro lado, todos os resultados dos estudos filogenéticos recentes podem ser convertidos em classificações. Novamente, o problema real aqui não é apenas a utilização de caracteres da venação para formular uma hipótese de classificação, mas todos os conceitos subjacentes e metodologias empregadas para gerar estas propostas. Portanto, as críticas mais severas ao pequeno número de sistemas de classificação propostos para Odonata não deve ser direcionado a suas fontes de dados (i.e. venação alar), mas ao invés disso, aos seus métodos de inferência, caso exista algum, e consequentemente, suas premissas subjacentes.

\section{A “NATUREZA” HOMOPLÁSTICA dOS CARACTERES DA VENAÇÃo ALAR}

"Many morphological studies of Odonata, however, have focused on wing vein characters [...] that may be homoplasious". (Ballare \& Ware 2011, p. 138)

"Wing venation characters clearly were not a useful means of delineating relationships between libellulid taxa, but can be useful for identifying the families of Anisoptera”. (Pilgrim \& von Dohlen 2008, p. 170). 
Ambos os trechos citados acima, ilustram eloquentemente o conceito atual sobre homoplasia e caracteres da venação entre os odonatólogos que trabalham com reconstrução filogenética, ou seja, que caracteres da venação são inúteis ou menos confiáveis para inferência filogenética já que apresentam altos níveis de homoplasia. Atrelada a essa crença, geralmente existe também declarações tais como "caracteres da venação são úteis apenas ao nível de família", o que é absolutamente sem sentido, visto que estudos adequados nunca foram conduzidos para testar esta afirmação. Para analisar essas declarações, deve-se responder algumas questões fundamentais: 1. O que é homoplasia? 2. Como é reconhecida como tal? 3. Caracteres de venação apresentam níveis mais altos de homoplasia do que outras fontes de dados? 4. E, finalmente, eles são piores do que outras fontes de dados, e, portanto, podem ser excluídos de estudos comparativos de análise filogenética?

Debates sobre homoplasia são extremamente extensivos na literatura da biologia comparada, pois, na maioria dos casos são tratados juntamente com seu conceito antagonista o de homologia (e.g. Patterson 1982, 1988; Rieppel 1988, 1991, 1992; de Pinna 1991; Nixon \& Carpenter 2012a-c; Brower \& de Pinna 2012). Alguns aspectos relevantes para nossa argumentação serão brevemente ilustrados, uma vez que uma revisão compreensiva está à parte de nosso objetivo. O termo homoplasia foi introduzido por Lankester (1870) como oposto ao de homogenia (atualmente homologia), "herança de uma parte comum (p. 42)" de seu ancestral imediato, assim homoplasia "inclui todos os casos de semelhança de forma que não são rastreáveis a homogenia (p. 41)". Curiosamente Hennig (1966) não fez qualquer menção à palavra homoplasia ao longo de seu livro, já que, de algum modo adotou o conceito de homoiologia de L. Plate (p. 117), no entanto, Hennig o distinguiu de outros conceitos como convergência e paralelismo. No atual paradigma da sistemática filogenética homoplasia pode ser resumida apenas ao conceito de ajuste, ajuste de um caráter sobre uma hipótese específica de relacionamento, em outras palavras, homoplasia corresponde a um caráter que quando otimizado não se ajusta perfeitamente sobre uma árvore (e.g. Brady 1983; Farris 1989; Goloboff 1991; Scotland 2011). Desse modo, diferentemente de sinapomorfia a qual é dependente da posição da raiz (polarização), homoplasia é prontamente identificada em árvores não enraizadas. Conceitos como reversão, paralelismo e convergência nada mais são que hipóteses ad hoc vinculadas ao processo, postuladas após a obtenção de um padrão de relacionamento, e há argumentos razoáveis para que as declarações sobre padrão terem precedência sobre as de processo ( $c f$. Rieppel 1988, 1991, 1992; Hall 1994, 2007). Contudo tentativas para caracterizar explicitamente tais processos, mesmo em relação ao padrão de relacionamento têm sido abordadas ( $c f$. Hall 2007; Scotland 2011). 
Consequentemente, atualmente existem duas categorias mutuamente exclusivas de caracteres na sistemática filogenética, aqueles que representam homologias (os bons) e outros homoplasias (os ruins). A equação de homologia com sinapomorfia defendida por Patterson (1982) e outros (veja também Rieppel 1988, 1992; de Pinna 1991; Brower \& de Pinna 2012; Pavnilov 2012) contribuiu com esta tortuosa divisão, tornando-a ainda mais problemática. Ao considerar homologia o mesmo que sinapomorfia, e que um grupo monofilético é suportado por sinapomorfias, consequentemente, homoplasia não pode ser uma sinapomorfia e tampouco justificar o monofiletismo de qualquer táxon. Isso se torna claro ao observar a definição de homoplasia no glossário de Kitching et al. (1998, p. 208): "Any character that is not a synapomorphy (homology)". No entanto, os algoritmos de parcimônia não fazem distinção entre transformações homoplásticas e não homoplásticas para suportar um nó, já que somente minimizam transformações independentes, portanto, as homoplasias identificadas através do teste de congruência podem ser as únicas transformações que suportam uma hipótese de relacionamento. Este é um dos aspectos que levou Williams \& Ebach (2009) a criticar a abordagem numérica para a cladística, a qual se baseia na "busca" por árvores não enraizadas para a seleção de hipóteses de relacionamento, uma vez que as conexões entre os táxons, já são conhecidas antes das sinapomorfias serem determinadas. Um aspecto geralmente negligenciado é que ao minimizar a homoplasia não resulta em um ajuste perfeito dos caracteres, mas sim no melhor ajuste, e que, portanto, o padrão selecionado é aquele que melhor explica os dados em mãos. Em resumo, homoplasias são declarações de homologia (ou homologia primária sensu de Pinna 1991) que não passam no teste de congruência, portanto, não podem ser explicadas por herança comum sem apelo a hipóteses ad hoc (e.g. convergência) e o teste de congruência é a única maneira cabal de detectar homoplasias. $\mathrm{O}$ teste apenas indica que nossas declarações a priori sobre homologias estão equivocadas, e não que uma transformação homoplásticas não pode ser uma sinapomorfia de um grupo. Este aspecto será mais detalhadamente discutido abaixo.

Mesmo nas mais recentes e largamente divergentes discussões sobre homologia (Nixon \& Carpenter 2012a, b; Williams \& Ebach 2012; Farris 2012a, b; Brower \& de Pinna 2012), caracteres foram reafirmados como construções abstratas carregadas de teoria, portanto, são hipotéticas em essência. Assim, homologia, tampouco homoplasia, são status adquiridos em determinado círculo científico e assim tornam-se uma propriedade irrefutável do caráter, ambos são hipóteses e como tal estão sempre sujeitas a teste, assim não há modo de propor "homologization" em tudo. A cladística como um método de inferência científica está sujeita a revisão, reinterpretação e a sua investigação está profundamente depositada 
sobre o teste de congruência, assim como amplamente discutido no final do século passado (e.g. Brady 1983, 1985; Rieppel 1988, de Pinna 1991).

Outro aspecto sobre homoplasia, o qual foi reiterado em uma das revisões mais recentes do conceito por Nixon \& Carpenter (2012a) é a compreensão de homoplasia como um erro de observação, o qual reflete uma declaração errônea de um caráter, em sua codificação, ou considerando dados moleculares, em seu alinhamento. Homoplasia é amplamente reconhecida como um "ruído", de fato, o teste de congruência não identifica sinapomorfias, mas na verdade detecta homoplasias, casos em que o estágio conjectural da declaração de homologia é rejeitado, nos quais não passa no teste de escrutínio considerando outros caracteres (de Pinna, 1991). Portanto, a interpretação padrão é de amplamente reconhecer homoplasia como menos informação ou no mínimo informação potencialmente enganosa, que os caracteres não homoplásticos. Evidentemente que uma MPT altamente congruente a um conjunto de dados específico, e, portanto perfeitamente hierárquica, é melhor que outra altamente incongruente e não totalmente hierárquica. Entretanto deve-se considerar que nem sempre níveis elevados de homoplasia correspondem a uma pior hipótese de relacionamento. A melhor hipótese é aquela que melhor explica (se ajusta) ao conjunto de dados investigado, assim, os níveis de homoplasia exibidos são intrínsecos à análise e, de alguma forma, são independentes da quantidade de homoplasia necessária para explicar os dados. Um aspecto sobre homoplasia que contradiz em grande parte a visão de que os níveis de homoplasia são diretamente proporcionais às hipóteses falsas ou hipóteses ruins de relacionamento, é a sua capacidade de discernir entre árvores concorrentes. Em um artigo verdadeiramente brilhante, Goloboff (1991) traçou uma distinção clara entre dois conceitos relacionados, e um tanto quanto equivocadamente compreendidos em sistemática filogenética, isto é, informação e decisão (decisiveness). O primeiro está ligado à informação dos caracteres em si, se um caráter específico, apresenta potencial para homoplasia (i.e. não é uma autapomorfia para um nó terminal), enquanto o segundo se refere exclusivamente ao conjunto de dados, se o conjunto de dados permite uma escolha ou decisão entre as classificações concorrentes (árvores). Goloboff (1991) desmistificou muitos conceitos equivocados, demonstrando que homoplasia não implica em menos informação (i.e. no sentido de decisão), e menor confiança nos resultados. Ele também mostrou que o ri (índice de retenção) do caráter não é uma medida precisa da homoplasia, desde que caráteres menos homoplásticos podem exibir valores baixos de ri (p. 217) e que o RI não é adequado para a comparação de homoplasia entre diferentes conjuntos de dados, mas para comparar homoplasia entre as árvores do mesmo conjunto de dados (p. 218), portanto, é um estimador útil para investigar 
diferenças de ajuste entre MPTs. Como resultado pode-se concluir que níveis elevados de homoplasia e consequentemente valores baixos de CI ou RI não necessariamente representam dados piores, isso porque a parcimônia não requer o mínimo de homoplasia, mas que a homoplasia seja minimizada. Dessa forma, uma quantidade máxima de homoplasia não implica confiança mínima nos resultados (Goloboff 1991). Portanto é verdadeiramente falacioso afirmar que um carácter altamente homoplástico sobre uma árvore será também homoplástico no contexto de outra análise, ou mesmo que algum nível específico de homoplasia demonstra uma hipótese errada de hierarquia.

Recentemente Pilgrim \& von Dohlen (2008) suportaram suas declarações sobre a "homoplasious nature" da venação alar com base no ajuste de seus caracteres selecionados sobre sua árvore molecular e concluíram que os caracteres "menos" homoplásticos são aqueles com valores mais elevados de ci e ri, sendo esses os únicos adequados para inferir hierarquia, os quais coincidentemente são aqueles utilizados para a distinção de Libellulidae de outras famílias de Anisoptera. Dois aspectos foram ignorados, o primeiro que um conjunto de dados totalmente congruente (valores máximos de $\mathrm{CI}$ ) pode não fornecer informação alguma sobre a preferência por uma árvore (undecisiveness) e segundo, que esses mesmos caracteres podem ser homoplásticos em uma análise mais inclusiva e, portanto, apresentar valores menores de ajuste do que outros caracteres. A presente discussão sobre a interpretação dos índices de homoplasia mostra que a argumentação de Pilgrim \& von Dohlen (2008) não se sustenta, e, portanto, sua "Table 4" (p. 170) tem pouca utilidade em suportar seus argumentos de que a venação alar é inútil para a inferência filogenética, ainda mais se considerarmos que não é comparativa com outras fontes de dados em sua análise, como por exemplo, os dados moleculares, ou mesmo entre os distintos loci em sua base de dados.

De fato, a única conclusão que pode ser obtida da comparação feita por Pilgrim \& von Dohlen (2008) é de que as suas hipóteses de homologia primária (declarações de caracteres) foram rejeitadas como homologia secundária e consequentemente, o compartilhamento entre os táxons não pode, ao menos primariamente, ser explicado por uma conexão histórica de ancestralidade. Assim, apenas as declarações de caracteres, i.e., a conjectura sobre ser a mesma coisa (sameness), são testados pelo teste de congruência ou durante a sua otimização sobre uma árvore previamente obtida, não a(s) estrutura(s) per se.

Além disso, é absolutamente questionável considerar uma hipótese obtida com base em caracteres da venação alar, como sendo primariamente errada apenas por divergir daquelas obtidas usando dados moleculares. Não existem estudos empíricos comparando homoplasia entre diferentes conjuntos de dados, ou entre dados morfológicos e moleculares que permitam 
uma diagnose confiável do assunto. Alguns casos de homoplasia são facilmente resolvidos após a reavaliação da declaração primária do caráter, especialmente quando envolve casos conhecidos como reversão. Um dos exemplos mais elucidativos é a ausência de asas em adultos de algumas ordens de Pterygota (insetos alados), amplamente explorada desde Hennig (1966) e, mais recentemente, recursivamente por Farris (2012a,b). Não há dúvida de que a "ausência" de asas em Siphonaptera (ordem das pulgas), por exemplo, representa uma sinapomorfia para a ordem, no entanto, dependendo dos táxons selecionados, ou se codificado como sendo o mesmo que o observado nas ordens de insetos sem asas (e.g. Zygentoma) é uma homoplasia. Porém, considerando que as pulgas evoluíram de insetos alados, esse caráter, é, portanto, interpretado como uma reversão. Seguindo a conexão lógica em considerar homologia o mesmo que sinapomorfia sensu Patterson (1982) esse caráter "homoplástico" não suporta o monofiletismo da ordem das pulgas desde que grupos monofiléticos são identificados por sinapomorfias!

Retornando para a questão envolvendo Anisoptera, Pilgrim \& von Dohlen (2008) consideram a "ausência" do triângulo anal nas asas posteriores de machos de Libellulidae como um dos caracteres mais confiáveis, pois apresenta valores elevados de ci e ri. Visto que esse caráter é geralmente usado para diagnosticar a família, levou-os a concluir que caracteres da venação alar são somente úteis para o nível de família. Concordamos que a "ausência" de triângulo anal é uma forte evidência do monofiletismo de Libellulidae, no entanto, dois aspectos devem ser verificados, primeiro a fraqueza lógica de declarações envolvendo ausência de caracteres, o que nós preferíamos considerar como ausências secundárias (neomorphic characters sensu Sereno 2007) e segundo, a ocorrência múltipla em outras famílias de Anisoptera. Como no exemplo sobre Siphonaptera referido acima, a correta transposição de uma observação particular em uma declaração de caráter (homologia primária) não é a ausência em si, mas todas as características que resultaram na observação negativa da "presença" de triângulo anal na asa posterior dos machos. Ausência não é um caráter já que não descreve a propriedade de uma estrutura ou táxon, e inclui todos os outros casos negativos em outros organismos (ou objetos) que também compartilham a mesma ausência (Nelson 1978; Fitzhugh 2006; mas veja Nixon \& Carpenter 2012c para um ponto de vista distinto). Por outro lado, não há dúvida de que a "ausência" de triângulo anal (bem como de aurículas no segundo segmento abdominal) em machos de Libellulidae seja uma sinapomorfia putativa para toda a família, uma vez que em quase todas as demais linhagens de Anisoptera o macho apresenta triângulos anais. No entanto, em um cenário em que representantes dos gêneros distantemente relacionados a Libellulidae como Anax Leach, 1815 
e Hemianax Selys, 1883 em Aeshnidae, (von Ellenrieder 2002), ou Agriogomphus Selys, 1869 e Archaeogomphus Williamson, 1919, em Gomphidae (Belle 1996), fossem também incluídos na análise, esta forte evidência do monofiletismo de Libellulidae torna-se uma homoplasia e, portanto, irá apresentar valores inferiores de ci e ri. Seguindo o raciocínio que apenas aqueles caracteres com altos valores de ci possuem sinal filogenético confiável ou adotar o conceito de sinapomorfia disseminado por Patterson (1982) e igualar sinapomorfia a homologia, irá levar a uma conclusão verdadeiramente errônea, i.e. que a "ausência" de triângulo anal em machos de Libellulidae não é uma sinapomorfia para a família. De fato, uma grande quantidade de homoplasias, em muitos casos se deve a observações ruins que resultam em hipótese de caracteres sem refinamento, as quais são descobertas por meio do teste de congruência e que devem ser reavaliados.

Von Ellenrieder (2002), em sua análise de Aeshnidae, considerou a ausência de triangulo anal nos gêneros Anax e Hemianax como uma característica sinapomórfica, a qual é homoplástica em uma análise incluindo gêneros Libellulidae e Gomphidae, assim como já mencionado. Nós não iremos tratar desse assunto novamente, por outro lado, para a mesma linhagem von Ellenrieder (2002) codificou a ausência de aurículas no segundo segmento abdominal em um caráter multiestado (quatro estados), desde a completa ausência até a presença com diferentes processos estruturais sobre a sua superfície, e ela também considerou a ausência de aurículas como uma sinapomorfia para a linhagem. Isso revela mais um aspecto quase ignorado do teste de congruência, o qual foi apenas brevemente discutido por Assis (2009) e Nixon \& Carpenter (2012b-c). Homoplasia, em essência, se refere somente ao estado, o qual controversamente não é totalmente testado por congruência. Usando o exemplo de von Ellenrieder (2002) sobre aurículas (caráter 24 em sua análise) torna esse aspecto claro. Considerando homoplasia como o ajuste não consistente de um caráter sobre uma árvore, ela pode ser adequadamente calculada com a fórmula do ci, assim o máximo número de passos possíveis para um caráter com quatro estados para que não seja homoplástico são três transformações. Entretanto, o caráter apresenta no mínimo oito transformações nas EW MPTs de von Ellenrieder (2002), sendo homoplástico e, portanto por definição não pode ser uma sinapomorfia. Para caracteres binários a relação entre o ci e homoplasia é direta, já que implica em uma única transformação, entretanto, para caracteres multiestado, isso não é recíproco, uma vez que para um, ou mais estados, são observados uma única transformação sobre uma árvore, enquanto os estados restantes podem apresentar transformações múltiplas. Isso é exatamente o caso de algumas transformações observadas no ramo de Rhodopygia em nossa análise (Capítulo 7). Finalmente, podemos considerar os estados com transformações 
únicas sobre uma árvore uma sinapomorfia, independentemente das transformações altamente homoplásticas observadas nos estados restantes? A resposta poderia ser sim, mas homoplasia se refere ao ajuste da declaração do caráter inspecionado (homologue ou primary homology) como um todo e não aos seus estados individualmente. Portanto, caracteres multiestados com ci $<1$ podem apresentar estados não homoplásticos que poderiam representar sinapomorfias verdadeiras, apesar do caráter em si ser homoplástico.

Alguns casos são muito mais intricados que uma óbvia codificação enganosa envolvendo ausências. Por exemplo, espécies dos provavelmente distantemente relacionados gêneros de Libellulidae Camacinia Kirby, 1889, Diastatops Rambur, 1842, Neurothemis Brauer, 1867 e Rhyothemis Hagen, 1867, todos apresentam reticulações secundárias nas asas (anastomose), resultando em um padrão muito denso de venação. Uma hipótese superficial de homologia primária com base no padrão observado aceitaria todos como sendo a mesma coisa, mas um teste de congruência irá demonstrar que, na verdade, corresponde a uma homoplasia, um erro de observação. A questão relevante é, estamos agindo corretamente ao considerar a reticulação observada nas asas de linhagens tão distantes, ou sob uma inspeção apurada demonstrar que estas não são conectadas, como sendo a mesma coisa (sameness)? Provavelmente, a resposta seja não. Por outro lado, o padrão deve ser testado, mas a hipótese não deve permanecer indefinidamente inalterada e deve ser reavaliada frente a novas evidências. Não existe observação livre de teoria, toda observação depende de nossos conceitos prévios e embasamento teórico, sendo assim, como tal, erros de observação são comuns e estão sujeitos a reinterpretação.

\section{CONSIDERAÇÕES FINAIS}

Os aspectos teóricos aqui discutidos, os quais de certo modo podem ser interpretados como uma a defesa a inclusão de caracteres da venação alar e consequentemente de dados morfológicos, objetivou desmistificar algumas ideias equivocadas sobre homoplasia, que estão amplamente disseminadas, e suas consequências, assim como evidenciar alguns aspectos obscuros e ainda persistentes dos conceitos em sistemática filogenética. Níveis de homoplasia são altamente dependentes do conjunto de dados analisado, táxons amostrados, formulação de hipóteses de caracteres e ao método de inferência ( $c f$. DeBry 2005; Heath et al. 2008). Assim, como já explorado e largamente demonstrado, níveis de homoplasia aumentam com o número de táxons terminais, os quais, portanto, diminuem o CI (Archie 1989; Sanderson \& Donoghue 1989); além disso, o índice de consistência é inadequado como 
medida de incongruência quando utilizado isoladamente (Swofford 1996), e níveis de homoplasia entre dados morfológicos e moleculares não são tão distintos, efetivamente em muitos casos foi demonstrado que dados morfológicos apresentam uma quantidade inferior de homoplasia que dados moleculares (Sanderson \& Donoghue 1989; Baker et al. 1998).

Recentemente, observamos um grande esforço na busca de padronização, pelo menos para aumentar a objetividade de dados morfológicos, esforços estes direcionados a delimitação de caracteres, problemas com codificação etc. (e.g. Fitzhugh 2006; Sereno 2007) e, portanto, teste de hipóteses de caracteres não deve ser baseado em análises descompromissadas e tendenciosas. A mesma precisão utilizada para selecionar os melhores loci, premissas de alinhamento, para testar uma hipótese específica de relacionamento e propor uma árvore de espécies deve se estender aos caracteres morfológicos para ser analisado conjuntamente com os dados moleculares. Existem inúmeras simplificações quando se trata de caráteres da venação alar, em alguns casos um caráter taxonômico útil para distinguir um grupo de táxons é utilizado sem qualquer tipo de filtro. De fato, análises filogenéticas por meio do teste de congruência tem recorrentemente demonstrado a pobreza dos caracteres taxonômicos, pelo menos como tradicionalmente empregados, em muitos casos sua inadequação para a inferência filogenética, uma vez que não refletem o relacionamento histórico entre os táxons.

Negar a relevância de caracteres da venação alar para investigação filogenética reflete a desigual tendência na ênfase aos métodos de análises e seus algoritmos, e a menor importância atribuída aos próprios dados e sua análise (Rieppel \& Kearney 2007; Williams \& Ebach 2008; Wheeler 2008). Esta banalização na formulação de hipóteses de caráter primária (fase conjectural) leva a preferência da quantidade sobre a qualidade dos dados, negligenciando assim uma análise profunda dos caracteres que devem ser testáveis por seu direito próprio (Rieppel \& Kearney 2002). Isto é claramente detectado inspecionando a literatura atual, onde os dados das matrizes ou da informação primária são relegados a simples apêndices das análises e no pior dos casos, principalmente considerando dados moleculares, raramente as sequências alinhadas (matriz de dados) utilizadas para obter os resultados são fornecidas. A questão mais relevante é o que formulações vagas de caracteres (os autores não se excluem de erros semelhantes na formulação de caracteres) podem nos dizer sobre as suas relações de homologia taxic interpretada como relacionamento filogenético?

Deve ser destacado aqui que obviamente não está sendo defendido que os caracteres homoplásticos são melhores para a inferência filogenética que os não homoplásticos, mas que pelo menos esses caracteres devem ser reestudados e mesmo quando homoplasias são 
observadas pode fornecer evidência de relacionamento verdadeiro. A maioria dos caracteres homoplásticos da venação alar resultam da nossa incapacidade em detectar condições semelhantes como não homólogas ( $c f$. Nixon \& Carpenter 2012a), mas também demonstra a inadequação dos caracteres taxonômicos, como atualmente estabelecidos, para inferência filogenética, de fato, declarações de caracteres grosseiras ou no mínimo descomprometidas, observações errôneas e essencialmente a falta de refinamento e do controle contínuo de conjuntos de dados sob uma abordagem da iluminação recíproca, assim como advogado por Hennig (1966), são as maiores causas dos elevados níveis de homoplasia.

Dispomos de metodologias, técnicas e fontes de dados diagnósticas, mas os resultados e hipótese não são necessariamente novos ou inovadores. Na enorme quantidade de dados bibliográficos disponíveis sobre sistemática de Odonata, diversos tipos de relacionamento foram propostos, sob diferentes pressupostos, e eles não podem ser simplesmente descartados devido a suas metodologias ou a fonte de dados apresentarem discrepância com a das mais modernas técnicas de análise moleculares. A dicotomia dos estudos moleculares versos morfológicos é fútil e certamente ruim para a ciência da sistemática e ambos os lados têm contribuído para as atuais relações hostis. Retornando às ideias de Hennig (1966) de holomorfologia, hoje reconhecidas como "evidência total" (Kluge, 1997) ou "análise simultânea" (Nixon \& Carpenter 1996b), certamente resultará em hipóteses mais falseáveis ( $c f$. Popper 1972) e estáveis de relacionamento filogenéticos em Odonata. Como já evocado recentemente por alguns autores (e.g. Rieppel \& Kearney 2007; Assis 2009). 


\section{INTRODUÇÃO}

Neste capítulo são apresentados os resultados e a discussão da análise cladística de 'Sympetrinae' com ênfase em Erythemismorpha, os trechos introdutórios referentes aos objetivos, material e métodos, introdução e justificativa, devem ser consultados nos Capítulos 2-4 respectivamente.

\section{RESULTADOS E DISCUSSÃo}

\section{RELAÇÃo dos CARACTERES ${ }^{7}$}

Para aos caracteres em que não há referência ao sexo, ou no caso dos apêndices o seu respectivo segmento, é sempre assumido que é irrelevante para o seu devido reconhecimento. Por exemplo, margem do lábio inteiramente pálido se aplica a ambos os sexos (ch. 1). O número de passos e os valores de ajuste para cada caráter se refere à árvore obtida utilizando IW com fator de concavidade de $K=15$. A matriz de dados completa com a codificação para todos os táxons terminais é apresentada no Apêndice 2.

\section{Subconjunto ("partition") A - Caracteres da Cabeça}

1. Lábio durante o período reprodutivo. $[$ passos $=20 ;$ fit $=0,53$; $\mathrm{ci}=0,15 ; \mathrm{ri}=0,39]$

(0) inteiramente pálido (amarelo-esbranquiçado);

(1) pálido com partes proximais negras, geralmente a lígula com uma linha mal definida sobre os palpos;

(2) pálido com uma distintiva faixa central negra da lígula para os palpos;

(3) inteiramente escuro, castanho-escuro ao negro.

2. Labro durante o período reprodutivo. $[$ passos $=22 ;$ fit $=0,57 ; \mathrm{ci}=0,09 ; \mathrm{ri}=0,31]$

(0) pálido;

(1) pálido com uma linha central negra e estreita;

\footnotetext{
${ }^{\text {APP6 }}$ Parte integrante do manuscrito de autoria de Pinto, Carvalho \& Lamas originalmente intitulado de Armed to kill: a morphological cladistics analysis of Erythemismorpha sensu Pinto \& Carvalho em preparação.

${ }_{\text {APP7 }}$ Comentários das mais diversas naturezas foram intencionalmente omitidos nesta apresentação.
} 
(2) castanho-escuro ao negro.

3. Margem lateroventral do pós-clípeo. $[$ passos $=7 ;$ fit $=0,29 ; \mathrm{ci}=0,14 ; \mathrm{ri}=0,75]$

(0) angulada;

(1) arredondada.

4. Ângulos laterais da pós-fronte. [passos $=4 ; \mathrm{fit}=0,17 ; \mathrm{ci}=0,25 ; \mathrm{ri}=0,80$ ]

(0) mal definidos, sem processos;

(1) definidos, com um par de tubérculos.

5. Superfície anterior da fronte. $[$ passos $=10 ; \mathrm{fit}=0,38 ; \mathrm{ci}=0,10 ; \mathrm{ri}=0,47]$

(0) distintamente achatada;

(1) arredondada.

6. Divisão entre a ante- e pós-fronte. $[$ passos $=6$; fit $=0,25 ; \mathrm{ci}=0,17 ; \mathrm{ri}=0,44]$

(0) carenada;

(1) plana, carena indistinta.

7. Margem dorsal da pós-fronte em vista anterior. [passos $=4$; fit $=0,17$; $\mathrm{ci}=0,25 ; \mathrm{ri}=0,25$ ]

(0) achatada, com depressão central pouco evidente ou indefinida;

(1) sinuosa, com depressão central definida.

8. Dorso da fronte. $[$ passos $=10 ; f i t=0,35 ; \mathrm{ci}=0,20 ; \mathrm{ri}=0,43]$

(0) de coloração uniforme com a antefronte (concolor);

(1) de coloração mais clara em relação à antefronte (discolor);

(2) de coloração mais escura em relação a antefronte (discolor).

9. Superfície dorsal da fronte. [passos $=5$; fit $=0,21 ; \mathrm{ci}=0,20 ; \mathrm{ri}=0,00]$

(0) reflexiva, com reflexos metálicos;

(1) opaca, sem reflexos metálicos distintos.

10. Superfície laterodorsal do ápice da fronte em vista anterior. $[$ passos $=2 ;$ fit $=0,06$; $\mathrm{ci}=$ $0,50 ; \mathrm{ri}=0,00]$

(0) arredondada;

(1) aguda.

11. Omatídios dos olhos compostos. [passos =1; fit =-; $\mathrm{ci}=1,00 ; \mathrm{ri}=0 / 0]$

(0) coloração quase uniforme, sem distinção em diferentes áreas;

(1) com diferente pigmentação, com distinção entre faixas claras e escuras.

12. Contato dorsal entre os olhos compostos ("eyes seam"). [passos $=12 ; \mathrm{fit}=0,38 ; \mathrm{ci}=0,25$; $\mathrm{ri}=0,74]$

(0) longo (razão entre distâncias do trecho em contato e região anterior dos olhos até o ápice do triângulo occipital 0,63-1,00); 
(1) médio $(0,35-0,56)$;

(2) curto $(0,19-0,28)$;

(3) em um único ponto $(<0,13)$.

13. Superfície dorsal do vértice. [passos $=4$; fit $=0,17$; $\mathrm{ci}=0,25 ; \mathrm{ri}=0,40$ ]

(0) irregular, projetada em um par de processos;

(1) quase uniforme, sem processos.

14. Par de processos no vértice. $[$ passos $=5 ; \mathrm{fit}=0,21 ; \mathrm{ci}=0,20 ; \mathrm{ri}=0,43$ ]

(0) mal definido, não mais que uma protuberância extremamente reduzida;

(1) bem definido, com projeções arredondadas ou agudas.

15. Margem posterior do triângulo occipital em vista dorsal. [passos $=11$; fit $=0,40$; ci $=$ $0,09 ; \mathrm{ri}=0,69]$

(0) convexa;

(1) quase linear.

16. Superfície póstero-dorsal do triângulo occipital. [passos $=5$; fit $=0,21$; $\mathrm{ci}=0,20$; ri $=$ $0,77]$

(0) retilínea, sem concavidade central distinta;

(1) irregular, com uma concavidade central ("heart shape").

17. Região posterior da cabeça em vista anteroposterior. [passos $=5 ; \mathrm{fit}=0,21 ; \mathrm{ci}=0,20 ; \mathrm{ri}=$ $0,00]$

(0) sem qualquer processo distinto próximo ao triângulo occipital;

(1) com um par de processos transversais ("ridges") distintos próximos ao triângulo occipital.

\section{Subconjunto ("partition") B - Protórax}

18. Região proximal do lobo posterior do protórax. [passos $=4$; fit $=0,17$; $\mathrm{ci}=0,25$; ri $=0,87$ ]

(0) alargada, margens laterais divergentes ou paralelos;

(1) estreita, margens laterais confluentes ("constricted").

19. Lobo posterior do protórax em vista lateral. [passos $=5$; fit $=0,21 ; \mathrm{ci}=0,20 ; \mathrm{ri}=0,85$ ]

(0) ereto, margem posterior direcionada dorsalmente ou de modo oblíquo;

(1) decumbente, margem posterior direcionada quase posteriormente.

20. Mesepisterno (pelo menos durante algum estágio ontogenético). $[$ passos $=6$; fit $=0,25$; ci $=0,17 ; \mathrm{ri}=0,71]$

(0) escuro, com faixa longitudinal clara distinta;

(1) coloração uniforme ou com faixa longitudinal clara indistinta. 
21. Margem lateral da carena subalar do processo antealar metapleural (Garrison et al. 2006)

(Fig. 10). $[$ passos $=12 ;$ fit $=0,40 ; \mathrm{ci}=0,17$; ri $=0,68]$

(0) arredondada;

(1) angulada, mas não projetada em processo espiniforme;

(2) angulada, projetada em um processo espiniforme.

22. Superfície da carena subalar do processo antealar metapleural. [passos $=2 ;$ fit $=0,06$; $\mathrm{ci}=$ $0,50 ; \mathrm{ri}=0,75]$

(0) lisa;

(1) coberta por processos espiciformes.

23. Carena dorsal de metepímero. [passos $=8 ; f i t=0,32 ; \mathrm{ci}=0,13 ; \mathrm{ri}=0,00$ ]

(0) lisa, sem espinhos;

(1) armada, coberta por espinhos diminutos.

\section{Subconjunto ("partition”) C - Caracteres das asas}

24. Superfície da margem látero-ventral do metapostepímero. [passos $=10 ;$ fit $=0,38$; $\mathrm{ci}=$ $0,10 ; \mathrm{ri}=0,61]$

(0) lisa, sem processos;

(1) armada, coberta por processos espiniformes diminutos.

25. Coloração do pterostigma. [passos $=6$; fit $=0,25 ; \mathrm{ci}=0,17$; $\mathrm{ri}=0,38]$

(0) unicolor, superfície dorsal e ventral com a mesma tonalidade;

(1) discolor, superfície dorsal distintamente mais escura.

26. Coloração do pterostigma. [passos $=3$; fit $=0,12$; $\mathrm{ci}=0,33$; ri $=0,33]$

(0) uniforme;

(1) com área central escura.

27. Espaço entre RA e RP1, posterior ao pt. [passos $=12$; fit $=0,40 ; \mathrm{ci}=0,17$; $\mathrm{ri}=0,29$ ]

(0) densamente reticulado, pt cobrindo duas ou mais células inteiras e três ou mais veias transversais;

(1) esparsamente reticulado, pt cobrindo uma célula e duas veias transversais;

(2) não reticulado, pt cobrindo apenas parte de uma célula e uma veia transversal $(0.33$ proximal do pt sem veia transversal sensu Garrison et al. 2006).

28. Superfície anterior da margem costal após o nó. $[$ passos $=5$; fit $=0,21$; $\mathrm{ci}=0,20$; ri $=$ $0,33]$

(0) quase uniforme com a cor das demais veias;

(1) contrastando com a cor mais escura das demais veias, distintamente mais clara. 

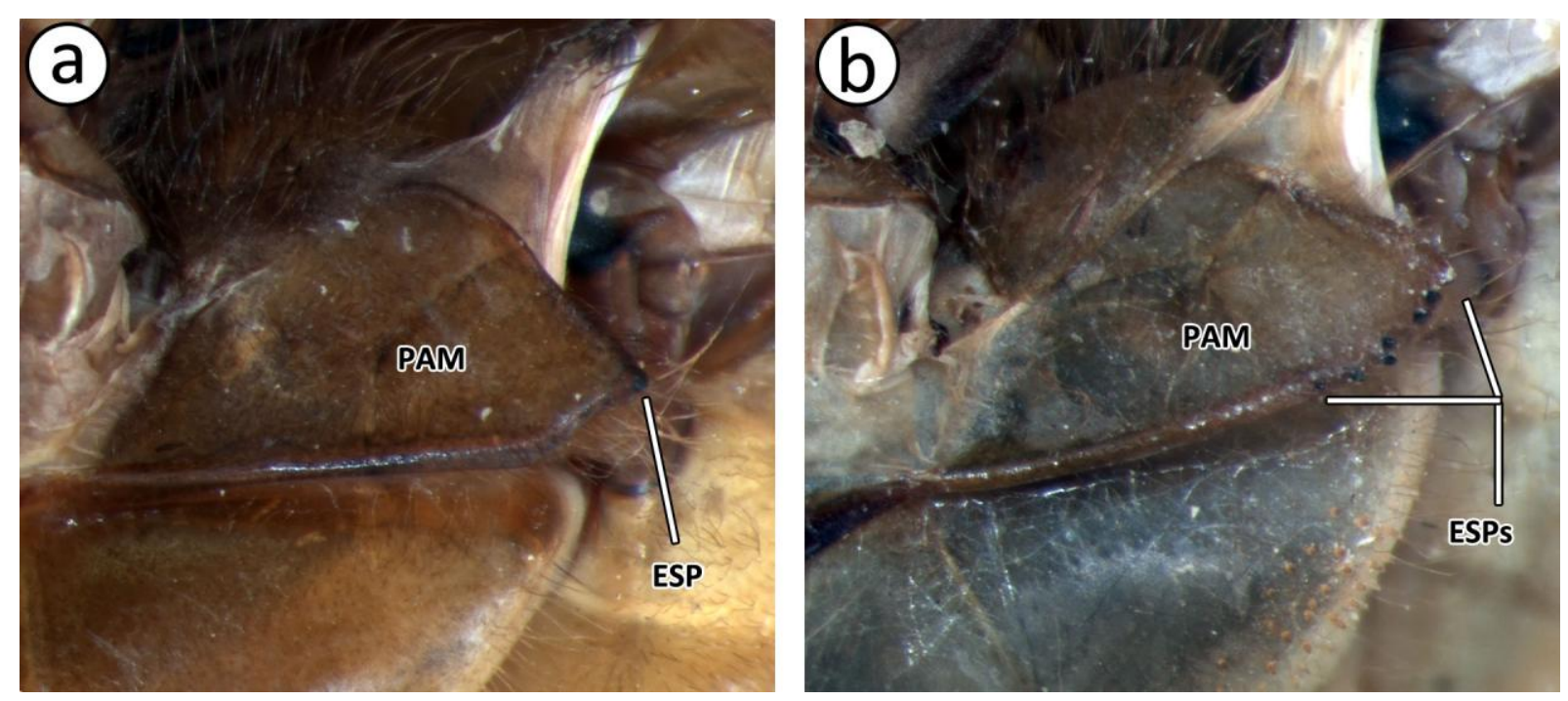

Figura 10. Processo antealar metapleural. a. Rhodopygia cardinalis (Erichson, 1848); b. Crocothemis mariannae Kiauta, 1983; Pam = processo antealar metapleural; Esp(s) = espinho(s)

29. Coloração ventral da porção inferior do nó (ncv sensu Bechly 1995) e o subnó (sncv sensu

Bechly 1995). [passos $=15 ;$ fit $=0,48 ; \mathrm{ci}=0,07$; $\mathrm{ri}=0,13$ ]

(0) clara (amarelada a acastanhada), com a porção central distintamente mais escura;

(1) uniformemente escura castanha a negra.

30. Veia transversal antesubnodal distal ("cordulegastrid gap" sensu Bechly et al. 1998). [passos $=7 ;$ fit $=0,21 ; \mathrm{ci}=0,43 ; \mathrm{ri}=0,79$ ]

(0) posicionada cerca da metade da distância entre a origem do IR2 e o subnó;

(1) posicionada distintamente entre origem do RP3-4 e do IR2;

(2) posicionada sobre ou próximo da origem do IR2;

(3) posicionada na origem do RP3-4.

31. Espaço da ponte ("bridge"). [passos $=4$; fit $=0,12 ; \mathrm{ci}=0,50 ; \mathrm{ri}=0,33$ ]

(0) atravessado por uma veia;

(1) atravessado por duas veias;

(2) atravessado por três ou mais veias.

32. Origem do RP1b. [passos $=5 ;$ fit $=0,21 ; \mathrm{ci}=0,20 ; \mathrm{ri}=0,20]$

(0) sob 0,5 proximal do pt;

(1) sob 0,5 distal do $\mathrm{pt}$;

33. IRP1. [passos $=10$; fit $=0,38$; $\mathrm{ci}=0,10 ; \mathrm{ri}=0,44]$

(0) mal definido;

(1) definido.

34. Espaço entre RP1 e IRP1. [passos = 1; fit = -; $\mathrm{ci}=1,00 ; \mathrm{ri}=0 / 0$ ] 
(0) composto por uma única fileira de células;

(1) composto por duas ou mais fileiras de células.

35. RP1-2 entre a origem do IRP2 e o subnó (Garrison et al. 2006). [passos $=1$; fit $=0,00$; ci $=1,00 ; \mathrm{ri}=1,00]$

(0) levemente convexo ou reto;

(1) fortemente côncavo.

36. RP2 na central porção de Rspl. [passos $=7$; fit $=0,29$; $\mathrm{ci}=0,14$; ri $=0,54$ ]

(0) regularmente curvo;

(1) sinuoso, com uma convexidade na margem anterior.

37. RP2 na porção distal do Rspl ("radial planate" sensu Needham et al. 2000). [passos = 4; fit $=0,17 ; \mathrm{ci}=0,25 ; \mathrm{ri}=0,40]$

(0) sinuoso, com uma leve concavidade;

(1) regularmente curvo, sem concavidade.

38. Espaço entre RP2 e IRP2. [passos $=3$; fit $=0,12 ; \mathrm{ci}=0,33$; $\mathrm{ri}=0,50]$

(0) composto por uma fileira de células;

(1) composto por duas fileiras de células.

39. Origem proximal do Rspl. [passos $=3$; $f i t=0,12$; $\mathrm{ci}=0,33$; $\mathrm{ri}=0,75$ ]

(0) mal definida e distintamente não conectada ao RP2;

(1) claramente definida e conectada ao RP2.

40. Origem distal do Rspl. [passos $=8$; $f i t=0,32 ; \mathrm{ci}=0,13 ; \mathrm{ri}=0,63$ ]

(0) mal definida e distintamente não conectada ao RP2;

(1) claramente definida e conectada ao RP2.

41. Espaço entre o IR2 e o Rspl. [passos = 14; fit =0,44; ci =0,14; ri = 0,29]

(0) duplo, com duas fileiras de células no mínimo na central porção;

(1) único, com uma fileira de células ao longo de todo comprimento;

(2) múltiplo, com mais que duas fileiras.

42. Espaço entre IR2 e RP3-4, a partir do RP-midfork (sensu Bechly 1995; Bechly et al. 1998) a origem do Rspl. [passos $=14 ;$ fit $=0,38 ; \mathrm{ci}=0,36 ; \mathrm{ri}=0,64$ ]

(0) composto por uma fileira de duas células;

(1) composto por duas fileiras de duas células;

(2) composto por três fileiras de duas células;

(3) composto por duas fileiras de duas células, seguida distalmente por uma fileira de três células;

(4) composto por uma fileira de uma célula; 
(5) composto por mais de três fileiras de duas células.

43. Porção distal do RP2-IRP2. [passos $=1$; fit $=-; \mathrm{ci}=1,00 ; \mathrm{ri}=0,00]$

(0) levemente curvo em direção à margem da asa;

(1) fortemente curvo em direção à margem da asa.

44. Ax distal na Fw ("última veia atenodal”). [passos = 7; fit =0,29; ci =0,14; ri = 0,25]

(0) estendida posteriormente a ScP (última Ax incompleta);

(1) estendida posteriormente ao RA (última Ax completa).

45. MA e RP distal ao árculo na Fw. [passos $=4$; fit $=0,17$; $\mathrm{ci}=0,25 ; \mathrm{ri}=0,00$ ]

(0) fusionado por uma longa distância (setores de árculo peciolado);

(1) fusionado por uma curta distância (setores de árculo não-peciolado).

46. Espaço do hipertriângulo na Fw. [passos = 2; fit =0,06; ci =0,50; ri = 0,75]

(0) não atravessado;

(1) atravessado.

47. Espaço do triângulo discoidal na FW. $[\operatorname{passos}=7$; fit $=0,29$; $\mathrm{ci}=0,14$; ri $=0,57$ ]

(0) dividido, com veias transversais (atravessado);

(1) não dividido, sem veias transversais (livre).

48. Margem costal de triângulo (veia MPa) na Fw (Garrison et al. 2006). [passos $=1$; fit =-; $\mathrm{ci}=1,00 ; \mathrm{ri}=0 / 0]$

(0) comprimento distintamente menor que a margem proximal ( $\mathrm{MPa}<\mathrm{MPb}$ );

(1) comprimento similar a proximal margem $(\mathrm{MPa} \approx \mathrm{MPb})$.

49. Alcance distal da MPa na Fw. [passos = 2; fit =0,06; $\mathrm{ci}=0,50 ; \mathrm{ri}=0,00$ ]

(0) sobre ou próximo ao "MA-fork", lado costal do triângulo quase reto;

(1) distintamente proximal ao "MA-fork", lado costal do triângulo "quebrado" no meio.

50. Espaço entre "CuP-crossing” e MP (célula subdiscoidal sensu Bechly 1995) na Fw. [passos $=3 ;$ fit $=0,12 ; \mathrm{ci}=0,33 ; \mathrm{ri}=0,60$ ]

(0) não dividido, sem veias transversais;

(1) dividido, com veias transversais.

51. Alcance distal da PsA na Fw. [passos = 1; fit =-; ci = 1,00; ri = 0,00]

(0) sobre ou levemente proximal ao "MP-fork", lado costal do subtriângulo quase reto;

(1) distintamente proximal ao "MP-fork", lado costal do subtriângulo quebrado.

52. Espaço do subtriângulo discoidal na FW. [passos $=4 ; \mathrm{fit}=0,17$; $\mathrm{ci}=0,25 ; \mathrm{ri}=0,70$ ]

(0) dividido, com veias transversais (atravessado);

(1) não dividido, sem veias transversais (livre).

53. Veia transversal do subtriângulo. [passos $=1 ;$ fit $=-; \mathrm{ci}=1,00 ; \mathrm{ri}=1,00$ ] 
(0) não especialmente curvada;

(1) anteriormente curvada.

54. Campo discoidal na Fw (espaço trigonal sensu Needham et al. 2000). [passos = 13; fit = $0,40 ; \mathrm{ci}=0,23 ; \mathrm{ri}=0,62]$

(0) composto por três fileiras de células, no mínimo até o nível do nó costal;

(1) composto por duas fileiras de células, no mínimo por uma distância de três células;

(2) composto por uma fileira de célula, no mínimo por uma distância de duas células;

(3) composto por quatro ou mais fileiras de células ao longo do campo.

55. Mspl na Fw. [passos = 9; fit $=0,35$; $\mathrm{ci}=0,11 ;$ ri $=0,50]$

(0) fortemente definida;

(1) indefinida ou fracamente definida.

56. Espaço entre MA e Mspl (median planate sensu Needhamm et al. 2000). [passos = 5; fit = $0,21 ; \mathrm{ci}=0,20 ; \mathrm{ri}=0,33]$

(0) composto por uma fileira de células;

(1) composto por duas fileiras de células.

57. Ápice da MP na margem posterior da Fw (Lohmann, 1984). [passos =12; fit = 0,42; ci = $0,08 ; \mathrm{ri}=0,58]$

(0) distal ao nível do nó costal;

(1) sob ou próximo ao nível do nó costal.

58. Células para-anais até o subtriângulo na Fw ("n o p" sensu Needham et al. 2000). [passos $=12 ;$ fit $=0,38 ; \mathrm{ci}=0,25 ; \mathrm{ri}=0,74]$

(0) cinco;

(1) seis;

(2) quatro;

(3) sete ou mais.

59. Célula paranal distal. $[$ passos $=1$; fit $=0,00 ; \mathrm{ci}=1,00 ; \mathrm{ri}=1,00$ ]

(0) pequena, levemente mais alta que a célula imediatamente posterior;

(1) grande, duas vezes mais alta que a célula imediatamente posterior.

60. Árculo na Hw. [passos $=9$; fit $=0,32 ; \mathrm{ci}=0,22 ; \mathrm{ri}=0,65]$

(0) posicionado próximo a $\mathrm{Ax} 2$;

(1) posicionado entre Ax1 e Ax2, porém próximo da Ax1;

(2) posicionado entre Ax2 e Ax3.

61. Espaço de triângulo discoidal na Hw. [passos = 6; fit = 0,25; ci = 0,17; ri =0,44]

(0) não atravessado; 
(1) atravessado.

62. "MP-fork" na Hw (posição da veia transversal conectando RP\&MA ao MP em relação ao “MP-fork"). [passos $=3 ;$ fit $=0,06 ; \mathrm{ci}=0,67 ; \mathrm{ri}=0,83]$

(0) sob ou levemente proximal ao árculo;

(1) distintamente proximal ao árculo;

(2) distintamente distal ao árculo.

63. Alcance distal da MPa no Hw. [passos =1; fit =-; $\mathrm{ci}=1,00 ;$ ri $=0,00]$

(0) ápice na MAb, MPa distintamente curva;

(1) ápice sobre ou próximo ao MA-fork, MPa levemente curva.

64. MP sobre MAb na Hw (sensu Nel et al., 1996; Bechly 1995, Bechly et al., 1998). [passos $=10 ;$ fit $=0,35 ; \mathrm{ci}=0,20 ; \mathrm{ri}=0,74]$

(0) sobre o ângulo anal do triângulo discoidal, próximo ao $\mathrm{AA}+\mathrm{CuA}$;

(1) separado do anal ângulo anal do triângulo discoidal, distante do AA+CuA;

(2) sobre AA+Cua.

65. $\mathrm{MPb}$ na Hw. $[$ passos $=2 ;$ fit $=0,06 ; \mathrm{ci}=0,50 ; \mathrm{ri}=0,50]$

(0) quase reta, tornando o triângulo agudo;

(1) distintamente oblíqua, tornando o triângulo isósceles.

66. Fileira(s) de célula(s) na região proximal do campo discoidal na Hw. [passos =14; fit = $0,42 ; \mathrm{ci}=0,21 ; \mathrm{ri}=0,63]$

(0) dupla, duas fileiras de células após a primeira célula;

(1) única, uma fileira de células a primeira célula pela distância de uma célula;

(2) única, um fileira de célula após a primeira célula pela distância de duas a três células;

(3) múltipla, mais que duas fileiras de células.

67. Fileiras de células no campo discoidal na Hw. [passos $=2$; $f i t=0,06$; $\mathrm{ci}=0,50 ; \mathrm{ri}=0,00$ ]

(0) sexualmente monomórfico;

(1) sexualmente dimórfico.

68. Espaço entre CuP-crossing e MP (célula subdiscoidal sensu Bechly 1995) no Hw. [passos $=7$; fit $=0,29 ; \mathrm{ci}=0,14 ; \mathrm{ri}=0,14]$

(0) não dividido, sem veias transversais;

(1) dividido, com veias transversais.

69. Alcance posterior do $(\mathrm{AA}+\mathrm{CuA}) \mathrm{b}$. [passos $=1 ; \mathrm{fit}=0,00 ; \mathrm{ci}=1,00 ; \mathrm{ri}=1,00]$

(0) anterior a margem da asa e fusionado ao AA1b, alça anal fechada;

(1) na margem posterior da asa, alça anal aberta; contrário. . 
70. Ápice da alça anal. [passos $=1 ; f i t=0,00 ; \mathrm{ci}=1,00 ; \mathrm{ri}=1,00]$

(0) prolongado, com formação de um "toe";

(1) encurtado, sem formação de "toe".

71. Cuspl no Hw. [passos $=4$; fit $=0,17$; $\mathrm{ci}=0,25$; ri $=0,00$ ]

(0) distintamente curvada em direção a margem posterior;

(1) quase reta em direção a margem posterior.

72. Espaço entre Cuspl e AA+CuA na Hw (sensu Fleck et al. 2003). [passos = 8; fit = 0,25; ci $=0,38 ; \mathrm{ri}=0,69]$

(0) com duas células;

(1) com três células;

(2) com uma célula;

(3) múltiplo, com inúmeras células (anastomosado);

73. Número de células para-anais (sensu Needham et al. 2000) até a AA1b na Hw. [passos = $2 ;$ fit $=0,06 ; \mathrm{ci}=0,50 ; \mathrm{ri}=0,00]$
(0) três;
(1) quatro;
(2) duas.

74. Células na patela da alça anal na Hw (Needham \& Brougthon 1927). [passos = 3; fit = $0,06 ; \mathrm{ci}=0,67 ; \mathrm{ri}=0,86]$
(0) uma célula;
(1) duas células;
(2) três ou mais.

75. Células marginais ao AA1b no campo anal da Hw (panels sensu Needham et al. 2000). [passos $=1 ;$ fit $=0,00 ; \mathrm{ci}=1,00 ; \mathrm{ri}=1,00]$
(0) não alongadas (razão entre comprimento/largura 00)
(1) alongadas (razão entre comprimento/largura de 00)

76. Membrana alar na base da asa posterior. [passos $=12 ; \mathrm{fit}=0,42 ; \mathrm{ci}=0,08 ; \mathrm{ri}=0,27]$

(0) hialina;

(1) pigmentada.

77. Veias na região basal da asa posterior. $[\operatorname{passos}=14$; fit $=0,46$; $\mathrm{ci}=0,07$; $\mathrm{ri}=0,28]$

(0) escuras, castanha a negra;

(1) claras, branca a amarela.

78. Campo anal. $[$ passos $=1 ;$ fit $=0,00 ; \mathrm{ci}=1,00 ; \mathrm{ri}=1,00]$

(0) regular, composto por no mínimo duas fileiras de células; 
(1) reduzido, composto quase inteiramente por uma fileira de células.

79. Superfície ventral das veias basais da Hw. $[$ passos $=5 ;$ fit $=0,21 ; \mathrm{ci}=0,20 ; \mathrm{ri}=0,20]$

(0) sem pruinosidade;

(1) com pruinosidade.

80. Superfície da AA\&AP na Hw. [passos = 1; fit =-; ci = 1,00; ri = 0,00]

(0) lisa, sem espinhos;

(1) armada, com espinhos diminutos (macrotríquias).

81. Coloração da membranula. $[$ passos $=6 ;$ fit $=0,25 ; \mathrm{ci}=0,17 ; \mathrm{ri}=0,44]$

(0) menos que 0,50 da área total clara;

(1) mais que 0,75 da área total clara.

82. Membranula. $[$ passos $=6 ;$ fit $=0,21 ; \mathrm{ci}=0,33 ; \mathrm{ri}=0,43$ ]

(0) longa, estendendo-se sobre três células, no mínimo;

(1) média, estendendo-se sobre uma célula e parte de uma segunda;

(2) reduzida, estendendo-se sobre uma pequena parte da primeira célula para-anal.

83. Margem anal na Hw. [passos $=1$; fit $=0,00$; $\mathrm{ci}=1,00$; $\mathrm{ri}=1,00]$

(0) regular não expandida, com limitado número de fileiras células;

(1) expandida, com numerosas fileiras células ("glinder type").

\section{Subconjunto ("partition") D - Pernas (Fig. 11)}

84. Garra tarsal subapical. [passos $=1 ; f i t=-; \mathrm{ci}=1,00 ; \mathrm{ri}=0,00$ ]

(0) levemente projetada, menor que garra apical;

(1). fortemente projetada, de comprimento similar ou maior que a garra apical.

85. Superfície da margem póstero-ventral do fêmur protorácico. $[$ passos $=5 ; f i t=0,17$; $\mathrm{ci}=$ $0,40 ; \mathrm{ri}=0,84]$

(0) coberta unicamente por cerdas rígidas;

(1) coberta por cerdas e por uma fileira de espinhos bem definidos;

(2) coberta por cerdas e por uma fileira de espinhos pouco definidos.

86. Margem ântero-ventral dos fêmures meso e metatorácicos. [passos $=1$; fit $=-;$ ci $=1,00$; $\mathrm{ri}=0,00]$

(0) arredondado,

(1) distintamente carenado.

87. Fileira de espinhos na margem ântero-ventral do fêmur mesotorácico. [passos $=5$; fit $=$ $0,21 ; \mathrm{ci}=0,20 ; \mathrm{ri}=0,80]$ 
(0) composta por espinhos similares no tamanho ou aumentando gradualmente, sem distinção em duas seções (fileira isométrica);

(1) composta por espinhos dissimilares, com distinção clara entre as seções proximal e distal (fileira heterométrica).

88. Espinhos na seção proximal da margem ântero-ventral do fêmur mesotorácico. [passos = $1 ;$ fit $=0,00 ; \mathrm{ci}=1,00 ; \mathrm{ri}=1,00]$

(0) triangulares, com base larga afilando em direção ao ápice;

(1) quadrangulares, com base e ápice largos, e direcionados proximalmente.

89. Superfície da margem póstero-ventral de fêmur mesotorácico. $[$ passos $=8 ; f i t=0,32 ; \mathrm{ci}=$ $0,13 ; \mathrm{ri}=0,73]$

(0) coberta somente por rígidas setas;

(1) coberta por setas e por uma fileira distinta de espinhos.

90. Fileira de espinhos sobre a margem póstero-ventral do fêmur mesotorácico. [passos = 1; fit $=0,00 ; \mathrm{ci}=1,00 ; \mathrm{ri}=1,00]$

(0) composta por pequenos espinhos ao longo da superfície inteira (espinhos isométricos);

(1) composta por espinhos mais longos e robustos sobre a porção distal (espinhos heterométricos).

91. Superfície da carena ântero-dorsal do fêmur mesotorácico. [passos $=12$; fit $=0,42$; ci $=$ $0,08 ; \mathrm{ri}=0,50]$

(0) lisa, sem processo espiniforme;

(1) armada, com processo espiniforme.

92. Espinhos sobre a carena ântero-dorsal do fêmur mesotorácico. [passos $=7$; fit $=0,21$; ci $=$ $0,43 ; \mathrm{ri}=0,56]$

(0) distribuídos em 0,5 proximal;

(1) distribuídos em 0,5 proximal e 0,25 distal;

(2) distribuídos ao longo de todo o comprimento;

(3) distribuídos apenas distalmente.

93. Ápice da carena ântero-dorsal do fêmur mesotorácico. [passos $=11$; fit $=0,40$; ci $=0,33$; $\mathrm{ri}=0,03]$

(0) arredondado, não projetado;

(1) agudo, projetado no processo espiniforme.

94. Superfície da carena ântero-dorsal da tíbia mesotorácica. $[$ passos $=4 ; f i t=0,17$; ci $=0,25$; $\mathrm{ri}=0,25]$ 
(0) armada com processos espiniformes;

(1) lisa, sem processo espiniformes.

95. Espinhos sobre a carena ântero-dorsal da tíbia mesotorácica. $[$ passos $=10$; fit $=0,38$; ci $=$ $0,10 ; \mathrm{ri}=0,31]$

(0) dispostos aproximadamente ao longo de todo comprimento;

(1) restritos a porção proximal.

96. Superfície da carena póstero-dorsal da tíbia mesotorácica. $[$ passos $=13$; fit $=0,44$; ci $=$ $0,08 ; \mathrm{ri}=0,40]$

(0) armado com processos espiniformes;

(1) liso, sem processos espiniformes.

97. Espinhos sobre a carena póstero-dorsal da tíbia mesotorácica. $[$ passos $=5 ;$ fit $=0,21$; $\mathrm{ci}=$ $0,20 ; \mathrm{ri}=0,43]$

(0) restritos a porção proximal;

(1) dispostos aproximadamente ao longo de todo comprimento.

98. Superfície ventral do trocanter metatorácico. [passos $=1$; fit $=0,00 ; \mathrm{ci}=1,00 ; \mathrm{ri}=1,00$ ]

(0) liso, não armada com processos espiniformes;

(1) armada com processos espiniformes negros.

99. Superfície póstero-ventral dos fêmures. [passos $=2 ;$ fit $=0,06 ; \mathrm{ci}=0,50 ; \mathrm{ri}=0,00]$

(0) esparsamente cobertas com setas;

(1) densamente coberta com setas.

100. Porção distal da superfície ântero-ventral do metafêmur. [passos $=1$; fit $=-$; ci $=1,00$; ri $=0,00]$

(0) com espinhos distantes um dos outros, sem qualquer formação especial;

(1) com espinhos próximos e longos, formando um conjunto especial (“comb”) de três a cinco.

101. Fileira de espinhos na margem ântero-ventral do fêmur metatorácico. [passos $=10$; fit $=0,35 ; \mathrm{ci}=0,20 ; \mathrm{ri}=0,78]$

(0) sem distinção em duas seções, com espinhos similares em tamanho (fileira isométrica) com o distal longo;

(1) sem distinção em duas seções, com espinhos gradualmente aumentando de tamanho em sentido distal;

(2) diferenciado em duas seções, uma proximal com espinhos pequenos e outra distal com espinhos longos e robustos (fileira heterométrica).

102. Espinhos na seção distal da margem ântero-ventral do fêmur metatorácico. [passos = 2; 
fit $=0,06 ; \mathrm{ci}=0,50 ; \mathrm{ri}=0,00]$

(0) aumentado de tamanho em sentido distal;

(1) diminuindo de tamanho em sentido distal.

103. Margem da superfície póstero-ventral do fêmur metatorácico. [passos $=4$; fit $=0,17$; ci $=$ $0,25 ; \mathrm{ri}=0,40]$

(0) coberta apenas por cerdas rígidas;

(1) coberta por cerdas e por uma distinta fileira de espinhos.

104. Espinhos na margem póstero-ventral do fêmur metatorácico. $[$ passos $=5 ;$ fit $=0,17$; ci $=$ $0,40 ; \mathrm{ri}=0,88]$

(0) pequenos, similares no tamanho ao longo de toda a superfície (isométricos);

(1) aumentando gradualmente de tamanho em sentido distal;

(2) aumentando abruptamente de tamanho em sentido distal (heterométricos).

105. Espinhos margem ântero-ventral do fêmur metatorácico. [passos $=2$; fit $=0,06$; ci $=$ $0,50 ; \mathrm{ri}=0,00]$

(0) triangulares, com base larga afilando ao ápice (cônicos);

(1) quadrangulares, com base e ápice largos.

\section{Subconjunto ("partition”) E - caracteres do abdômen}

106. Superfície ventral do esternito do $\mathrm{S} 1$. $[$ passos $=1$; fit $=0,00 ; \mathrm{ci}=1,00 ; \mathrm{ri}=1,00]$

(0) lisa, sem processos;

(1) armada, com pequenos processos espiniformes.

107. Superfície da carena ventral do tergito do $\mathrm{S} 2$. $[\operatorname{passos}=2$; fit $=0,06$; $\mathrm{ci}=0,50 ; \mathrm{ri}=0,80$ ]

(0) lisa ao longo de todo comprimento;

(1) armada, geralmente com três espinhos negros próximos ao lobo genital.

108. Superfície do tergito do $\mathrm{S} 2$. [passos $=1 ; \mathrm{fit}=-; \mathrm{ci}=1,00 ; \mathrm{ri}=0,00$ ]

(0) irregular, carena transversa definida;

(1) plana, carena transversa indefinida;

109. Porção ântero-ventral da carena transversa do S2. [passos $=7$; fit $=0,29$; ci $=0,14$; ri $=$ $0,63]$

(0) indefinida;

(1) fortemente definida.

110. Carena transversa no S2. [passos $=7$; fit $=0,29$; $\mathrm{ci}=0,14$; $\mathrm{ri}=0,25]$

(0) arredondada, curvada quase em ângulo obtuso;

(1) quadrangular, curvada quase em ângulo reto. 
(a)
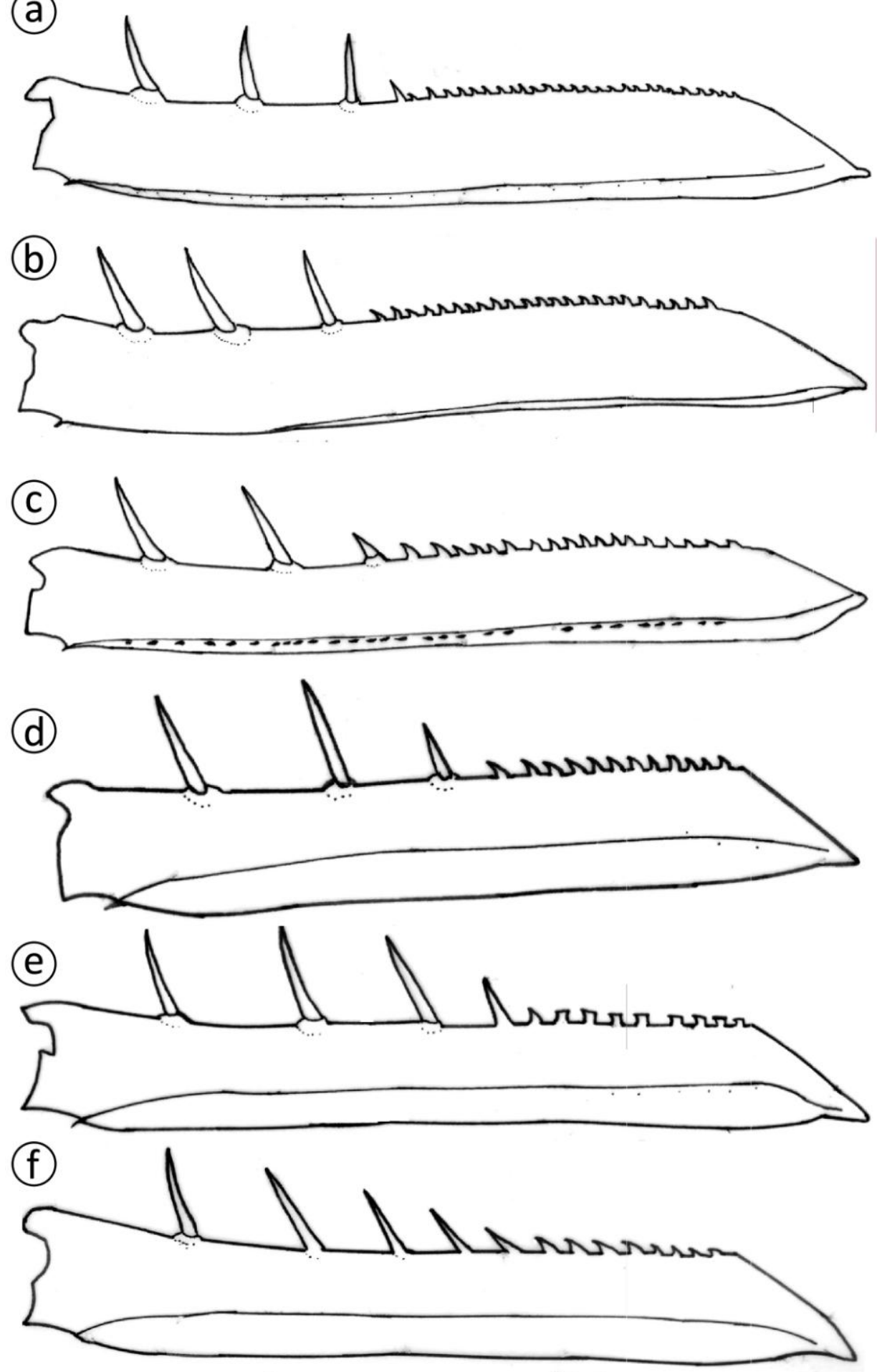

Figura 11. Fêmures de machos de Libellulidae em vista lateral, evidenciando a armadura de espinhos da margem ântero-ventral. a-c, fêmures metatorácicos; d-f, fêmures mesotorácicos; a, Erythemis carmelita Williamson, 1923. b, Erythemis simplicicollis (Say, 1840); c, Rhodothemis mauritsi Lohmann, 1984; d, Erythemis mithroides (Brauer in Therese, 1900); e, Rhodopygia hollandi Calvert, 1907; f, Brachymesia furcata (Hagen, 1861).

111. Carena lateral de S3-4. [passos $=2 ; f i t=0,06 ; \mathrm{ci}=0,50 ; \mathrm{ri}=0,50]$ 
(0) definida ao longo do comprimento total dos segmentos;

(1) indefinida ou pouco definida.

112. Superfície laterodorsal do tergito do $\mathrm{S} 4$. $[$ passos $=5 ; \mathrm{fit}=0,21$; $\mathrm{ci}=0,20 ; \mathrm{ri}=0,56$ ]

(0) plana, sem TC definida;

(1) carenada, com um TC definido.

113. Largura do S4 em relação ao S5. [passos $=1 ;$ fit $=0,00 ; \mathrm{ci}=1,00 ;$ ri $=1,00]$

(0) regular, similar ao S5;

(1) expandida em relação ao S5.

114. Superfície ventral dos tergitos do $\mathrm{S} 4-7$. [passos $=4$; fit $=0,17$; $\mathrm{ci}=0,25 ; \mathrm{ri}=0,00$ ]

(0) carenada, com carena ventral definida;

(1) plana, com carena ventral mal definida ou indistinta.

115. Carena ventral do S8 do macho (Dijkstra \& Matushkina 2009). [passos $=1$; fit $=-; \mathrm{ci}=$ $1,00 ; \mathrm{ri}=0 / 0]$

(0) retilínea, levemente torcida, com poucos dentículos dispersos;

(1) convexa, medialmente com um lobo definido, com grande número de dentículos.

116. Superfície dorsal do tergito do S10. [passos = 1; fit = -; $\mathrm{ci}=1,00 ; \mathrm{ri}=0 / 0$ ]

(0) não projetada em um processo mediano;

(1) projetada em um processo mediano (“dorsal keel”).

\section{Subconjunto ("partition") F - genitália acessória masculina}

117. Lâmina anterior em vista lateral. $[$ passos $=4$; fit $=0,17$; $\mathrm{ci}=0,25 ; \mathrm{ri}=0,40]$

(0) levemente ou não projetada ventralmente;

(1) acentuadamente projetada ventralmente.

118. Margem posterior da lâmina anterior em visão ventral. $[$ passos $=5 ; f i t=0,21 ; \mathrm{ci}=0,20$; $\mathrm{ri}=0,20]$

(0) inteira;

(1) dividida em dois lobos.

119. Margem posterior do hâmulo posterior. $[$ passos $=3 ; \mathrm{fit}=0,12 ; \mathrm{ci}=0,33 ; \mathrm{ri}=0,78]$

(0) projetada, formando um ramo externo (hâmulo bífido);

(1) levemente projetada, sem a formação de um ramo externo (hâmulo não ramificado).

120. Margem póstero-lateral do ramo externo do hâmulo posterior. $[$ passos $=16$; $f i t=0,46$; ci $=0,19 ; \mathrm{ri}=0,50]$

(0) levemente projetada, arredondada;

(1) projetada, truncada; 
(2) projetada, angulada, porém sem formar um espinho definido;

(3) fortemente projetada, angulada, formando um "espinho" definido.

121. Hâmulo posterior em vista lateral. [passos $=10 ; \mathrm{fit}=0,35 ; \mathrm{ci}=0,20 ; \mathrm{ri}=0,56$ ]

(0) levemente "torcido" internamente;

(1) dirigido lateralmente, com ramo interno e externo ao mesmo nível;

(2) acentuadamente "torcido" internamente, com ramo interno não visível.

122. Lobo genital em vista lateral. [passos $=5 ; \mathrm{fit}=0,21 ; \mathrm{ci}=0,20 ; \mathrm{ri}=0,20]$

(0) posteriormente oblíquo;

(1) aproximadamente perpendicular ao eixo do abdômen.

123. Lobo genital em visão lateral. [passos $=8 ; f i t=0,32 ; \mathrm{ci}=0,13 ; \mathrm{ri}=0,22$ ]

(0) mais largo que longo;

(1) mais longo que largo.

124. Ápice do lobo genital. [passos $=3$; fit $=0,06$; $\mathrm{ci}=0,67$; $\mathrm{ri}=0,67$ ]

(0) arredondado ou truncado;

(1) angulado;

(2) agudo.

125. Superfície ventral do V1. [passos $=4$; fit $=0,17$; $\mathrm{ci}=0,25 ; \mathrm{ri}=0,00$ ]

(0) regularmente convexa;

(1) projetada em um par de processos.

126. Quarto segmento da VS. [passos $=5 ;$ fit $=0,21 ; \mathrm{ci}=0,20 ; \mathrm{ri}=0,692$ ]

(0) não alongado, quadrangular;

(1) alongado, cilíndrico.

127. Superfície da porção ântero-dorsal do capuz. [passos $=2$; fit $=0,00 ; \mathrm{ci}=1,00 ; \mathrm{ri}=1,00$ ]

(0) regular;

(1) levemente expandida dorsalmente;

(2) fortemente expandida dorsalmente.

128. Porção mediana da margem póstero-dorsal do capuz. [passos $=2 ; f i t=0,06 ; \mathrm{ci}=0,50$; ri $=0,96]$

(0) regular em relação ao capuz;

(1) projetada em um par de processos esclerosados (processos paramedianos).

129. Processos paramedianos. [passos $=1 ;$ fit $=0,00 ; \mathrm{ci}=1,00 ; \mathrm{ri}=1,00]$

(0) em forma de placa;

(1) em forma de lâmina.

130. Processos paramedianos na margem posterodorsal do capuz. [passos $=4$; fit $=0,12$; $\mathrm{ci}=$ 
$0,50 ; \mathrm{ri}=0,83]$

(0) aproximadamente paralelos;

(1) convergentes;

(2) divergentes.

131. Margem posterior do processo paramediano. [passos $=1$; fit $=0,00 ; \mathrm{ci}=1,00 ; \mathrm{ri}=1,00]$

(0) lisa, sem projeções espiniformes;

(1) armada, com projeções espiniformes.

132. Área dorsal mediana distal do capuz. $[\operatorname{passos}=5 ; \mathrm{fit}=0,21 ; \mathrm{ci}=0,20 ; \mathrm{ri}=0,33]$

(0) sem projeção, reta;

(1) projetada em um processo em forma de quilha.

133. Área posterior da porção laterodorsal do capuz. [passos $=3 ;$ fit $=0,12$; $\mathrm{ci}=0,33$; $\mathrm{ri}=$ $0,67]$

(0) regular, sem projeção;

(1) projetada dorsalmente em um processo.

134. Ápice do processo laterodorsal do capuz em vista lateral. [passos $=1$; fit $=0,00$; $\mathrm{ci}=$ $1,00 ; \mathrm{ri}=1,00]$

(0) agudo;

(1) arredondado.

135. Lobo lateral em relação ao comprimento total do capuz em vista lateral. [passos $=14$; fit $=0,44 ; \mathrm{ci}=0,14 ; \mathrm{ri}=0,61]$

(0) tão longo quanto ou levemente mais longo;

(1) um pouco mais longo $(0.5>$ lobo lateral $<0.8)$;

(2) menos que a metade $(<0,5)$.

136. Lobo lateral da VS. $[$ passos $=3 ; f i t=0,12 ; \mathrm{ci}=0,33 ; \mathrm{ri}=0,50]$

(0) mais largo que longo (?)

(1) mais longo que largo (em forma de espada)

137. Cornua. $[$ passos $=10 ;$ fit $=0,35 ; \mathrm{ci}=0,20 ; \mathrm{ri}=0,43$ ]

(0) flageliforme;

(1) espatulada;

(2) cilíndrica.

138. Direção da “cornua” em relação ao eixo ântero-posterior do V4. [passos = 12; fit = 0,40; $\mathrm{ci}=0,17 ; \mathrm{ri}=0,63]$

(0) ventral;

(1) dorsal; 
(2) paralelo.

139. Conexão entre o par de "cornuas". [passos $=11$; fit $=0,38 ; \mathrm{ci}=0,18 ; \mathrm{ri}=0,70]$

(0) por uma longa extensão;

(1) apenas basalmente;

(2) sem conexão, paralelas ao longo de todo comprimento.

140. Esclerito dorsal de processo mediano. $[$ passos $=1 ; \mathrm{fit}=0,00 ; \mathrm{ci}=1,00 ; \mathrm{ri}=1,00]$

(0) sem ramificação dorsal;

(1) ramificado dorsalmente em um ramo externo e outro interno.

141. Rotação do lobo interno. [passos $=6$; fit $=0,25$; $\mathrm{ci}=0,17$; ri $=0,55$ ]

(0) maior parte da superfície dorsal;

(1) maior parte da superfície lateral.

142. Lobo interno em relação ao comprimento total do capuz. $[$ passos $=4$; fit $=0,17$; ci $=$ $0,25 ; \mathrm{ri}=0,70]$

(0) distintamente menor;

(1) tão longo quanto ou levemente maior.

143. Porção ventral do capuz. [passos $=6$; fit $=0,25$; $\mathrm{ci}=0,17$; $\mathrm{ri}=0,29$ ]

(0) expandida em lobo apical;

(1) não expandida em lobo apical.

144. Lobo apical em posição de repouso (vesica spermalis não inflada). [passos $=6$; fit $=$ $0,25 ; \mathrm{ci}=0,17 ; \mathrm{ri}=0,62]$

(0) exteriorizado;

(1) internalizado.

145. Direção do lobo apical. [passos $=17$; fit $=0,50 ; \mathrm{ci}=0,12 ; \mathrm{ri}=0,55$ ]

(0) ventralmente oblíquo;

(1) dorsalmente oblíquo;

(2) aproximadamente paralelo ao eixo do capuz.

146. Nível de esclerose do lobo apical. [passos $=1$; fit $=0,00$; $\mathrm{ci}=1,00 ; \mathrm{ri}=1,00$ ]

(0) forte, com pequena capacidade de inflação;

(1) fraco, principalmente membranoso, alta capacidade de inflação.

\section{Subconjunto ("partition”) G - apêndices caudais masculinos}

147. Ápice posterior do epiprocto do macho. [passos $=2 ; \mathrm{fit}=0,06 ; \mathrm{ci}=0,50 ; \mathrm{ri}=0,00$ ]

(0) truncado (epiprocto triangular);

(1) côncavo (epiprocto quadrangular). 
148. Dentículos sobre a superfície ventral do cerco. $[$ passos $=4$; fit $=0,17$; $\mathrm{ci}=0,25$; ri $=$ $0,70]$

(0) alinhados em uma única fileira;

(1) maioria alinhada, mas com alguns desalinhados.

149. Dentículos sobre a superfície ventral do cerco. [passos $=6$; fit $=0,25$; ci $=0,17$; ri $=$ $0,58]$

(0) dispostos regularmente sobre a superfície do cerco;

(1) dispostos sobre um processo em forma de quilha.

150. Fileiras de dentículos na superfície ventral do cerco. $[$ passos $=12 ; f i t=0,38$; ci $=0,25$; ri $=0,67]$

(0) estendidas sobre aproximadamente toda a extensão;

(1) localizadas subapicalmente (posterior 0,5 do comprimento);

(2) localizadas basalmente (anterior 0,5 do comprimento);

(3) localizadas em dois grupos um proximal e outro com interrupção mediana.

151. Superfície dorsal dos cercos. [passos $=1 ;$ fit $=-; \mathrm{ci}=1,00 ; \mathrm{ri}=0,00]$

(0) retilínea, sem projeção;

(1) projetada em um processo cônico (cerco bifurcado).

\section{Subconjunto ("partition") H - genitália e estruturas associadas femininas}

152. Margem lateroventral do tergito do S8. $[$ passos $=1 ;$ fit $=0,00 ; \mathrm{ci}=1,00 ; \mathrm{ri}=1,00]$

(0) não expandida, retilínea;

(1) expandida ventralmente em um processo foliáceo.

153. Margem posterior da placa subgenital em vista lateral. $[$ passos $=23 ; f i t=0,55$; $\mathrm{ci}=0,22$; $\mathrm{ri}=0,42]$

(0) entre as margens anterior e posterior do $S 8$ (0,5-0,6 do comprimento total do $S 8)$;

(1) na margem posterior do S8 (entre a carena posterior e o campo posterior do S8);

(2) na porção anterior do S9 (0,1-0,25 do comprimento do S9);

(3) na porção ântero-mediana do $S 9$ (0,33-0,50 do comprimento do S9);

(4) na porção anterior do S10 (posterior ao S9);

(5) distal a margem posterior do abdômen.

154. Margem ventral da placa subgenital. $[\operatorname{passos}=21$; fit $=0,56$; $\mathrm{ci}=0,10 ; \mathrm{ri}=0,35$ ]

(0) não projetada, no máximo ao nível do tergitos do S8-9;

(1) levemente projetada ventralmente, entre $0,1-0,5$ da altura do S8-9;

(2) fortemente projetada ventralmente, entre $0,66-0,85$ da altura do S8-9. 
155. Margem lateroposterior da placa subgenital em vista lateral. $[\operatorname{passos}=2 ; f i t=0,06$; $\mathrm{ci}=$ $0,50 ; \mathrm{ri}=0,83]$

(0) retilínea, sem formação de lobos, sem formação de lobos diferenciados;

(1) com uma concavidade dividindo a placa em lobos proximal e distal.

156. Ápice de lobo distal da placa subgenital em visão lateral. [passos $=5$; fit $=0,21$; $\mathrm{ci}=$ $0,20 ; \mathrm{ri}=0,67]$

(0) direcionado ventralmente;

(1) direcionado posteriormente.

157. Ápice da margem posterior da placa subgenital em vista lateral. [passos $=7$; fit $=0,29$; $\mathrm{ci}$ $=0,14 ; \mathrm{ri}=0,54]$

(0) "cortado" obliquamente, base projetada posteriormente além do ápice distal;

(1) "não cortado", ápice distal ao nível ou além da margem posterior da base.

158. Superfície ventral do esternito do $\mathrm{S} 8$. $[$ passos $=6$; fit $=0,25 ; \mathrm{ci}=0,17$; $\mathrm{ri}=0,38]$

(0) plana, sem carena;

(1) carenada, com uma carena central ao longo do comprimento do esternito.

159. Carena central do esternito do S8. $[$ passos $=17$; fit $=0,48 ; \mathrm{ci}=0,18 ; \mathrm{ri}=0,52]$

(0) sobre no máximo 0,5 anterior do comprimento total do esternito;

(1) distintamente anterior à placa subgenital (indistinta subapicalmente);

(2) ao longo do esternito exceto sobre a placa;

(3) contínua ao longo do comprimento total até ao ápice da placa subgenital.

160. Margem posterior da placa subgenital em vista ântero-ventral. [passos $=12$; fit $=0,42$; ci $=0,08 ; \mathrm{ri}=0,52]$

(0) côncava, com uma endentação central;

(1) convexa, sem endentação central.

161. Superfície interna da placa subgenital. $[$ passos $=2 ; f i t=0,06 ; \mathrm{ci}=0,50 ; \mathrm{ri}=0,00]$

(0) plana, não projetada em um par de processos;

(1) projetada em um processo par.

162. Esterno do S9 (Garrison et al. 2006) . [passos $=1$; fit $=0,00 ; \mathrm{ci}=1,00 ; \mathrm{ri}=1,00]$

(0) prolongado no máximo até o ápice do abdômen;

(1) prolongado posteriormente além do ápice abdômen.

163. Esterno do S9 das fêmeas. [passos $=1 ;$ fit $=0,00 ; \mathrm{ci}=1,00 ; \mathrm{ri}=1,00$ ]

(0)planar;

(1) cilíndrico.

164. Placa do esterno do S9 da fêmea. [passos = 1; fit =-; $\mathrm{ci}=1,00 ; \mathrm{ri}=0,00$ ] 
(0) arredondada, de superfície lisa;

(1) retangular, de superfície irregular.

165. Ápice do esterno do S9 da fêmea. [passos $=1$; fit $=-; \mathrm{ci}=1,00 ; \mathrm{ri}=0,00$ ]

(0) direcionado posteriormente;

(1) direcionado ventralmente.

\section{Subconjunto ("partition") I - apêndices caudais femininos}

166. Margem posterior do epiprocto das fêmeas em vista dorsal. [passos $=2$; fit $=0,06$; $\mathrm{ci}=$ $0,50 ; \mathrm{ri}=0,96]$

(0) regular, não dividida;

(1) irregular, com um pequena concavidade mediana, dividida em dois lobos.

167. Superfície dorsal do epiprocto da fêmea. $[$ passos $=1 ;$ fit $=-; \mathrm{ci}=1,00 ; \mathrm{ri}=0,00]$

(0) regular, sem processos espiniformes;

(1) irregular, com um par de fileiras de pequenos processos espiniformes.

168. Cercos da fêmea. [passos $=6 ; f i t=0,25 ; \mathrm{ci}=0,17 ; \mathrm{ri}=0,62]$

(0) curtos, menores que duas vezes o comprimento epiprocto;

(1) longos, maiores que duas vezes o comprimento epiprocto.

169. Cercos em vista lateral. [passos $=4$; $\mathrm{fit}=0,17$; $\mathrm{ci}=0,25 ; \mathrm{ri}=0,00$ ]

(0) cilíndricos, não achatados, sem qualquer carena;

(1) laminares, distintamente achatados, com carenas dorsal e ventral definidas.

170. Cercos em vista lateral. [passos $=1 ;$ fit $=-; \mathrm{ci}=1,00 ; \mathrm{ri}=0,00$ ]

(0) lineares, ápice direcionado posteriormente;

(1) fortemente curvos, ápice direcionado ventralmente.

171. Ápice do cerco. [passos $=2 ; f i t=0,06 ; \mathrm{ci}=0,50 ; \mathrm{ri}=0,50]$

(0) arredondado;

(1) agudo.

ANÁlISE Cladística. A análise com pesos iguais (EW) utilizando a parcimônia de Fitch resultou em 734 MPTs, com 956 passos, fit de 75,95-76,69, CI = 0,23, RI = 0,59, enquanto com a parcimônia de Sankoff resultou em 480 MPTs, 1182 passos, fit 83,76-84,55, CI = 0,22, $\mathrm{RI}=0,60$. A análise de sensibilidade ( $\mathrm{WW}, \mathrm{K}=1-30$ ) com diferentes valores de constante de concavidade selecionou uma única hipótese para cada um dos valores investigados com ambas as abordagens, Fitch e Sankoff, porém incongruentes para diversos nós (Fig. 13b,d). 
Os valores de Bremer relativo $(\mathrm{RB})$ com IW $(\mathrm{K}=15)$ foram calculados com base em 236.354 árvores com a parcimônia de Fitch e 16.977 com Sankoff. Inúmeras tentativas foram
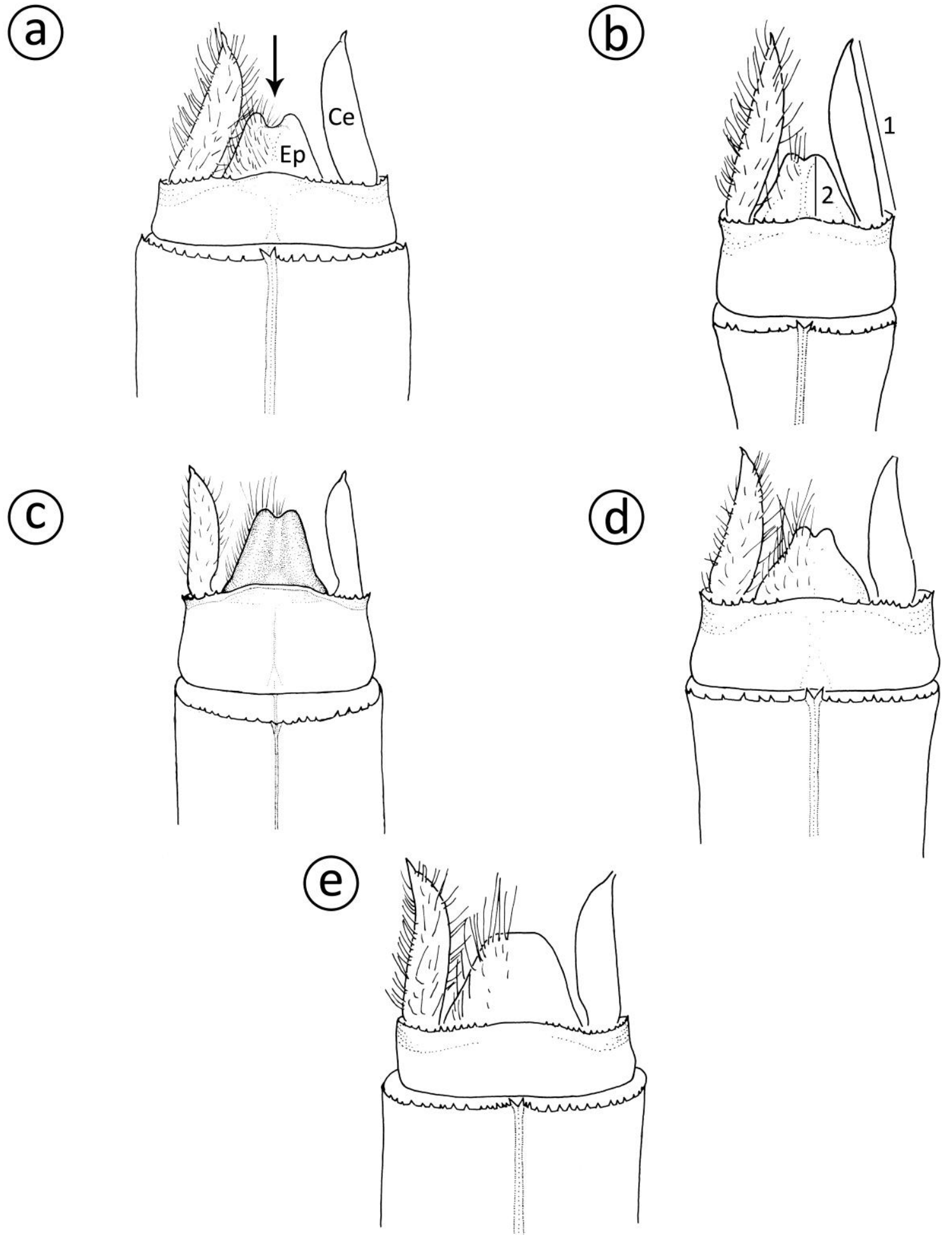

Figura 12. Apêndices caudais de fêmeas de Erythemismorpha em vista dorsal. a, Rhodopygia hollandi Calvert, 1907; b, Acisoma trifidum Kirby, 1889; c, Erythemis carmelita Williamson, 1923; d, Rhodothemis mauritsi Lohmann, 1984; e. Cyanothemis simpsoni Ris, 1915. Ep, epiprocto, Ce, cerco, seta indica a concavidade no Ep, barras de medidas utilizadas nos caracteres. 1 = comprimento do cerco; 2 = comprimento do epiprocto. 
realizadas para se obter os valores de reamostragem utilizando a parcimônia de Sankoff, as quais foram mal sucedidas, pois paralisavam os computadores após algumas dezenas de pseudoréplicas, mesmo com os parâmetros de busca reduzidos a um nível extremo, e, portanto, não puderam ser comparados com aqueles da parcimônia de Fitch. A árvore obtida com a parcimônia de Fitch com IW e constante de concavidade de 15 (fit $=75,22, \mathrm{CI}=0,23$, $\mathrm{RI}=0,58)$ foi selecionada como a principal hipótese de relacionamento a ser discutida, essa árvore com valores dos índices de estabilidade de ramos e a otimização dos caracteres utilizando o critério de ACCTRAN é mostrada nas Figs. 14-15, 17-18. Embora o conjunto de árvores obtidas seja discordante em diversos pontos, existem congruências em nós mais inclusivos (Fig. 13b-d). Alguns nós mais inclusivos apresentaram baixo suporte e além do valor escolhido de $\mathrm{K}$ são sustentados apenas com valores de 20 e 25 , o que demonstra incerteza em alguns dos relacionamentos recuperados, esse nós não serão discutidos aqui.

'Sympetrinae'. Assim como em análises anteriores (Carle \& Kjer 2002; Ware et al. 2007; Bybee et al. 2008; Fleck et al. 2008a,b; Pilgrim \& von Dohlen 2008; Pinto 2008; Pinto \& Carvalho em prep.) 'Sympetrinae' foi novamente demonstrado como não monofilético com 11 a 17 linhagens distintas (Figs. 13a-d). Certamente, essa subfamília representa diversos grupos monofiléticos menores distantemente relacionados uns aos outros, os quais estão sendo gradualmente identificados e devem ser testados em análises compreensivas próprias, configuradas para responder questões específicas. O atual arranjo de 'Sympetrinae' representa um dos mais polimórficos agrupamentos em Libellulidae, reunindo alguns dos grupos mais modificados do baupläne da família, e ao longo de sua história sistemática, gêneros com posicionamento incerto têm sido recorrentemente atribuídos a esta subfamília (e.g. Ophippus Navás, 1916 no catálogo de Davies \& Tobin 1985, veja também Capítulo 4).

Contudo, seu gênero-tipo Sympetrum Newman, 1833, com mais de 60 espécies, as quais estão distribuídas virtualmente em quase todas as regiões biogeográficas, foi demonstrado ser monofilético com a inclusão do gênero Havaiano Nesogonia Kirby, 1898 e próximo filogeneticamente aos gêneros de Leucorrhiniinae tais como Leucorrhinia Brittinger, 1850 e Celithemis Hagen, 1861 (Pilgrim \& von Dohlen 2008, 2012). Na presente análise Sympetrum foi recuperado como monofilético na parcimônia de Fitch, em ambos EW e IW com todos os valores de K testados, porém não monofilético na parcimônia de Sankoff, já que a espécie Norte Americana S. rubicundulum (Say, 1840) (Fig. 13c-d, ramo terminal em vermelho) está posicionada em um ramo contendo táxons de outras três subfamílias, i.e. 'Leucorrhiniinae', 'Brachydiplacinae' e Libellulinae. Nas árvores em que Sympetrum demonstrou ser monofilético Nesogonia é grupo-irmão de S. risi Bartnef, 1915 com relativo alto índices de estabilidade (Fig. 14), a qual pertence ao grupo S. infuscatum (Selys, 1883) que 
(a)

(b)
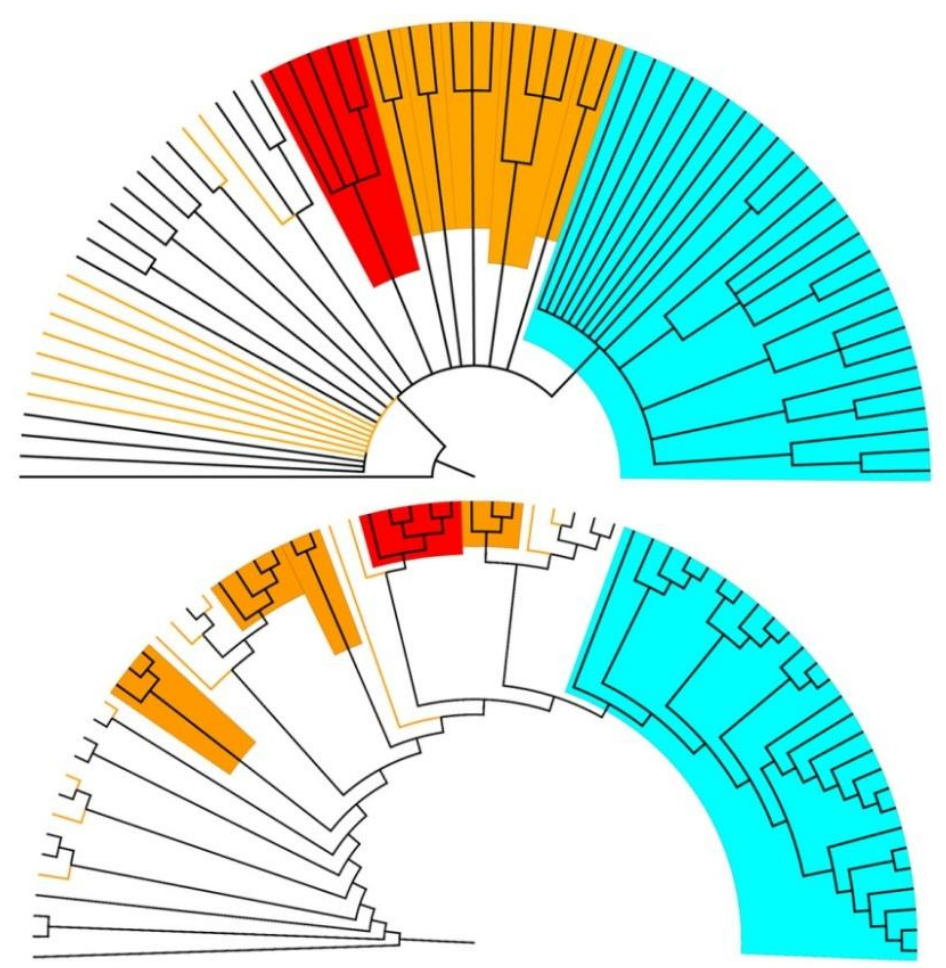

(c)

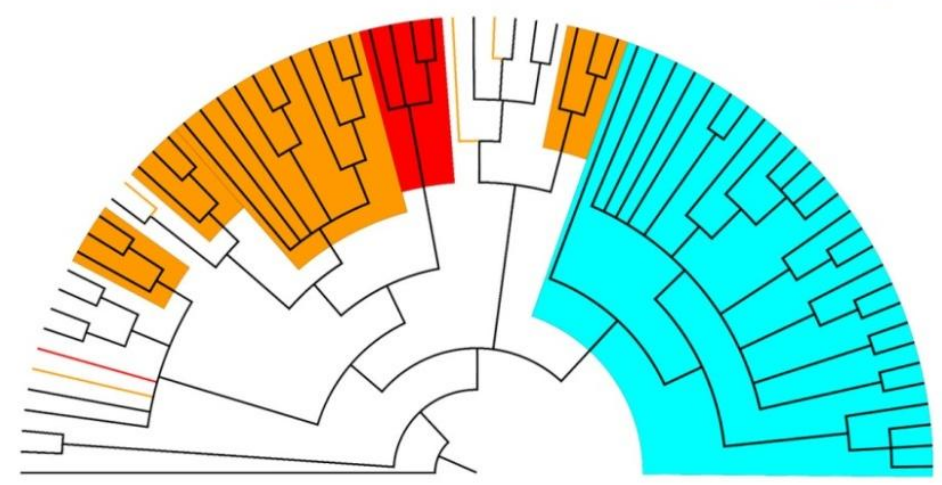

(d)

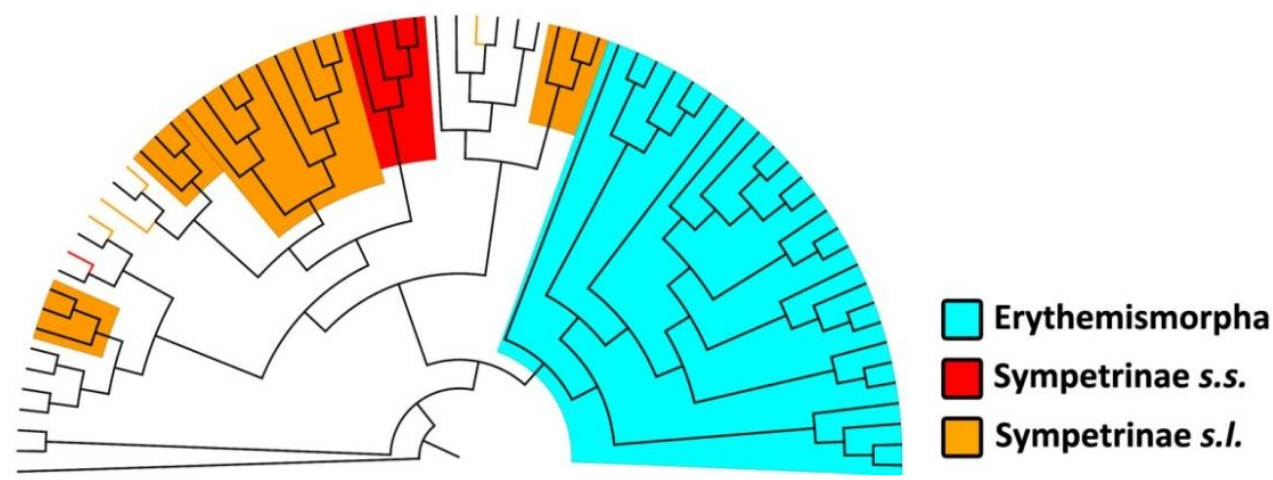

Figura 13. Árvores com hipóteses de relacionamento filogenético entre representantes de 'Sympetrinae' obtidas em diferentes análises, todas com 69 táxons e 171 caracteres não ordenados. ab. parcimônia de Fitch; c-d. dados não aplicáveis analisados com parcimônia de Sankoff; a. consenso estrito das 734 árvores (956 passos, $\mathrm{CI}=0,23, \mathrm{RI}=0,59)$ obtidas com os caracteres com pesos iguais; b. árvore única com pesos implicados $(\mathrm{K}=15)$; c. consenso estrito das 480 árvores obtidas com os caracteres com pesos iguais; $d$. árvore única com pesos implicados $(K=15)$. 
inclui espécies com ocorrência no extremo leste asiático ao Japão (Davies \& Tobin 1985). Embora em uma análise recente de Sympetrum o grupo $S$. infuscatum seja considerado monofilético e distante filogeneticamente de Nesogonia, os nós internos apresentam baixo suporte (Pilgrim \& von Dohlen 2012), portanto, a hipótese de Nesogonia como grupo-irmão de espécies de Sympetrum centradas no leste Asiático deve ser investigada.

O status genérico de Nesogonia tem sido questionado há um longo tempo ( $c f$. Carle 1993), sendo o primeiro estudo objetivo realizado por Kiauta (1969), o qual, baseado em uma análise citológica Nesogonia foi comparado com 15 espécies de Sympetrum e apesar da relativa baixa diferença concluiu que Nesogonia seria um imigrante recente no arquipélago do Havaí e que poderia ser considerado um gênero distinto. Mais recentemente Pilgrim \& von Dohlen $(2008,2012)$ em análises combinadas com dados morfológicos e moleculares reconheceram Nesogonia como possível sinônimo júnior de Sympetrum, porém a nova combinação só foi feita por Dijkstra \& Kalkman (2012).

Considerando que o gênero-tipo de 'Sympetrinae' é mais proximamente relacionado a gêneros tradicionalmente posicionados em outras subfamílias, do que com os demais gêneros da subfamília o nome deve estar limitado a Sympetrum e a seus gêneros associados (i.e. Celithemis e Leucorrhinia), portanto Sympetrinae s.s. para esse grupo e provisoriamente Sympetrinae s.l. para os demais. Já a o relacionamento de Pachydiplax longipennis (Burmeister, 1839) como grupo-irmão de Sympetrinae s.s. deve ser considerado um artifício da análise (devido aos táxons amostrados) já que é suportado apenas em algumas árvores e quando recuperado com monofilético com baixo níveis de estabilidade de ramos. O próximo passo em Sympetrinae s.l. é investigar os putativos grupos monofiléticos menores para obter hipóteses de relacionamento e propor formalmente novos agrupamentos taxonômicos.

Deielia + Zygonyx + Elasmothemis (Fig. 14, Nós A-B). A posição de Deielia Kirby, 1889 nesse ramo é controversa, embora seja suportado com valores de K de 5-25 o ramo possui índices de estabilidade muito baixos, não sendo recuperado com EW na parcimônia de Fitch (Fig. 14, nó A), assim como em nenhuma das análises utilizando Sankoff. Esse gênero inclui D. phaon (Selys, 1883), espécie asiática que possui uma série de características peculiares não encontradas nos demais gêneros da família, a qual em análises moleculares é considerada próxima filogeneticamente a Brachythemis Brauer, 1868 (Ware et al. 2007; Pilgrim \& von Dohlen 2008) e sugerido como sinônimo desse gênero (Dijkstra \& Matushkina 2009; Dijkstra \& Kalkman 2012). Essa hipótese de relacionamento de Deielia + Brachythemis foi suportada apenas nas análises de Sankoff, porém diferente dos resultados obtidos por Pilgrim \& von Dohlen (2008) em que está o relacionamento (B. leucosticta (B. 
contaminata, $D$. phaon)) é proposto, aqui $D$. phaon está como grupo-irmão de $B$. contaminata (Fabricius, 1793) e B. leucosticta (Burmeister, 1839). Os resultados das análises aqui realizadas são largamente contraditórios quanto ao relacionamento de Deielia, assim como para Brachythemis que demonstra ser parafilético com a inclusão de P. mooma Kirby, 1889 na análise com a parcimônia de Fitch e IW, porém com baixa estabilidade e sustentado apenas por alguns valores de K (Fig. 14, nó C). Embora Deielia-Brachythemis sejam tradicionalmente posicionados em 'Sympetrinae', de fato, ambos parecem estar mais relacionados com espécies de Trameinae s.l. (tribo Zyxommatini) largamente reconhecidas pelo seu hábito crepuscular como Tholymis Hagen, 1867 (cf. Dijkstra 2003; Pilgrim von Dohlen 2008; Dijkstra \& Kalkman 2012). Essa grande instabilidade evidencia a necessidade de abordagens mais amplas com todas as linhagens de Brachythemis, Deielia e também demais gêneros de Trameinae s.l., assim como sugerido por Dijkstra \& Matushkina (2009).

Porto outro lado o monofiletismo de Elasmothemis + Zygonyx é altamente sustentado em todas as análises com ambas as abordagens (Fitch e Sankoff) e em todos os esquemas de ponderação de caracteres, com relativos altos índices de estabilidade nos ramos (Fig. 14, nó B). Esses dois gêneros reúnem espécies com algumas características raramente encontradas em Libellulidae como reflexos metálicos no tórax (menos evidente na espécie aqui estudada de Elasmothemis), característica comum em espécies de Corduliidae s.l., além da grande similaridade na forma dos segmentos abdominais incluindo a genitália secundária, e sobre tudo na forma da vesica spermalis e suas estruturas associadas. Embora tradicionalmente sejam posicionados em subfamílias distintas Elasmothemis (Neotropical) em Trithemistinae e Zygonyx (trópicos do Velho Mundo) em Zygonychinae, provavelmente façam parte de um grupo monofilético maior juntamente com Onychothemis Brauer, 1868 (sudeste Asiático e Australásia) de Onychothemistinae e os gêneros de Trithemistinae Dythemis Hagen, 1861 (Novo Mundo) e o recentemente descrito da Bahia Orionothemis (cf. Fleck et al. 2009). Além disso, Celebothemis Ris, 1909 (Zygonychinae, Ilha de Sulawesi), Huonia Förster, 1903 (Trithemistinae, Australásia) e Nannophlebia (Tetrathemistinae, Australásia) também devem ser investigados com base em resultados de análises moleculares ( $c f$. Ware et al. 2007) e devido à similaridade da genitália secundária ( $c f$. Lieftinck 1955, 1963). Controversamente e aparentemente de modo equivocado Dijkstra \& Kalkman (2012) consideram Zygonyx próximo a Pantala Hagen, 1861 e Trithemis Brauer, 1868, interpretando erroneamente resultados de análises filogenéticas moleculares (e.g. Fleck et al. 2008, não mostra Zygonyx com esse relacionamento) extremamente parciais e inadequadas para tais afirmações sobre o relacionamento do gênero. Apenas a análise de Dumont et al. (2010) suporta Zygonyx + 
Trithemis + Pantala, porém com uma baixa amostragem de táxons de Libellulidae comparado com as análises já mencionadas.

Libellulinae (Libellula + Orthemis). A subfamília Libellulinae, representada por duas espécies, L. herculea Karsch, 1890 e O. discolor (Burmeister, 1839), teve seu monofiletismo fortemente sustentado sendo recuperado em todas as análises e com todos os esquemas de ponderação de caracteres. $\mathrm{Na}$ árvore com $\mathrm{K}=15$ é um dos nós mais fortemente suportados com altos índices de estabilidade (Fig. 14, nó D). O monofiletismo dessa subfamília é um dos únicos que são geralmente corroborados em análises filogenéticas com maior ou menor suporte (Carle \& Kjer 2002; Pilgrim \& von Dohlen 2008, Ware et al. 2007). A mais significante alteração é a inclusão de gêneros originalmente posicionados em 'Tetrathemistinae' em que a morfologia larvar apresenta grande similaridade a aquelas dos gêneros de Libellulinae (Fleck et al. 2008a). Entretanto a relação entre os gêneros aqui selecionados é altamente discordante nas análises existentes, por exemplo, Orthemis Hagen, 1861 é considerado grupo-irmão de Libellula Linnaeus, 1758 apenas na árvore bayesiana de Pilgrim \& von Dohlen (2008, fig. 3), enquanto em suas demais árvores, assim como em todas aquelas apresentadas em outros trabalhos (Ware et al. 2007; Fleck et al. 2008a,b) toda sorte de agrupamentos é proposto. Todas as árvores obtidas com a parcimônia de Sankoff posicionam Libellulinae como grupo-irmão de Elasmothemis + Zygonyx.

Bradinopyga + Micrathyria. O monofiletismo desse ramo (Fig. 14, nó E) muito provavelmente esta relacionado aos táxons analisados ou procedimentos adotados na análise, considerando que é sustentado apenas com a parcimônia de Fitch com valores de K de 15-30. Nas análises com Sankoff o gênero Afro-Asiático Bradinopyga Kirby, 1893 está incluído em um ramo com outros Sympetrinae s.l. como Crocothemis Brauer, 1868, Erythrodiplax Brauer, 1868, Indothemis Ris, 1909, Pseudoleon Kirby, 1889, Neurothemis e Ypirangathemis Santos, 1945 e parece estar em maior concordância com as análises anteriores que posicionam Bradinopyga como próximo a outros Sympetrinae s.l. Crocothemis, Diplacodes Kirby, 1889 e Erythrodiplax (Ware et al. 2007; Pilgrim \& von Dohlen 2008).

Sympetrinae s.l. Embora, como mencionando, 'Sympetrinae' não seja monofilético, alguns grupos monofiléticos com espécies, gêneros ou grupos de gêneros quase que exclusivamente pertencentes a essa subfamília foram identificados como o monofiletismo de Crocothemis, Diplacodes, Indothemis e Neurothemis (Fig. 14, nós F, K-L, R). Por outro lado, as três espécies de Erythrodiplax não foram identificadas como pertencentes a um grupo monofilético em nenhuma das análises (Figs. 14-18). Esse gênero corresponde ao mais rico e bem sucedido gênero de Libellulidae do Novo Mundo, ocorrendo em quase todos os tipos de 
habitat e com uma ampla distribuição desde o sul do Canadá até o sul do Chile (Garrison et al 2006). Possui mais de cinquenta espécies, trata-se de um gênero de difícil delimitação com caracteres compartilhados com outros gêneros ( $c f$. Garrison et al. 2006). Embora tenha sido suportado como monofilético em algumas das árvores de Pilgrim \& von Dohlen (2008), provavelmente seu monofiletismo resultou da amostragem taxonômica, considerando que dos onze grupos de espécies propostos na última revisão completa do gênero (Borror 1942, 1957) foram selecionadas apenas cinco espécies de quatro grupos, alguns deles proximamente relacionados. Na presente análise, embora tenham sido estudadas apenas três espécies de três grupos, estas pertencem a linhagens bastante distintas como evidenciado pelos resultados aqui obtidos. Sem dúvida Erythrodiplax representa um grupo polifilético com algumas espécies mais proximamente relacionadas a outros gêneros de Sympetrinae s.l. como Crocothemis, Diplacodes e Neurothemis, e outras com gêneros posicionados em outras subfamílias como Uracis Rambur, 1842 de 'Brachydiplacinae', além disso, no mínimo parte de um dos grupos de Erythrodiplax pode ser incluído em Erythemismorpha (veja discussão abaixo). Os resultados aqui obtidos e além dos relacionamentos discutidos por Borror $(1942,1947)$ mais uma vez negam a proposta de Dijkstra \& Kalkman (2012) como Erythrodiplax sendo relacionado apenas com as linhagens de Sympetrinae s.l. - i.e. Crocothemis-DiplacodesNeurothemis.

As três espécies de Crocothemis formaram um grupo monofilético altamente suportado, sendo identificado em todas as análises e com altos índices de estabilidade de ramos (Fig. 13, nó F), entretanto o relacionamento entre as espécies não apresentou o mesmo suporte, sendo indeciso. O monofiletismo de Crocothemis tem sido suportado tanto por dados morfológicos (Pinto 2008; Pinto \& Carvalho, em prep.), quanto moleculares (Ware et al. 2007; Pilgrim \& von Dohlen 2008). O caráter morfológico que atribui uma forte evidência ao seu monofiletismo são os processos espiniformes sobre a carena subalar do processo antealar metapleural (ch 22, Figs. 10, 14, 17) anteriormente considerado uma característica exclusiva a esse gênero ( $c f$. Pinto 2008; Pinto \& Carvalho, em prep.). Porém, na presente análise com uma maior abrangência, foi possível verificar que espécies dos gêneros Erythrodiplax (E. nigricans e E. umbrata), Uracis e Ypirangathemis também apresentam processos sobre a carena (Fig. 17, ch 22). Contudo, em nenhuma espécie desses gêneros esses processos são tão evidentes e com a mesma organização e forma, que aqueles observados em Crocothemis, além disso, sua ocorrência é variável, já que apenas alguns exemplares das duas espécies de Erythrodiplax apresentam processos, portanto talvez indique que não sejam homólogos ou 
que esses táxons possam formar um grupo monofiléticos maior em que Crocothemis esteja incluído.

Um dos grupos que merecem ser investigados futuramente é o formado unicamente por espécies as quais possuem extensas manchas escuras nas asas (Fig. 13, nó G), embora tenha apresentado baixo suporte e inclua espécies normalmente posicionadas em cinco gêneros distintos, i.e. Erythrodiplax, Neurothemis, Pseudoleon, Uracis e Ypirangathemis, alguns desses gêneros são próximos filogeneticamente e podem representar um grupo monofilético maior. Nesse grupo de espécies com marcas escuras nas asas, dois agrupamentos apresentam altos índices de suporte, os quais são identificados como monofiléticos em todas as análises, o primeiro formado por Uracis e Ypirangathemis e o segundo exclusivamente por espécies de Neurothemis (Fig. 13, nós J-K). A próxima relação de Uracis (sete espécies) com o atualmente monotípico Ypirangathemis foi extensivamente discutida por Borror (1947) baseado na morfologia da vesica spermalis, porém comparando com $Y$. calverti Santos, 1945, uma espécie distinta da incluída na presente análise que se trata um espécie não descrita. Três transformações únicas são consideradas as principais sinapomorfias, todas associadas à altamente modificada genitália feminina: (1) margem posterior da placa subgenital em vista lateral estendida distal a margem posterior do abdômen (ch. 153, estado 5); (2) esterno do S9 prolongado posteriormente além do ápice do abdômen (ch. 162, estado 1) e (3) Esterno do S9 das fêmeas cilíndrico (ch. 163, estado 2). A descoberta da larva desses gêneros possivelmente fornecerá maior evidência ao seu monofiletismo. Já Neurothemis (fig. 13, nó K) é um dos gêneros mais característicos do sudeste asiático e Australásia, sendo equivalente em termos de abundância e ocupação de habitat ao americano Erythrodiplax, o qual possui estreito relacionamento com algumas espécies (Pilgrim \& von Dohlen 2008). Na presente análise, Neurothemis possui apenas uma transformação exclusiva (Fig. 17) três ou mais células na patela da alça anal na Hw (ch. 74, estado 2).

Para Diplacodes os resultados são bastante contraditórios já que foi considerado polifilético em análises moleculares, com duas linhagens, uma formada por $D$. bipunctata e $D$. trivialis e outra com D. nebulosa, D. lefebvrii e D. luminans, a última ainda considerada como única espécie de Philonomon (Pilgrim \& von Dohlen 2008). Em nossa análise três espécies foram estudadas e D. luminans considerado grupo-irmão de D. bipunctata e D. trivialis, embora com baixo suporte e não monofilético em algumas das árvores com EW.

O ramo que contém as espécies 'nano', todas com tamanho reduzido, embora Microtrigonia Förster, 1903 seja maior que as demais, reúne as menores espécies de Anisoptera, tanto em relação ao porte quanto a envergadura. Alguns dos relacionamentos 


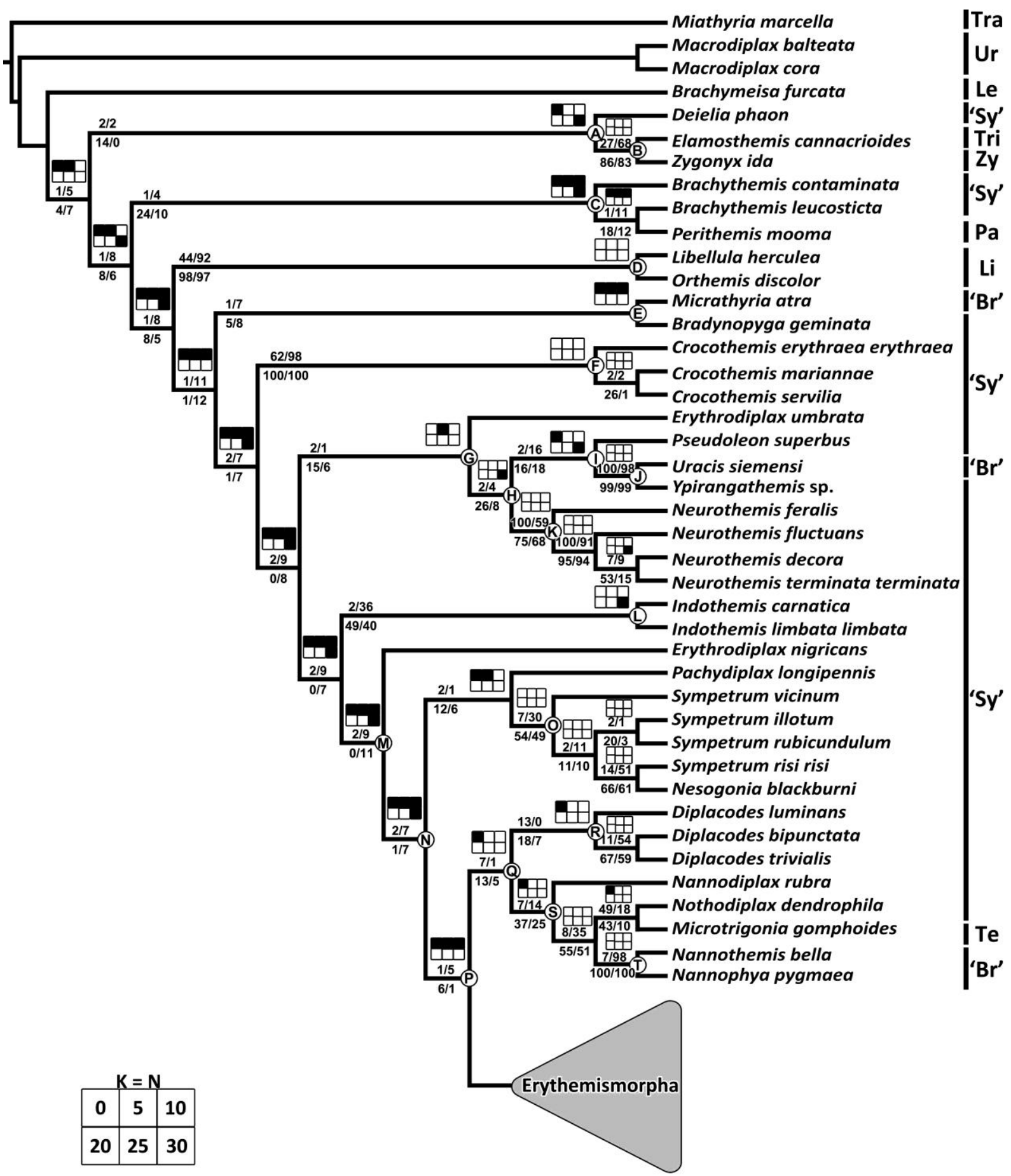

Figura 14. Único cladograma obtido aplicando parcimônia de Fitch com pesos implicados $(\mathrm{K}=15)$ com uma hipótese de relacionamento filogenético entre representantes de 'Sympetrinae' (69 táxons e 171 caracteres, fit $=75,22, \mathrm{CI}=0,23, \mathrm{RI}=0,58$ ), subárvore com o relacionamento do grupo com armadura femoral modificada (Erythemismorpha) omitido. Valores nos ramos correspondem respectivamente aos índices de Bremer relativo e reamostragem Poisson (bootstrap modificado $\mathrm{p} \approx$ 37) com frequência "GC" (grupo presente e contraditório) acima, aqueles abaixo a reamostragem simétrica (jackknife com $p=33$ ) com frequência absoluta e "GC". Retângulos acima dos nós exibem os valores de $\mathrm{K}$ em que o nó também é obtido conforme legenda; $\mathrm{K}=0$ corresponde ao consenso estrito com pesos iguais. Nós internos rotulados de A-T discutidos no texto. 'Br' = Brachydiplacinae; $\mathrm{Le}=$ Leucorrhiniinae; $\mathrm{Li}=$ Libellulinae; $\mathrm{Pa}=$ Paupopleurinae; 'Sy' = Sympetrinae; $\mathrm{Te}=$ Tetrathemistinae; $\operatorname{Tra}=$ Trameinae; Tri = Trithemistinae; Ur $=$ Urothemistinae; Zy = Zygonychinae. 
embora tenham sido identificados em diversas das árvores parecem estar mais relacionados a um efeito da miniaturização do que propriamente da relação histórica de ancestralidade comum, especialmente Nannodiplax Brauer, 1868 ('Sympetrinae') como grupo-irmão das demais que apresenta o menor suporte. A posição de Microtrigonia ('Tetrathemistinae') nesse grupo reforça a hipótese de Fleck et al. (2008), que parte de 'Tetrathemistinae' estaria mais relacionado com alguns Sympetrinae s.l. e outra a Libellulinae, sendo surpreendente a formação de um grupo monofilético com o enigmático Nothodiplax, conhecido apenas dos machos da série-tipo, o qual é grupo irmão de Nannothemis + Nannophya. Como Nothodiplax foi incluído apenas com base nas informações e ilustrações disponíveis na literatura, embora sejam excelentes (Belle 1984, Garrison et al. 2006) merece certa cautela em considerar como pertencente a esse grupo. O relacionamento de Nannothemis bella (Neártica) com Nannophya pygmaea (Indo-Australasiano) possui alto suporte sendo largamente congruente com as análises anteriores (e.g. Ware et al. 2007). Nesta análise pelo menos cinco transformações exclusivas (Fig. 17) justificam seu monofiletismo, das quais duas são fortes sinapomorfias: (1) RP1-2 entre a origem do IRP2 e o subnó fortemente côncavo (ch 35, estado 1) e (2) alcance posterior do $(\mathrm{AA}+\mathrm{CuA}) \mathrm{b}$ na margem posterior da asa, alça anal aberta (ch 68, estado 1). Fleck (2004) em um estudo da morfologia larvar considerou próximo a aos gêneros de Erythemismorpha, na verdade ele antecipou parte dos resultados de suas análises moleculares (Fleck et al. 2008). Contudo, alguns representantes desse grupo muito provavelmente representem o grupo-irmão de Erythemismorpha, pela morfologia larvar e armadura femoral o que seria no mínimo curioso do ponto de vista evolutivo já que Erythemismorpha conta com algumas espécies que configuram entre os maiores Libellulidae.

\section{ERYTHEMISMORPHA}

O conjunto de gêneros em que os adultos possuem armadura femoral altamente modificada, especialmente os machos, com espinhos heteromórficos, sendo pequenos na metade proximal e robustos e longos em sua metade distal, proposto como Erythemismorpha (sensu Pinto \& Carvalho, em prep.) foi identificado como monofilético em todas as análises, assim como em todos os esquemas de ponderação de caracteres (Figs. 13a-d, 15-16, 18). Na hipótese com parcimônia de Fitch e pesos implicados $(K=15)$ o ramo apresenta um valor relativamente baixo de $\mathrm{RB}$, enquanto os valores de reamostragem (BSG, SR e SRG) são significativamente mais elevados (Fig. 15, nó A). Esse aspecto pode ser explicado pelo fato do índice de Bremer estar fundamentado no princípio na parcimônia, de tal modo que a 
medida se refere à diferença de ajuste dos caracteres entre a MPT e as hipóteses subótimas concorrentes, sendo o Bremer relativo (ou diferença relativa de ajuste) a razão entre as somas dos ajustes dos caracteres sobre a MPT (F) menos os ajustes sobre as árvores subótimas (C), pela soma dos ajustes na MPT, RB = F - C / F (Goloboff \& Farris 2001). De modo simples demonstra quanto os caracteres que suportam um dado grupo se ajustam melhor sobre as hipóteses subótimas, ou seja, quanto o grupo é contestado devido haver melhor ajuste dos caracteres que o suportam sobre as árvores subótimas ( $c f$. Goloboff \& Farris 2001).

Por outro lado, os métodos de reamostragem são largamente dependentes na frequência ou quantidade, mesmo que os procedimentos aqui adotados minimizem esse efeito. Considere, por exemplo, que apenas um caráter suporte o monofiletismo de um dado grupo e não há caráter algum que contrarie esse relacionamento, a chance deste carácter único ser amostrado aleatoriamente a ponto de estar presente em mais que 50\% das pseudoréplicas, em um universo de dezenas de caracteres é extremamente baixa, embora o referido nó seja monofilético em todas as análises. Esse aspecto apenas ilustra que se deve ter cautela na interpretação dos resultados de "suporte de ramos" que de fato devem ser entendidos como medidas de estabilidade que obviamente indicam que os nós com maiores índices são mais estáveis frente aos dados analisados ( $c f$. Grant \& Kluge 2003, 2008; Egan 2006 para uma revisão sobre o assunto). Com a parcimônia de Sankoff Erythemismorpha apresentou valor máximo de RB (Fig. 16, nó A), possivelmente devido à eliminação da influência dos estados não comparáveis que atuam como curingas assumindo qualquer um dos estados de um dado caráter.

Erythemismorpha é sustentado por nove sinapomorfias das quais duas são transformações exclusivas (Fig. 18, nó A) e fornecem grande suporte ao seu monofiletismo, i.e. (1) porção mediana da margem póstero-dorsal do capuz projetada em um par de processos esclerosados, aqui denominados de processos paramedianos (ch. 128, estado 1) e (2) margem posterior do epiprocto das fêmeas com um pequena concavidade mediana, dividindo em dois lobos (ch. 166, estado 1) (Figs. 13, 18). As duas sinapomorfias apresentam 'reversão' em nós internos, (1) não é observada no ramo de Rhodothemis (Fig. 18, nó h) e (2) na linhagem africana Cyanothemis + Porpax (Fig. 18, nó G). Com a parcimônia de Sankoff são observadas oito sinapomorfias, porém, três das quais foram otimizadas com a parcimônia de Fitch são excluídas e duas adicionadas, nenhuma exclusiva. No entanto, mesmo os caracteres que demonstraram ser homoplásticos, inclusive aqueles em que nenhum estado é exclusivo devem ser cuidadosamente inspecionados. Por exemplo, para o ch. 12, contato dorsal entre os olhos compostos ("eyes seam") curto de 0,19-0,28 (estado 2) ou em um único ponto $<0,13$ 


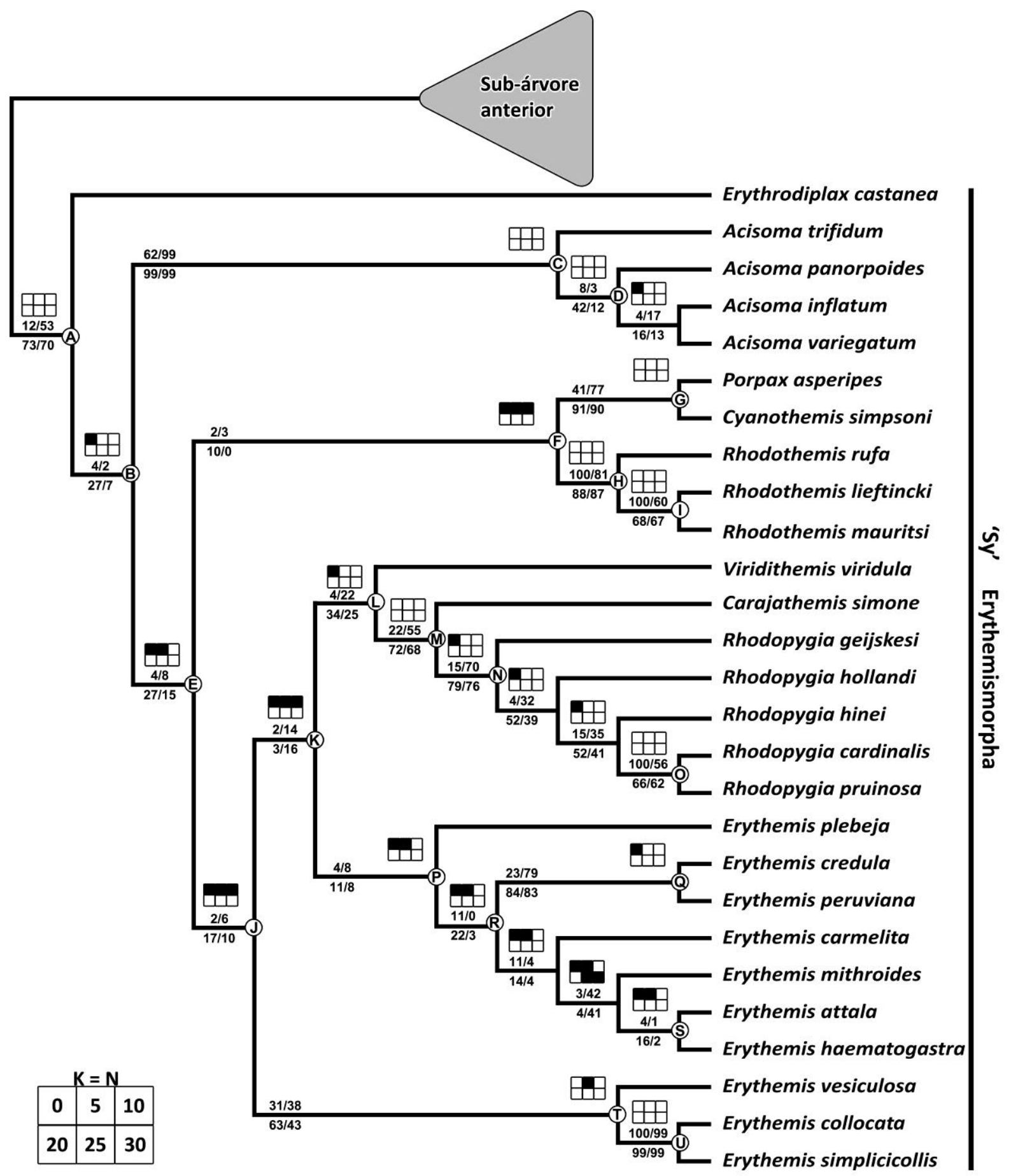

Figura 15. Continuação do cladograma da Figura 14 obtido aplicando parcimônia de Fitch sob pesos implicados ( $\mathrm{K}=15$; 69 táxons e 171 caracteres), representando apenas a subárvore com o relacionamento do grupo com armadura femoral modificada (Erythemismorpha) omitido na figura anterior. 
(estado 3), ocorrem quase que exclusivamente nesse grupo, apenas Pseudoleon superbus (nesta análise no ramo das espécies com manchas escuras extensas nas asas) apresenta o estado 2. Portanto, a curta distância de contanto dorsal entre olhos também pode ser considerado uma característica que atribui suporte ao grupo. Para alguns dos caracteres que deram passos extras (homoplásticos) aparentemente isso ocorreu por terem sido codificados em caracteres multiestados, talvez com a decomposição de alguns deles e posterior recodificação se ajustem perfeitamente a árvore ou mesmo, tratar alguns desses caracteres como quantitativos talvez possa melhorar os resultados e todas essas possibilidades devem ser investigadas no futuro.

A maior parte dos nós internos em Erythemismorpha apresenta baixo suporte, não sendo recuperados em todas as análises, e quando identificados como monofiléticos apresentam baixo suporte, pois são observados com apenas alguns valores de $\mathrm{K}$ e com índices de estabilidade baixos (e.g. Figs. 15-16, nós B, E, K-L). Isso demonstra que os resultados aqui obtidos são altamente indecisos quanto ao relacionamento entre os grupos de espécies de Erythemismorpha. Entretanto alguns resultados são bastante sólidos e parcialmente congruentes com análises anteriores.

Erythrodiplax castanea + Erythemismorpha. A inclusão de E. castanea, uma espécie com ampla distribuição na América do Sul, nesse grupo, de certa forma pode ser considerada surpreendente, no entanto a espécie possui as duas principais sinapomorfias de Erythemismorpha, ou seja, os processos paramedianos na vesica spermalis (Fig. 3) e epiprocto da fêmea bilobado (chs. 128 e 166) (Fig. 12). Essa espécie é considerada grupoirmão dos demais Erythemismorpha em quase todas as análises exceto em parte das árvores com parcimônia de Fitch e EW. Borror (1942), em sua revisão de Erythrodiplax, propôs o grupo E. castanea para abrigar além da espécie nominal também E. amazonica e E. melanica (a última como subespécie de E. amazonica) e considerou esse grupo um dos mais divergentes dos demais Erythrodiplax, com relacionamento incerto dentro do gênero. Além disso, considerou a vesica spermalis (pênis) similar aquela observada em Rhodopygia. No presente estudo a morfologia da vesica spermalis de E. castanea demonstrou ser extremamente similar a Carajathemis e Rhodopygia spp., principalmente em relação aos processos paramedianos do capuz (Figs. 3a-d). Soma-se a esse fato o formato do abdômen (similar a algumas espécies de Erythemis como E. credula e E. mithroides); a cor vermelha comum em espécies de Erythemismorpha ( $c f$. apêndice 3, Figs. 19-21, observada em todas as espécies de Rhodopygia, Rhodothemis e parte de Erythemis) e sua provável larva (associada a essa espécie apenas por exclusão) que apresenta grande semelhança com aquelas de 


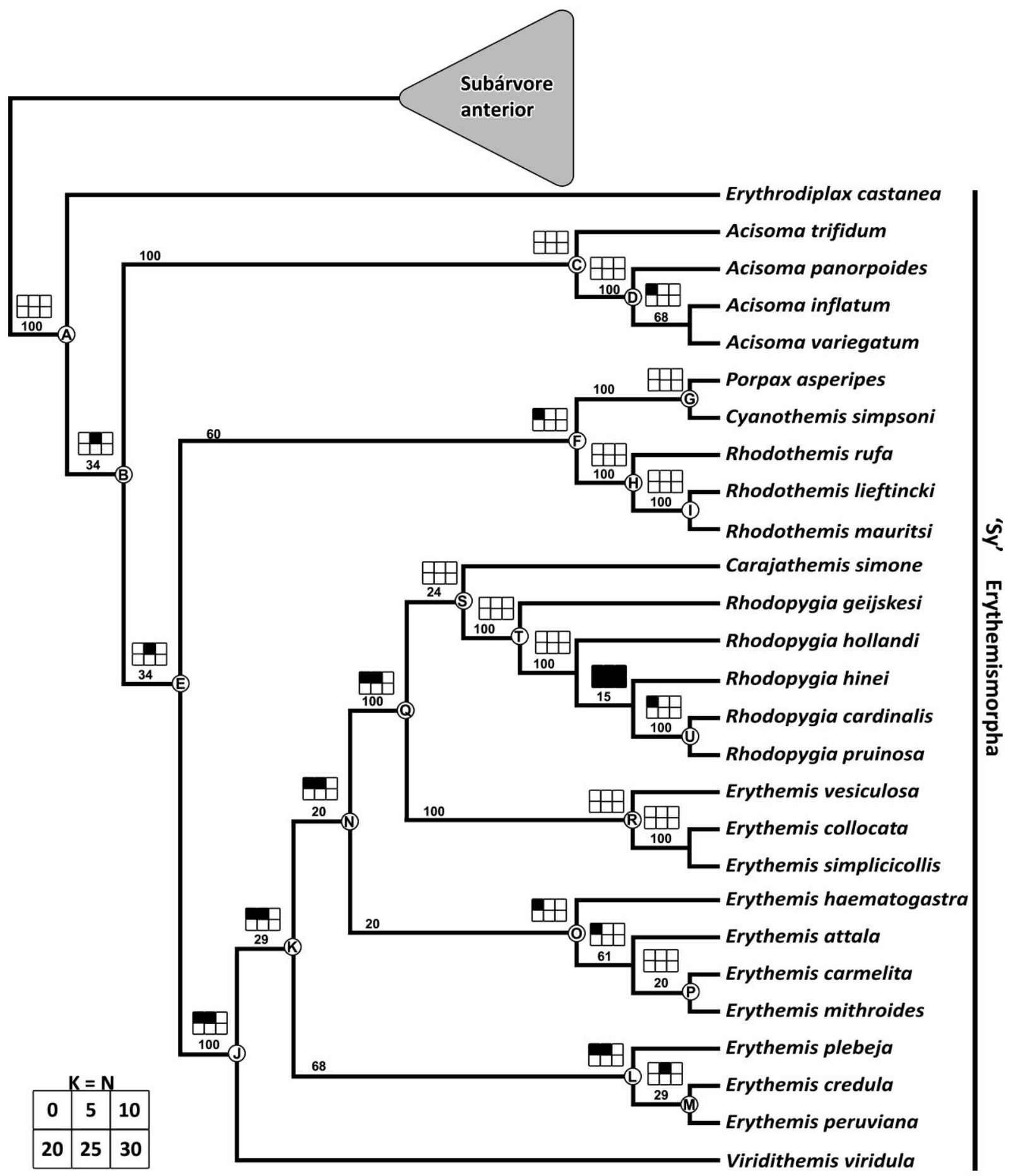

Figura 16. Cladograma único obtido aplicando parcimônia de Sankoff para os caracteres não comparáveis com pesos implicados $(\mathrm{K}=15)$ com hipótese de relacionamento filogenético entre representantes de Sympetrinae (69 táxons e 171 caracteres), mostrando apenas a subárvore com o relacionamento do grupo com armadura femoral modificada (Erythemismorpha). Valores acima dos nos ramos correspondem ao índice de Bremer relativo. Retângulos acima dos nós exibem os valores de $\mathrm{K}$ em que o nó também é obtido conforme legenda; $\mathrm{K}=0$ corresponde ao consenso estrito com pesos iguais. Nós internos rotulados de A-U, discutidos no texto. 'Sy' = Sympetrinae.

Erythemis devido à forma e tamanho dos espinhos laterais do S9 e pirâmide anal com paraproctos curvados ventralmente, sendo praticamente inseparáveis com base nos caracteres 
atualmente utilizados (APP observação pessoal). As demais espécies do grupo E. amazonica e E. melanica precisam ser examinadas para verificar se também pertencem a Erythemismorpha, contudo com base no estudo de Borror (1942) muito provavelmente também estejam próximas filogeneticamente, já que são morfologicamente similares a $E$. castanea.

Acisoma. O monofiletismo desse gênero foi suportando por todas as análises realizadas, sendo um dos nós mais robustos com valores de índices de estabilidades elevados (Figs. 15-16). Incluí espécies de morfologia altamente modificada, devido a isso foi um dos primeiros a serem propostos com um gênero distinto de Libellula (Rambur 1842). O ramo de Acisoma é um dos mais longos com vinte sinapomorfias (Fig. 18, nó C), três delas exclusivas: (1) células marginais ao AA1b no campo anal da $\mathrm{Hw}$ alongadas (ch. 75, estado 1); (2) superfície ventral do esternito do S1 armada, com pequenos processos espiniformes (ch. 106, estado 1); e (3) S4 expandida em relação ao S5 distintamente mais largo (ch. 113, estado 1).

Seu relacionamento com os demais gêneros de Erythemismorpha permanece extremamente inconclusivo, Fleck (2004) considerou como grupo-irmão de Cyanothemis + Rhodothemis + Erythemis, por sua vez Pinto (2008) e Pinto \& Carvalho (em prep.) como grupo-irmão de Rhodothemis, em análises moleculares tem sido proposto como grupo-irmão de Erythemis + Pachydiplax (Ware et al. 2007), Porpax (Pilgrim \& von Dohlen 2008) ou Rhodothemis + Nannophya (Fleck et al. 2008).

Cyanothemis + Porpax. O monofiletismo desse ramo contendo Cyanothemis (uma espécie de grande porte) e Porpax (cinco espécies de médio porte, representada aqui apenas por $P$. asperipes), foi suportado em todas as análises com todos os esquemas de ponderação de caracteres e com altos valores de índices de estabilidade de ramos (Figs. 15-16, nó G), embora, apesar do grande número de transformações, nenhuma exclusiva foi identificada para esse ramo. Esse grupo de espécies está amplamente distribuído da Bacia do Congo, na África Tropical ( $c f$. Dijkstra 2006, 2007). Ris (1915) ao descrever Cyanothemis, comparou com diversos gêneros de Sympetrinae s.l. entre eles Crocothemis, mas considerou mais similar a Rhodopygia e especialmente Rhodothemis em Erythemismorpha, o qual considerou um representante Africano azul do Indo-Australasiano vermelho Rhodothemis. Baseado na morfologia do último estádio larvar Fleck (2004) propôs que fosse o grupo-irmão de Erythemis + Rhodothemis, gêneros os quais possuem larvas extremamente semelhantes, Apenas após as análises moleculares de Pilgrim \& von Dohlen (2008) é que o possível relacionamento de Porpax, originalmente posicionado em 'Brachydiplacinae' com 


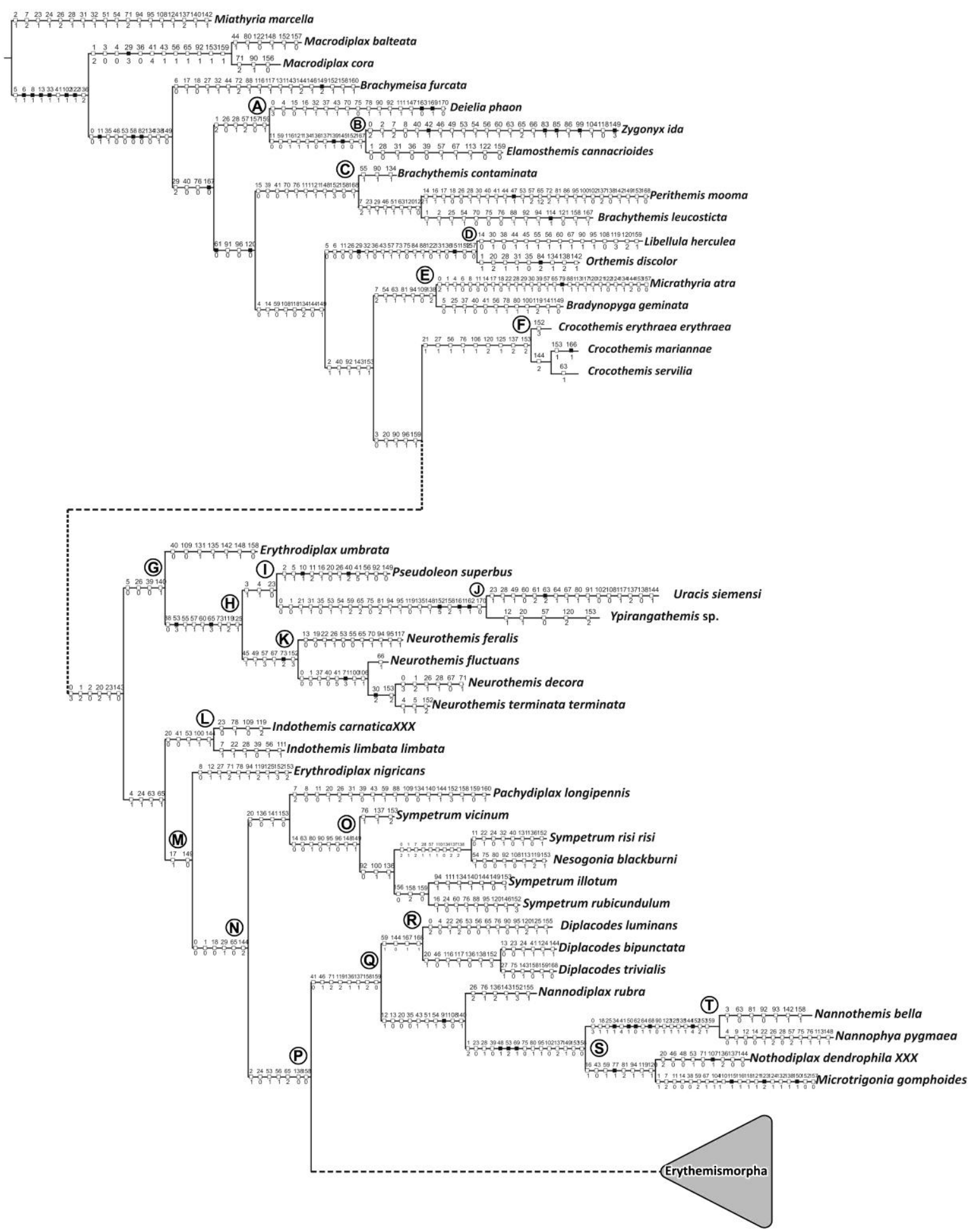

Figura 17. Único cladograma obtido aplicando parcimônia de Fitch sob pesos implicados $(\mathrm{K}=15)$ com uma hipótese de relacionamento filogenético entre representantes de 'Sympetrinae' (69 táxons e 171 caracteres), subárvore com o relacionamento do grupo com armadura femoral modificada (Erythemismorpha) omitido. Caracteres numerados a partir de zero ("0"), otimizados segundo o critério de ACCTRAN, quadrados negros correspondem a transformações únicas.

Erythemismorpha e mais precisamente Cyanothemis foi sugerido. Embora no trabalho de Pilgrim \& von Dohlen (2008) apenas Porpax tenha sido analisado em todas as árvores o 
gênero é considerado próximo a Rhodothemis, Acisoma, Rhodopygia e Erythemis. De fato a vesica spermalis é muito semelhante entre Cyanothemis e Porpax, e apesar dos machos serem a primeira vista divergentes, a morfologia geral das fêmeas é muito similar. Esses dois gêneros representam os únicos representantes se Erythemismorpha em que o epiprocto da fêmea é regularmente convexo (ch. 166), sendo possível ter ocorrido uma reversão ou ausência secundária que justificaria seu monofiletismo (epiprocto feminino de Carajathemis e Viridithemis não foram examinados).

Rhodothemis. Tradicionalmente apenas esse gênero tem sido considerado como grupo-irmão de Erythemis (Ris 1911; Kennedy 1923; Needham \& Broughton 1927; Fleck 2004). Esta hipótese tem sido recorrentemente rejeitada em análises moleculares Pilgrim \& von Dohlen (2008) e morfológicas (Pinto 2008; Pinto \& Carvalho e prep.), com relações de grupo irmão inconclusivas. Rhodothemis foi considerado monofilético em todas as análises realizadas e em todos os esquemas de ponderação de caracteres com altíssimos índices de suporte de ramos. O resultado corrobora os previamente obtidos (Pinto 2008, Pinto \& Carvalho em prep.) e fornece suporte a hipótese de que esteja dividido em duas linhagens, proposto com grupos R. lieftincki e R. rufa por Lohmann (1984). Pelo menos um sinapomorfia exclusiva foi identificada para esse gênero superfície ventral do trocânter metatorácico armada com processos espiniformes negros (ch. 98, estado 1).

Viridithemis + Carajathemis + Rhodopygia. A posição de Viridithemis como grupoirmão de Carajathemis e Rhodopygia é apenas sustentada na análise com a parcimônia de Fitch e com alguns valores de pesos implicados. Esse enigmático gênero quando descrito foi comparado apenas com Rhodothemis de Erythemismorpha por Fraser (1960), existe uma única espécie fêmea preservada em museu, o restante das informações são de algumas poucas fotografias ( $c f$. Crewe \& Cohen 2009 e Apêndice 3). As informações disponíveis na literatura não permitem uma adequada comparação com os demais terminais e certamente qualquer afirmação sobre seu possível grupo-irmão no presente contexto é questionável, no entanto, sua inclusão em Erythemismorpha, mesmo sendo, o táxon codificado com muitos dados ausentes (“"?) é altamente significativa. O relacionamento de Rhodopygia com o recentemente descrito Carajathemis é fortemente suportado em todas as análises com alto suporte (Fig. 15 nó M, Fig. 16, nó S), embora seja apenas por transformações homoplásticas o ch. 72, espaço entre Cuspl e $\mathrm{AA}+\mathrm{CuA}$ na Hw com três células seja observado apenas em Neurothemis decora um gênero distantemente relacionado. Carajathemis superficialmente é muito similar a Rhodopygia que por outro lado, a exemplo de Rhodothemis e Acisoma é um dos gêneros mais uniformes, com as espécies muito semelhantes entre si. É paradoxal que 
Machado (2012) ao descrever o gênero não tenha comparado mais diretamente com Rhodopygia, já que em quase todos os aspectos se assemelha a esse gênero como genitália acessória, cor e forma do abdômen, espinho quadrangular nos fêmures mesotorácico e, sobretudo a vesica spermalis. Controversamente a configuração dos espinhos metatorácicos é praticamente igual da àquela observada em Erythemis, e sua suposta larva (associada a essa espécie apenas por exclusão) é mais semelhante a Erythemis que Rhodothemis pela forma do espinhos do S9 (APP observação pessoal). Ambos Carajathemis e Cyanothemis podem ser considerados gêneros "amálgamas" ou de "transição" sob um ponto de vista tipológico, pois compartilham largamente caracteres com outros gêneros de Erythemismorpha. Em Rhodopygia o relacionamento com maior suporte é $R$. cardinalis $+R$. pruinosa que compartilham uma sinapomorfia exclusiva: margem posterior do processo paramediano armada com projeções espiniformes (ch 131, estado 1).

Erythemis. Certamente esse é um dos gêneros mais polimórficos de todos de Erythemismorpha, contendo espécies de pequeno (E. credula) a grande porte (E. vesiculosa), e suas espécies são claramente distintas umas das outras, sendo que mesclam algumas das características dos demais gêneros desse grupo. A hipótese inicial de que fosse um grupo monofilético baseado na armadura femoral com pequenos espinhos nos dois terços proximais e com três longos e robustos espinhos no terço distal já havia sido colocada à prova com as espécies do grupo $R$. lieftincki de Rhodothemis, que em alguns casos podem apresentar a mesma configuração ( $c f$. Lohmann 1984), no entanto, com a descrição de Carajathemis essa hipótese se tornou mais frágil pois sua única espécie apresenta a mesma configuração observada em Erythemis ( $c f$. Machado 2012). Pinto (2008) e Pinto \& Carvalho (em prep.) deram suporte ao monofiletismo do gênero embora com baixos índices de estabilidade de ramos. Com a presente análise, mais abrangente, talvez de fato represente um grupo parafilético. No entanto, alguns dos grupos monofiléticos identificados nas análises anteriores ganharam suporte como E. peruviana + E. credula (Fig. 15, nó Q; Figura 16, nó M) e grupo formado pelas espécies verdes E. vesiculosa + E. simplicicollis + E. collocata . Caso essa última hipótese seja confirmada a petição solicitada a Comissão Internacional de Nomenclatura Zoológica para que Lepthemis fosse considerado sinônimo júnior de Erythemis (Capítulo 5) torna-se desnecessária já que Libellula peruviana espécie-tipo de Erythemis e Libellula vesiculosa espécie-tipo de Lepthemis não formam um grupo monofilético.

A presente análise pode ser considerada a mais abrangente para composição de Erythemismorpha e sem dúvida o teste mais robusto de seu monofiletismo, composição esta sugerida por Pinto \& Carvalho (em prep.), porém envolvendo um grupo muito menor de 
táxons e sem propor a inclusão de E. castanea. As análises tanto moleculares como morfológicas parcialmente sustentam os resultados aqui apresentados embora novamente com uma composição de táxons bastante diferentes (Fleck 2004; Pilgrim \& von Dohlen 2008; Fleck et al. 2008).

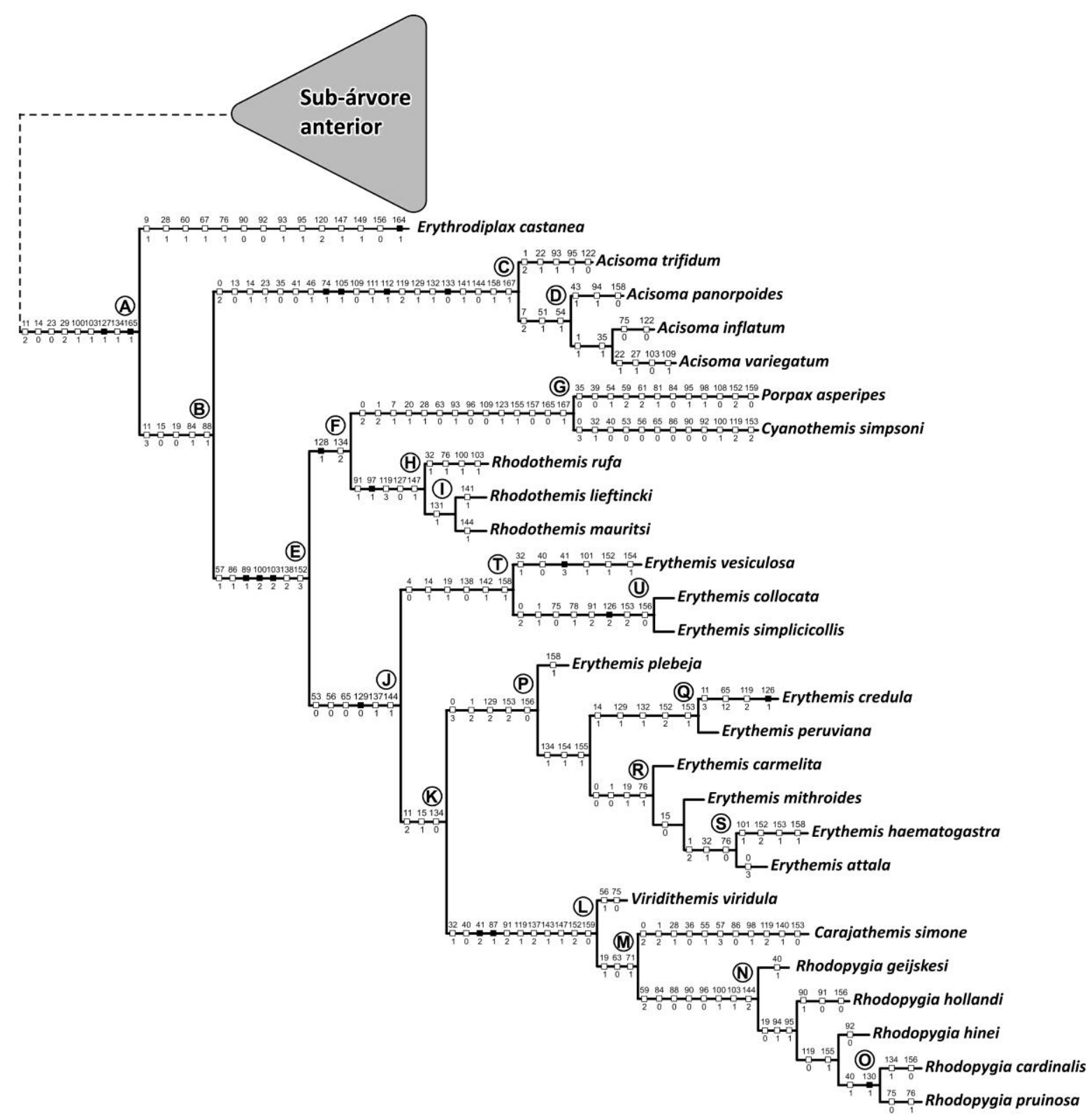

Figura 18. Continuação do cladograma da figura 17.

O monofiletismo de Erythemismorpha é um dos resultados mais significativos aqui obtidos assim com a inclusão de E. castanea e o relacionamento de grupos-irmãos de Rhodopygia + Carajathemis e Cyanothemis + Porpax respectivamente. Deve ser creditado a Ris $(1911,1915,1919)$ como sendo o primeiro pesquisador a associar representantes desses gêneros em seu grupo "VI.EE" assim como Fleck (2004) com uma abordagem filogenética 
baseado na morfologia larvar, embora utilizando algo como o método conhecido de argumentação Hennigiana. Com a inclusão de E. castanea nesse grupo a composição completa desse grupo permanece aberta e além dos gêneros aqui testados alguns dos "nanos" e outros Sympetrinae s.l. devem ser investigados incluindo as demais espécies do grupo $E$. castanea de Erythrodiplax.

O relacionamento filogenético próximo de alguns desses gêneros possivelmente remetem a remanescentes de uma distribuição Gondwânica. A proposição de uma categoria taxonômica formal para receber esses gêneros, pelos menos os táxons com morfologia dos espinhos femorais altamente diferenciada depende de uma investigação ainda mais ampla com a inclusão de um número maior de táxons, principalmente com caracteres dos estádios larvais que possuem alto sinal filogenético ( $c f$. Fleck et al. 2009 para uma discussão) bem como dados moleculares para que talvez uma hipótese mais robusta do relacionamento entre esses gêneros seja proposta. 


\section{DisCuSSÃO GERAL E CONCLUSÕES}

A análise dos nomes genéricos incluídos em Erythemismorpha demonstrou que Lepthemis Hagen, 1861 possui prioridade sobre Erythemis Hagen, 1861 conforme o princípio do primeiro revisor e a adoção do nome Lepthemis acarretaria uma grande instabilidade na nomenclatura desses dois gêneros, portanto uma petição foi submetida à Comissão Internacional de Nomenclatura Zoológica para proteger o nome Erythemis. Contudo, a presente análise indica que esse pedido talvez seja desnecessário, pois os tipos destes gêneros podem não formar um grupo monofilético.

O estudo da morfologia externa demonstrou ser uma fonte útil de caracteres para inferência filogenética, porém, grande parte das declarações iniciais de homologia, principalmente aquelas utilizadas regularmente na taxonomia devem ser reavaliadas, para que reflita de modo mais adequado a história evolutiva dos táxons. Além disso, a morfologia da vesica spermalis em Libellulidae necessita urgentemente ser revista devido a inúmeras incongruências e dificuldades na identificação de seus mais diferentes lobos, para que uma proposta compreensiva seja formulada. A parcimônia de Sankoff deve ser aprimorada para evitar a atração de ramos devido ao alto custo das transformações, contudo demonstrou ser útil e baseado no número de passos obtido o efeito de atração de ramos foi irrelevante.

'Sympetrinae' em seu tradicional senso engloba um grupo altamente polifilético como demonstrado em outras análises e novamente evidenciado pelo presente estudo. Alguns grupos monofiléticos sólidos em Sympetrinae s.l. foram identificados os quais possuem correspondência com as demais análises. O nome 'Sympetrinae' deve se referir exclusivamente ao gênero Sympetrum e demais gêneros relacionados, entretanto um estudo sobre a prioridade dos nomes deve ser realizado já que os gêneros-tipos de outras subfamílias como Leucorrhinia fazem parte do mesmo grupo monofilético.

Em Erythemismorpha todos os gêneros não monotípicos demonstraram ser monofiléticos exceto Erythemis que mostrou ser parafilético com algumas espécies mais próximas da linhagem Viridithemis + Carajathemis + Rhodopygia. A maior parte dos relacionamentos entre os gêneros de Erythemismorpha permanece inconclusiva, contudo o relacionamento de Carajathemis como grupo-irmão de Rhodopygia e Cyanothemis de Porpax é bem suportado, para os demais, futuras investigações devem ser realizadas já que os resultados são contraditórios. Dois dos relacionamentos obtidos são fontes instigantes para as próximas investigações, o grupo E. castanea em Erythrodiplax e Porpax como sendo Erythemismorpha, certamente um significativo avanço na compreensão do relacionamento desses gêneros ocorrerá com a inclusão de caracteres dos imaturos. 


\section{REFERÊNCIAS BIBLIOGRÁFICAS}

Amorim, D. S. (2002). Fundamentos de sistemática filogenética. Ribeirão Preto: Holos Editora.

Artiss, T., Schultz, T. R., Polhemus, D. A. \& Simon, C. (2001). Molecular phylogenetic analysis of the dragonfly genera Libellula, Ladona, and Plathemis (Odonata: Libellulidae) based on mitochondrial cytochrome oxidase I and 16S rRNA sequence data. Molecular Phylogenetics and Evolution, 18, 348-361.

Asahina, S. (1954). A morphological study of a relic dragonfly Epiophlebia superstes Selys (Odonata, Anisozygoptera). Tokyo: The Japan Society for Promotion of Science.

Assis, L. C. S. (2009). Coherence, correspondence, and the renaissance of morphology in phylogenetic systematics. Cladistics, 25, 528-544.

Baker R. H., Xiaobo, Y. \& DeSalle, R. (1998). Assessing the relative contribution of molecular and morphological characters in simultaneous analysis trees. Molecular Phylogenetics and Evolution, 9, 427-436.

Ballare, E. F. \& Ware, J. L. (2011). Dragons fly, biologists classify: an overview of molecular odonate studies, and our evolutionary understanding of dragonfly and damselfly (Insecta: Odonata) behavior. International Journal of Odonatology, 14, 137-147.

Bartnef, A. N. (1915). Insectes Pseudoneuroptères (Insecta Pseudoneuroptera), Volume I, Libellulidae, Livraison 1. In Faune de la Russie et des pays limitrophes fondèe principalement sur les collections du Musee Zoologique de L'Academie Imperiale des Sciences de Petrograd, 1, 1-352. [em Russo].

Baskinger, G., Ware, J. L., Cornell, D., May, M. L. \& Kjer, K. (2008). A phylogenetic exploration of Celithemis (Odonata: Libellulidae): the pennants of North America. Odonatologica, 37, 101-109.

Bechly, G. (1995). Morphologische Untersuchungen am Flügelgeäder der rezenten Libellen und deren Stammgruppenvertreter (Insecta; Pterygota; Odonata) unter besonderer Berücksichtigung der Phylogenetischen Systematik und des Grundplanes der *Odonata. Petalura, especial volume, 1, 1-341.

Bechly, G. (1996). Morphologische Untersuchungen am Flügelgeäder der rezenten Libellen und deren Stammgruppenvertreter (Insecta; Pterygota; Odonata) unter besonderer Berücksichtigung der Phylogenetischen Systematik und des Grundplanes der Odonata. Petalura, especial volume, 2, 1-402. 
Bechly, G., Nel, A., Martínez-Declòs, X. \& Fleck, G. (1998). Four new dragonflies from Upper Jurassic of Germany and the Lower Cretaceous of Mongolia (Anisoptera: Hemeroscopidae, Sonidae, and Protrogomphidae fam. nov.). Odonatologica, 27, 149-185.

Belle, J. (1984). Nothodiplax dendrophila, a new genus and a new species from Surinam (Odonata: Libellulidae). Entomologische Berichten, 44, 6-8.

Belle, J. (1996). Higher classification of the South-American Gomphidae (Odonata). Zoologische Mededelingen, 70, 297-324.

Blanke, A., Wipfler, B., Letsch, H., Koch, M., Beckmann, F., Beutel, R. \& Misof, B. (2012). Revival of Palaeoptera-head characters support a monophyletic origin of Odonata and Ephemeroptera (Insecta). Cladistics, in press [DOI: 10.1111/j.1096-0031.2012.00405.x]

Borror, D. J. (1931). The genus Oligoclada (Odonata). Miscellaneous Publications, Museum of Zoology, University of Michigan, 22, 1-42.

Borror, D. J. (1942). A revision of Libellulinae genus Erythrodiplax (Odonata). Columbus: The Ohio State University. [Graduate School Studies. Contributions in Zoology and Entomology n. 4. Biological Series]

Borror, D. J. (1947). Notes on Ypirangathemis Santos (Odonata: Libellulidae) with a description of the female of Y. calverti Santos. Annals Entomological Society of America, $40,247-256$.

Borror, D. J. (1957). New Erythrodiplax from Venezuela (Odonata: Libellulidae). Acta Biologica Venezuelica, 2, 31-42.

Brady, R. H. (1983). Parsimony, hierarchy, and biological implications. In Platnick, N. \& V. A. Funk. Advances in Cladistics, Volume 2. (pp. 3-??). New York: Columbia University press.

Brady, R. H. (1985). On the independence of systematics. Cladistics, 1, 113-126.

Bremer, K. (1994). Branch support and tree stability. Cladistics, 10, 295-304.

Bridges, C. A. (1994). Catalogue of the family-group, genus-group and species-group names of the Odonata of the world (Third Edition). Privately published: Urbana.

Brower, A. V. Z. \& de Pinna, M. C. C. (2012). Homology and errors. Cladistics, 28, 113-114.

Bryant, H. N. (1989). An evaluation of cladistic and character analyses as hypotheticdeductive procedures, and the consequences for character weighting. Systematic Zoology, $38,214-227$.

Bryant, H. N. (1995). Why autapomorphies should be removed: a reply a Yates. Cladistics, $11,381-384$.

Bybee, S. M., Ogden, T. H., Branham, M. A. \& Whiting, M. F. (2008). Molecules, 
morphology and fossils: a comprehensive approach to odonate phylogeny and the evolution of the odonate wing. Cladistics, 23, 1-38.

Carle, F. L. (1982). The wing vein homologies and phylogeny of the Odonata: a continuing debate. Societas Internationalis Odonatologica Rapid Communications, 4, 1-66.

Carle, F. L. (1986). The classification, phylogeny and biogeography of the Gomphidae (Anisoptera). I. Classification. Odonatologica, 15, 275-326.

Carle, F. L. (1993). Sympetrum janeae spec. nov. from eastern North America, with a key to the Nearctic Sympetrum (Anisoptera: Libellulidae). Odonatologica, 22, 1-16.

Carle, F. L. (1995). Evolution, taxonomy, and biogeography of ancient Gondwanian libelluloides, with comments on anisopteroid evolution and phylogenetic systematics (Anisoptera: Libelluloidea). Odonatologica, 24, 383-506.

Carle, F. L. \& Kjer, K. M. (2002). Phylogeny of Libellula Linnaeus (Odonata: Insecta). Zootaxa, 87, 1-18.

Carle, F. L., Kjer, K. M. \& May, M. L. (2008). Evolution of Odonata, with Special Reference to Coenagrionoidea (Zygoptera). Arthropod Systematics \& Phylogeny, 66, 37-44.

Carle, F. L. (2012). A new Epiophlebia (Odonata: Epiophlebioidea) from China with a review of epiophlebian taxonomy, life history, and biogeography. Arthropod Systematics \& Phylogeny, 70, 75-83.

Carpenter, J. M. (1987). Cladistics of cladists. Cladistics, 3, 363-375.

Carpenter, J. M. (1988). Choosing among multiple equally parsimonious cladograms. Cladistics, 4, 291-296.

Calvert, P. P. (1893). Catalogue of the Odonata (dragonflies) of the vicinity of Philadelphia, with an introduction to the study of this group of insects. Transactions of the American Entomological Society, 20, 152-272 + pl. II-III.

Córdoba-Aguilar, A. (2008). Dragonflies and Damselflies: Model organisms for ecological and evolutionary research. Oxford: Oxford University Press.

Crewe, M. D. \& Cohen, C. (2009). Viridithemis viridula Fraser, 1960 - discovery of the first known male. Agrion, 13, 54-55.

Damm S., Dijkstra, K.-D. B. \& Hadrys, H. (2010). Red drifters and dark residents: the phylogeny and ecology of a Plio-Pleistocene dragonfly radiation reflects Africa's changing environment (Odonata, Libellulidae, Trithemis). Molecular Phylogenetics and Evolution, $54,870-882$.

Davies, D. A. L. \& Tobin, P. (1985). The dragonflies of the world: a systematic list of the extant species of Odonata. Vol. 2. Anisoptera. Societas Internationalis Odonatologica, 
Rapid Communications, Supplement, 5, 1-151.

DeBry, R. W. (2005). The Systematic Component of Phylogenetic Error as a Function of Taxonomic Sampling under Parsimony. Systematic Biology, 54, 432-440.

Degnan, J. H. \& Rosenberg, N. A. (2006). Discordance of species trees with their most likely gene trees. PLOS Genetics, 2, 762-768.

De Pinna, M. C. C. (1991). Concepts and tests of homology in the cladistic paradigm. Cladistics, 7, 367-394.

Dijkstra, K.-D. B. (2003). Fooled by the double: Brachythemis liberiensis is Parazyxomma flavicans, with a note on the Zyxommatini (Odonata: Libellulidae). International Journal of Odonatology, 6, 17-21.

Dijkstra, K.-D. B. (2006a). Taxonomy and biogeography of Porpax, a dragonfly genus centered in the Congo Basin (Odonata, Libellulidae). Tijdschrift voor Entomologie, 149, $71-88$.

Dijkstra, K.-D. B. (2006b). The Atoconeura problem revisited: taxonomy, phylogeny and biogeography of a dragonfly genus in the highlands of Africa (Odonata, Libellulidae). Tijdschrift voor Entomologie, 149, 121-144.

Dijkstra, K.-D. B. (2006c). African Diplacodes: the status of the small species and the genus Philonomon (Odonata: Libellulidae). International Journal of Odonatology, 9, 119-132.

Dijkstra, K.-D. B. (2007). Demise and rise: the biogeography and taxonomy of the Odonata of tropical Africa. pp. 143-187In: Dijkstra, K.-D. B. (ed.). Demise and rise: the biogeography and taxonomy of the Odonata of tropical Africa. Leiden University.

Dijkstra, K.-D. B., Bechly, G. Bybee, S. N., Dow, R. A., Dumont, H. J., von Ellenrieder, N. V., Fleck, G., Garrison, R. W., Hämäläinen, M., Kalkman, V. J., Karube, H., May, M. L., Orr, A. G., Paulson, D. R., Rehn, A. C., Theischinger, G., Trueman, J. W. H., Tol, J. V. \& Ware, J. (in prep.). The classification of dragonflies and damselflies (Odonata). Zootaxa.

Dijkstra, K.-D. B. \& Kalkman, V. J. (2012). Phylogeny, classification and taxonomy of European dragonflies and damselflies (Odonata): a review. Organisms Diversity \& Evolution, in press [DOI 10.1007/s13127-012-0080-8]

Dijkstra, K.-D. B. \& Matushkina, N. (2009). Kindred spirits: "Brachythemis leucosticta", Africa's most familiar dragonfly, consists of two species (Odonata: Libellulidae). International Journal of Odonatology, 12, 237-256.

Dijkstra, K.-D. B. \& Vick, G. S. (2006). Inflation by venation and the bankruptcy of traditional genera: the case of Neodythemis and Micromacromia, with keys to the continental African species and the description of two new Neodythemis species from the 
Albertine Rift (Odonata: Libellulidae). International Journal of Odonatology, 9, 51-70.

Donnelly, T. W. (1997). History of the study of Odonata (part 3). Argia, 9, 18-21.

Dumont, H. J., Vanfleteren, J. R., de Jonckheere, J. F. \& Weekers, P. H. H. (2005). Phylogenetic relationships, divergence time estimation, and global biogeographic patterns of calopterygoid damselflies (Odonata, Zygoptera) inferred from ribosomal DNA sequences. Systematic Biology, 54, 347-362.

Dumont, H. J., Vanfleteren, J. R., Vierstraete, A. (2010). A molecular phylogeny of the Odonata (Insecta). Systematic Entomology, 35, 6-18.

Egan, M. G. (2006). Support versus corroboration. Journal of Biomedical Informatics, 39, $72-85$.

Ebach, M. C., Morrone, J. J. \& Williams, D. M. (2008). A new cladistics of cladists. Biology and Philosophy, 23,153-156.

Farris, J. S. (1970). Methods for computing Wagner trees. Systematic Zoology, 19, 83-92.

Farris, J. S. (1983). The logical basis of Phylogenetic analysis. In Platnick, N. \& Funk, V. A. Advances in Cladistics, Volume 2. (pp. 7-36). New York: Columbia University press.

Farris, J. S. (1989). The retention index and the rescaled consistency index. Cladistics, 5, 374-385.

Farris, J. S. (2001). Support weighting. Cladistics, 17, 389-394.

Farris, J. S. (2011). Systemic foundering. Cladistics, 27, 207-221.

Farris, J. S. (2012a). Homology and historiography. Cladistics, in press [DOI: 10.1111/j.1096-0031.2012.00415.x]

Farris, J. S. (2012b). Counterfeit cladistics. Cladistics, in press [DOI: 10.1111/j.10960031.2011.00389.x]

Fitch, W. M. (1971). Toward defining the course of evolution: minimum change for a specific tree topology. Systematic Zoology, 20, 406-416.

Fitzhugh, K. (2006). The philosophical basis of character coding for the inference of phylogenetic hypotheses. Zoologica Scripta, 35, 261-286.

Fleck, G. (2004). The larva of the genus Cyanothemis Ris, 1915 (Odonata: Anisoptera: Libellulidae). Phylogenetic consequences. Annales de la Societe Entomologique de France, 40, 51-58.

Fleck, G.; Bechly, G.; Martínez-Delclòs; X.; Jarzembowski, E.; Coram, R. \& Nel, A. (2003). Phylogeny and classification of the Stenophlebioptera (Odonata: Epiproctophora). Annales de la Société entomologique de France, 39, 55-93.

Fleck, G., Brenk, M. \& Misof, B. (2008a). Larval and molecular characters help to solve 
phylogenetic puzzles in the highly diverse dragonfly family Libellulidae (Insecta: Odonata: Anisoptera): The Tetrathemistinae are a polyphyletic group. Organisms, Diversity \& Evolution, 8, 1-16.

Fleck, G., Hamada, N. \& Carvalho, A. L. (2009). A remarkable new genus and species of dragonfl y (Odonata: Anisoptera: Libellulidae) from Brazil and notes on its bionomics and phylogenetic affinities. Annales de la Société entomologique de France, 45, 3, 275-284.

Fleck, G. \& Legrand, J. (2006). La larve du genre Nesocordulia McLachlan, 1882, conséquences phylogénétiques [Odonata, Anisoptera, Corduliidae]. Revue Francaise d'Entomologie (Nouvelle-Serie), 28, 31-40.

Fleck, G., Nel, A. \& Martínez-Delclòs, X. (1999). The oldest record of libellulid dragonflies from the Upper Cretaceous of Kazakhstan (Insecta: Odonata, Anisoptera). Cretaceous Research, 20, 655-658.

Fleck, G., Ullrich, B., Brenk, M., Wallnisch, C., Orland, M., Bleidissel, S. \& Misof, B. (2008b). A phylogeny of anisopterous dragonflies (Insecta, Odonata) using mtRNA genes and mixed nucleotide / doublet models. Journal of Zoological Systematics and Evolutionary Research, 46, 310-322.

Fraser, F. C. (1957). Reclassification of the order Odonata. Sydney: Royal Zoological Society of New South Wales.

Fraser, F. C. (1960). A new genus and species of Odonata f[r]om Madagascar. Naturaliste Malgache, 12, 71-72.

Garrison, R. W. 1991[2009]. A synonymic list of the New World Odonata. Argia, 3, 1-30. [Updated version accessed in 1 August 2009 available in http://www.odonatacentral.org/views/pdfs/NWOL.pdf]

Garrison, R.W., von Ellenrieder, N. \& Louton, J. A. (2006). Dragonfly genera of the New World: an illustrated and annotated key to the Anisoptera. Baltimore: The John Hopkins University Press.

Goldstein, P. Z. \& DeSalle, R. Phylogenetic species, nested hierarchies, and character fixation. Cladistics, v.16, p.364-384, 2000.

Goloboff, P. A. (1991). Homoplasy and the choice among cladograms. Cladistics, 7, 215232.

Goloboff, P. A. (1993). Estimating character weights during tree search. Cladistics, 9, 83-91.

Goloboff, P. A. (1995). Parsimony and weighting: a reply to Turner and Zandee. Cladistics, $11,91-104$.

Goloboff, P. A. (1999). Analyzing large data sets in reasonable times: solutions for composite 
optima. Cladistics, 15, 415-428.

Goloboff, P. A. \& Farris, J. S. (2001). Methods for quick consensus estimation. Cladistics, 17, $\mathrm{S} 26-\mathrm{S} 34$.

Goloboff, P. A., Farris, J. S., Källersjö, M., Oxelmann, B., Ramírez, M. J., \& Szumik, C. A. (2003). Improvements to resampling measures of group support. Cladistics, 19, 324-332.

Goloboff, P. A., Farris, J. S. \& Nixon, K. C. (2008). TNT, a free program for phylogenetic analysis. [Computer software and manual]. Cladistics, 24, 774-786.

Goloboff, P. A., Carpenter, J. M., Arias, J. S. \& Miranda Esquivel, D. R. (2008). Weighting against homoplasy improves phylogenetic analysis of morphological data sets. Cladistics, $24,758-773$.

Grant, T. \& Kluge, A. G. (2003). Data exploration in phylogenetic inference: scientific, heuristic, or neither. Cladistics, 19, 379-418.

Grant, T. \& Kluge, A. G. (2005). Stability, sensitivity, science and heurism. Cladistics, 21, 597-604.

Grant, T. \& Kluge, A. G. (2008). Clade support measures and their adequacy. Cladistics, 24, 1051-1064.

Hall, B. K. (Ed.) (1994). Homology: The hierarchical basis of comparative biology. San Diego: Academic Press.

Hall, B. K. (2007). Homoplasy and homology: dichotomy or continuum? Journal of Human Evolution, 52, 473-479.

Heath, T. A., Hedtke, S. M. \& Hillis, D. M. (2008). Taxon sampling and the accuracy of phylogenetic analyses. Journal of Systematics and Evolution, 46, 239-257.

Hennig, W. (1965). Phylogenetic Systematics. Annual Review of Entomology, 10, 97-116.

Hennig, W. (1966). Phylogenetic Systematics. Urbana: University of Illinois Press. [Reissue of 1999].

Hovmöller, R. \& Johansson, F. (2004). A phylogenetic perspective on larval spine morphology in Leucorrhinia (Odonata: Libellulidae) based on ITS1, 5.8S, and ITS2 rDNA sequences. Molecular Phylogenetics and Evolution, 30, 653-662.

Ingley, S. J., Bybee, S. M., Tennessen, K. J., Whiting, M. F. \& Branham, M. A. (2012) Life on the fly: phylogenetics and evolution of the helicopter damselflies (Odonata, Pseudostigmatidae). Zoologica Scripta, in press [DOI: 10.1111/j.14636409.2012.00555.x].

International Commission on Zoological Nomenclature (ICZN). (1999). International Code of Zoological Nomenclature (Online). Fourth Edition. Available at: 
http://www.nhm.ac.uk/hosted-sites/iczn/code/ [Accessed 15.VIII.2011].

Jarzembowski, E. A. \& Nel, A. (1996). New fossil dragonflies from the Lower Cretaceous of SE England and the phylogeny of the superfamily Libelluloidea (Insecta: Odonata). Cretaceous Research, 17, 67-85.

Jordan, S., Simon, C. \& Polhemus, D. (2003). Molecular systematics and adaptive radiation of Hawaii’s endemic damselfly genus Megalagrion (Odonata: Coenagrionidae). Systematic Biology, 52, 89-109.

Kalkman, V. J., Clausnitzer, V., Dijkstra, K.-D.B., Orr, A. G., Paulson, D. R. \& van Tol, J. (2008). Global diversity of dragonflies (Odonata) in freshwater. Hydrobiologia, 595, 351363.

Kambhampati, S. \& Charlton, R. E. (1999). Phylogenetic relationship among Libellula, Ladona, and Plathemis (Odonata: Libellulidae) based on DNA sequence of mitochondrial 16S rRNA gene. Systematic Entomology, 24, 37-49.

Kennedy, C. H. (1922). The phylogeny and geographical distribution of the genus Libellula. Entomological News and Proceedings of the Entomological Section, 33, 65-71, plate IV

Kennedy, C. H. (1923). The phylogeny and the distribution of the genus Erythemis (Odonata). Miscellaneous Publications of the Museum of Zoology, 11, 19-22.

Kiauta, B. (1969). The Chromosomes of the Hawaiian endemic dragonflies, Megalagrion oahuense (Blackburn) (Coenagrionidae: Pseudoagrioninae) and Nesogonia blackburni (McLachlan), (Libellulidae: Sympetrinae), with a note on the cytotaxonomic affinities between the genera Nesogonia Kirby, and Sympetrum Newman (Odonata). Proceedings, Hawaiian Entomological Society, 20, 429-433.

Kirby, W. F. (1889). A revision of the subfamily Libellulinae, with descriptions of new genera and species. Transactions of the Zoological Society of London, 12, 249-348.

Kitching, I. J., Forey, P. L., Humphries, C.J. \& Williams, D. M. (1998). Cladistics: The theory and practice of parsimony analysis. (2ed.) Oxford: Oxford University Press. [Systematic Association Publication 11].

Kluge, A. G. (1997). Testability and the refutation and corroboration of cladistic hypotheses. Cladistics, 13, 81-96.

Lankester, E. R. (1870). On the use of the term homology in modern zoology, and the distinction between homogenetic and homoplastic agreements. The Annals and Magazine of Natural History. Series 4, 6, 34-43.

Li et al. (2011). A third species of the relict family Epiophlebiidae discovered in China (Odonata: Epiproctophora). Systematic Entomolgy, 37, 408-412. 
Lieftinck, M. A. (1955) Notes on species of Nannophlebia Selys from Moluccas and New Guinea (Odonata). Zoologische Mededelingen, 33, 301-318.

Lieftinck, M. A. (1963). New species and records of Libellulidae from the Papuan region (Odonata). Nova Guinea, Zoology, 25, 751-780.

Lieftinck, M. A. (1977). New and little known Corduliidae (Odonata: Anisoptera) from the Indo-Pacific region. Oriental Insects, 11, 157-179.

Lohmann, H. (1984). Zwei neue Rhodothemis-Arten, mit bemerkungen zur systematik der gattung (Anisoptera: Libellulidae). Odonatologica, 13, 119-127.

Lohmann, H. (1996a). Das phylogenetische System der Anisoptera (Odonata). Entomologische Zeitschrift mit Insekten-Börse, 106, 209-252.

Lohmann, H. (1996b).Das phylogenetische System der Anisoptera (Odonata) (schluß). Entomologische Zeitschrift mit Insekten-Börse, 106, 253-266.

Lohmann, H. (1996c). Das phylogenetische System der Anisoptera (Odonata) Erster Nachtrag. Entomologische Zeitschrift mit Insekten-Börse, 106, 360-367.

Machado, A. B. M. (2012). Carajathemis simone, new genus and species from Brazil (Odonata: Libellulidae). Anais da Academia Brasileira de Ciências, 84, 1039-1049

May, M. L. (2002). Phylogeny and taxonomy of the damselfly genus Enallagma and related taxa (Odonata: Zygoptera: Coenagrionidae). Systematic Entomology, 27, 387-408.

Miller, P. L. (1990). Mechanisms of sperm removal and sperm transfer in Orthetrum coerulescens (Fabricius) (Odonata: Libellulidae). Physiological Entomology, 15, 199-209.

Miller, P. L. (1991). The structure and function of the genitalia in the Libellulidae. Zoological Journal of the Linnean Society, 102, 43-73.

Mirande J. M. (2009). Weighted parsimony phylogeny of the family Characidae (Teleostei: Characiformes). Cladistics, 25, 574-613.

Misof, B., Anderson, C. L. \& Hadrys, H. (2000). A Phylogeny of the damselfly genus Calopteryx (Odonata) using mitochondrial 16S rDNA markers. Molecular Phylogenetics and Evolution, 15, 5-14.

Misof, B., Rickert, A. M., Buckley, T. R., Fleck, G. \& Sauer, K. P. (2001). Phylogenetic signal and its decay in mitochondrial SSU and LSU rRNA gene fragments of Anisoptera. Molecular Biology and Evolution, 18, 27-37.

Needham, J. G. (1903). The genealogical study of Dragonfly wing vention. Proceedings of the U.S. National Museum, 26, 703-764.

Needham, J. G. \& E. Broughton. (1927). The venation of the Libellulinae (Odonata). Transactions of the American Entomological Society, 53, 157-190. 
Needham, J. G., Westfall Jr., M. J. \& May, M. L. (2000). Dragonflies of North America. Gainsville: Scientific Publishers.

Nelson, G. J. (1978). Ontogeny, phylogeny, paleontology, and the biogenetic law. Systematic Zoology, 27, 324-345.

Nelson, G. J. (1989). Cladistics and evolutionary models. Cladistics, 5, 275-289.

Nichols, R. (2001). Gene trees and species trees are not the same. Trends in Ecology and Evolution, 16, 358-364.

Nixon, K. (1999). The parsimony ratchet, a new method for rapid parsimony analysis. Cladistics, 15, 407-414.

Nixon, K. C. (2002). Winclada version 1.00.08. Ithaca: Published by the author.

Nixon, K. C. \& Carpenter, J. M. (1993). On outgroups. Cladistics, 9, 413-426.

Nixon, K. C. \& Carpenter, J. M. (1996a). On consensus, collapsibility, and clade concordance. Cladistics, 12, 305-321.

Nixon, K. C. \& Carpenter, J. M. (1996b). On simultaneous analysis. Cladistics, 12, 221-241.

Nixon, K. C. \& Carpenter, J. M. (2012a). On homology. Cladistics, 28, 160-169.

Nixon, K. C. \& Carpenter, J. M. (2012b). More on errors. Cladistics, in press [DOI: 10.1111/j.1096-0031.2012.00409.x].

Nixon, K. C. \& Carpenter, J. M. (2012c). More on Absences. Cladistics, in press [DOI: 10.1111/j.1096-0031.2012.00430.x].

Ogden, T. H. \& Whiting, M. F. (2003). The problem with "the Paleoptera Problem:" sense and sensitivity. Cladistics, 19, 432-442.

Ogden, T. H., Whiting, M. F. \& Wheeler, W. C. (2005). Poor taxon sampling, poor character sampling, and non-repeatable analyses of a contrived dataset do not provide a more credible estimate of insect phylogeny: a reply to Kjer. Cladistics, 21, 295-302.

O'Grady, E. W. \& May, M. L. (2003). A phylogenetic reassessment of the subfamilies of Coenagrionidae (Odonata: Zygoptera). Journal of Natural History, 37, 2807-2834.

Page, R. D. M. (2001). NDE 0.5.0. [Computer software]. Distributed by the author.

Patterson, C. (1982). Morphological characters and homology. In Joysey, K. A. \& Friday, A. E. (Eds.). Problems in Phylogenetic Reconstruction. (pp. 21-74). London: Academic Press.

Patterson, C. (1988). Homology in Classical and Molecular Biology. Molecular Biology and Evolution, 5, 603-625.

Pavnilov, I. Ya. (2012). The contemporary concepts of homology in biology: a theoretical review. Biology Bulletin Reviews, 2, 36-54. 
Pessacq, P. (2008). Phylogeny of Neotropical Protoneuridae (Odonata: Zygoptera) and a preliminary study of their relationship with related families. Systematic Entomology, 33, $511-528$.

Pilgrim, E. M., \& von Dohlen, C. D. (2007). Molecular and morphological study of specieslevel questions within the dragonfly genus Sympetrum (Odonata: Libellulidae). Annals of the Entomological Society of America, 100, 688-702.

Pilgrim, E. M. \& von Dohlen C. D. (2008). Phylogeny of the Sympetrinae (Odonata: Libellulidae): further evidence of the homoplasious nature of wing venation. Systematic Entomology, 33, p.159-174.

Pilgrim, E. M. \& von Dohlen C. D. (2012). Phylogeny of the dragonfly genus Sympetrum (Odonata: Libellulidae). Organisms Diversity \& Evolution, in press [DOI: 10.1007/s13127012-0081-7]

Pinto, A. P. (2008). Análise cladística de Erythemis Hagen, 1861 com avaliação de seu posicionamento filogenético em Sympetrinae (Insecta, Odonata, Libellulidae) [Cladistic Analysis of Erythemis Hagen, 1861 with assessment of its phylogenetic placement in Sympetrinae]. xiv, 144 pp. UFRJ / MN, Rio de Janeiro. [Dissertation presented in the postgraduate program in Biological Sciences (Zoology)/UFRJ, as requirement for degree of Master of Science].

Pinto, A. P. \& A. L. Carvalho. (2010). A new species of Lauromacromia (Odonata: Corduliidae) from Southeastern Brazil, with a cladistic analysis of the genus and comments on Neotropical dragonfly biogeography. Zootaxa, 2425, 45-68.

Pinto, A. P. \& Carvalho, A. L. (em prep.). A morphological cladistic analysis of the Pondhawks dragonflies of the genus Erythemis and the significance of congruence test of characters for homology statements of wing venation in Anisoptera (Odonata, Libellulidae).

Pinto, A. P., Garrison, R. W., Paulson, D. R., Donnelly T. W. \& May, M. L. (2012). CASE 3584. Erythemis Hagen, 1861: proposed precedence over Lepthemis Hagen, 1861 (Insecta, Odonata). Bulletin of Zoological Nomenclature, 69, 1-9.

Pinto, A. P. \& Lamas, C. J. E. (2011). Oligoclada mortis sp. nov. from Rondônia State, Brazil, and distributional records of others Brazilian species of the genus (Odonata: Libellulidae). International Journal of Odonatology, 14, 291-303.

Pfau, H. K. (1971). Struktur und Funktion des sekundären Kopulations apparates der Odonaten (Insecta, Palaeoptera), ihre Wandlung in der Stammesgeschichte und Bedeutung für die adaptive Entfaltung der Ordnung. Zeitschrift für Morphologie und Ökologie der 
Tiere, 70, 281-371.

Pfau, H. K. (1991). Contributions of functional morphology to the phylogenetic systematics of Odonata. Advances in Odonatology, 5, 109-141.

Pfau, H. K. (2002). Tandem grip mechanics and tandem linkage shifting in Odonata reconstruction of evolution and phylogenetic significance. International Journal of Odonatology, 5, 129-179.

Pfau, H. K. (2005). Structure, function and evolution of the 'glans' of the anisopteran vesica spermalis (Odonata). International Journal of Odonatology, 8, 259-310.

Pfau, H. K. (2011). Functional morphology and evolution of the male secondary copulatory apparatus of the Anisoptera (Insecta: Odonata). Zoologica, 156, 1-103.

Platnick, N. I. (1979). Philosophy and the transformation of cladistics. Systematic Zoology, $28,537-546$.

Rehn, A. C. (2003). Phylogenetic analysis of higher-level relationships of Odonata. Systematic Entomology, 28, 181-239.

Reif, W. E. (2007). Problematic issues of cladistics 23: Darwin's concept of phylogenetic relationship. Neues Jahrbuch fur Geologie und Palaontologie. Abhandlungen, 244, $227-$ 245.

Riek, E. F. \& Kukalová-Peck, J. (1984). A new interpretation of dragonfly wing venation based upon Early Upper Carboniferous fossils from Argentina (Insecta: Odonatoidea) and basic character states in pterygote wings. Canadian Journal of Zoology, 62, 1150-1116.

Rieppel, O. (1988). Fundamentals of Comparative Biology. Basel: Birkhauser.

Rieppel, O. (1991). Things, taxa and relationships. Cladistics, 7, 93-100.

Rieppel, O. (1992). Homology and logical fallacy. Journal of Evolutionary Biology, 5, 701715 .

Rieppel, O. \& Kearney, M. (2002). Similarity. Biological Journal of the Linnean Society, 75, 59-82.

Rieppel, O. \& Kearney, M. (2007). The poverty of taxonomic characters. Biology and Philosophy, 22, 95-113.

Ris, F. (1909). Libellulines 1, Libellulinen 1. In: Catalogue Systématique et Descriptif des Collections Zoologique Du Baron Edmond Selys de Longchamps, 9, 1-121, pl. I.

Ris, F. (1911). Libellulines 2, Libellulinen 5. In: Catalogue Systématique et Descriptif des Collections Zoologique Du Baron Edmond Selys de Longchamps, 13, 529-700, pl. v.

Ris, F. (1915). New dragonflies (Odonata) of the subfamily Libellulinae from Sierra Leone, W. Africa. The Annals and Magazine of Natural History Series 8, 15, 213-223. 
Ris, F. (1919). Libellulines 3, Libellulinen 9. In: Catalogue Systématique et Descriptif des Collections Zoologique Du Baron Edmond Selys de Longchamps, 16, 1043-1278.

Rodrigues Capitulo, A. (1983). Descripción de los estadios preimaginales de Erythemis attala Selys (Odonata Libellulidae). Limnobios, 2, 533-548.

Rodrigues Capitulo, A. (2000). Population dynamics of larval stages of Tauriphila risi Martin and Erythemis attala Selys in Punta Lara Gallery Forest, Buenos Aires, Argentina (Anisoptera: Libellulidae). Odonatologica, 29, 333-340.

Sanborn, A. F. (1996). The cicada Diceroprocta delicata (Homoptera: Cicadidae) as prey for the dragonfly Erythemis simplicicollis (Anisoptera: Libellulidae). Florida Entomologist, $79,69-70$.

Sanderson; M. J. \& Donoghue, M. J. 1989. Patterns of Variation in Levels of Homoplasy. Evolution, v.43, n.8, p.1781-1795.

Sankoff, David \& Rousseau, P. (1975). Locating the vertices of a Steiner tree in an arbitrary metric space. Mathematical Programming, 9, 240-246.

Santos, N.D. (1945). Oligoclada nemesis (Ris, 1911), nova combinação e notas sôbre outras espécies (Odonata: Libellulidae). Boletim do Museu Nacional, 46, 1-4.

Saux, C., Simon, C. \& Spicer, G. S. (2003). Phylogeny of the dragonfly and damselfly order Odonata as inferred by mitochondrial $12 \mathrm{~S}$ ribosomal RNA sequences. Annals of the Entomological Society of America, 96, 693-699.

Scotland, R.W. (2011). What is parallelism? Evolution \& Development, 13, 214-227.

de Sélys-Longchamps, M. E. (1850). Revue des Odonates ou Libellules d'Europe. Mémoires de la Société Royale des Sciences de Liége, 6: i-xxii, 1-408.

Sereno, P. C. (2007). Logical basis for morphological characters in phylogenetics. Cladistics, $23,565-587$.

Simon, S., Strauss, S., von Haeseler, A. \& Hadrys, H. (2009). A Phylogenomic approach to resolve the basal Pterygote divergence. Molecular Biology and Evolution, 26, 2719-2730.

Sober, E. (1988). Reconstructing the past: parsimony, evolution, an inference. Cambridge: TH Mit Press.

Sober, E. (2004). The Contest Between Parsimony and Likelihood. Systematic Biology, 53, 644-653.

Sokal, R. R. \& Rohlf, F. J. (1981). Taxonomic congruence in the Leptopodomorpha reexamined. Systematic Zoology, 30, 309-325.

Steinmann, H. 1997. World catalogue of Odonata, Volume II Anisoptera. Berlin: Walter de Gruyter. xiv $+636 \mathrm{pp}$ 
Swofford, D. L. (1996). When are phylogeny estimates from molecular and morphological data incongruent? In Miyamoto, M. M. \& Cracraft J. Phylogenetic Analysis of DNA Sequences. (pp. 295-333). New York: Oxford University Press.

Swofford, D. L. (1998). PAUP*. Phylogenetic Analysis Using Parsimony (* and other methods). Version 4.0 beta 10. [Computer software and manual]. Sunderland: Sinauer Associates.

Swofford, D. W. \& Maddison, W. P. (1987). Reconstructing ancestral character states under Wagner parsimony. Mathematical Biosciences, 87, 199-229.

Swofford, D. L. \& W. P. Maddison. (1992). Parsimony, character-state reconstructions, and evolutionary inferences. In Mayden, R. L. (ed.). Systematics, historical ecology, and North American freshwater fishes. (pp. 187-223). Stanford: Stanford University Press.

Tillyard, R. J. (1917). The biology of dragonflies (Odonata or Paraneuroptera). Cambrige: University Press.

Tillyard, R. J. \& Fraser, F. C. (1938). A reclassification of the order Odonata based on some new interpretation of the venation of the dragonfly wing. Australian Zoologist, 9, 125-169. [Part I].

Tillyard, R. J. \& Fraser, F. C. (1939). A reclassification of the order Odonata based on some new interpretation of the venation of the dragonfly wing. Australian Zoologist, 9, 195-221. [Part II].

Tillyard, R. J. \& Fraser, F. C. (1940). A reclassification of the order Odonata based on some new interpretation of the venation of the dragonfly wing. Australian Zoologist, 9, 359-396. [Part III].

Trueman, J. W. H. (1996). A preliminary cladistic analysis of odonate wing venation. Odonatologica, 25, 59-72.

Trueman, J. W. H. (2007). A brief history of the classification and nomenclature of Odonata. Zootaxa, 1668, 381-394.

Turner, H. \& Zandee, R. (1995). The behaviour of Goloboff's tree fitness measure F. Cladistics, 11: 57-72.

von Ellenrieder, N. (2002). A phylogeny analysis of extant Aeshnidae (Odonata: Anisoptera). Systematic Entomology, 27, 437-467.

von Ellenrieder, N. (2003). A synopsis of the Neotropical species of "Aeshna" Fabricius: the genus Rhionaeschna Föster (Odonata: Aeshnidae). Tijdschrift voor Entomologie, 146, 67207.

Walker, E. M. (1912). The North American Dragonflies of the Genus Aeshna. Toronto: 
University of Toronto Studies, Biological Series no. 11.

Ware, J., May, M. \& Kjer, K. (2007). Phylogeny of the higher Libelluloidea (Anisoptera: Odonata): An exploration of the most speciose superfamily of dragonflies. Molecular Phylogenetics and Evolution, 45, 289-310.

Ware, J. L., Simaika, J. P. \& Samways, M. J. (2009). Biogeography and divergence time estimation of the relict Cape dragonfly genus Syncordulia: global significance and implications for conservation. Zootaxa, 2216, 22-36.

Westman, A., Johansson, F. \& Nilsson, A. N. (2000). The phylogeny of the genus Leucorrhinia and the evolution of larval spines (Anisoptera: Libellulidae). Odonatologica, 29, 129-136.

Wighton, D. C. \& Wilson, M. V. H. (1986). The Gomphaeschninae (Odonata: Aeshnidae): new fossil genus, reconstructed phylogeny, and geographical history. Systematic Entomology, 11, 505-522.

Williams, D. M. \& Ebach, M. C. (2008). Foundations of Systematics and Biogeography. New York: Springer.

Williams, D. M. \& Ebach, M. C. (2009). What exactly, is cladistics? Re-writing the history of Systematics and Biogeography. Acta Biotheoretica, 57, 249-268.

Williams, D. M. \& Ebach, M. C. (2012). "Phenetics" and its application. Cladistics, 28, 229230.

Williams, D. M., Ebach, M. C. \& Wheeler, Q. D. (2010). Beyond belief: the steady resurrection of phenetics. P. 169-195. In: D. M. Williams \& S. Knapp (eds.). Beyond cladistics: the branching of a paradigm. Los Angeles: University of California press [Species and Systematics vol.3].

Wheeler, Q. D. (2008). The New Taxonomy. Boca Raton: CRC Press.

Wheeler, W. C. (1995). Sequence Alignment, Parameter Sensitivity, and the Phylogenetic Analysis of Molecular Data. Systematic Biology, 44, 321-331.

Yeates, D. (1992). Why remove autapomorphies? Cladistics, 8, 387-389. 


\section{APÊNDICE 1. RELAÇÃo COMPLETA do MATERIAL EXAMINADO}

Microtrigonia gomphoides Lieftinck, 1933. INDONESIA. N[etherlands] N[ew] Guinea, [Papua province]: 1 female, Hollandia [Jayapura], Humboldt [Baai], W. Stüber leg. (MNRJ 14199; APE 733); 2 males, 1 female, same data but Cycloop [Mountain], 400 m, IV-VI.1931, W. Stüber leg. (MNRJ 14200, 14243, 14277; APE 734-736).

Macrodiplax balteata (Hagen, 1861). UNITED STATES OF AMERICA. California state: 1 male, 1 female, Riverside Co[unty], Lake St. Anthony R. V. Park, Mecca, 189 ft. elev., 27.V.1984, R. W. \& J. A. Garrison (MNRJ, APE 726); Arizona state: 1 male, Maricopa Co[unty], Phoenix [City] Moon Valley Golf Course, 22.VIII.1972, Rosser W. Garrison leg. (MNRJ, APE 725); Florida state: 1 male, [Monroe County] Boca Chica Key, Pinchot Expedition lot 154, 10.IV.1929, Dr. H. A. Pilsbry leg. (MNRJ, APE 722); 2 males, [Brevard County], Titusville City, Ceratopog[nidae?] fly loose in envelope, 16.IX.[19]38 M. J. Westfall Jr. leg. (MNRJ, APE 723-724).

Macrodiplax cora (Brauer, 1867). INDONESIA. N[etherlands] N[ew] Guinea, [Papua province]: 2 males, 2 females, Hollandia [Jayapura], Humboldt [Baai], VI-VII.1930, W. Stüber leg MNRJ 1411014111, 14173-14174; APE 727-730).

Zygonix ida Selys, 1869. INDONESIA. E[st] Java [province]: 1 female, Banyuwangi [Regency?], G[oenoeng] Raoeng [Mt. Raung?], 600 m, VII.1935, H. Lucht (MNRJ 14165, APE 740); C[entral] Java [Province]: 1 male, Mt. Slamat [sic. Mountain Slamet], 800 m, 17.II.1929 (MNRJ 14122; APE 739); W[est] Java [Province]: 1 male, Priangan [Chain Mountains], G. Tiruboeng [?], 700 m, 29.VII.[19]34, (MNRJ 14058; APE 737); 1 female, G[arut Regency?], Tjisoeroe [?], 600 m, VII.1935, M. E. Walsh leg. (MNRJ 14158; APE 738).

Elasmothemis cannacrioides (Calvert, 1906). PERU. Departamento de Junin: 1 male, Satipo (ABMM; APE 210). BRAZIL. Amapá state: 1 female, Serra do Navio municipality, Rio Amapari, 26.IX.1963, Berla leg. (MNRJ; APE 442); Pará state: 6 males, [Paragominas municipality], Coraci - 15 Km NW [of Indigenous station] Canindé, Rio Gurupi, iv 1963, B[orys] Malkin leg. (MZSP; APE 159-163, 166); 1

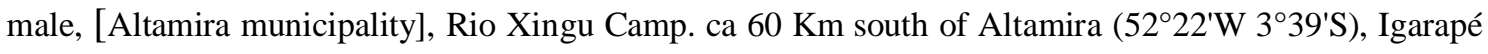
Jabuti, Malaise trap, during day, 15.X.1986, P. Spangler \& O. Flint leg. (MZSP; APE 164); Pernambuco state: 1 male, Cabo de Santo Agostinho municipality, Represa Gurjau $\left(08^{\circ}-09^{\circ} \mathrm{S} 35-36^{\circ} \mathrm{W}\right), 14 . \mathrm{II} .2001$, J. M. Costa \& L. D. R. Borges leg. (MNRJ; APE 438); 1 male, Igarassu municipality, Refúgio Ecológico Charles Darwin, 12.II.2001, J. M. Costa \& L. D. R. Borges leg. (MNRJ; APE 437); 1 male, same data but 18.IV.2001, L. D. R. Borges leg. (MNRJ; APE 439); Distrito Federal: 1 male, Brasília municipality, Rio Bartolomeu, excursão 221 col. 12 26.XI.1963, N. D. Santos, Machado \& Borges leg. (MNRJ; APE 440), 1 male, same data but Rio Guará excursão 221 col. 12 25.XI.1963. N. D. Santos, Machado \& Borges leg. 
(MNRJ; APE 441); 2 males, Brasília, Rio Mestre...[ilegeble handwritten], col. 13, 27.X.1980, N. D. Santos \& H. Mesquita leg. (MNRJ; APE 443); Minas Gerais state: 1 male, Buritizeiro municipality, Buritizeiro-Jatobá, I.1979, A. B. M. Machado leg. (ABMM; APE 285); 2 males, same data but Ribeirão Jatobá, I.1979, A. B. M. Machado leg. (ABMM; APE 284, 311); 1 male, Juiz de Fora municipality, Rio da Fazenda da Floresta, 05.II.1987, A. L. Carvalho leg. (DZRJ 1050; APE 205); Rio de Janeiro state: 2 males, Maricá municipality, Rio Ubatiba, 24.XI.1999, E. R. Calil \& A. L. Carvalho leg. (DZRJ; APE 207-208); São Paulo state: 1 male, Ubatuba municipality, Parque Estadual da Serra do Mar, Núcleo

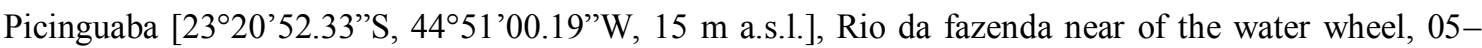
06.III.1999, Lab. Entomologia \& A. L. Carvalho leg. (DZRJ ; APE 206); 1 male, Palomeu KarvatéJoecue [?] 06.IV.1952 (MZSP; APE 165). PARAGUAY: 1 male, Arroyo Valvina adiante do Parque Nacional Guayaquil, Col. 2, 09.II.1983, N. D. Santos, J. M. Costa \& L. F. Neto leg. (MNRJ; APE 444 ).

Perithemis mooma Kirby, 1889. BRAZIL. Rio de Janeiro State: 1 male, Rio de Janeiro municipality, Horto Florestal da Quinta da Boa Vista, 06.III.2007, Ângelo P. Pinto (DZRJ 1516; APE 790); 1 male same data but 09.II.2012, Ângelo P. Pinto \& M.V.O. Almeida (DZRJ 1492; APE 770); 8 males, Piraí municipality, Arrozal District, Sítio Arrozal, 23.IX.2006, Ângelo P. Pinto leg. (DZRJ 1496-1497, 14991504; 771-778); 1 male, Cachoeiras de Macacu municipality, Reserva Ecológica de Guapiaçu (REGUA, $22^{\circ} 27^{\prime} 10.11^{\prime}$ S, 42 $46^{\prime} 13.01$ 'W, $34 \mathrm{~m}$ a.s.1.), sunny dam with abundant macrophytes, 28.II-02.III.2012, Ângelo P. Pinto (DZRJ 1519; APE 791); Rio Grande do Sul state: 1 male, 1 female, Porto Alegre municipality, Campus Central da Pontifícia Universidade Católica do Rio Grande do Sul (PUCRS), 03.III.2005, Ângelo P. Pinto (DZRJ 1508-1509; APE 782-783); 1 female, same data but 09.III.2005 (DZRJ 1510, APE 784); 1 male, Guaíba municipality, Sítio do Prof. Matzembacher, pond with abundant Salvinia sp., 20.III.2005, A. P. Pinto \& J. G. da Silva leg. (DZRJ 1505; APE 779), 2 males, Viamão municipality, Chácara Nossa Senhora das Graças [Instituto de Educação Marista Nossa Senhora das Graças, 3004'37.88'S, 5103'10.65”W, $76 \mathrm{~m}$ a.s.1.], pond for fish production ("açude”) with reddish clay bottom and abundant Eichornia crassipes as vegetation, 29.I.2006, A.P. Pinto \& J.G. da Silva leg. (DZRJ 1506-1507; APE 780-781); 1 male, Imbé municiplaity, Braço Morto, pond with few emergent vegetation, 08.III.2006, A. P. Pinto \& J. G. da Silva leg. (DZRJ 1511; APE 785); 1 male, same data but 10.II.2004 (DZRJ 1512; APE 786); 1 male, 2 females, same data but 11.II.2004 (DZRJ 1513-1515; APE 787-789).

Libellula herculea Karsch, 1889. BRAZIL. Rio de Janeiro state: 1 male, Teresópolis municipality, Garrafão, 29-31.III.2002, P. C. Werneck-de-Carvalho leg. (DZRJ 1529; APE 906); 2 males, Parque Nacional da Floresta da Tijuca, polls near to visitor's center (barbecue spot), 13.II.2010, Ângelo P. Pinto (DZRJ 684-685; APE 899-900); 1 male, same data but 17.II.2010 (DZRJ 686; APE 901); 1 male, same data but 18.II.2011 (DZRJ 981; APE 902); 1 female, Itatiaia municipality, III.1968, [Richard von] Dirings[hofen] (MZSP 1043; APE 911); 2 males, Angra dos Reis municipality, Rio Caputera, Caputera I, 16.III.2001 (DZRJ 1526-1527; APE 903-904); 1 male, Parque Nacional da Serra da Bocaina, Rio Bracuí, [village of] Bracuí, 17.III.2001, N. Ferreira-Jr. (DZRJ 1530; APE 907); 1 female, Ilha Grande, Abraão Village, Rio Cachoeira do Aqueduto, Exc[urtion] 02/col. 01, 15.I.1986 (as F-1 larva, adult emerged at 
10.III.1986), A. L. Carvalho \& R. Pujol (DZRJ 1531; APE 908); São Paulo state: 2 males, Salesópolis municipality, Estação Biológica de Boracéia, 24-28.III.2011, Expedição MZUSP/FFCLRP (MZSP 10401041; APE 909-910); Santa Catarina state: 1 male, Seara municipality, Nova Teutônia, XI.[19]48, [Richard von] Dirings[hofen] leg. (MZSP 1044; APE 912); 1 male without references (DZRJ 1528; APE 905).

Orthemis discolor (Burmeister, 1839). BRAZIL. Pará state: 1 male, Altamira municipality, Rio Iriri Camp ca. $100 \mathrm{Km}$ S[outh] of Altamira 0350’S, 5240’W [134 m a.s.1.], 17.x.1986, P. Spangler \& O. Flint leg. (MZSP); Maranhão state: 2 males, [probably Centro Novo do Maranhão municipality], Igarapé Gurupi-Uma, Aldeia Araçu, $50 \mathrm{Km}$ E[ast] of [indigenous station] Canindé, v.1963, [B.] Malkin leg. (MZSP); Bahia state: 1 male, Caetité municipality, INB, decantation basin, 14.I.2000, J. L. Nessimian leg. (DZRJ 673); Minas Gerais state: 3 males, Marliéria municipality, Parque Estadual do Rio Doce, Ponte Queimada, collecting point PERD_7 (1944'55.50"S, 42²8'43.10"W, $245 \mathrm{~m}$ a.s.1.), 03.III.2011, A. P. Pinto \& J.G. Da Silva leg. (MZSP); 1 female, Sete Lagoas municipality, III.1968, U. Martins \& L. Silva leg. (MZSP); Rio de Janeiro state: 1 male, Angra dos Reis municipality, Parque Nacional da Serra da Bocaina, Rio Bracuí, [village of] Bracuí, 17.III.2001, N. Ferreira-Jr. leg. (DZRJ 1805); 2 males, same data but, Praia Brava, 12.V.2002, Lab. de Entomologia leg. (DZRJ 664, 1804), 1 male, same data but, streams close to power station, 11.V.2002, Lab. de Entomologia leg. (DZRJ 1803); 1 female, same data but, 26-27.V.2002, Lab. De Entomologia leg. (DZRJ 665); 1 male, 1 female, same municipality Rio Bracuí, Bracuí - Baixada, 10.V.2002, Lab. De Entomologia leg. (DZRJ 658-659); 2 males, 1 female, same data but 11.V.2002, Lab. de Entomologia (DZRJ 661-663); 1 male, Rio Bracuí, Bracuí Ritral, 1011.V.2002, Lab. de Entomologia leg. (DZRJ 1802); 3 males, 4 females, Cachoeiras de Macacu municipality, Reserva Ecológica de Guapiaçu (REGUA, 22²7’10.11”S, 4246’13.01”W, 34 m a.s.1.), sunny dam with abundant macrophytes, 01.XII.2011, A. P. Pinto, A. L. Carvalho \& Disciplina Técnicas de Coleta PPGZOO/UFRJ leg. (DZRJ 1351-1352; 1422-1426); 1 male, 1 female, same data but 28.II02.III.2012, A. P. Pinto leg. (DZRJ 1525, MZSP); 1 female, Maricá municipality, Rio Ubatiba, upstream of the dam, 29.III.2001, Lab. De Entomologia leg. (DZRJ 667); 1 male, Niterói municipality, Charitas, 16.III.1986, A. L. Carvalho leg. (DZRJ 668); 4 males, Rio de Janeiro municipality, Horto Florestal da Quinta da Boa Vista fountain pool with Eichornia sp. and shady muddy channels with organic matter (22 ${ }^{\circ} 54^{\prime} 30.48^{\prime}$ 'S, 4313'25.50”W, 14 m a.s.1.), 09.II.2012, A. P. Pinto \& M. V. O. Almeida leg. (DZRJ 1476-1479); São Paulo state: 1 female, Ubatuba municipality, Parque Estadual da Serra do Mar, Núcleo

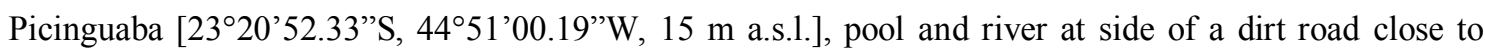
tronco trail, 01-04.VI.2000, A. L. Carvalho \& Equipe Lab. de Entomologia leg. (DZRJ 670); 2 males, Cananéia municipality, Parque Estadual da Ilha do Cardoso, collecting point PEIC_04, 06 (2504’56.54”S, 4755’38.02”W, 13 m a.s.1.), 20.X.2011, A. P. Pinto leg. (MZSP).

Brachymesia furcata (Hagen, 1861). BRAZIL. Pará state: 1 male, Parauapebas municipality, FLONA de Carajás, collecting point ETA I (604’55.49” S, 5009'06.10”W, 664 m a.s.1.), 19.III.2006, N. Ferreira-Jr. \& L. L. Dumas leg. (DZRJ); Bahia state: 1 male, 2 females, Canudos muncipality, Rio Vaza Barris, 08.VII.1951, N. D. Santos leg. (MNRJ 16512-16514); Minas Gerais state: 1 males, Governador 
Valadares municiplaity, Lagoa Dourada, Fazenda Urupuca, 10.II.1955, N. D. Santos \& Machado leg. (MNRJ 19576-19577); 2 females, Marliéria municipality, Parque Estadual do Rio Doce, camping area at Lagoa Dom Helvécio, collecting point PERD_4 (1946'41.95"S, 42³5'41.62"W, 261 m a.s.l), 02.III.2011 (as F-0 larvae, adult emergeneces 07 and 10.V.2011), A. P. Pinto \& J. G. da Silva leg. (DZRJ 13641365); 1 male, same data but Lagoa do Aníbal, collecting point PERD_6 (1947’6.44’'S 42²9’46.87’'W, $260 \mathrm{~m}$ a.s.l.), lagoon in an open sunny area with muddy bottom, emergent vegetation Poaceae and Typha sp., 03.III.2011 (MZSP); 1 female, same data but Ponte Queimada, collecting point PERD_7 $\left(19^{\circ} 44^{\prime} 55.50^{\prime \prime} \mathrm{S}, 42^{\circ} 28^{\prime} 43.10^{\prime \prime} \mathrm{W}, 245 \mathrm{~m}\right.$ a.s.l.), 03.III.2011 (MZSP); Rio de Janeiro state: 1 male, Cachoeiras de Macacu municipality, Reserva Ecológica de Guapiaçu (REGUA, 22²7’10.11’'S, 42 46'13.01”'W, 34 m a.s.1.), sunny dam with abundant macrophytes, 01.XII.2011, A. P. Pinto, A. L. Carvalho \& Disciplina Técnicas de Coleta PPGZOO/UFRJ leg. (DZRJ 1427); 1 female, same data but 28.II-02.III.2012, A. P. Pinto leg. (MZSP); 1 female, Macaé municipality, Parque Nacional da Restinga de Jurubatiba, 30.V.2001. P. Werneck-de-Carvalho leg. (DZRJ 0000); Rio Grande do Sul state: 2 females, Guaíba municipality, Sítio do Prof. Matzembacher, pond with abundant Salvinia sp., 20.III.2005, A. P. Pinto \& J. G. da Silva leg. (DZRJ 724-725); 3 males, Imbé municiplaity, Braço Morto, pond with few emergent vegetation, 08.III.2006, A. P. Pinto \& J. G. da Silva leg. (DZRJ 721-723). ARGENTINA. Corrientes Province: 1 male, 1 female, Mburucuyá Department, Parque Nacional Mburucuyá, I.2008, A. C. Gonçalves leg. (DZRJ 719-720).

Micrathyria atra (Martin, 1897). BRAZIL. Amazonas state: 1 male, Manaus municipaity, [highway] BR$17 \mathrm{Km}$ 38, XII.1959, [P.] Elias leg. (MNRJ); 2 males, same data but Igarapé...[?], $30 \mathrm{~km}$ on the road to Itacoatiara, 27.X.1959, N. D. Santos leg. (MNRJ); 2 males, same data Paraqueguara [Paranaquara island?], I.1973, N. Tangerini leg. (MNRJ); Pará state: 3 males, 3 females, Tucuruí municipality, I.1979, Alvarenga leg. (MNRJ); Mato Grosso state: 1 male, Chapado dos Guimarães municipality, Riacho do.... [?], 28.X.1989, N. D. Santos \& Ulisses [S. Carvalho] leg. (MNRJ).

Pachydiplax longipennis (Burmeister, 1839). UNITED STATES OF AMERICA. Arizona state: 1 male, Graham County, Poper Lake, 4 miles S of Safford and 1 mile E[ast] of US Highway 666, 3060 fts., 03.VIII.1970, J. A. Garrison leg. (RWG); California state: 1 female, San Bernardino County, Needles Marina Park, by Colorado River Needles, 02.VIII.1972, J. Haternik leg. (RWG); 1 male, Stanislaus County, Del Puerto Cyn. At N[orth] Fork of Del Puerto creek about 14 miles W[est] of Patterson, 1819.IX.1978, R. G. Garrison leg. (RWG); Florida state: 2 males, Coral Gables, 14.IV.1946, R. L. Chermock leg. (MNRJ 14489; 14495); 1 male, same data but 21.X.1945 (MNRJ 14481); Kentucky state: 2 males, [Metcalfe County, Center City], Crail Hope [Road], 04.VI.1946, C. Cook leg. (MNRJ 14484; 14493); 2 males, same data but 17.VI.1946 (MNRJ 14485-14486); 2 males, same data but 19.V.1946 (MNRJ 14487 14488); 1 male, same data but 20.V.1946 (MNRJ 14490); 1 female, same data but 20.VI.1946 (MNRJ 14494); 2 females, same data but 22.V.1946 (MNRJ 14482 14483); 1 male, 1 female, same data but 28.VI.1946 (MNRJ 14491-14492); Texas state: 1 male, 1 female, Hidalgo County, Santa Ana Wild Refuge, 22.VIII.1972, J. Haternik leg. (RWG); 1 female, same data but 09.IX.1972 (RWG). 
Uracis siemensis Kirby, 1897. BRAZIL. Para State: 2 males, 1 female, Parauapebas municipality, Flona de Carajás, collecting point Buritizal I, 07.IX.2006, N. Ferreira Jr. \& L. L. Dumas leg. (DZRJ; APE 1145-1147); 2 males, same data but 11.IX.2006 (DZRJ; APE1148-1149); 1 female, same data but collecting point Ponto mais baixo do Buritizal I, 16.IX.2006, N. Ferreira-Jr. \& L. L. Dumas leg. (DZRJ; APE 1155); 2 males, same data but collecting point Buritizal I - parte baixa (riacho), 28.IX.2007, N. Ferreira-Jr. \& V. Alecrim leg. (DZRJ; APE 1156-1157); 2 males, same data but collecting point N4A, 09.IX.2006, N. Ferreira-Jr. \& L. L. Dumas leg. (DZRJ; APE 1150-1151); 3 males, same data but collecting point N4D, 10.IX.2006, N. Ferreira-Jr. \& L. L. Dumas leg. (DZRJ; 1152-1154).

Ypirangathemis sp. BRAZIL Matto Grosso [sic. Rondônia state]: 5 males, 1 female, [Porto Velho municipality], Abunã, 06.III.1922, J. H. W[illiamson] \& J. W. S[trohm] (MNRJ; APE 696-700); 1 male, same data but M[adeira]-M[amoré] Ri[vers], above Jaci Paraná, 08.III.1922 (MNRJ; APE 701).

Sympetrum illotum illotum (Selys, 1884). UNITED STATES OF AMERICA. California state: 1 female, Contra Costa County, Point Richmond, 30.III.76, J. Hafernik leg. (RWG); 1 male, Marin County, Lily Pond by Alpine Lake, 07.IV.1979 (as F-0 larva, adult emerged at 19.IV.79), R. W. Garrison \& J. A. Garrison leg. (RWG); 1 male, Monterey County, China Camp. Los Padres Nat'l for Chewsrose ca. 4500 fts., 30.VI.1974 , P. S. L. Szerli leg. (RWG); 1 male, Napa County, Pope Creek About 1.5 milles W[est] of Lake, Berryessa, 27.V.1978, R. W. Garrison \& J. A. Garrison leg. (RWG); 1 male, Solana County, Rockville Hills Park 5 mills W[est] Rockville, 22.V.1973, J. Hafernik leg. (RWG).

Sympetrum rubicundulum (Say, 1840). UNITED STATES OF AMERICA. Illinois state: 2 males, 2 females, Cook county, Marian Byrnes Natural Area $41.7146^{\circ} \mathrm{N}, 87.5775^{\circ} \mathrm{W}, 22$. VII.2003, R. E. DeWalt leg. (INHS 9880; APE 1126); New York state: 2 males, [Tompkins County], Ithaca, 14.VII.[19]46, (MNRJ 14475, 14479; APE 1127-1128); 1 male, same data but 28.VII.[19]46 (MNRJ 14477, APE 1131); 1 female, same data but 04.VIII.1946, F. Fernández leg. (MNRJ 14476, APE 1132); 1 female, same data but 6.[?] miles Creek, 18.IX.1946, F. Fernández leg. (MNRJ 14480, APE 1133); Indiana state: 2 males, [Tippecanoe County], pond about 2-3 miles N. of [?] West Lafayette [City] [ ${ }^{\circ}{ }^{\circ}$ 4040, 23.IX.1940 (MNRJ, APE 1134); 2 males, Wells Co[unty], Vanemon Swamp [nº 4023, 11.VII.1940, BEM (MNRJ, APE 1129-1130).

Sympetrum risi risi Bartenef, 1914. JAPAN. [Shikoku Region, Takoaka District], Kōchi pref[ecture]: 4 males, Nakamura City [now Shimanto City], 30.VIII.1994, Taguro [leg.?] (MNRJ; APE 760-763); 1 male, 1 female same data but [30.VIII.1994] (MNRJ; APE 764); 1 male, 1 female same data but Ōgata town [now Kuroshio town], Ōkibuchi [?], 31.VIII.1994 (MNRJ; APE 765-766). 
Sympetrum vicinum (Hagen, 1861). UNITED STATES OF AMERICA. Connecticut state: 1 male, 1 female, Litchfield Co[unty], Salisbury, Twin Lakes, 06.IX.1998, Mark O'Brien leg. (UMMZ MF0980906-1; APE 694); New York state: 1 female, [Tompkins County], Ithaca, 28.VII.[19]46 (MNRJ; APE 1142); Illinois state: 2 males, 1 female, Cook Co[unty], Marian Byrnes Natural Area $\left(41.7146^{\circ} \mathrm{N}\right.$; 87.5775 ${ }^{\circ}$ W), 03.IX.2003, R. E. DeWalt leg. (INHS 10.699; APE 1118-1120); 2 males, Vermilion Forest Glen Preserve 7 miles SE of Westville, 02.X.1991, C. A. Bridges leg. (INHS Odonata 311-312; APE 1121, 1136); Indiana state: 3 males, 1 female, LaGrange County [Milford Township] marsh, 1 mile s[outh] of M[ount] Pisgah, 04.IX.1928, (MNRJ, 1137-1139); 1 male, Knox [County?], Orchard near hy[?], 22.VII.1924, R. W. M. (MNRJ; APE 1140); 1 female, [Gibson County], Oakland City, Water Supply Lake, teneral, 29.VII.1928, (MNRJ; APE 1141).

Nesogonia blackburni Mclachlan, 1883. UNITED STATES OF AMERICA. Hawaii state: 1 male, 1 female, Kauai Na Pali Coast [State Park], 21.VI.1985, Hugh Robertson leg. (RWG, APE 667).

Brachythemis contaminata (Fabricius, 1793). INDONESIA. S[outh?] Java [sic. Central Java]: 1 male, [Cilacap Regency], Djeroeklegi [Jeruklegi?], 04.III.1929 [F. C. Drescher leg.?] (MNRJ 14214,; APE 731 1 female, same data but 13.VIII.1930 (MNRJ 14270; APE 732).

Brachythemis leucosticta Rambur, 1842. UGANDA. Busheni District: 1 male, Queen Elizabeth National Park, sw of Lake George 00[ $\left.{ }^{\circ}\right] 03$ 'S, 30 07E, el[evation] 1000, 24.IV.2002, F. C. Sibley leg. (FSCA FCS02-144; APE 640); 1 female, Lake Victoria Shore, 08.XI.1930, Mrs. J. D. Tothill leg. (FSCA; APE 641); DEMOCRATIC REPUBLIC OF CONGO. 1 male, 1 female, Bukama, Belgian Congo, without date, Smithsonian African Expedition leg. (USNM ENT 00277142, 00277147; APE 642-643).

Indothemis carnatica (Fabricius, 1798). THAILAND. Chaiyaphun Prov[ince]: 2 males, Lotus Ponds and temporary roadside pools at Salaphrom Forest Protection Unit, ( 16²2'14"N, 101³4'08"E, $878 \mathrm{~m}$ a.s.1.), 19.VII.1966, R. W. \& J. A. Garrison leg. (RWG; APE 1171-1172).

Indothemis limbata limbata (Selys, 1891). THAILAND. Chaiyaphun Prov[ince]: 1 male, Lotus Ponds and temporary roadside pools at Salaphrom Forest Protection Unit, ( 16 $23^{\prime} 14 " \mathrm{~N}, 101^{\circ} 34^{\prime} 08^{\prime \prime E}, 878 \mathrm{~m}$ a.s.1.), 19.VII.1966, R. W. \& J. A. Garrison leg. (RWG; APE1169); 1 male, same data but 20.VII.1966 (RWG; APE 1170).

Deielia phaon (Selys, 1883). CHINA. 1 male, Shanghai, 12.VIII.1936, E. Sueson leg. (USNM ENT 00273526; APE 650); Kiangsu prov[ince]: 2 females, Yutoan, 10-20.VII.1939 Becquart leg. (USNM ENT 00273496; APE 651). JAPAN. Okinawa pref[ecture]: 1 male, Okinawa Island, Nakazato-village, 09.VII.1996, Yasuyuki Fukuhara leg. (RWG, APE 648); [Kantō Region], Tokyo [Prefecture]: 1 male, [Nerima City], Shakujii, 02.VIII.[1]933 (MNRJ; APE 703); [Shizuoka Prefecture]: 1 female, Mis[h]ima, 
17.VIII.1929, Kado-ike [?] (MNRJ; APE 702); [Shikoku Region, Takoaka District], Kochi pref[ecture]: 1 female, Kago Hidaka-vellage, 19.V.1994 (RWG; APE 649); 1 female, Nakamura City [now Shimanto City], 05.VI.1990 (MNRJ; APE 704); 1 male, same data but 06.VII.1992, M. Sugimura leg. (MNRJ; APE 705); 2 females, same data but 29.VIII.1994, Taguro [leg. ?] (MNRJ; APE 706-707);

Crocothemis erythraea (Brullé, 1832). NAMIBIA. Kavango Region : 1 male, 1 female, Kvango River at

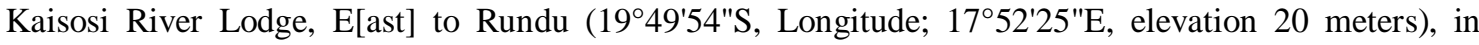
grassy field with trees, 24.IV.2007, R. W. Garrison \& N. von Ellenrieder leg. (RWG; APE 668).

Crocothemis mariannae Kiauta, 1983. JAPAN. [Shikoku Region, Takoaka District], Kōchi pref[ecture]: 1 male, Nakamura City [now Shimanto City], 29.VIII.1994, Taguro [leg. ?] (MNRJ); but 2 males, 1 female, same data 30.VIII.1994 (MNRJ); 1 female, same data but Ōgata town [now Kuroshio town], Ōkibuchi [?], 31.VIII.1994 (MNRJ); Tokyo [prefecture]: 1 female, Tokyo City, Sekido [neighborhood], 26.VII.1935 (MNRJ); Sikoku (sic. Shikoku Region), [Kagawa Prefecture?]: 1 male, Nagao [line?], 23.VIII.1934 (MNRJ); 1 male, without data but envelope similar to those from 1994 collected in Kōchi.

Crocothemis servillia (Drury, 1773). UNITED STATES OF AMERICA. Florida state: 1 male, 1 female, Dade County Old Cutler Lakes, 03.V.1981, S. W. Dunkle leg. (RWG); THAILAND. Lampang, Lampang Pond 6 Km E[ast] on Highway 11, 14.VII.1996, R. W. Garrison \& J. A. Garrison leg. (RWG).

Erythrodiplax nigricans (Rambur, 1842). BRAZIL. Rio Grande do Sul state: 14 males, 11 females, Viamão municipality, Chácara Nossa Senhora das Graças [Instituto de Educação Marista Nossa Senhora das Graças, $30^{\circ} 04^{\prime} 37.88^{\prime \prime} \mathrm{S}, 51^{\circ} 03^{\prime} 10.65^{\prime} \mathrm{W}, 76 \mathrm{~m}$ a.s.l.], pond for fish production ("açude") with reddish clay bottom and abundant Eichornia crassipes as vegetation, 29.I.2006, A.P. Pinto \& J.G. da Silva leg. (DZRJ 1069-1093; APE 792-816).

Erythrodiplax umbrata (Linnaeus, 1758) BRAZIL. Para State: 1 female, Parauapebas municipality, Flona de Carajás, collecting point ETA, 07.IX.2006, N. Ferreira-Jr. (DZRJ 1706, APE 863); 4 males, 2 females, same data but, ETA II, 26.II.2008, N. Ferreira-Jr. \& A. P. M. Santos leg. (DZRJ 1716-1721; APE 873-878); 2 males same data but N5 Sul, 26.IX.2005, N. Ferreira-Jr. leg. (DZRJ 1707-1708; APE 864-865); 1 male, 1 female, ponto mais abaixo do Buritizal I "(pique-nique) errado", 16.IX.2006, N. Ferreira-Jr. \& L. L. Dumas (DZRJ 1709-1710, APE 866-867); 3 males, 1 female, Canaã dos Carajás municipality, Flona de Carajás, collecting point S11D-C, IX.2005, N. Ferreira-Jr. leg. (DZRJ 1712-1715; APE 869-872); 1 male, same data but 14.IX.2006 (DZRJ 1711; APE 868); Ceará state: 1 male, Cascavel municipality, disctrict of Jacarecoara, Barra Nova locality, lagoons near to sea, little aquatic vegetation, "buritis", sandy bottom, some of them with shalom depth and bottom with accumulation of organic matter $\left(04^{\circ} 05^{\prime} 42.63^{\prime}\right.$ 'S $\left., 36^{\circ} 09^{\prime} 40.62^{\prime \prime} \mathrm{W}, 10 \mathrm{~m}\right)$, 01.I.2010, A. P. Pinto leg. (DZRJ 529; APE 838); Rio de Janeiro state: 2 females, Cachoeiras de Macacu municipality, Reserva Ecológica de Guapiaçu (REGUA, 
$22^{\circ} 27^{\prime} 10.11^{\prime} \mathrm{S}, 42^{\circ} 46^{\prime} 13.01^{\prime \prime} \mathrm{W}, 34 \mathrm{~m}$ a.s.1.), sunny dam with abundant macrophytes, 03.XII.2009, A. L. Carvalho \& Equipe Disc. Téc. Coleta leg. (DZRJ 1694-1695; APE 851-852); 2 males, 2 females, Magé municipality, Citrolândia, Campo do Escoteiro Chefe Geraldo Hugo Nunes, forest border, poll in open areas, 24-25.IX.2005, A. L. Carvalho leg. (DZRJ 1701-1703; APE 858-860); 2 males, same data but 16.XII.2005, A. L. Carvalho / Biologia de Odonata leg. (DZRJ 1704-1705; APE 861-862); 1 male, 1 female, Rio de Janeiro municipality, Tijuca, Usina, área de mata impactada, 26.X.2008, Â. P. Pinto (DZRJ 645-646; APE 839-840); 2 females, same data but 23.X.2008, A. P. Pinto (DZRJ 647-648; APE 841-842); 2 males, Mangaratiba municipality, Reserva Ecológica Rio das Pedras (RERP), 0305.XII.2003, A. L. Carvalho leg. (DZRJ 1696-1697; APE 853-854); 1 female, RPPN Fazenda Cachoeirinha (Santa Justina, Empresa Santa Justa LTDA), Point 1, 05.XII.2008, Equipe Disciplina Técnicas de Coleta MNRJ/UFRJ (DZRJ 1698; APE 855); São Paulo state: Ubatuba municipality, Parque Estadual da Serra do Mar, Núcleo Picinguaba [2320'52.33”S, 4451'00.19”W, $15 \mathrm{~m}$ a.s.1.], pool at forest border, 14.XII.1992, M. E. Felix (DZRJ 1632; APE 850); 1 male, same data but 05-06.III.1999, A. L. Carvalho \& Equipe Entomológica (DZRJ 1631; APE 849); 2 females, same data but 31.V.2007, A. P. Pinto leg. (DZRJ 1114-1115; 847-848); 2 males, same data but 01.VI.2007, A. P. Pinto leg. (DZRJ 1112-1113; APE 845-846); 1 female, Cananéia municipality, Parque Estadual da Ilha do Cardoso, collecting point Poça para Trilha das Bromélias/Morro das Almas, PEIC_02 (2504’25.03”S, 4755'28.76”'W, $11 \mathrm{~m}$ a.s.1., 19.X.2011, A. P. Pinto leg. (MZSP; APE 879); 3 females, same data but 20.X.2011 (MZSP; APE 880-882); 1 male, same data but 21.X.2011 (MZSP, APE 883). ARGENTINA. Del Chaco province: 2 male, Parque Nacional Chaco, 10.I.2008, A. C. Gonçalves (DZRJ 930-931; APE 843-844); Corrientes province: 1 male, Mburucuyá, Parque Nacional Mburucuyá, 10.I.2008, A. C. Gonçalves (DZRJ 1699-1700; APE 856-857);

Neurothemis feralis (Burmeister, 1839). INDONESIA. S[outh?] Java [sic. Central Java]: 1 male, [Cilacap Regency], Djeroeklegi [Jeruklegi?], 20.VI.1930, [F. C. Drescher leg.?] (MNRJ 14141; APE 1122); 1 male, same data 07.VII.1931, [F. C. Drescher leg.?] (MNRJ 14080; APE1123); 2 females, same data but [Cilacap Regency], Patimoean [Patimuan?], 09.III.[19]29, [F. C. Drescher leg.?] (MNRJ; APE 1124-1125).

Neurothemis decora (Brauer, 1866). INDONESIA. N[etherlands] N[ew] Guinea, [Papua province]: 1 male, Hollandia [Jayapura], Humboldt [Baai], XI-XII.1930, W. Stüber leg. (MNRJ 14092; APE 753); same data but 1 male VII.1930, H. Stüber leg. [?] (MNRJ 14177; APE 754); 1 female, same data but VIII.1930, W. Stüber leg. (MNRJ 14217; APE 755); 1 male, same data but Humbolt Baai, Tamirlakke, II.1933 W. Stüber leg. (MNRJ 14232; APE 756); 1 male, same data but Humbolt Baai, IX.1930 W. Stüber (MNRJ 14253; APE 758); 1 male same data but without date (MNRJ 14233; APE 757). PAPUA NEW GUINEA. Eeast Sepik province: 1 male [Angoram district], Village or Ylmas M2, Ylmas Lanes Region [?], Karawari River, 29.XII.[19]88, R. Mittemayer leg. (MNRJ; APE 759). 
Neurothemis fluctuans (Fabricius, 1793). INDONESIA. Borneo [island, West Kalimantan province]: 1 male Kajan [Kayan] River, Mjöberg leg. (UMMZ, APE 692); S[outh] E[ast] Borneo [island] [Central Kalimantan province, East Barito Regency]: 2 males, 2 females, Ampah, 0-20 km, IV-V.1948, L. S. Liong leg. (MNRJ 1452-1453, 14056-1457; APE 741-744).

Neurothemis terminata terminata (Brauer, 1866). PHILIPPINES. Pangasinan [province]: 3 males, 1 female, 03.I.1931, Nicario Garcia leg. (INHS Odonata 5651; APE 746-749); Luzon Island [Calabarzon Region, Quezon province]: 2 males, Novaliches [Disctrict], Critas, 03.VI.1931 (UMMZ; APE 693); Laguna Province: 2 males, 2 females, Los Baños, 08.I.1931, P.C. Gabertan leg. (INHS Odonata 5654; APE 745). INDONESIA. C[entral] Java [Province]: 1 male, Mt. Slamat [sic. Mountain Slamet], $800 \mathrm{~m}$, 27.II.[19]28, Btr [leg.?] (MNRJ 14175; APE 750); S[outh?] Java [sic. Central Java province]: 1 male, [Cilacap Regency], Djeroeklegi [Jeruklegi?], 18.I.[19]30, F. C. Drescher leg. (MNRJ 14278; APE 751); M[id]. Java [Central Java province]: 1 male, 1 female, Djorjo [?], 22.III.[19]35, Hoverbeck leg. (MNRJ 14180-81; APE 752)

Pseudoleon superbus (Hagen, 1861). MEXICO. Morelos state: 1 male, 1 female, Huajibtlan $40 \mathrm{Km}$ SW of Cuernavaca $\left(99^{\circ} 25.5^{\prime} \mathrm{W}, 18^{\circ} 35.6^{\prime} \mathrm{N}, 1200 \mathrm{~m}\right.$ a.s.l.), [G. Beatty leg.?] (DZRJ, APE 679-680); Tamaulipas [state]: 1 male, Hacienda Santa Engracia, 01.V.1936, Plummer leg. (MNRJ; APE 720); Baja California state: 1 male, Commandu, III.1893, Chas C. Haines [leg.] (MNRJ; APE 721) [Det by Calvert (B.C.A.)]

Bradinopyga geminata (Rambur, 1842). INDIA. Pondicherry state: 1 male, 1 female, Karaikal [1055'32"N, 7950'17"E, 5 m a.s.1.], XI.1961, P. S. Nathan leg. (RWG; APE 1174); Tamil Nadu state: 1

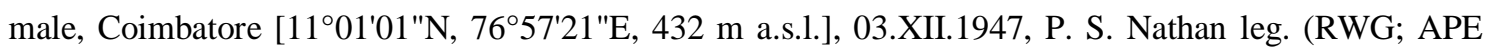
$1175)$.

Diplacodes bipunctata (Brauer, 1865). NEW ZEALAND. North Island [Northland region]: 1 male, 1 female, [Turangi town], Motuoapa, 1.I.1982, W. J. Winstanley leg. (FSCA; APE 699).

Diplacodes trivialis (Rambur, 1842). INDIA. Madras state: 1 male, 1 female Madurai, grounds of Hotel Pandian, 20.I.1988, M. J. Westfall leg. (FSCA; APE 673-674). PHILIPPINES. Luzon [Island, Calabarzon Region, Quezon province]: 1 male, Manila, 25-30.IX.1976, L. A. Burges (FSCA; APE 672).

Diplacodes luminans (Karsch, 1893). Southern Rhodesia [ZIMBABWE]. 1 male, Wankie, XI.1961, Pinhey leg. (USNM 278941; APE 652); 1 female, Bulawayo a suburb of Douglasdale, XII.1959, [E.] Pinhey leg. (USNM 278944; APE 653). 
Nannodiplax rubra Brauer, 1868. AUSTRALIA. N. Queensland [Queensland state]: 1 male, [Far North Region], Clohesy River at Clohesy River Rd., 13 km SW of Kuranda, 02.XII.1986, R. W. Garrison leg. (RWG; APE 661); 1 female, same data but Pond at Rosebud Farm, Douglas Track, 5 km W of Kuranda (1652'18"S; 145³6'56"E; 460 m a.s.1.), 09.XII.1986, R. W. Garrison (RWG; APE 660).

Nannothemis bella Uhler, 1857. UNITED STATES OF AMERICA. Maine [state]: 2 males, 1 female, Lincoln Co[unty], Webber Pond \#56, 16.VI.1953, D. J. Borror leg. (MNRJ; 715-717); Wisconsin state: 2 males, Vilas, 27.VII.1965, M. D. Ries leg. (INHS; APE 663-664); N[ew] J[ersey] state: 2 males, [Burlington County, Woodland Township] Chatsworth, 06.VII.[19]47, J. W. Green leg. (MNRJ; APE 713-714); O[hio] state: 2 males, Champaign Co[unty], Cedar Swamp, 18.VII.1954, D. J. Borror leg. (MNRJ; APE 718-719); Indiana state: 3 males, 1 female, [Elkart County] ? [Indiana and Baldwin Lakes, thirteen miles north-east of Elkhart, on the boundary line that divides Indiana from Michigan?] ? 0625.[VII.18]99 R.J. Weith leg. (UMMZ, MNRJ; APE 690-712); North Caroina state: 2 males, Hoke County, Montrose, 9.V.1979, R.D. Cuyler leg. (FSCA; APE 665); South Carolina state: 1 male 1 female, Chesterfield Co[ounty], Lake Hartsville, E side, 01.V.1965, D. R. \& M. L. Paulson (DRP; APE 662); Mississippi state: 1 male, George County, Movella, 1 1/2 ml S on S-613m bog, 16.VI.1968, W. F. Mauffray \& A. Rekas (FSCA; APE 666);

Nannophya pygmaea Rambur, 1842. JAPAN. [Kantō Region, Gunma Prefecture]: 1 male, 1 female, [Minaki Town] OZE [National Park], Ozegahara, 12.VII.1935 (MNRJ; APE 708); [Chūbu region, Aichi Prefecture]: 1 male, Nagoya [city], Nekohora, 18.VIII.1965, Y. Yamamoto leg. (DRP; APE 654); 1 female, same data but 31.VII.1965, Y. Yamamoto leg. (DRP; APE 655); [Kyūshū region], Miyazaki [Prefecture]: 1 male, 1 female, [Koyu District], Takanabe [Town], 23.V.1993, Y. Eda (MNRJ; APE 709); CHINA [TAIWAN]. Fukien Prov[ince]: 2 males, 2 females, Plains around Foochow, without date, Claude R. Kellog leg. (USNM Ent 00274823-00274824, 00274825-00274826; APE 656-659).

Porpax asperipes Karsch, 1896. REPUBLIC OF CONGO. (Region Kouilou): 1 male, Conkouati[-Douli] National Park, forest border, (S0402'07.2" E011¹7'34.6"), 21.II.2010, Philippe H. Lambret leg. (RWG; APE 1173).

Erythrodiplax castanea (Burmeister, 1839). BRAZIL. Para State: 2 males, Barcarena municipality, Igarapé Dendê, T[ransect] B[arcarena] 050 [01³3'57.93”S, 4844'48.24”W, 14 m a.s.l.], north sector, area of construction of the E[letricity] T[rasmission] U[nit], VIII or X.2006, N. Ferreira-Jr \& J. Nessimian leg. (DZRJ 1731-1732; APE 895-896); 1 male, 1 female, same data but Igarapé Pramajó, T[ransect] B[arcarena] 110, crossing the transmission line, VIII or X.2006, N. Ferreira-Jr \& J. Nessimian (DZRJ 1733-1734; APE 897-898); 1 female, Parauapebas municipality, FLONA de Carajás, collecting point Buritizal I, 07.IX.2006, N. Ferreira-Jr. \& L. L. Dumas leg. (DZRJ; APE 886); 2 males, 1 female, same data but 25.III.2006, N. Ferreira-Jr. leg. (DZRJ 1723-1725; APE 887-889); 1 male same data but collecting point ETA II, III.2005, N. Ferreira-Jr. leg. (DZRJ 1726; APE 890); 2 males, same data but 
collecting point N4D, 10.IX.2006, N. Ferreira-Jr. \& L. L. Dumas leg. (DZRJ 1727-1728; APE 891-892); 2 males, same data but collecting point Buritizal I - parte baixa (riacho), 28.IX.2007, N. Ferreira-Jr. \& V. Alecrim leg. (DZRJ 1729-1730; APE 893-894). São Paulo state: 2 males, Cananéia municipality, Parque Estadual da Ilha do Cardoso, collecting point PEIC_04, 06 (2504'56.54”S, 4755’38.02”'W, $13 \mathrm{~m}$ a.s.1.), 20.X.2011, A. P. Pinto leg. (MZSP; APE 884-885).

Carajathemis simone Machado, 2012. BRAZIL. [Pará state]: 1 male, [Parauapebas municipality, FLONA de] Carajás, 26.III.1994, H. Lapertosa \& S. Lapertosa leg. (DZRJ 1396; APE 695).

Rhodopygia cardinalis (Erichson, 1848). COLOMBIA. Sucre Departament: 1 female, Caquetá, Rio Orteguaza, 26.VIII.1947 (MNRJ 112); 1 male, same data but 17.X.1947 (MNRJ 138). [SURINAME]. 1 male, [Para District], Tibiti [Savanne, $05^{\circ} 23^{\prime} \mathrm{N}, 55^{\circ} 56^{\prime} \mathrm{W}, 8 \mathrm{~m}$ a.s.l.], ilegible data... Km 0.1, 06.I.1949, [D.C. Geijskes leg.]. ECUADOR. Napo Province: 2 males, 3 Km S[outh] Tena, 13.V.1977, P. J. Splanger \& D. R. Givens leg. (USNM, ENT 00321096-00321097); 1 male, Puerto Napo, 3.2 Km E[ast] on Jatun Sacha R[oa]d, ponds and flowing marsh, 1,300 ft, 23.VII.1996, B. Mauffray leg. (USNM ENT 00321098). BRAZIL. Amapá state: 3 males, Calçoene municipality, 19.XII.1998, P. Magno, J. M. Costa \& E. L. Oliveira leg. (MNRJ); 2 males, Macapá municipality, Fazendinha, I[nstituto de] P[esquisas Científicas e Tecnológicas do Estado do] A[mapá], (Parque Zoobotânico) [Centro De Pesquisas Zoobotânicas e Geológicas], I.2001, P. Magno \& J. M. Costa leg. (MNRJ); 1 male, Mazagão municipality, Rio Piaçacá, D.Z. 5/61, II.[1]961, J. C. M. Carvalho leg. (MNRJ); 1 male, Serra do Navio municipality, (settlement) Serra da Canga, I.2001, P. Magno \& J. M. Costa leg. (MNRJ); [Amazonas state]: 1 male, [Manaus municipality], R[eserva Adolpho] Ducke, forest, 21.V.2002, J. Vidal leg. (INPA); 1 male, Manaus manicipality, Estrada M1, Km 45, 07.VII.1960, Flávio leg. (ABMM); 1 male, same data but Lago Janauacá, 26.III.[19]88, L. C. Machado leg. (INPA); Pará state: 1 male, Santarém municipality, Fazenda Taperinha, 17-18.II.1968, Expedição Permanente a Amazônia leg. (MZSP); 5 males, [Belém municipality], Museu [Paraense Emílio] Goeldi, 04.VIII.[1]959, N. D. Santos leg. (MNRJ); 1 male, same data but Parque do Museu [Paraense Emílio Goeldi], VI.1964, A. Souza leg. (ABMM); 1 male, Belém municipality, [Reserva Ambiental do] Utinga, 01.II.[19]63, [O.] Roppa \& [O.] Mielke leg. (MNRJ); 2 males, same data but 03.VIII.[1]959, N. D. Santos leg. (MNRJ); 1 male, Jacareacanga municipality (shore of Rio Tapajós), II.1966, L. S. Otero leg. (MNRJ); 1 male, Santarém municipality, Rio Tapajós, VIII.1955, [R. von] Dirings[hofen] leg. (MSZP); Acre state: 1 male, Feijó municipality, pond, 08.V.1963, Evangelista leg. (ABMM); Rondônia state: 1 female, Porto Velho municipality, T[ransect] 6, pasture, point 200, 11.V.2010, T. P. Mendes leg. (MZSP); Mato Grosso state: 1 female, Barra do Bugres municipality, main street close to restaurant at 17h, 18.XII.[19]83 (MNRJ); 2 males, Barra do Garças, Córrego Papagaio, $150 \mathrm{~m}$ from 3th order, 08.I.2005, J. D. Batista \& L. A. Castro leg. (DZRJ 763; UFG 3502); Bahia state: 1 male, Mucuri municipality, Rio Mucuri, above of highway BR-101 ca of $7 \mathrm{Km}$ [ca $18^{\circ} 03^{\prime} 3.58^{\prime \prime}$ S, 3955’59.49”W, 34 m a.s.1.], 25-27.I.1987 (F-0 larva, adult emerged in lab.), A. L. Carvalho \& J. L. Nessimian leg. (DZRJ 1758); Espírito Santo state: 1 female, Linhares municipality, New Road to Regência Km 8, collected near to small pond into the forest, 10-15.IV.1972, [Claudionor] 
Elias \& Paulo [C. Elias] leg. (MNRJ); Minas Gerais state: 2 males, [between] Leopoldina and Recreio municipalities, 14.V.1973, Machado Filho leg. (MNRJ); 3 males, same data but 16.V.1973 (MNRJ); Rio de Janeiro state: 1 male, [Nova Iguaçu municipality, Reserva Biológica do], Tinguá, 27.VII.1958, O. Mielke (ABMM); 7 males, same data but 20.I.1970, H. Sandim leg. (MNRJ); 4 males, same data but I.1970 (MNRJ); 1 male, same data but Serra Janjana, lagoon in a particular smallholding, exc[ursion] 387, col[lecting] 3, 05.VI.1970, N. D. Santos leg. (MNRJ); 8 males, same data but Haroldo' smallholding, 04.IV.1970, N. D. Santos \& H. Sandim leg. (MNRJ); 1 male, same data but pool of fish production, exc[ursion] 387, col[lecting] 1, 05.VI.1970, N. D. Santos leg. (MNRJ); 1 male, 1 female, Cachoeiras de Macacu municipality, Reserva Ecológica de Guapiaçu (REGUA, 22²7'10.11”S, 4246’13.01”W, $34 \mathrm{~m}$ a.s.1.), sunny dam with abundant macrophytes, 03.XII.2009, A. L. Carvalho \& Equipe Disc. Téc. Coleta leg. (DZRJ 576-577); 2 males, same data but 01.XII.2011, A. P. Pinto, A. L. Carvalho \& Disciplina Técnicas de Coleta PPGZOO/UFRJ leg. (DZRJ 1369-1370); 9 males, same data but 28.II-02.III.2012, A. P. Pinto leg. (MZSP); São Paulo state: 1 male, Bertioga municipality, Praia do Guaratuba, 01.III.1968, F. V. Val leg. (MZSP).

Rhodopygia geijskesi Belle, 1964. FRENCH GUIANA. 1 male, 1 female, small pond by N2 at PK25, 19.II.1988, R.W. Garrison (RWG; APE 538); [Departament of Cayenne], 1 male, [Roura Commune], Montagne-des-Chevaux 18.XI.1990, [P. Machet leg.] (MNRJ; APE1036). BRAZIL. Amapá state: 1 female, [Porto Grande municipality, settlement] Nova Colina, 06.X.[20]00, J. Madson leg. (MNRJ; APE 1035); 1 male, Ressurreição [sic. Restauração municipality?], II.[1]964, J. C. M. Carvalho \& Dirce (MNRJ; APE 1037); 1 male, Laranjal do Jari municipality, Água Comadubu [?], 08.XI.[19]99, [P. Magno leg.?] (MNRJ; APE 1033); 1 female, Santana municipality, Igarapé do Lago (06), 13.V.1998, J. Madson (MNRJ; APE 1034); Amazonas state: 1 male, [probably Manaus municipality], 2004, J. L. Nessimian (DZRJ 575; APE 539); 1 male, Santo Antônio municipality, DZ-3/961 [?]III.1960, C.[?] Elias leg. (MNRJ; APE 545); 2 males, Manaus municipality, ca. $6 \mathrm{~km}$ from camp Porto Alegre, Igarapé do Porto Alegre in the ZF3, col[ection] 6, 15.VII.1986, Luiz Fernando [Neto?] leg. (MNRJ 31, 32B; APE 10311032); Pará state: 1 male, Belém municipality, [Reserva Ambiental do] Utinga, 01.II.[19]63, [O.] Roppa \& [O.] Mielke leg. (MNRJ; APE 1038); 3 males, Canaã dos Carajás municipality, collecting point S11DC (06²4'28.28”S, 50²1'05.45”W, 820 m a.s.l.), 15.III.2006, N. Ferreira-Jr. \& L. L. Dumas leg.(DZRJ, APE 540-542); São Paulo state: 1 male, 1 female, Luiz Antonio municipality, 24.II.1999, B. F. C., A. M. V., R. V. R. (MZSP ; APE 543-544).

Rhodopygia hinei Calvert, 1907. NICARAGUA. [Río] San Juan [Department]: 1 male, Refugio Bartola, ca 5 Km N[orth] of jct. of Rio San Juan \& Rio Bartola, Dammed Pond, 12.VIII.2002, Bill Mauffray leg. (FSCA; APE 549). COSTA RICA. Guanacaste [province]: 1 male, 1 female, H[acien]da Taboga, 04.VII.1967, D.R. Paulson leg. (DRP; 546-547); 1 male, 1 female, 1.5 miles south Potrerillos, $27-$ 28.VII.1967, O. S. Flint Jr. \& M. A. Ortiz B. leg. (USNM ENT 00321120-00321121; APE 551-552); PANAMA. Canal Zone: 1 male, Gatun River, 27.VIII.1950, R. B. Cumming leg. (FSCA; APE 548); 1 female, Panama Gamboa [town], 27.XI.1980, A. Cotrancesco leg. (FSCA; APE 550); 2 males, ard's Nat[ural] Sci[ence] Estab[lishment], (UMMZ; APE 688-689); 1 female, San Blas, 2 Km S Nusagandi, 
03.III.1985, Flint \& Louton (USNM ENT 00321137 APE 554). COLOMBIA. Chocó [Department]: 1 male, Quebrada Pichinde, 2 km E[ast of] San Pablo, 19.II.1983, O.S. Flint Jr. leg. (USNM ENT 00321112; APE 553).

Rhodopygia pruinosa Buchholz, 1953. VENEZUELA. Amazonas state: 1 male, San Carlos de Rio Negro $\left(1^{\circ} 56^{\prime} \mathrm{N}, 67^{\circ} 03^{\prime} \mathrm{W}\right), 06-12 . X I I .1984$, R. L. Brown leg. (USNM ENT 00299718; APE 555). ECUADOR. Sucumbíos prov[ince]: 1 male,. Lago Agrio (0006'00"N, 7652'00"[W]; 396 m a.s.1.), 24.VIII.1975, Andrea Langley \& J. Cohen lewg. RWG; APE 557); Napo prov[ince]: 1 male, Puerto Napo, 3.2 Km E[ast] on Jatun Sacha Rd ponds and flowing marsh, 1300 ft; 23.VII.1996, Bill Mauffray (USNM ENT 00321138; APE 556). BRAZIL. Rio de Janeiro state: 2 males, 1 female, [Nova Iguaçu municipality, Reserva Biológica do], Tinguá, I.1970, H. Sandim leg. (MNRJ; APE 1092); same data but Haroldo' smallholding, 04.IV.1970, N. D. Santos \& H. Sandim leg. (MNRJ; APE 1087-1089); 1 male, 1 female, same data but Exc[ursion] 380, col[lecting] 1, 11.IV.1970, H. Sandim leg. (MNRJ; APE 1090-1091)

Rhodopygia hollandi Calvert, 1907. BRASIL. Amapá state: 1 male, 17-18.XI.[1999?], [P. Magno leg.] (MNRJ); 3 males, [Porto Grande municipality, settlement] Nova Colina, 06.X.[20]00, J. Madson leg. (MNRJ); 2 males, same data but 07.X.[20]00, C. Henrique leg. (MNRJ); 1 female, same data but J. Madson leg. (MNRJ); 1 male, same data but 09.X.[20]00, C. Henrique leg. (MNRJ); 1 female, same data but J. Madson leg. (MNRJ); 1 female, same data but 10.X.[20]00, C. Henrique leg. (MNRJ); 1 female, same data but Fazendinha, 09.II.1999, P. Magno leg. (MNRJ); 1 male, same data but Fazendinha, I[nstituto de] P[esquisas Científicas e Tecnológicas do Estado do] A[mapá], (Parque Zoobotânico) [Centro De Pesquisas Zoobotânicas e Geológicas], I.2001, P. Magno \& J. M. Costa leg. (MNRJ); 1 female, Tartarugalzinho municipality, Mutuca' smallholding, 22.X.1999, P. Magno \& J. M. Costa leg. (MNRJ); Pará state: 2 males, Parauapebas municipality, FLONA de Carajás, Collecting point N5 Sul $\left(06^{\circ} 05^{\prime} 50.01\right.$ ”S, 5007'50.08”W, 676 m a.s.1.), 26.III.2005, N. Ferreira-Jr. leg. (DZRJ 1760-1761); 2 males same data but IX.2005, (DZRJ); 1 male, Canaã dos Carajás municipality, FLONA de Carajás, Córrego Leito de Pedra, 27.IX.2007, N. Ferreira-Jr. \& V. Alecrim leg. (DZRJ 1765); 2 males, 1 female, same data but collecting point S11D-C (06 ${ }^{\circ} 24 ' 28.28^{\prime}$ S, 50 $21^{\prime} 05.45^{\prime \prime} \mathrm{W}, 820 \mathrm{~m}$ a.s.1.), 15.III.2006, N. Ferreira-Jr. \& L. L. Dumas leg. (DZRJ 1762-1764). Mato Grosso state: 3 males, 2 females, [Santa Terezinha municipality?], Barra do Tapirapés, 01-02.II.1964, B. Malkin leg. (MZSP); 5 males, 2 females, same data but 02-16.I.1966 (MZSP); 1 male, Barra do Bugres municipality, X.1989, P. Magno leg. (MNRJ); 1 male, [Campo Novo do Parecis / Sapezal municipalities, Indigenous Territory of] Utiariti [coordinates of the waterfall Salto Utiariti 1301'33.39’'S, 58 ${ }^{\circ} 16^{\prime} 40.87^{\prime \prime} \mathrm{W}, 377 \mathrm{~m}$ a.s.1.], 01.XI.1966, [K. Lenko \& Pereira leg.] (MZSP); Goiás state: 1 male, Formosa municipality, Lagoa Feia, Exc[ursão] 221, col[eta] 9, 24.XI.1963, N. D. Santos, Machado \& Borges leg. (MNRJ); Bahia state: 1 male, 2 females, Cruz das Almas municipality, into the forest, 15.XII.1988, J. Becker leg. (MNRJ); 1 female, same data but 16.XII.1988, J. Becker leg. (MNRJ); 1 male, same data but 22.XII.1989, J. Becker leg. (MNRJ); 1 female, São Gonçalo dos Campos municipality, in the lianas forest, 20.XII.1989, J. Becker leg. (MNRJ); Espírito Santo state: 1 female, Linhares municipality, 1-10.VII.1972, [Claudionor] Elias \& Paulo [C. Elias] leg. (MNRJ); 1 female, same data but 22-27.V.1972 (MNRJ); 2 males, same data but New Road to 
Regência Km 7 (forest), 1-08.IV.1972 (MNRJ); 1 male, same municipality but Forest [Goitacazes?], 2227.V.1972, [Claudionor] Elias \& Paulo [C. Elias] leg. (MNRJ); Minas Gerais state: 1 male, Marliéria municipality, [Parque Estadual do Rio Doce], Lagoa Carioca, 08.II.[19]96, A. O. Latini leg. (UFG 000258); 1 female, same data but Porto Capim, Lagoa Dom Helvécio, collecting point PERD_3

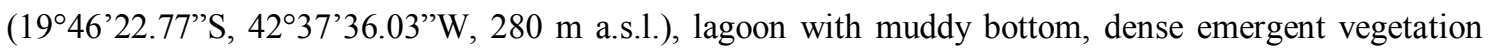
Eichornia sp. and Eleocharis sp., 03.III.2011, A. P. Pinto \& J. G. da Silva leg. (MZSP).

Acisoma inflatum Selys, 1882. CÔTE D'IVOIRE. [Vallée du Bandama Region, Bouaké Departament]: 1 male, 2 females, Bouaké [city], 13.VIII.[?], (MNRJ 14639, 14660, 1470; APE 338-339, 1143).

Acisoma panorpoides panorpoides (Rambur, 1842). CHINA. Guangdong Province: 1 male, 1 female,

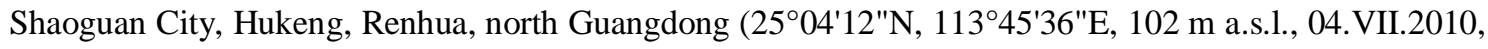
Haomiao Zhang leg. (RWG; APE 1167). THAILAND. Chaiyaphun prov[ince]: 1 male, 1 female, Lotus Ponds and temporary roadside pools at Salaphrom Forest Protection Unit (16 23'14"N, 101 34'08"E, 878 m a.s.1.), 20.VII.1966, R. W. \& J. A. Garrison leg. (RWG; APE 1165); Kanchanaburi prov[ince]: 1 female, Li Chia By Hwy. 323 SE of Sangklaburi marshy meadow nr. River, 24.VII.1996, R. W. \& J. A. Garrison leg. (RWG; APE 1166). INDONESIA. [Bangka-Belitung Province, Belitung Regency]: 1 male, 1 female, Tandjung Pandan [town], 22-24.IX.1935 (MNRJ 14262); same but 2 males, 24.IX.1935 (MNRJ 14108-14109).

Acisoma trifidum Kirby, 1889. CÔTE D'IVOIRE. [Vallée du Bandama Region, Bouaké Departament]: 1 female, Bouaké [city], 28.VIII.[?], (MNRJ 14739; APE 1144). GABON. 1 male, Pot Gentil, 12.VII.1957 E.S. Ross \& R.E. Leech (DRP, APE 531). UGANDA. 1 male, 1 female, E. Uganda [?], II.1972, H. Falke (RWG, APE 529-530); Kabarole District: 1 male, Ndail Lodge at Kabata, Kofuruka (Lily) Lake $\left(00^{\circ} 29.2^{\prime} \mathrm{N}, 30^{\circ} 17.3\right.$ 'E; $1400 \mathrm{~m}$ a.s.1.), 28.IV.2002, F. C. Sibley leg. (FSCA FCS02-252; APE 528).

Acisoma variegatum Kirby, 1898. UGANDA. Kabarole District: 2 males, Ndail Lodge at Kabata, Kofuruka (Lily) Lake $\left(00^{\circ} 29.2^{\prime} \mathrm{N}, 30^{\circ} 17.3^{\prime} \mathrm{E}\right.$; $1400 \mathrm{~m}$ a.s.1.), 28.IV.2002, F. C. Sibley leg. (FSCA, FCS02-253, FCS02-260; APE 526-527.)

Cyanothemis simpsoni Ris, 1915. CAMEROON. South West Province: 1 male, Okpambe, 11.XI.1998, Otto Mesumbe \& Enongehe leg. (RWG; APE 532). LIBERIA. Nimba County: 1 female, LugbeyeeBonlah Road stream on eastern side of Bonlah, large, gravelly and sandy stream in farmbush, (07 $34^{\prime} 36$. "N, 08³9' 28.7994"W; 437 m a.s.1.), 13.X.2010, K.-D. B. Dijkstra leg. (RWG; APE 1168).

Rhodothemis lieftincki Fraser, 1954. AUSTRALIA. Northwestern Territory: 1 male, Katherine Gorge, [Nitmiluk National Park], Low Level Bridge, 29-30.VII.1981, G. Theischinger \& L. Müller leg. (FSCA); Queensland state: 1 male, Pond at rosebud Farm, Douglas Track, $5 \mathrm{~km}$ W[est] of Kuranda (16 52'18"S, 
145³6'56"E, 460 m a.s.1., 13.XII.1986, R. W. Garrison (RWG; APE 1164); 1 male, Black Rock Creek South of Proserpine [town ] (26 meters), 30.X.1980, G. Theischinger leg. (DZRJ); 1 male, 1 female, same data but Mareeba Wetlands (16 $59^{\prime} 42^{\prime \prime S}, 145^{\circ} 25^{\prime} 24^{\prime \prime E} ; 460 \mathrm{~m}$ a.s.1.), 25.XI.2000, G. Theischinger \& L. Müller leg. (RWG).

Rhodothemis mauritsi Lohmann, 1984. INDONESIA. N[etherlands] N[ew] Guinea [Papua province]: 1 male, Hollandia [Jayapura], Humboldt Baai, III.1931, [W.] Stüber leg. (MNRJ 14172); 1 male, 1 female, same data but XI-XII.1930 (MNRJ 14212, 14228).

Rhodothemis rufa (Rambur, 1842). CHINA. Guangdong Province: 1 male, Conghua City Liuxihe River, Weidong (2339'N, 11340'E, 91 m a.s.1.), 11.IX.2011, Haomiao Zhang leg. (RWG; APE 1158); 1 female same data but 10.X.2011 (RWG; APE 1159); 1 female, same data but 27.X.2011 (RWG; APE 1160); Hainan Province: 1 male, Xinglong Country Nanling, SE Hainan (18²41'N, 10909'E; 164 m a.s.l.), 18.IV.2011, Haomiao Zhang leg. (RWG; APE 1161); 1 male, same data but 23.IV.2011 (RWG; APE 1162). THAILAND. 1 male, Bangkok, 20.II-7.III.1971, P. \& P. Spangler leg. (USNM ENT 00326984); Chiang Mai Province: 1 male, Ban Mae Wan Forestry Camp E. of Doi Saket (Stream), 18 ${ }^{\circ} 59^{\prime} \mathrm{N}$, 99¹4.50’E,10.VII.1996, R. W. Garrison \& J. A. Garrison leg. (DZRJ). MALAYSIA. Sarawak state: 1 male, Sibu division, Sibu district, Sungai (stream) Tenu aru, [SAR09_10_LIB355] ([0]2³5'[0]0"N, 11341'[0]0"E, 55 m a.s.1.), 10.V.2010, Graham Reels (RWG; APE 1163); 1 male, 1 female, reservoir in Kuching, 19.VIII.1980, Dennis Paulson leg. (DRP 80-18; APE); SOLOMON ISLANDS. Guadalcanal Province: 1 female, Tetere Area, Upper Schack, lagoon flying, 11.I.1944, V. R. Knapp leg. (USNM ENT 00326972); INDONESIA. W[est] Java province, Tasikmalaya Regency: 1 female, Bantan 15.V.1957, A. M. R. Wegner. leg. (USNM ENT 00326975); East Kalimantan Province: 1 male, Saramarinda city, 07.XII.1956, A. M. R. Wegner (USNM ENT 00326976).

Erythemis attala (Selys in Sagra, 1857). (2 male and 38 female). MEXICO. Veracruz state: 1 female, lanes and fence-rows (50') near of Dos Bocas, 9 mi[les] E[ast] of Casamaloapan, 21-24.viii.1957, G. H. Beatty III leg. [First Beatty Mexican Expedition, 1957] (ABMM); 1 male, 1 female same data but (MNRJ). BRAZIL. Amapá state: 1 male, 1 female, [Macapá municipality], Fazendinha, Souza's smallholding, 29.X.1999, [P. Magno leg.] (MNRJ); 1 female, [Porto Grande municipality, settlement] Nova Colina, 10.X.[20]00,C. Henrique leg. (MNRJ); Amazonas state: 1 female, São Paulo de Olivença [municipality], Alto Amazonas, vii.1968, [Richard von Diringshofen leg.] (MZSP; APE 584); 1female, Presidente Figueiredo municipality, Est[rada] de Balbina Km 24 (0201'05"S, 5949'60"W), 0112.ix.2002, without collector (INPA; APE 468); 1female, Manaus [municipality], Campus FUA (UFAM), 26.viii.[1]989, M. Mesquita leg. (INPA; APE 467); 1female, same municipality but Campus do INPA (vg?), 31.x.[19]88, H. Mesquita leg. (INPA; APE 473); 2 males, 1 female, Colônia Santo Antônio, 29.vii.1960, Flávio leg.(ABMM; APE 330); 1 male, same datae but [Igarapé] Barro Branco, 14.X.[19]95, C. Delgado leg. (INPA); 1female, same municipality but C[onjunto] Santo Antônio, 06.ix.1967, Mozorth leg. (INPA 2276; APE 471); 3 males, same data but Colônia Santo Antônio, Igarapé do Caxias, 
08.VIII.1960, A. B. M. Machado (ABMM); 3 males, same data but Colônia Santo Antônio, Varadouro Grande[?], 15.VIII.1960 (ABMM); 2 males, same municipality but road M1 Km 50, 21.VII.1960, A. B. M. Machado (ABMM); 2 males, same municipality bu Igarapé do Caneco, road M 1 Km 45, 06.VII.1960, A. B. M. Machado (ABMM); 1 female, same municipality but Ilha da Marchantaria, 12.viii.2001, J. L. Nessimian leg. (DZRJ; APE 2); 1 female, same municipality but Est[rada do] Aleixo, 29.x.1973, A. Castrilon leg. (INPA; APE 470); 1 male, R[eserva Adolphe] Ducke, entomological net, 02.X.2001, J. Vidal leg. (INPA); 1 female same municipality but without date, without collector (ABMM; APE 331); Rondônia state: 1 male, Ji-Paraná municipality, Lagoa no Rio Urupá, 30.I.1961, A. B. M. Machado leg. (ABMM); Pará state: 1 female, Belém [municipality], Parque do Museu, vii.1964, [A. B. M.] Machado \& Pereira leg. (ABMM; APE 229); 1 male, [Aveiro municiplaity], Juruti, 02.V.1967, Expedição Permanente à Amazônia (USP?) leg. (MZSP); 1 female, Óbidos [municipality], ii.1952, [J. B. Ferreira] leg. (ABMM; APE 228); 1 male, same data but 13.X.1961, [J. B. Ferreira] leg. (ABMM); 2 males, 1 female, same data but viii.1955, [Richard von Diringshofen leg.] (MZSP; APE 581); 1 male, Oriximiná, municipality, 15.I.[19]68, E[xpedição] P[ermanente à] A[mazônia MZUSP] (MZSP); 12 males, 6 females, near to Santarém [municipality], Faz[enda] Taperinha, 1-11.ii.1968, Exp[edição] Perm[anente à] Amaz[ônia MZUSP] leg. (MZSP; APE 147-150; 634-635); 2 females, same data but x-xi.1968 (MZSP; APE 151-152); 1 female, [Mecidilândia municipality], Furo do Jaruparu [sic. Jurupari?], 19.x.1970, E[xpedição] P[ermanente à] A[mazônia MZUSP] leg. (MZSP; APE 153); 3 males, 1 female, [Tucuruí municipality], Estrada da Base IV, 19.vii.1989, R. G. Neto leg. (ABMM; APE 225); Mato Grosso state: 1 male, Poconé municipality, Fazenda Ipiranga, 13-18.II.2000, P. C. Werneck-de-Carvalho, \& A. C. Capparelli leg. (DZRJ); Mato Grosso [do Sul] state: 1 male, Riacho do Herval, Rio Paraná, X.1952, [Richard von Diringshofen leg.] (MZSP); Rio de Janeiro state: 1 female, Maricá [municipality], Restinga de Maricá, swamp into the forest, 03-04.i.1992, A. L. Carvalho leg. (DZRJ; APE 36); São Paulo state: 1 male, Barueri [municipality], 05.IV.1955, K. Lenko leg. (ABMM); 1 female, same data but 07.i.1968, K. Lenko leg. (MZSP; APE 155); 1 female, same data but 26.iii.1958 (ABMM; APE 227); 2 males, same data but 30.III.1958 (ABMM); 1 male, same data but 16.IV.1958 (ABMM); 1 male, same data but 26.III.1967, K. Lenko leg. (MZSP); Santa Catarina state: 1 males, 4 females, [São Bento do Sul municipality, $26^{\circ} 14^{\prime} 58^{\prime}$ S, 49²2’59’W, $858 \mathrm{~m}$ a.s.1., railway station] Rio Vermelho, iii.1956, [Richard von Diringshofen leg.] (MZSP; APE 575-578); Rio Grande do Sul state: 1 female, Guaíba [municipality], Sítio do Prof. Matzembacher, açude com abundância de Salvinia sp., 20.xi.2004, A. P. Pinto leg.( DZRJ 539; APE 459); 1 female, same data but 20.iii.2005, A. P. Pinto \& J. G. da Silva leg. (DZRJ 538; APE 458); 1 male, 1 female, Porto Alegre [municipality], Bairro Serraria, 20.i.1957, T.D.L. Petersen \& G.V.Z. leg. (ABMM; APE 226); 1 female, same municipality but Campus Central da PUCRS, 22.iii.2005, A. P. Pinto leg. (DZRJ 540; APE 457); 1 male, 1 female same municipality but Ilha do Pavão, Posto Fiscal da Secretaria da Fazenda/RS, as margens do Rio Guaíba próximo à ponte, vegetação herbácea com trechos arbóreos (Fabaceae), toda área sujeita a inundação alguns pontos de banhado com Pistia stratioides e Poaceae (2959'46.47"S, 51²1'49.99"W, 5 m), 04.i.2008, A.P. Pinto leg. (DZRJ 537, 840; APE 465); 1 male, 1 female, same data but 22.xii.2008 (DZRJ 837-838; APE 637); 1 female, same data but 06.i.2009 (DZRJ 525; APE 466); 1 male, 1 female, Viamão mun[icipality], Parque [Municipal] Saint-Hilaire, 
18.x.[19]61, A. J. Ditadi leg. (ABMM; APE 324). [States of Pará/Bahia/Maranhão?]: 1 male, São Felix, 08.XI.1960, Italo leg. (ABMM)

Erythemis carmelita Williamson, 1923. (8 males, 5 females). VENEZUELA. Falcón state: 1 female Paratype, Tucacas, 13.III.1920, J. H. Williamson, E. B. Williamson \& W. H. Ditzler leg. (UMMZ) [Williamson (1923) cited March 23]. COLOMBIA. [Departament of Magdalena]: 1 male Paratype, El Banco, 25.I.1917, J. H. Williamson \& E. B. Williamson leg. (UMMZ); BRAZIL. Amazonas state: 1 male, [Benjamin Constant municipality?], Médio Javari, III.1963, J. C. M. Carvalho leg. (MNRJ); Roraima state [sic! might be Rondônia state]: Ariquemes [municipality], col. 2, viii.1980, Bento leg. (1 $q$ MNRJ; APE 381); Pará state: 1 male, Belém municipality, Parque do Museu, vlii.1964, A. B. M. Machado leg. (ABMM); Minas Gerais state: 3 males, Coronel Fabriciano municipality, II.1952, [A. B. M. Machado leg.] (UFG 1050 ); 1 male, same data but IX.1959, A. B. M. Machado leg. (ABMM); 1 male, [Parque estadual do Rio Doce], Lagoa do Aníbal, Sitio Jaguanharam, Ponte queimada, 07.II.1955, N. D. Santos \& Machado leg. (MNRJ 20903); 1 male, Lagoa Santa municipality, VI.1979, A. B. M. Machado leg. (ABMM); M[ato] Grosso [do Sul] state: 2 females [Miranda municipality], Salobra, 19.ii.1941, C[omissão] [do] I[nstituto] O[swaldo] Cruz leg. (MNRJ 4884, 4994; APE 378-379); 1 female, same data but excursion 221 col.12, 26.IX.1963 (MNRJ 6816; APE 380). Rio de Janeiro state: 1 female, Cachoeiras

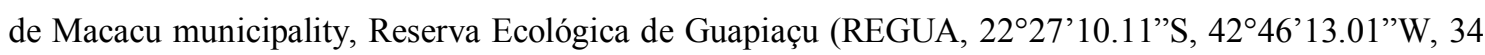
m a.s.1.), 25.VII. 2012, T. Kompier leg. (DZRJ).

Erythemis collocata (Hagen, 1861). (2 male and 4 + $)$. UNITED STATES OF AMERICA. Wyoming state: 1 male, 1 female, Yellowstone National Park, Thermal Springs nr. Madison Jct, 06.VIII.1959, W. B. Cutts leg. (UMMZ); Nevada state: 1 male, 1 female, Pershing, 3 miles NE Lovelock 44, 31.VII.1938, F. V. Hubbs leg. (UMMZ); California state: 1 female, Inyo County, pond at gravel quarry, end of five bridges Rd., 3 mi[les] N[orth] of Bishop, 06.vii.1974, R. W. Garrison leg. (FSCA; APE 519); 1 male, 1 female, Napa Co[unty], Cattle tank and seepage area at Samuel Spring, S[outh] of Pope Cr[eek] and W[est] of Lake Berryessa, elev. 700 ft., 27.v.79, R. W. Garrison \& J. A. Garrison leg. (DZRJ; APE 64); 1 male, 1 female, Riverside Co[unty], Dos Palmas Preserve, 4.8 milles E[ast of] North Shore (Salton Sea), elev[ation] 46 m, 04-05.v.1991, R. W. Garrison leg. (DZRJ; APE 65); 1 male, Stanislaus County, Del Puerto Cyn. at North foor of Del puerto creek about 14 milles W of Patterson, 20.VI.1978, R. W. Garrison \& J. A. Garrison leg. (DZRJ); Arizona state: 1 male, Cochise County, Ashton Draw, 01.VII.1958, M. J. Westfall Jr. leg. (FSCA); 1 male, Maricopa County, Theba, Paloma Road at 1-8, irrigation ditch (32 $55^{\prime} 39^{\prime \prime N} 112^{\circ} 53^{\prime} 17^{\prime} \mathrm{W}, 218$ m. a.s.1.), 30.IX.[20]02, R. W. Garrison \& N. Ellenrieder leg. (DZRJ); 1 male, Pima County, Tuscon, Lower Sabino Canyon, below dam @ Bear Canyaon Road, GPS: 32.18.5N; 110.48.7W, Lot\#: 000041, 06.IX.1999, Bill Mauffray leg. (FSCA); Washington state: 1 male, 1 female, Walla Walla County, Snake River embayment, Hwy. 12, 15.vii.1993, K. J. Tennessen leg. (FSCA; APE 520). 
Erythemis credula (Hagen, 1861). (2 male and 17 O). SURINAME. Marowijne distr[ict]: 2 males, 2 females, Christhian Kondre, x.1963, B. Malkin leg. (MZSP; APE 93-94); 1 male, same data but Forest Trail, 04.X.1963 (MZSP); 4 males, same data but Forest Trail, 07.X.1963 (MZSP); BRAZIL. Amapá: 1 female, Oiapoque municipality, Res[erva] Ind[ígena] Manga, 16.XII.1998, P. Magno, J. M. Costa \& E. L. Oliveira leg. (MNRJ); 1 female same municiplity but BR-156, 18.XII.[19]98, P. Magno, J. M. Costa \& E. L. Oliveira leg. (MNRJ); Pará state: 1 female, Santarém [municipality], Fazenda Taperinha, x-xi.1970, Ex[pedição] Perm[anente] à Amaz[ônia MZUSP] leg. (MZSP; APE 92); Pernambuco state: 1 female, Recife [municipality], Reserva Florestal do Açude Prata (08-09 $\left.\mathrm{S}, 34-35^{\circ} \mathrm{W}\right), 07 . i i .2001$, J. M. Costa \& L. Borges leg. (MNRJ; APE 451); 1 female, same data but 08.ii.2001 (MNRJ; APE 453); 2 females, same data but 09.ii.2001 (MNRJ; APE 450, 452); Alagoas state: 1 male, Engenho Riachão, without date, E. Dente leg. (ABMM); Bahia state: 1 male, 1 female, Salvador municipality, [Lagoa do] Abaeté-Catu [Abrantes], 14.II.[19]87, J. B[ecker] leg. (MNRJ); 1 male, same data but Lagoa do Abaeté, 15.X.1955, A. B. M. Machado leg. (ABMM); Espírito Santostate: 1 male, [Serra municipality], Jacareípe neibourhood, swamp and forest, 19.I.1973, N. [D.] Santos leg. (MNRJ); Minas Gerais state: 3 females, Lagoa Santa municipality, iv.[19]49, [N. D.] Santos \& Machado leg. (MNRJ 12247, 12252, 12254; APE 447-449); 2 females, same data but 13.i.[19]51 (MNRJ 15371, 15373; APE 445-446); 1 male, Coronel Fabriciano municipality, IX.1959, A. B. M. Machado leg. (ABMM); São Paulo state: 1 male, Mutuca municipality,

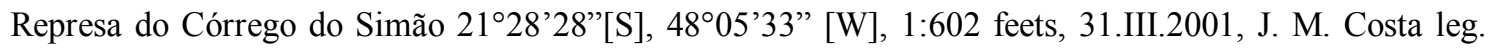
(MNRJ); Rio de Janeiro state: 1 female, Maricá [municipality], Restinga de Maricá, without date, Laboratório de Entomologia-IB/UFRJ leg. (DZRJ; APE 7); 1 male, 1 female, same data but 17.xii.1988, A. L. Carvalho leg. (DZRJ; APE 8); 2 males, 1 female, same data but ix.1987 (DZRJ 549-551; APE 00); 1 fêmea, same data but 13-14.iii.1987 (collected in larva; adult's emergence 3-4.v.1987), A. L. Carvalho \& N. Ferreira-Jr. leg. (DZRJ; APE 9); 1 female, same data but adult's emergence 4-5.v.1987 (DZRJ; APE 10); 1 male, same data but 06.V.1988 (DZRJ); 3 males, same data but 21-22.I.1988, A. L. Carvalho \& N. Ferreira-Jr. leg. (DZRJ); 2 males, same data but 03-04.I.1992, A. L. Carvalho leg. (DZRJ); 1 male, Macaé municipality, Parque Nacional da Restinga De Jurubatiba, 30.V.2001, P. C. Werneck-de-Carvalho leg. (DZRJ); 1 male, São João de Barra municipality, Fazenda São Pedro, I.1980, A. B. M. Machado leg. (ABMM).

Erythemis haematogastra (Burmeister, 1839). (1 male and 22 甲). SURINAME. Marowijne district: 3 males, Christhian Kondre, x.1963, B. Malkin leg. (MZSP); BRAZIL. Amapá state: 1 male, Serra do Navio municipality, I.1957, A. B. M. Machado leg. (ABMM);1 male, same data but settlement, X.1997, P. Magno leg. (MNRJ); Amazonas state; 1 male, Benjamin Constant municipality, Rio Javari, I.1961, [Richard von] Dirings[hofen] leg. (MZSP); 1 male, Manaus municipality, road M $1 \mathrm{Km} \mathrm{50,}$ Igarapé,26.V.1960, Flávio leg. (ABMM); 1 male, same data but Reserva Florestal Adolpho Ducke, 01.VIII.1971, J. Becker leg. (MNRJ); 1 male, same data but 21.XI.2001, J. Vidal leg. (INPA); Pará state: 1 female, Belém [municipality, Parque Ambiental] Utinga, ii.1957, A. B. M. Machado leg. (ABMM; APE 253); 1 male, 1 female, Juruti mun[icipality], 02.v.1967, E[xpedição] P[ermanente à] A[mazônia MZUSP] leg. (MZSP; APE 114); 1 female, Óbidos [municipality], viii.1962, José Braselino leg. (ABMM; APE 254); 1 male, same data but XII.1963, [Richard von Diringshofen leg.] (MZSP); 1 female, 
same municipality but [Igarapé] Traíra, without date, [Richard von Diringshofen leg.] (MZSP; APE 586); 1 female, [Paragominas municipality], Coraci, $15 \mathrm{Km} \mathrm{NW}$ [from indigenous post] Canindé, iv.1963, B. Malkin leg. (MZSP; APE 118); 1 male, [Santarém municipality], Alter do Chão, 20.VIII.1968, E[xpedição] P[ermanente à] A[mazônia MZUSP] (MZSP); 1 male, 1 female, Santarém [municipality], Fazenda Taperinha, x-xi.1970, E[xpedição] P[ermanente à] A[mazônia MZUSP] leg. (MZSP; APE 120); 3 males, 4 females, near to Santarém municipality, Fazenda Taperinha, 1-11.ii.1968, Exp[edição] Perm[anente à] Amaz[ônia MZUSP] leg. (MZSP; APE 123-126); 1 male, same data but 17-18.II.1970 (MZSP); 1 male, same data but 16-23.VI.1968 (MZSP); 1 female, [Santarém municipality], Fordlândia; ii.1957, A. B. M. Machado leg. (ABMM; APE 252); Paraíba state: 1 female, [João Pessoa municipality], 01.i.1954, Jorge Kesselring leg. (MZSP; APE 591); Alagoas state: 1 male, Satuba municipality, BR 101, $20 \mathrm{Km}$ north of Maceió, 21.II.1981, Roberts, Roppa \& Carbonell leg. (DZRJ 781); Espírito Santo state: 4 males, 2 females, Linhares [municipality], 1-10.vii.1972, [C.] Elias \& Paulo [Elias] leg. (MNRJ; APE 400-401); 4 males, 4 females, same municipality but est[rada] nova para Regência Km 7 (forest), 0108.iv.1972, (MNRJ; APE 406-408); 2 females, same municipality but coletada na mata Goitacazes, 0814.ii.1972, Elias \& Paulo leg. (MNRJ, APE 409); 2 males, same data but 10-15.III.1972 (MNRJ); 2 females, same data but 17-22.iii.1972 (MNRJ; APE 411); 1 male, same data but forest of the Empresa Capixaba de Pesquisas Agropecuárias (EMCAPA), 25.VIII.1977, J. Becker leg. (MNRJ); Minas Gerais state: 1 male, Vespasiano municipality, R[ua] Jardim Encantado, $n^{\circ}$ 159, 28.XII.1953, A. B. M. Machado leg. (ABMM); Rio de Janeiro state: 1 male, Cachoeiras de Macacu municipality, Reserva Ecológica de

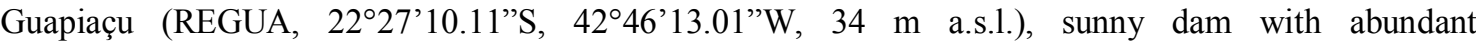
macrophytes, 28.II-02.III.2012, A. P. Pinto leg. (DZRJ 1498).

Erythemis mithroides (Brauer in Therese, 1900). (9 9). COSTA RICA. Guanacaste prov[vince]: 1 female, H[acien]da Taboga, 11.vii.1967, D. R. Paulson leg. (DRP; APE 567); SURINAME. [Paramaribo District]: 1 male, Paramaribo city, 23.X.1959, Charles Lurg (ABMM); VENEZUELA. Barinas state: 1 female, Torunos, Hacienda la Isla, Rio Santo Domingo (Rio Apure Dr.), $8^{\circ} 30.54^{\prime} \mathrm{N}, 70^{\circ} 05.05^{`} \mathrm{~W}$, DCT 93-6, large turbid river, gravel \& sand, 03.i.1993, K. S. Cummings \& C. A. Mayer leg. (INHS 12587; APE 523); Zulia state: 1 male, 1 female, El Guayabo, 20.IV.1920, J. H. Williamson , E. B. Williamson \& W.H. Ditzler leg. (UMMZ); PERU. Madre de Dios [Region]: 1 female, Tambopata Nature Reserve, 30 Km SW [from] Puerto Maldonado, 2.0 Km main trail, swamp forest, 22.iii.1982, J. M. Patt leg. (DRP; APE 566); BRAZIL. Para state: 1 male, Belém municipality, IX.1964, E. Dente leg. (MZSP); 1 male, Altamira municipality, Rio Xingu Camp. ca $60 \mathrm{Km}$ S[outh] of Altamira 0339'S, 52²2’W, [110 m a.s.l], 20.X.1986, P. Spangler \& O. Flint leg. (MZSP); Acre state: 1 male, Tarauacá municipality, [Rio] Tarauacá, without date, W. Bokerman leg. (ABMM); Paraíba state: 1 female, [João Pessoa municipality], 06.xii.1953, Jorge Kesselring leg. (MSZP; APE 593-594); 1 male, same data but 16.XII.1954 (MZSP); 1 female, same data but 21.XII.1953 (MZSP); 1 male, same data but 23.XII.1954 (MZSP); Pernambuco state: 2 males, Cabo de Santo Agostinho municipality, Represa Gurjau $08-09^{\circ} \mathrm{S} 35-36^{\circ} \mathrm{W}$, 14.II.2001, J. M. Costa \& L. Borges leg. (MNRJ); Sergipe state: 1 male, Faz[enda] Cruzeiro 13 Km SSL de Cristinápolis municipality, 1-15.III.[19]91, C. Caetano leg. (MNRJ); Bahia state: 1 male, 1 female, [Salvador municipality, Praia da] Pituba, 20.XII.1988, J. Becker leg. (MNRJ); [Minas Gerais state]: 1 
female, Machacalis [municipality], lagoa, 18.xii.[1]954, A. B. M. Machado leg. (ABMM; APE 300); 1 female, Raul Soares [municipality], ix.1947, Machado \& Berla leg. (MNRJ 9758; APE 382); 1 male,

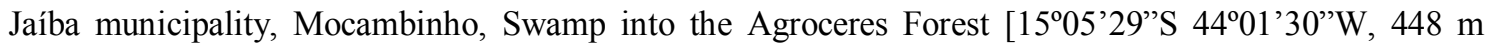
a.s.l.], 25.X.1992, A. L. Carvalho leg. (DZRJ); 1 female (and its respective F-0 exuvia), Marliéria municipality, Parque Estadual do Rio Doce, Lagoa Preta, Collecting Point PERD_9 (1940'26.23”'S, $42^{\circ} 31^{\prime} 20.52^{\prime \prime}$ W, 254 m.s.l.), lagoon with muddy bottom, emergent vegetation Poaceae and Salvinia sp., 04.III.2011 (date of its F-0 larva, adult emergence at 06.IV.2011), A.P. Pinto \& J.G. da Silva leg. (DZRJ 974); Espírito Santo state: 1 female, Conceição da Barra [municipality], estrada de Itauna Km 8, capoeira a beira da estrada, 1-7.x.1969, Elias leg. (MNRJ; APE 383); Rio de Janeiro state: 1 male, Cachoeiras de

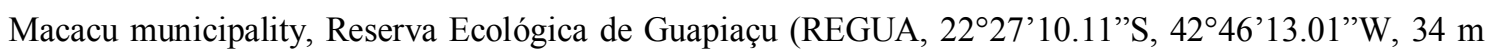
a.s.1.), sunny dam with abundant macrophytes, 03.XII.2009, A. L. Carvalho \& Equipe Disc. Téc. Coleta leg. (DZRJ 559); 3 males, 1 female, same data but 01.XII.2011, A. P. Pinto, A. L. Carvalho \& Disciplina Técnicas de Coleta PPGZOO/UFRJ leg. (DZRJ 1368, 1413-1414); 1 male, 1 female, same data but 02.XII.2011 (DZRJ 1418-1419); 6 males, 5 females, same data but 28.II-02.III.2012, A. P. Pinto leg. (DZRJ 1567-1568; MZSP); 1 male, Maricá [municipality], Restinga de Maricá, swamp into the forest, 03-04.i.1992, A. L. Carvalho leg. (DZRJ 00); 1 male, same municipality but Rio Ubatiba, under the bridge, 26.VIII.1999, P. C. Werneck-de-Carvalho leg. (DZRJ); 1 male, same data but 24.XI.1999, A. L. Carvalho \& E. R. Calil leg. (DZRJ); 1 male, same data but 24.IV.2000, A. L. Carvalho leg. (DZRJ); 1 male, same data but 26.II.2000, A. L. Carvalho leg. (DZRJ); 1 male, same data but Julian's point, 27.V.2000, A. L. Carvalho, E. R. Calil \& P. C. Werneck-de-Carvalho leg. (DZRJ); 1 male, same data but under the bridge upstream of the dam, 29.III.2001, Laboratório de Entomologia - IB/UFRJ leg. (DZRJ); 1 male, Rio de Janeiro municipality, Horto Florestal da Quinta da Boa Vista, fountain pool with Eichornia sp. and shady muddy channels with organic matter (22 $54^{\prime} 30.48^{\prime \prime S} 43^{\circ} 13^{\prime} 25.50^{\prime \prime} \mathrm{W}, 14 \mathrm{~m}$ a.s.1.), 03.XI.2009, A.P. Pinto leg. (DZRJ 560); PARAGUAY. [Departamento del Alto Parana]: 1 female, Puerto General Dias; iv.1944, Miss[ão] Cient[ífica] Brasil[eira] leg. (MNRJ 8052; APE 386).

Erythemis peruviana (Rambur, 1842). (4 male and 45 P). VENEZUELA. Barinas [state]: in Torunos (Hacienda la Isla), Rio Santo Domingo (Rio Apure Dr.), large turbid river; gravel \& sand $\left(08^{\circ} 30.54^{\prime} \mathrm{N}\right.$; 7005.05'W, DCT 93-6), 03.I.1993, K. S. Cummings \& C. A. Mayer leg. (1 q INHS 12587; APE 523). SURINAME. Marowijne distr[ict]: 7 males, 10 females, Christian Kondre, x.1963, B. Malkin leg. (MZSP; APE 111-112); [Paramaribo District]: 1 male, Paramaribo city, 23.X.1959, Charles Lurg leg. (ABMM); 1 male, same data but 24.X.1959 (ABMM). BRAZIL. Amazonas state: 1 female, Manaus [municipality], Lago Janauacá, 26.iv.[19]88, José Camilo Hurtado leg. (INPA 318; APE 479); 2 males, same data but L[ago] Jan[a]uari, 13.II.1972, Expedição Permanente a Amazônia (MZSP); 3 females, same municipality but L[ago] Jan[a]uari, Rio Negro, 14.II.[19]72, Exp[edição] Perm[anente à] Amaz[ônia MZUSP] leg. (MZSP; APE 598-600); 1 male, same municipality but Sis[ema] Janauacá, Lago Castanho, 18.VI.[19]76, Selita M. Santos leg. (INPA); 1 female, same municipality but Rio Solimões, Ilha da Marchantaria, 12.viii.2001, J. L. Nessimian leg. (DZRJ; APE 44); 1 female, same data but 17.viii.2001 (DZRJ; APE 45); 1 male, same data but XI.2002, J. L. Nessimian leg. (DZRJ 1045); 1 female, Est[rada] mauá - Km 7, 23.iv.[19]76, E. Rufino leg. (INPA; APE 476 ); 1 male, same data but 
18.V.[19]77, L. A. L Ruquer leg. (INPA); 1 male, Vila Amazônica near a Parintins municipality, 19.X.1969, Expedição Permanente a Amazônia (MZSP); 1 male, [Manaus?], Est[rada do] Aleixo Km 10, 20.V.[19]77, Mirian Serrano leg. (INPA); 1 male, Itacotiara muncipality, VI.[19]60, [Richard von Diringshofen leg.] (MZSP); Pará state: 4 males, [Mecidilândia municipality], Furo do Jaruparu [sic. Jurupari?], 19.x.1970, E[xpedição] P[ermanente à] A[mazônia MZUSP] leg. (MZSP); 1 male, [Santarém municipality], Fordlândia, ii.1957, A. B. M. Machado leg. (ABMM); 1 male, 2 females, near to Santarém, Fazenda Taperinha, 1-11.ii.1968, Exp[edição] Perm[anente à] Amaz[ônia MZUSP] leg. (MZSP; APE 602-603); 1 male, 3 females same data but x-xi.1970 (MZSP; APE 604-606); 3 males, 2 females, Santarém [municipality], Ponta Negra, 28.xii.1967, Exp[edição] D[epartamento de] Z[oologia] leg. (MZSP; APE 608-609); 1 male, 3 females, Óbidos [municipality], ii.1952, B. Ferreira leg. (ABMM; APE 271-273, 313); 1 male, same municipality but [Igarapé] Traíra, IX.[19]64, [Richard von Diringshofen] (MZSP); 1 male, 2 females, Tucuruvi [municipality], Base 03 Reservatório; 03.i.1993, J. Leal leg. (ABMM; APE 267, 269); 3 males, 5 females, same data but 27.i.1993 (ABMM; APE 264-266, 293, 318); Paraíba state: 1 female, [João Pessoa municipality], 03.i.1954, Jorge Kesselring leg. (MSZP; APE 611); 1 female, same data but 23.i.1954 (MSZP; APE 612); Mato Grosso state: 2 males, 1 female, Pantanal, between Rio Cuiabá and Barão de Melgaço municipalities, without date, C. A. Caetano leg. (DZRJ; APE 43); 4 males, [Poconé municipality, Ilha de Taiamã?], R[io] Paraguai, 14.VII.1980, [R. von Diringshofen leg.?] (MZSP); Mato Grosso do Sul state: 1 female, Ilha Taquarusú, Rio Paraná, x.1952, [Richard von Diringshofen leg.] (MZSP; APE 613); Bahia state: 1 male, [Salvador municipality, Praia da] Pituba, 20.XII.1988, J. Becker leg. (MNRJ); 1 female, Salvador, [Lagoa do] Abaeté-Catu [Abrantes], 14.II.[19]87, J. B[ecker] leg. (MNRJ); 1 male, Simões Filho municipality, Res[erva] Ecol[ógica] da CIA Cotegipe, 19.II.[19]94, J. Becker leg. (MNRJ); Minas Gerais state: 1 male, Marliéria municipality, Parque Estadual do Rio Doce, Porto Capim, Lagoa Dom Helvécio, collecting point PERD_3

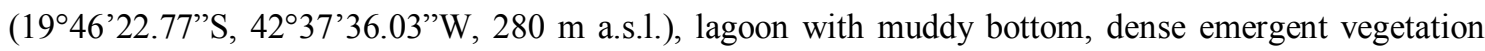
Eichornia sp. and Eleocharis sp., 03.III.2011, A. P. Pinto \& J. G. da Silva leg. (DZRJ 971); 1 male, 1 female, same data but Lagoa do Aníbal, collecting point PERD_6 (1947’6.44”S 42²9’46.87’’W, $260 \mathrm{~m}$ a.s.1.), lagoon in an open sunny area with muddy bottom, emergent vegetation Poaceae and Typha sp., 03.III.2011 (MZSP); 1 male, Coronel Fabriciano municipality, IX.1959, A. B. M. Machado leg. (ABMM); Rio de Janeiro state: 3 males, 2 females, Cachoeiras de Macacu municipality, Reserva

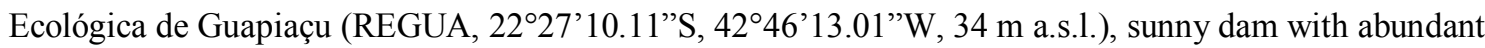
macrophytes, 03.xii.2009, A. L. Carvalho \& Equipe Disciplina de Técnicas de Coleta leg. (DZRJ 554558; APE 499-500); 4 males, 4 females, same data but 01.XII.2011, A. P. Pinto, A. L. Carvalho \& Disciplina Técnicas de Coleta PPGZOO/UFRJ leg. (DZRJ 1350, 1362, 1403-1408); 2 females, same data but 02.XII.2011 (DZRJ 1420-1421); 4 males, 5 females, same data but 28.II-02.III.2012, A. P. Pinto leg. (MZSP); 1 male, Macaé municipality, Lagoa de Emboacica, Point 4, near to road, in front to Shell' gas station, 8.II.2001, A. L. Carvalho leg. (DZRJ); 1 male, same municipality, Rio Macaé under the bridge of BR-101, 16.IV.2002, N. Ferreira-Jr. leg. (DZRJ); 1 male, same data but 17.IV.2002 (DZRJ); 1 male, 1 female, Magé [municipality], Citrolândia, Campo do Escoteiro Chefe Geraldo Hugo Nunes, borda de mata, poças em áreas abertas, 20-25.ix.2005, A. L. Carvalho leg. (DZRJ 552-553; APE 498); São Paulo state: 1 female, Mutuca municipality, Represa do Córrego do Simão 21²8’38’[S], 4805’33” [W], 1:269 
feets, 01.IV.2001, J. M. Costa leg. (MNRJ); 3 males, Lagoa Grande, Rio Paraná, X.1952, [Richard von Diringshofen leg.] (MZSP); Rio Grande do Sul state: 1 male, Porto Alegre municipality, Jardim Lindóia neighborhood, into a store of Assis Brasil Strip Center, 06.III.2006, A. P. Pinto leg. (DZRJ 1768). ARGENTINA. [Corrientes province]: 2 males, [Mburucuyá departament], Parque Nacional Mburucuyá (2803'30"S, 58 02'37"W, 70 m), 08.I.2008, A. C. Gonçalves leg. (DZRJ 573-574); 1 male, 1 female, same data but 10.I.2008 (DZRJ 570-571; APE 505); same data but 1 female, I.2008 (DZRJ 569; APE 504); Del Chaco Province: 1 male, Parque Nacional Chaco, [I.2008], A. C. Gonçalves leg. (DZRJ 572).

Erythemis plebeja (Burmeister, 1839). (7 male and 28 \%). CUBA. Las Villas Province [nowadays Cienfuegos]: 1 male, Soledad Atkins Botanic Garden, 06.VI.1959, M. J. Westfall Jr. leg. (ABMM). COLOMBIA. [Valle del Cauca Department]: 1 female, Cali, viii.[19]59, [R. von Diringshofen leg.] (MZSP; APE 617). SURINAME. Marowijne [district]: 11 males, 15 females, Christian Kondre, x.1963, B. Malkin leg. (MZSP; APE 127-138); 1 male, same data but 03.X.1963 (MZSP). BRAZIL. Paraíba state: 1 male, [João Pessoa municipality], ii.1954, Jorge Kesselring leg. (MZSP); Piauí state: 1 male, Piracuruca municipality, Desejo, VII.1961, A. Escarci leg. (ABMM); Bahia state: 1 female, Salvador municipality, Pituaçú,16.IX.1987, J. Becker (MNRJ); 1 female, Cruz das Almas municipality, into the forest, 26.VII.1991, J. Becker leg. (MNRJ); M[ato] Grosso [do Sul] state: 2 females, [Miranda municipality], Salobra, ii.1941, C[omissão do] I[nstituto] O[swaldo] Cruz leg. (MNRJ 4897, 4902; APE 417-418); Minas Gerais state: 1 male, Jaiba municipality, Mocambinho, Brejo ao lado da Estrada, 22.X.1992, A. L. Carvalho leg. (DZRJ); 2 males, 1 female, same data but Lagoa do Sossego (Agroceres) e sandy swamp, 23.x.1992, A. L. Carvalho leg. (DZRJ 00, APE 33); 1 male, 1 female, Lagoa Santa [municipality], Fazenda Jaguara, 18.xii.1970, A. B. M. Machado leg. (ABMM; APE 250); 1 female, same data but ii.1985 (ABMM; APE 247); 1 male, Itambacuri municipality, Fazenda Urupaca, 15.I.1958, K. Lenko leg. (ABMM); 1 male, Turimitinga, 03.II.1958, Italo leg. (ABMM); Rio de Janeiro state: 1 female, Angra dos Reis [municipality], Bracuhy, condomínio Porto Marina, 11.v.2002, Laboratório de Entomologia - IB/UFRJ leg. (DZRJ 00; APE 38); 4 males, 1 female, Cachoeiras de Macacu municipality,

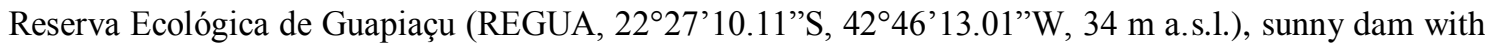
abundant macrophytes, 03.xii.2009, A. L. Carvalho \& Equipe Disciplina de Técnicas de Coleta leg. (DZRJ 561-565); 6 males, 4 females, same data but 01.XII.2011, A. P. Pinto, A. L. Carvalho \& Disciplina Técnicas de Coleta PPGZOO/UFRJ leg. (DZRJ 1361, 1409-1412, 1415-1417, 1565-1566); 6 males, 4 females, same data but 28.II-02.III.2012, A. P. Pinto leg. (MZSP); 1 male, 1 female, Macaé [municipality], Ilha do Santana, INSULAR - RIO [project], 30-31.iii.1984, A. L. Carvalho \& M. A. Mathias leg. (DZRJ 00; APE 34); 1 female, Rio de Janeiro [municipality], Ilha do Fundão, collected in larva, 06.vi.1986 [adult's emergence 11.VI.1986], A. L. Carvalho leg. (DZRJ 00; APE 35); 3 males, 1 female, same municipality but horto florestal da Quinta da Boa Vista, tanque com Pistia stratioides, in wheel perched at $2.3 \mathrm{~m}$ of heitgh $\left(22^{\circ} 54^{\prime} 30.48^{\prime \prime} \mathrm{S}, 43^{\circ} 13^{\prime} 25.50^{\prime \prime} \mathrm{W}, 14 \mathrm{~m}\right), 03 . x i .2009$, A. P. Pinto leg. (DZRJ 566-568; APE 515); 1 male, Maricá municipality, 14.IV.1987, N. Ferreira-Jr. leg. (DZRJ); 1 male, same municipality but Restinga de Maricá, swamp into the forest, 03-04.i.1992, A. L. Carvalho leg. (DZRJ); 1 male, same municipality but Rio Ubatiba, under the bridge, 30.v.1999, A. L. Carvalho leg. (DZRJ); 1 female, same data but under the bridge (Juliana locality), 27.v.2000, A. L. Carvalho, E. R. 
Calil \& P. C. Werneck-de-Carvalho leg. (DZRJ 00; APE 37); 2 males, same data but upstream of the dam, 29.III.2001, Lab. De Entomologia leg. (DZRJ); São Paulo state: Barueri [municipality], eucalipto, 09.iii.1955, K. Lenko leg. (1 † ABMM 164; APE 249); 1 male, 1 female, Mutuca municipality, road Mutuca / Matão, 31.III.2001, J. M. Costa leg. (MNRJ); Rio Grande do Sul state: 1 male, Porto Alegre, F[undação] J[ardim] B[otânico] do R[io Grande do] S[ul], Lago das Tartarugas, 23.XII.1983 (ABMM).

Erythemis simplicicollis (Say, 1840). (3 male and 11 +). UNITED STATES OF AMERICA. Michigan state: 1 female, Cass Co[unty], Wakelee, 06.vii.1971, I. Leeuw leg. (DZRJ; APE 63); Illinois state: 1 male, 1 female, Plattt Co[ounty], Lodge Park Pond, 3.5 m[i]l[es] NNE of Monticello, 1991, C. A. Bridges leg. (INHS 00236; APE 525); 1 male, 1 female, same data but 22.viii.1991 (INHS 00235; APE 524); Ohio state: 1 male, Warren County, Wayne Township 1 mile S of Waynesville, 18.VII.1969, T. D. Center \& R. K. Finley leg. (DZRJ); Indiana state: 3 females, Gibson Co[unty], Oakland City, New Lake, 16.viii.1940, (MNRJ 4027[?]; APE 394-396); 1 male, Carrol County, Tippecanoe River, $\mathrm{n}^{\circ} 4035$, 08.IX.1940, C. Cook leg. (MNRJ); 2 males, Clark County, Schlamon Lake state Forest Henryville ,15.VI.1938 (MNRJ); Kentucky state: 1 male, 1 female, [Metcalfe County, Center City?], Crail Hope [Road], 06.IX.1949, C. Cook leg. (MNRJ 14510, 14572; APE 391); Texas state: 1 female, Kleberg Co[unty], Padre Island National Seashore, 21.viii.1972, J. Hafernik leg. (DZRJ; APE 61); 1 female, Crocokett Co[unty], Pecos River at United States H[igh]w[a]y 290, 21.vii.1977, R. W. Garrison leg. (DZRJ; APE 62); 1 male, Real County, Nueles River at Texas Highway 55, south to Barisdale, $22-$ 23.VII.1977, R. W. Garrison leg. (DZRJ); 1 male, Williamson County, Field NR. Road to Manor, Taylor, 16.VIII.1975, R. W. Garrison leg. (DZRJ); Florida state: 1 male, 1 female, Orange County, 30.iii.1941, D. W. Thorton leg. (ABMM 848-849; APE 301); 1 female, Winter Park, 22.iv.1941, M. J. Westfall Jr. leg. (ABMM 850; APE 302); 3 males, Coral Gables, 25.II.1946 (MNRJ 14508-14509, 14571); 1 female, Kleberg County, Padre Island, National Seashore, 21.VIII.1972, J. Hafernik leg. (DZRJ); 1 male, Williamson County, Field NR. Road to Manor, Taylor, 16.VIII.1975, R. W. Garrison leg. (DZRJ); 1 female, Crocokett County, Pecos River, 21.VII.1977, R. W. Garrison leg. (DZRJ); 1 amle, Real County, Nueles River at Texas Highway 55, south to Barisdale, 22-23.VII.1977, R. W. Garrison leg. (DZRJ).

Erythemis vesiculosa (Fabricius, 1775). (28 + ). COLOMBIA. [Valle del Cauca Department]: 1 male, Cali, VIII.1959, [Richard von Diringshofen leg.] (MZSP); 1 female, same data but IX.1959 (MZSP; APE 620); SURINAME. [Coronie District]: 1 female, Coronieweg 216 [highway from Coronie to Paramaribo], Swamp Luidbji[?], 18.xii.1948, [D. C. Geijskes leg.] (MZSP; APE 90); Marowijne distr[ict]: 3 males, Christhian Kondre, x.1963, B. Malkin leg. (MZSP); 1 male Kristrelb [?], Kampong Moengo [Moengotapoe, Wia Wia], 18.II.1947, [D. C. Geijskes leg.] (MZSP). PERU. [Junin region]: 1 female, Satipo [province], ii.1982 (ABMM; APE 290); BRAZIL. [Roraima state]: 1 female, [Caracaraí municipality, VIII-IX.2011, G. Biffi \& L. R. Prado] (MZSP); Amapa state: 1 female, [Porto Grande municipality, settlement] Nova Colina, 10.X.[20]00, Carton leg. (MNRJ); Amazonas state: 3 females, Itacotiara [municipality], VI.[19]60, [Richard von Diringshofen leg.] (MZSP; APE 622-624); 1 male, same data but VI.[19]64 (MZSP); 1 male, same municipality but E[strada do] Aleixo k[?]-7, 25.IV.1996, B. Mascarenhas leg. (INPA 534); 1 female, [Manaus municipality], INPA, 25.V.1996, B. Mascarenhas 
leg. (INPA 276; APE 481); 1 male, Campus INPA, 04.V.[19]88, A. L. Mascikelli leg. (INPA 1210); 1 male, same municipality, faz[enda] NAF_6 Km 31, Est[rada] BR 171, 31.IV.1976, Mario Dantas leg. (INPA); 1 female, 1 male, same municipality but Lago Poraquequara, 22.VI.[19]89, Mesquita \& Peralta leg. (INPA 263; APE 484); 1 male, Est[rada] BR 174 Km 45, 25.V.1978, J. A. Rafael leg. (INPA); Pará state: 1 male, 1 female, Belém [municipality, Parque ambiental] Utinga, iii.1957, A. B. M Machado leg. (ABMM; APE 261); 1 female, Óbidos [municipality], 14.iv.1962, José Brazelino leg. (ABMM; APE 258); 1 female, near to Santarém [municipality], Fazenda Taperinha, 1-11.ii.1968, Exp[edição] Perm[anente à] Amaz[ônia MZUSP] leg. (MZSP; APE 84); 1 female, same data but 17-18.ii.1968 (MZSP; APE 85); 1 male, same data but X-.XII.1970, Expedição Permanente à Amazônia leg. (MZSP); 1 female, [Paragominas municipality, indigenous post] Canindé, Rio Gurupi, iv.1963, B. Malkin leg. (MZSP; APE 87); Rondônia state: 1 male, 2 females, Vila Suruma, 20.x.1998 (MNRJ; APE 429-430); Ceará state: 1 female, Cascavel municipality, disctrict of Jacarecoara, Barra Nova locality, lagoons near to sea, little aquatic vegetation, "buritis", sandy bottom, some of them with shalom depth and bottom with accumulation of organic matter $\left(04^{\circ} 05^{\prime} 42.63^{\prime}\right.$ 'S, 36 $06^{\circ} 40.62^{\prime}$ 'W, $\left.10 \mathrm{~m}\right), 31 . x i 1.2009$, A. P. Pinto leg. (DZRJ 528; APE 518); Paraíba state: 1 female, [João Pessoa municipality], 16.i.1954, Jorge Kesselring leg. (MSZP; APE 628); 1 male, same data but 21.XII.1953 (MZSP); Mato Grosso state: 1 female, Chapada dos Guimarães [municipality], Buriti, 26.vi.1972, O. Milke leg. (MNRJ; APE 431); 1 female, same data but 20.i.1970, N. Tangerini leg. (MNRJ; APE 432); 1 female, same data but $10 \mathrm{~km}$ before Buriti, 10.iv.1963, N. D. Santos \& Machado leg. (MNRJ 24601; APE 433); 1 female, same data but ca of $20 \mathrm{~km}$ beyond of Chapada [dos Guimarães], tributary of Rio Casca in direction to usina of Rio Casca, 13 iv.1963, N. D. Santos \& Machado leg. (MNRJ 24868; APE 434); 1 female, Poconé [municipality], Fazenda Ipiranga, 13-18.ii.2000, P. C. Werneck-de-Carvalho \& A. C. Capparelli leg. (DZRJ 00; APE 56); 1 female, same municipality but Pixaim, transpantaneira, 20.ii.2000, A. L. Carvalho leg. (DZRJ 00; APE 57); 2 females, [Santa Terezinha municipality], Rio Tapirapé, [locality of] Porto Velho [1045'27.94”'S, 5101'26.60”W, 181 m a.s.1.], iv.1964, R. T. Lima leg. (MZSP; APE 625-626); Goiás state: 1 male, Aruanã municipality, Rio Araguaia, II.[1962], [Richard von Diringshofen leg.] (MZSP); Bahia state: 2 males, 1 female, Muritiba municipality, Morro do Aporá, 28.XII.1988, J. Becker leg. (MNRJ); 1 female, Camaçari municipality, Guarajuba, 23.XI.1993, O[lmyro Roppa?] leg. (MNRJ); 1 female, Conceição de Feira municipality, 13.VIII.1991, J. Becker leg. (MNRJ); 3 males, Santa Rita de Cássia municipality, 29.III.1958, A. B. M. Machado leg. (ABMM); Espírito Santo state: 1 male, 1 female, São Mateus [municipality], Mocambinho, 19.xi.1988, J. L. Nessimian leg. (DZRJ 00; APE 55); Minas Gerais state: 1female, Marliéria municipality, Parque Estadual do Rio Doce, Lagoa do Aníbal,

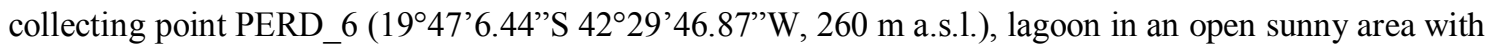
muddy bottom, emergent vegetation Poaceae and Typha sp., 03.III.2011, A. P. Pinto \& J.G. Da Silva leg. (MZSP); 2 males, same data but Ponte Queimada, collecting point PERD_7 (1944'55.50"S, 42 $28^{\prime} 43.10^{\prime \prime} \mathrm{W}, 245$ m a.s.1.), 03.III.2011 (MZSP); Rio de Janeiro state: 1 male, Rio de Janeiro municipality, Barra da Tijuca, 28.X.2006, A. P. Pinto leg. (DZRJ); 1 male, same municipality but Recreio dos Bandeirantes near to Parque Chico Mendes, 2003, P. C. Werneck-de-Carvalho leg. (DZRJ); 1 male, Mangaratiba municipality, Reserva Ecológica Rio das Pedras (RERP), 04.XII.2008, A. L. Carvalho leg. (DZRJ 1757); 1 male, Cachoeiras de Macacu municipality, Reserva Ecológica de Guapiaçu (REGUA, 
$22^{\circ} 27^{\prime} 10.11^{\prime \prime} \mathrm{S}, 42^{\circ} 46^{\prime} 13.01^{\prime \prime} \mathrm{W}, 34 \mathrm{~m}$ a.s.1.), sunny dam with abundant macrophytes, 28.II-02.III.2012, A. P. Pinto leg. (MZSP); 1 male, Maricá [municipality], Restinga de Maricá, swamp into the forest, 0304.i.1992, A. L. Carvalho leg. (DZRJ); 2 males, same data but 21-22.I.1988, A. L. Carvalho \& N. Ferreira-Jr. leg. (DZRJ); 1 male, same municipality but Rio Ubatiba, under the bridge, 20.XII.1999, A. L. Carvalho leg. (DZRJ); 1 male, Macaé [municipality], Ilha do Santana, INSULAR - RIO [project], 3031.III.1984, A. L. Carvalho \& M. A. Mathias leg. (DZRJ 00); 1 male, same municipality, Lagoa de Emboacica poitn 4, in front to Shell' gas station, 08.II.2001, A. L. Carvalho leg. (DZRJ); 1 male, same municipality, Parque Nacional da Restinga de Jurubatiba, 17.XI.20[0]1 (MNRJ); 1 male, Carapebus municipality, Sítio Boa Vista, 26.II.2001, Barbara [Oldrini?] leg. (MNRJ); São Paulo state: 1 male, Ubatuba municipality, Parque Estadual da Serra do Mar, Núcleo Picinguaba, 07-10.X.1999, Laboratório de Entomologia - IB/UFRJ leg. (DZRJ); 1 male, same data but 08-12.VI.2005, A. L. Carvalho \& Equipe Lab. de Entomologia leg. (DZRJ 1188); 1 female, São Paulo [municipality], 24.v.2010 (MSZP; APE 630); 1 female, Cananéia municipality, Parque Estadual da Ilha do Cardoso, collecting point PEIC_04, 06 (2504'56.54”S, 4755’38.02”'W, 13 m a.s.1.), 21.X.2011, A. P. Pinto leg. (MZSP); Santa Catarina state: 1 male, Itajaí municipality, hill near to the university, 14.II.2008, A. P. Pinto leg. (DZRJ 836); BRAZIL. 1 female, without data, Daniel Pereira dos Santos leg. (ABMM; APE 259). 


\section{APÊNDICE 2. MATRIX DE DADOS}

Matriz de dados com 69 táxons e 171 caracteres utilizados na análise cladística de Sympetrinae. Táxons em negrito referem-se aos representantes de Erythemismorpha. "?”, dados não observados ou ambíguos; “-”, dados não aplicáveis; “*” táxons incluídos apenas com base nas informações da literatura e de fotografias; polimorfismo como segue: $A=\{01\}, B=\{02\}, C=\{04\}, D=\{12\}, E=\{13\}, F=\{23\}$.

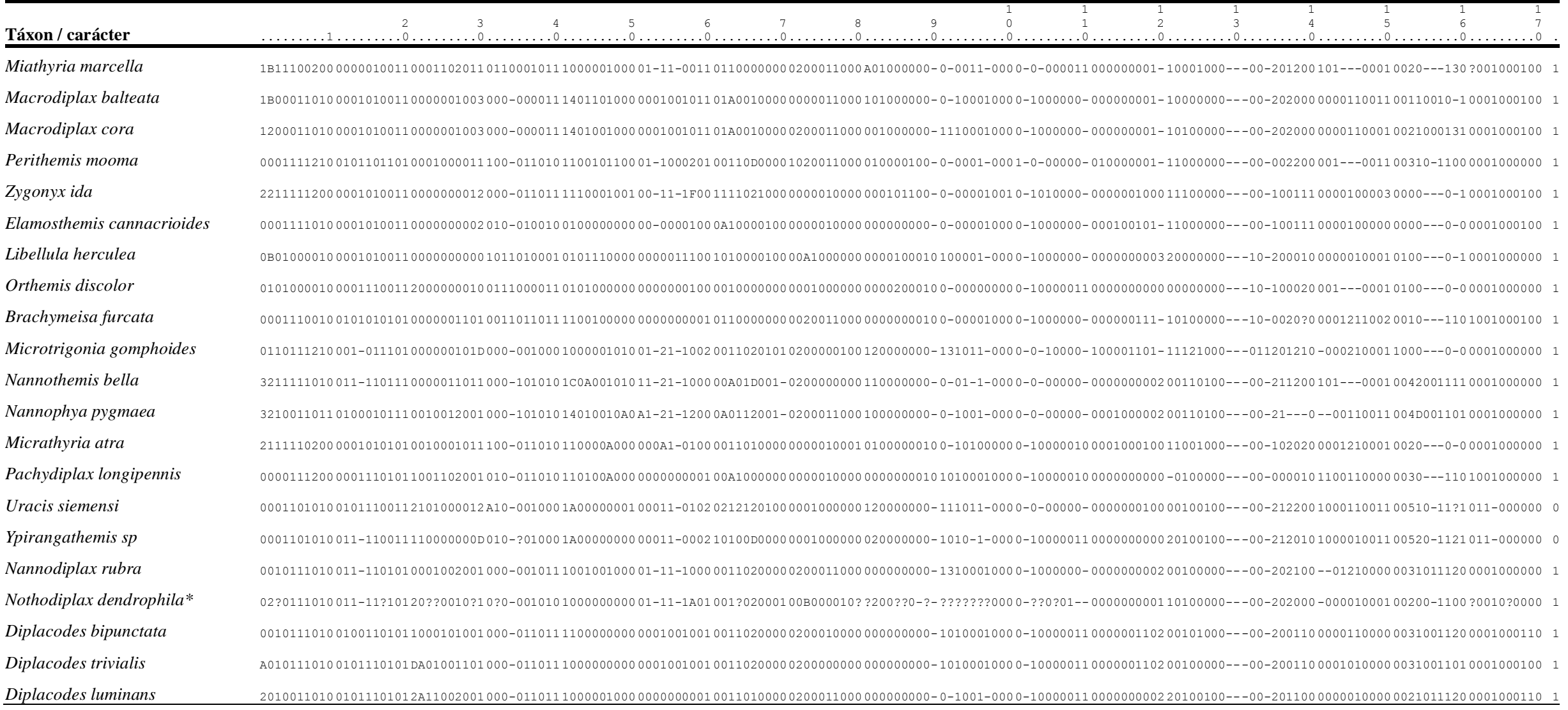

Continua 
Tabela 00. Continuacão.

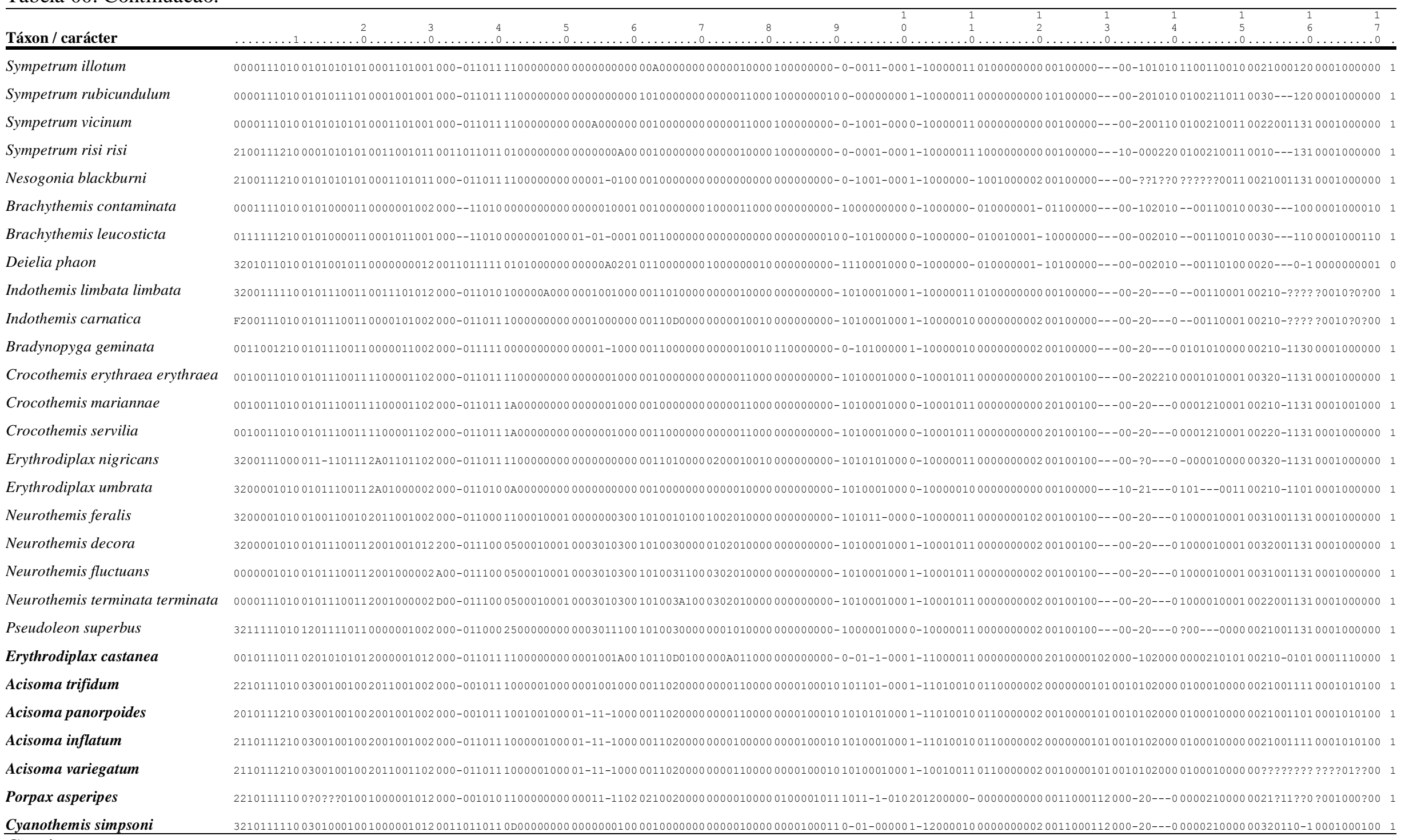

Continua 
Tabela 00. Conclusão

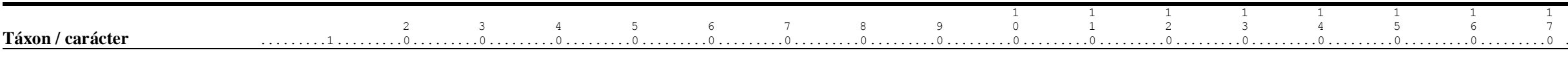

Rhodothemis rufa

Rhodothemis mauritsi

Carajathemis simone

Rhodopygia geijskesi

Rhodopygia hollandi

Rhodopygia hinei

Rhodopygia cardinalis

Rhodopygia pruinosa

Erythemis vesiculosa

Erythemis collocata

Erythemis simplicicollis

Erythemis haematogastra

Erythemis plebeja

Erythemis credula

Erythemis peruviana

Erythemis attala

Erythemis carmelita

Erythemis mithroides

Viridithemis viridula*
$001011101003010001002000001002000-0110111100000000000100110000110200000000010000000010101111100011002012000011000000000300100000--010-2020200100210100003100110100010100001$ $001011101003010001002000001002000-0110111100000000000100110000110200000000010000000010101111100011002012000011000000000300100000--010-2020200000110100003100110100010100001$ $22101110100201010101200000101200110100110 D 0000000000000103000010000000010001000000001001111210001010201200001100000000020010000100000-00---010011101000020---? ? 000010 ? 0000$ $00101110100201010101200000100200110110111200000000000000010200100000000100010000000000110-0-100000001-1100001100000000010010000100000-0022200001210100002100110000010100001$ $00101110100201010100200000100200110110110200000000000000010200100000000100010000000000110-101011-0001-1100001100000000010010000100000-0022200001210100002100010000010100001$ $001011101002010101002000001002001101101102000000000000000 E 0200100000000100010000000000110-0-0011-0001-1100001100000000000010000100000-002220000121010000210111000001010000$ $00101110100201010100200000100200110110111200000000000000010200100000000100010000000000110-0-1011-0001-1100001100000000000010000100100-1022200001210100002101010000010100001$ $001011101002010101002000001002001101101112000000000000000 \mathrm{E} 0200100000000100001000000000110-\mathrm{A} 21011-0001-1100001100000000000010000100100-002220000121010000210111000001010000$ $0010011010030110010120000010020011011011030000000000000001000011000000000001000000001010111010001000211200001100000000000010000100000-102100001---000000111011110001010000$ 2A1001101003011001012000001002000-011011110000000000000001000011000000000000001000001010111210001000201200001100000000000010002100000-102100001---0000000320001110001010000 $211001101003011001012000001002000-011011110000000000000001000011000000000000001000001010111210001000201200001100000000000010002100000-102100001---000000320001110001010000$ A210111010020100010120000010020011011011110000000000000001000011000000000001000000001010111010001000211200001100000000000010000102000-102120000011000000211101110001010000-1. $321011101002010101002000001002000-011011110000000000000001000011000000000001000000001010111010001000201200001100000000000010000102000-0021200000110000003200011100010100001$ $321011101003011101002000001002000-01101111000000000008000100001100000000000100000000101011101000100020120000110000000002001000110100111021200000110000002111010100010100001$ $321011101002011101002000001002000-0110111100000000000000010000110000000000010000000010101110100010002012000011000000000000100001010011102120000011000000211101010001010000$ $3210111010020100010120000010020011011011110000000000000001000011000000000001000000001010111010001000201200001100000000000010000102000-1021200000110000003211010100010100001$ $001011101002010101012000001002000-011011110000000000000001000011000000000001100000001010111010001000201200001100000000000010000102000-102120000011000000321101010001010000$ A01011101002010001012000001002000-011011110000000000000001000011000000000001100000001010111010001000201200001100000000000010000102000-102120000011000000321101010001010000

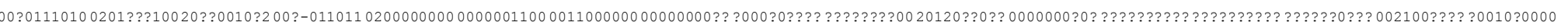




\section{APÊNDICE 3. FotogRAFIAS DAS ESPÉCIES DE ERYTHEMISMORPHA}
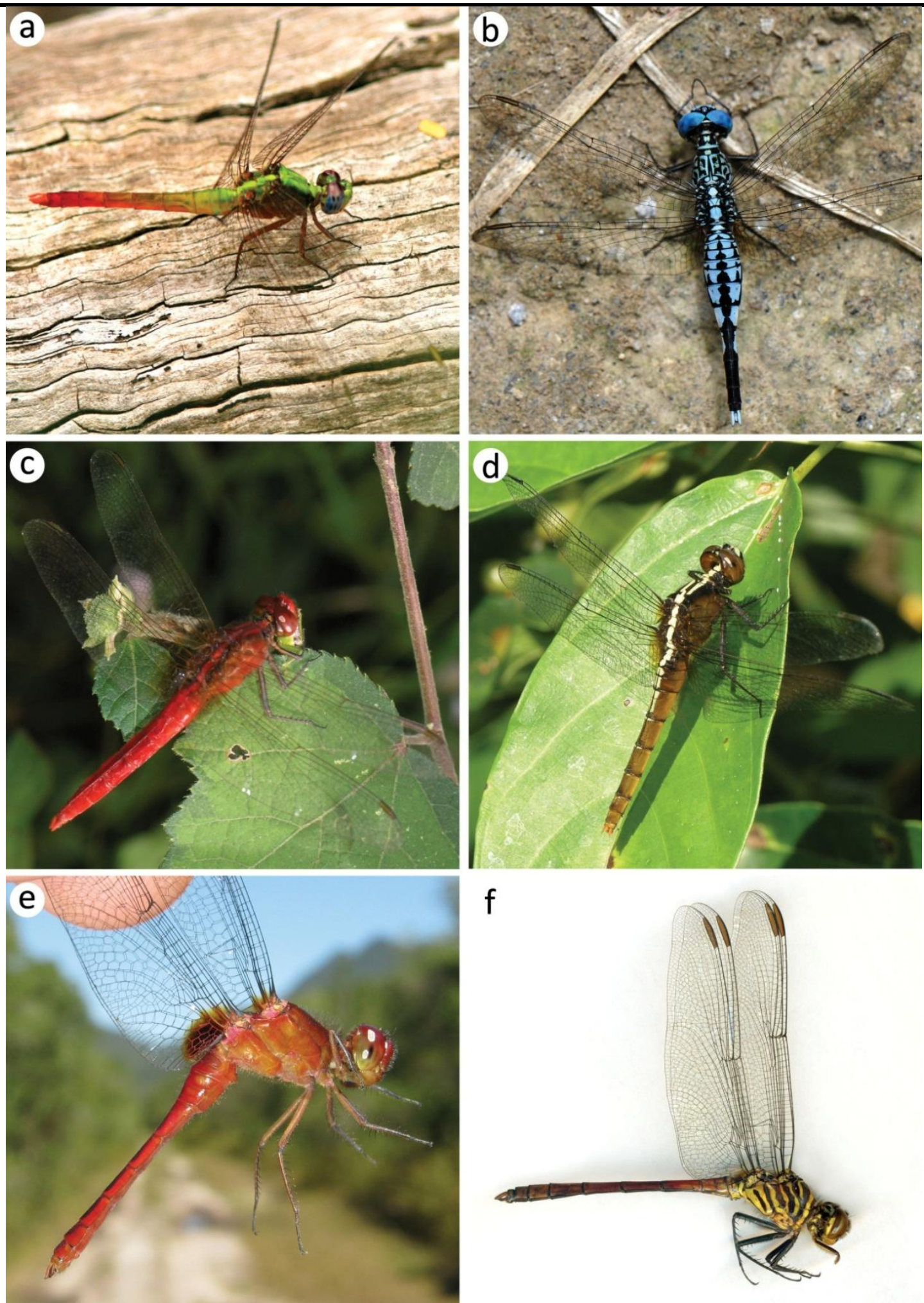

Figura 19. Adultos de Erythemismorpha. a. Viridithemis viridula Fraser, 1960, macho (Madagascar. Manabe: Zombitse Forest, 8.XI.2007); b. Acisoma panorpoides panorpoides Rambur, 1842, macho (Indonésia. Batang Serangan: Bukit Lawang); c-d. Rhodothemis rufa (Rambur, 1842), macho (c), fêmea (d), (Camboja. Kep Province: Platystylus brook valley, 6-7.XII.2010); e. Erythrodiplax castanea (Burmeister, 1839), macho (Brasil. SP: Cananéia, PARES da Ilha do Cardoso, 20.X.2011); f. Carajathemis simone Machado, 2012, (Brasil. PA: Parauapebas, FLONA de Carajás, 26.III.1994. Fotos: a. Callan Cohen; b. Dries Nys; c-d. Oleg Kosterin; e. Ângelo P. Pinto. 

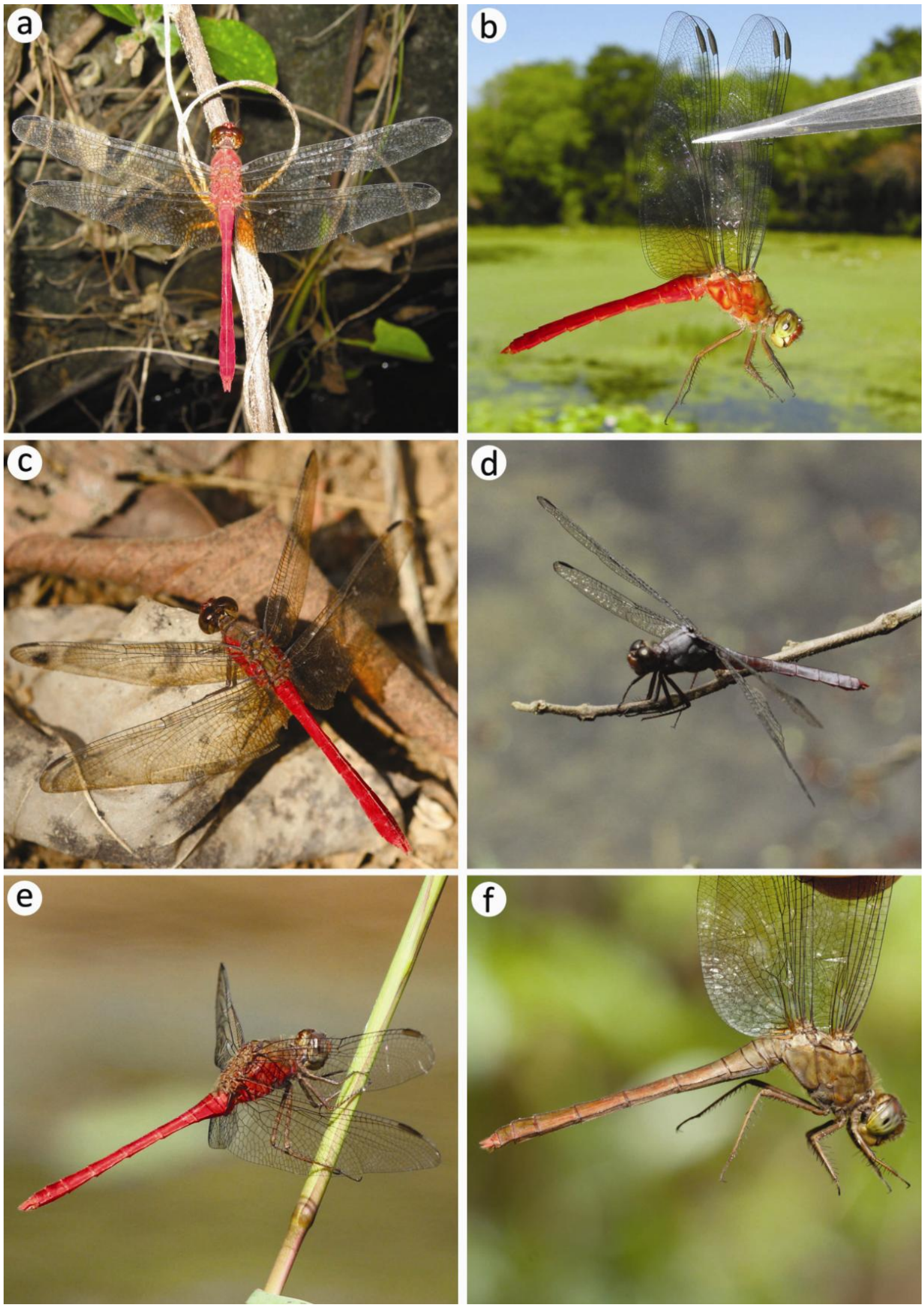

Figura 20. Adultos de Erythemismorpha. a-f. Rhodopygia Kirby, 1889; a-b. R. cardinalis (Erichson, 1848), macho (Brasil. RJ: Cachoeiras de Macacu, Reserva Ecológica de Guapiaçu, 01.II.2012); c. $R$. hinei Calvert, 1907 (Panamá. Canal Zone: Gamboa); d. R. pruinosa Buchholz, 1953 (Brasil. RJ: Cachoeiras de Macacu, Reserva Ecológica de Guapiaçu, 18.XII.2011); e-f. R. hollandi (mesma localidade), macho (e, 26.VII.2012), fêmea (f, 20.VII.2012). Fotos: a-b. Ângelo P. Pinto; c. Herwig Leinsinger; $\mathrm{d}-\mathrm{f}$. Tom Kompier. 

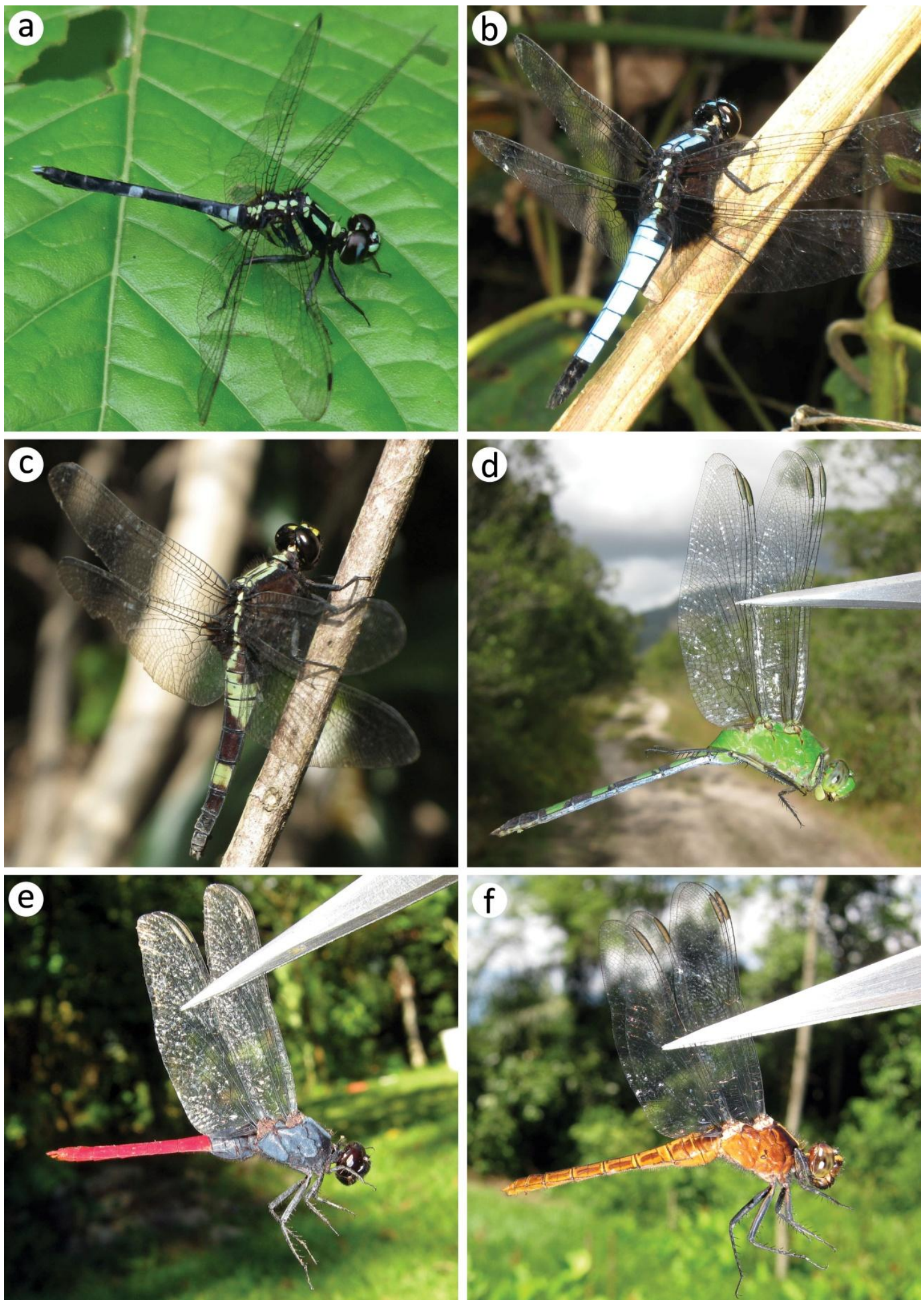

Figura 21. Adultos de Erythemismorpha. a. Porpax asperipes Karsch, 1896, macho (Gabão. Akok, 02.I.2011); b-c. Cyanothemis simpsoni Ris, 1915 (Libéria), macho (b, Putu, 08.II.2011), fêmea (c, Nimba County, 27.II.2012); d. Erythemis vesiculosa Fabricius, 1775, fêmea (Brasil. SP: Cananéia, PARES da Ilha do Cardoso, 20.X.2011); e-f. Erythemis peruviana (Rambur, 1842) (Brasil. RJ: Cachoeiras de Macacu, Reserva Ecológica de Guapiaçu, 28.II.2012), macho (e), fêmea (f). Fotos: a. Nicolas Mézière; b-c. Klaas-Douwe B. Dijkstra; d-f. Ângelo P. Pinto. 

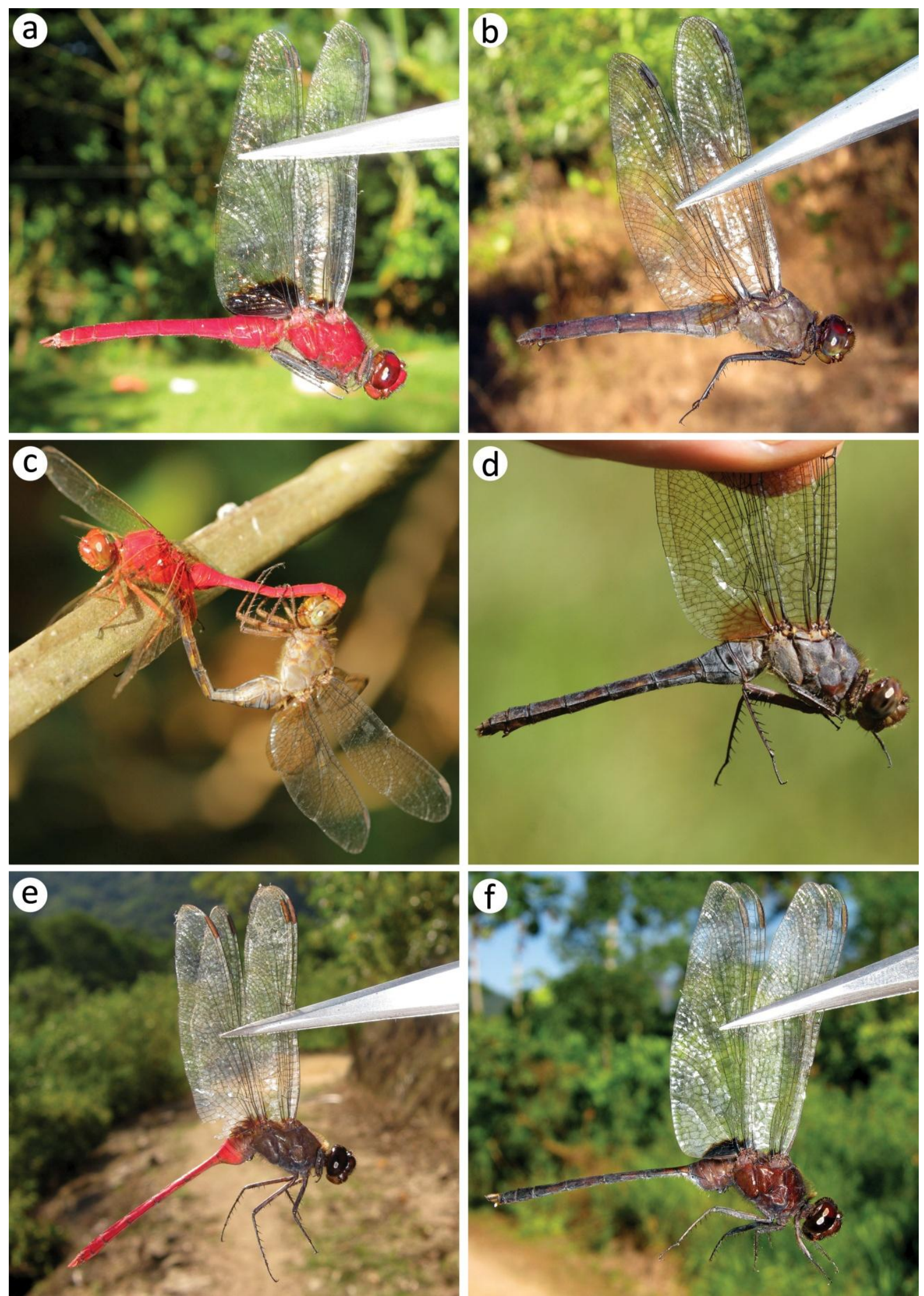

Figura 22. Adultos de Erythemismorpha. a-f. Erythemis Hagen, 1861; a-b. E. mithroides Brauer in Therese, 1900 (Brasil. RJ: Cachoeiras de Macacu, Reserva Ecológica de Guapiaçu, 28.II.2012), macho (a), fêmea pruinosa (b); c-d. E. carmelita Williamson, 1923 (mesma localidade, 25.VII.2012), casal (c), fêmea pruinosa (d); e. E. haematogastra (Burmeister, 1839), macho (mesma localidade, 28.II.2012); f. E. plebeja macho (28.II.2012). Fotos: a-b; e-f. Ângelo P. Pinto; c-d. Tom Kompier. 


\section{Bulletin of American Odonatology [ISSN 1061-3781] - 2009}

Bulletin of AMERICAN

ODONATOLOGY

On a Small Collection of Dragonflies from Barcarena Municipality, Pará State, Brazil, with the Rediscovery of Acanthallagma luteum

Published by the Dragonfly Society of the Americas

Ángelo P. Pinto and Alcimar L. Carrallo Williamson \& Williamson

On a Small Collection of Dragonflies from Barcarena Municipality, Pará State, Brazil, with the Rediscovery of Acantballagma luteum Williamson \& Williamson

Anglo P. Pinto' and Aldimar L. Carralho'

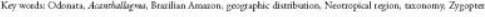

Abstrac

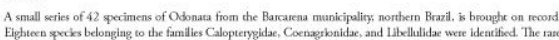

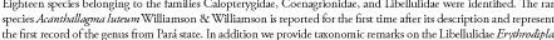

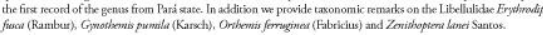

Resumo

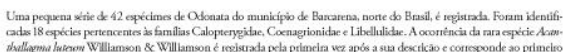

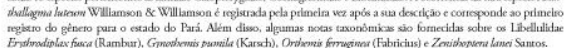
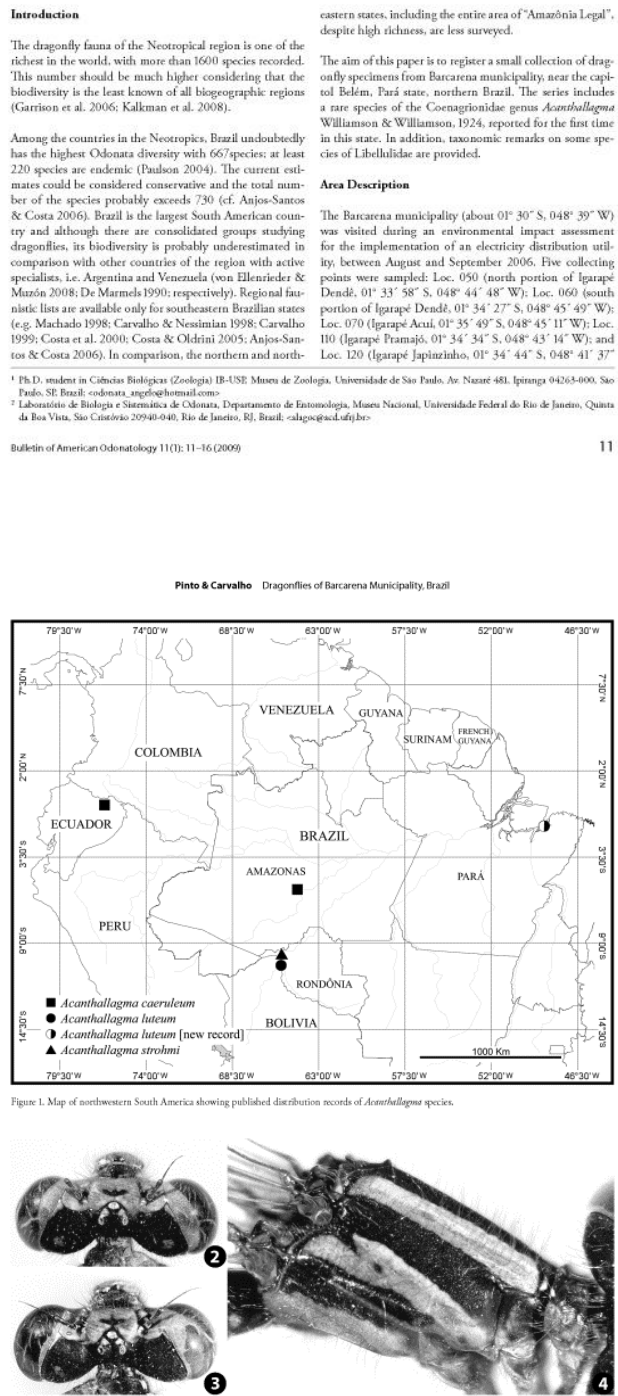

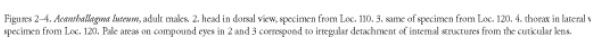

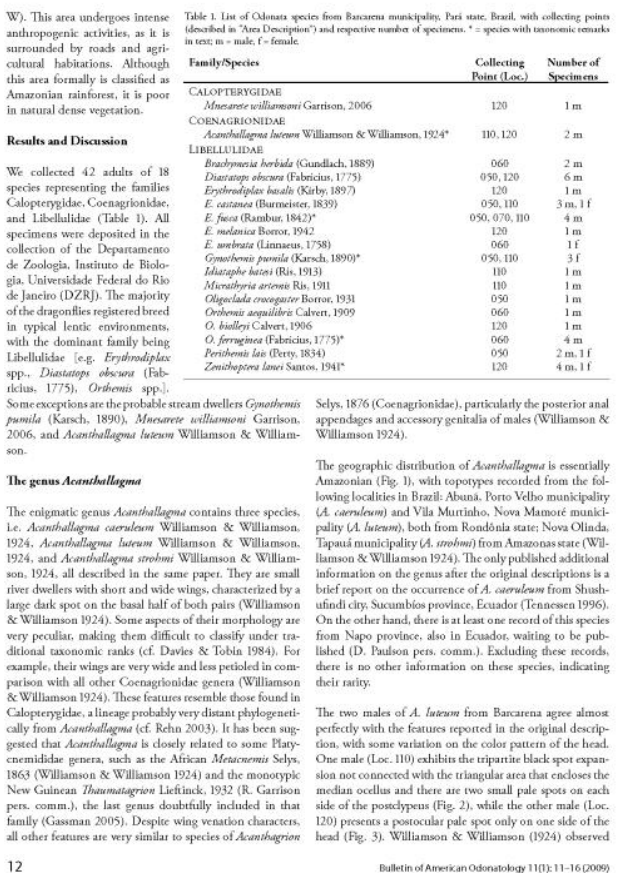



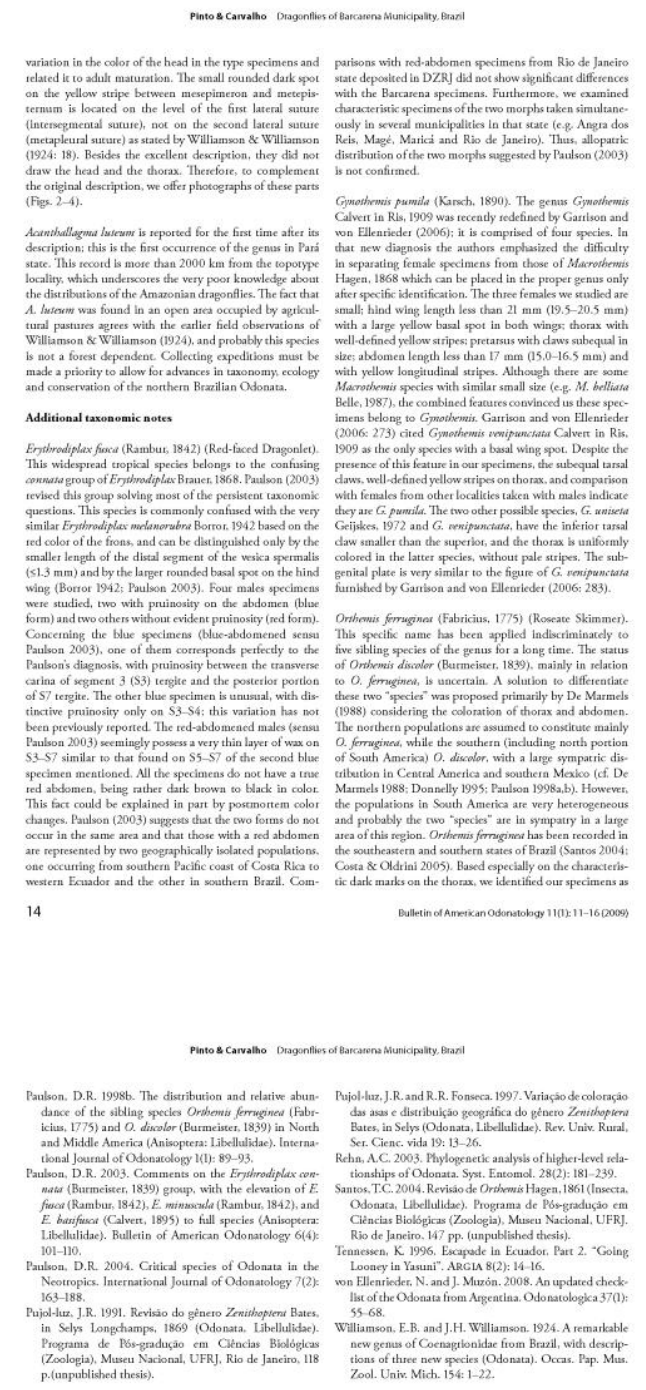
2. ZOOTAXA [ISSN 1175-5326] - 2010

\begin{tabular}{|c|c|}
\hline 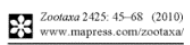 & Article \\
\hline
\end{tabular}

A new species of Lauromacromia (Odonata: Corduliidae) from Southeastern Brazil, with a cladistic analysis of the genus and comments on Neotropical dragonfly biogeography

ANGELO PARISE PINTO ${ }^{12}$ \& ALCIMAR DO LAGO CARVALHO

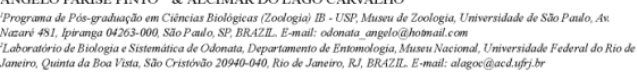

Abstract

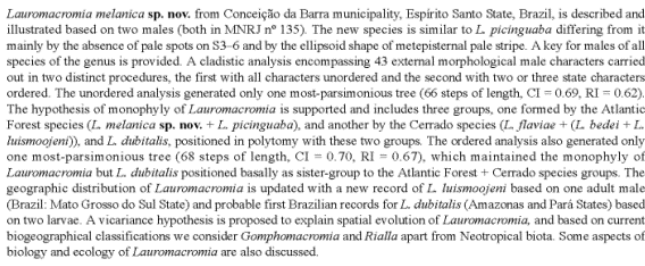

Key words: Atlantic Forest, Gomphomacromiinae, Lauromacromia melanica sp. nov., morphology, phylogeny,

Resumo

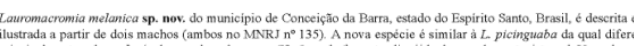
ara machos de todass as especies do género $\dot{e}$ apresentada Uma analise cladistica com 43 caracteres da morfolog

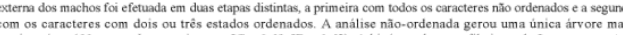

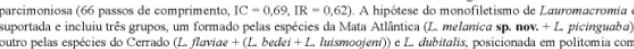

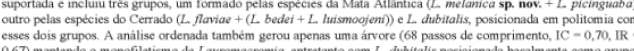

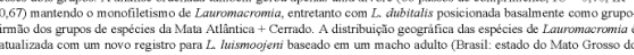

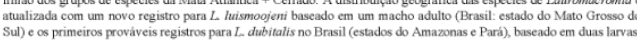

Acecpeded by R. Garrivon: IMar. 2010; published. 13. .4pr. 2010 45 Nomenclature of gencral skcletal morphology follows Asahina (1954) and Garrison et al. (2006); wing
venation terminology follows Rick \& Kukalovi-Pcck (1984) with additions as summarized by Fleck et al.
(2003). In spite of the difficulties in identifying structures of the vesica spermalis the nomenclature proposed by Pfau (2005) was followed. The vesica spermalis of a specimen of $L$. luismoojeni was extracted together with the $\mathrm{S} 3$ sternite after relaxing the specimen with some drops of $10 \%$ ammonia solution on the venter of
S2-3. Afer it was immersed in $10^{\circ}$ KOH for few hours under room temperature and subsequenty rineed water for fifteen minutes. Material was afferward stored in a vial with glycerin, except the vesica spermalis of the new species paratype that was maintained as previously preserved in an alcohol-glycerin mixture Specimens were photographed with a stereomicroscope equipped with a camera, and source images combine using CombineZS. All measurements and illustrations were made with the aid of a stereomicroscope equipped
with a camera lucida. Illustrations of the vesica spermalis of $L$. dubitallis were kindly made by Dr. Jürg De

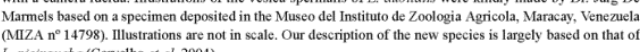
L. picinguaba (Carvalho et al. 2004).

The following abbreviations were used in the text: Ax for antenodal crossvcins; $b$ for Bremer support; $b s$ for Bootstrap; ch for character; Cl for ensemble consistency index; ei for consistency index of a specific
character. Fw for fore wing: Hw for hind wing. MPT(s) for most parsimonious tree(s): Px for postnodd crossveins; pt for pterostigma; RI for ensemble retention index; ri for retention index to specific character,
S1-10 for abdominal segments; TC for transverse carina; VS for vesica spermalis; V1-V4 for segments of

vesica spermalis.
The distribution map was based on the literature records (Fraser 1939; Santos 1967; Geijskes 1970; De 1991: Machado 2002, 2005b; Fleck 2002; Ferreira-Peruquetti \& Fonseca-Gessn 2003; Carvalho et al. 2004, 2008; Araujo \& Bescra 2007) and voucher spccimens, and was gencrated using
ArcView 3.2 (ESRI 1999). Geographic coordinates not provided on collection labels or references were acquired from digital databases (IBGE 2007; Falling Rain Genomincs Inc. 2007).

Cladistic Analysis. A simultancous analysis of maximum parsimony (unconstrained) was performed and character polarity was determinate after rooting (Nixon \& Carpenter 1993). Two taxa were chosen a. Traditionally Gomphomacromia, Lauromacromia and Neocordulia are considered the only Amerio representatives of Gomphomacromiinac (Davies \& Tobin 1985). Morphological data of $G$ p paradoxa wer obtained primarily from von Ellenricder \& Garrison (2005), those of $L$. flaviae and $L$. bedei from origin authors. Characters were treated as unordered (Fitch 1971) and with equal weight for determining the primary
hypothesis of relationship. Atternative to Fitch (1971) approach, we ran a second analysis with the characters ordered (Wagner criterion, Farris 1970). This "mixed-parsimony" approach was implemented to increas resolution on internal nodes, with the characters of up to three states treated as ordered, hence only line
transformation was accepted (Slowinski 1993) Lincar transformation is the only hypothesis for threc-stata characters, but for foursstate characters there is 0.25 likelihood of presenting branching transformations a thus ordering of four-state characters should be avoided (Slowinski 1993). Missing characters were represented with "?" and non-applicable data with "-"." Polymorphism was treated as uncertain (Mstaxa = uncertain in PAUP command). Retention and consistency indexes are presented for the entire tree and for all
characters (cf. Farris 1989). Autapomorphies were included in the data matrix as results of cladisticts investigation (Veates 1992), but not computed for the calculation of ensemble value of consistency inder (C) as proposed by Bryant (1995). Relative stability of individual branches was evaluated with Bremer support
(Bremer 1994) and Bootstrap (Felsenstein 1985) indexes. All procedures were carried out using PAUP" version 4.0 beta 10 (Swofford 1998 )

Most parsimonious trees (MPTs) and Bremer $(b)$ support index were obtained using exhaustive search command All Trees. Bootstrap index ( $b s$ ) was calculated using heuristic search (Hsearch) with the following
parameters: random addition of taxa (AddSeq $=$ Random), thousand replicates (Nreps $=1,000)$, ten tres

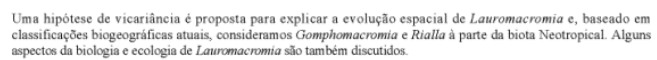
Palavras-chave: Mata Atlântica, Gomphomacrominae, Lauromacromia melanica sp. nov, morfologia, filogenia,
taxomania Introduction

Cordulids are a minor component of the dragonfly fauna of the Neotropical region (senss Morrone 2001, see below), representing ca. $13 \%$ of world family spccies (Garrison et al. 2006). About 38 species distributed in uthors (e.g. Geijskes 1970; Machado \& Costa 1995; Machado 2005a) have discussed their apparent rarity in this region, which is reflected by scarcity of collections and resulting limited information about their biology. "Corduliidae" comprises a paraphyletic or polyphyletic group (Jarzembowski \& Nel 1996; Pfau 2005; 1985: Wa Necdham et al. 2000; Garrison et al. 2006). The dissagreement on "Cordullidace" taxonomic status is due to the absence of comprehensive and robust analyses which could allow for an updated classification. The group needs to be revised in order to establish phylogenetic relationships among the genera and, especially, with

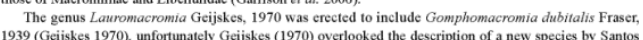

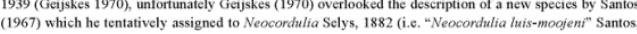
1967). Santos (1967) discussed the assignment of Fraser's species to Gomphomacromia Brauer, 1868,

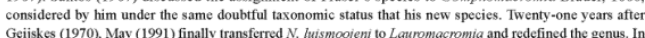
the last decade three more new species from Brazil were described, two from the Cerrado biome in Ninas Gerais State (i.e. Lauromacromia flaviae Machlado, 2002 and Lauromacromia bedei Machado, 2005), and one from the Atlantic Forest in Săo Paulo State (Lauromacromia picinguaba Carvalho, Salgado \& Wemeck-deCarvalho, 2004). Phylogenctic relationships of Lauromacromia with other cordullid genera are poorly
understood, however Fleck \& Legrand (2006) considered the genus the sister-group of the Afrotropical
lineage Idomacromia Karsch, 1896 + Nesocordullia MeL Lachlan, 1882 .

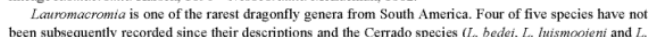

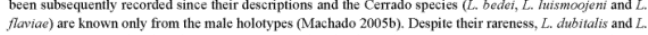

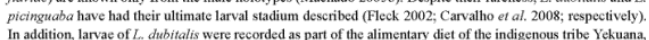
habitants of the region of "Alto Orinoco" in Venezuclan Amazon Forest (Araujo \& Beserra 2007). In the present study we describe a new specics of Latromacromia from Altantic Forrest, provide a key for
males, and perform the first phylogenetic analysis of the genus. We also update its geographic distribution and males, and perform the first phylogenentic analysis of the genns. In
discuss biogeographical and ecological aspects of the genus.

Material and methods

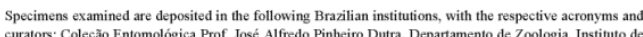

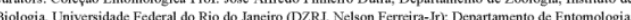
Museu Nacional, Universidade Federal do Rio do Janeiro (MNRJ, Janira Martins Costa) and Serviço de
Invertebrados, Museu de Zoologia, Universidade de Săo Paulo (MZSP, Carlos Lamas and Sonia Casari).

46 - Zootatara 2425 O 2010 Magendia Press PNTO \& CARVALHO

retained by replicate (Hold - 10), swap by tree bisection and reconnection (TBR), ten thousand

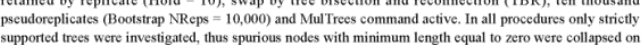
supported trees were investigated, thus spurious nodes with minimum length equal to zero were collapsed on
all trees (Nixon \& Carpenter 1996). WINCLADA version 1.00.08 was used to optimize characters (Nixon 2002), via both accelerated (ACCTRAN) and delay transformations (DELTRAN) (Swofford \& Maddison 2002),

Description

Lauromacromia melanica sp. nov.
Figures $1 ; 5 ; 7 ; 12 ; 13 a-c ; 1 ; ; 17 a-b ; 21 ; 22$

Type specimens: Holotype (1 §), [BRAZII]]. E[spirito] Santo [State]: Conceị̧ăo da Barra, Sitio de José Campista (mata), 1-6.XII. 1969, Elias
$\left.n^{0} 135\right)$ [recently emerged specimen].

Male holotype description (variations present in the paratype in parentheses).
Head. Labium ochreous; body of palpi darkened on distal margins of internal and distal borders (uniformly ochre), covered by dark brown, sparsely distributed setae, those at posterior margins longer and yellowish. Labrum orange-ochre, with dark brown, sparsely distributed setae, which become longer and

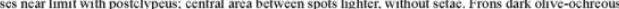
deeply bilobed, with median ocellus completely exposed in anterior view; anterior surface irregular, covered with anteriorly directed long dark hair-like setae, and with numerous setac laterally. Vertex brown, slightly Milobed dorsally; apex of lobes rounded; setae more numerous on anterior region (setac equally distributed). lighter and numerous on posterior border. rear of head black. Posterior mangin of eye with a reduced yellow stripe restricted to ommatidia of ocular lobe (yellow stripe wider, occupying at least eleven rows of ommatidia stripe restricted to o
beyond ocular lobe)

Thorax. Pronotum yellowish, lateral extremities black; posterior lobe cnlarged basally, brown, bearing on with iridescent metallic green and blue and purple reflections, mainly laterally, covered uniformly with leos brown and yellowish setae (most setae yellowish); metepistemal stripe whitish-ycllow, ellipsoid, wider at level of metathoracic spiracle; upper portion of that stripe longer, not reaching dorsal limit of sclerite and inferior portion limited by interpleural suare inclading spiracle (1.9. 1), mesinfraspisternum close to brown: metepimeral pale stripe nawow in lateral views extending from ventral anterior limit of selente to leves of antenior portion of metapostepimeron; posterior region of metepimeron above metapostepimeron with a
pale spot (Fig. 5); metapostepimeron pale (Fig. 1), darker on its external borders. Legs black, coxa and trochanters lighter (legs almost entirely brown, darker on articulations between femurf tibia and tibiat tarsi); coxa, trochanter and femur of first pair with a pale postero-dorsal stripe; claws black to brown towards apex;
tibial keels ochreous, occupving $0.46(0.48)$ of first, $0.50(0.43)$ of second and $0.80(0.83)$ of third pairs; apex of keels acutely projected but not exceeding distal limit of respective tibiac.

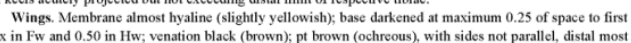
Ax in Fw and 0.50 in Hw; venation black (brown); pt brown (ochreous), with sides not parallel, distal most oblique; membranula enlarged, whititish-ochreous (ochreous), lighter basally. Venation as follows: Ax in $\mathrm{Fw} 11$
(10-12), some not perfectly aligned, in $\mathrm{Hw} 7$; costal row of $\mathrm{Px}$ in $\mathrm{Fw} 6$ (7), in $\mathrm{Hw} 7-8$; subcostal row of Px in Fw 4-5 (4), in Hw 5 (4); bridge crossvein rising on RP2, beyond of subnodus and closer of oblique vein; RP34 undulate in Fw under costal nodus level; Rspl weakly distinct, with one cell row; arculus between Ax1 and Ax2, but closer to $A \times 2$ in four wings; sectors of arculus in HW stalked (not stalked, origin located on basal
0.25 of arculus. Discoidal triangles, supratriangles and subtriangles not crossed in four wings; Hw triangle

48 - Zootaxa 2425 O 2010 Magndia Press $\quad$ PINTO \& CARVALHO 


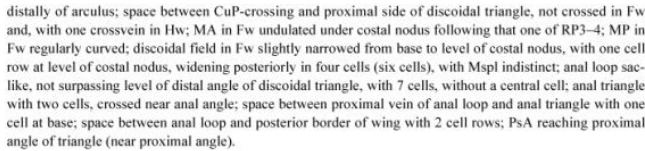

(1)

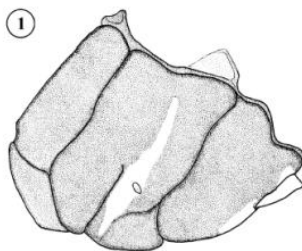

(3)
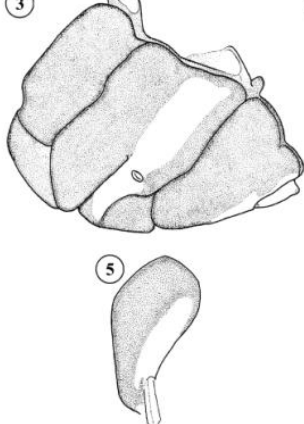

(2)

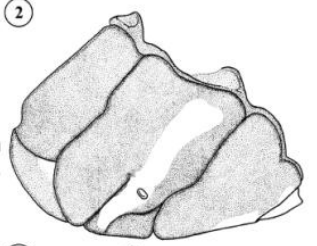

(4)

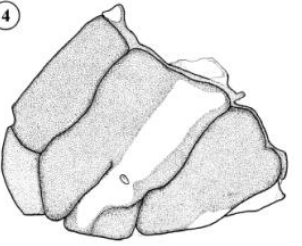

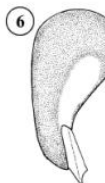

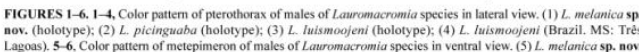

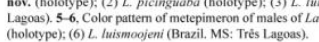

NEW BRAZLIAN LAUROMACROMA

(2)

bordering auricle; 3) a larger and wider subtriangular between auricle and border of genital fossac; 4) rounded on posterior limit of tergite at base of genital lobe; $\mathrm{S} 7$ with a small rounded dorso-lateral spa

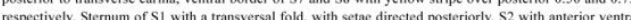
angles poorly projected with atth of rigid short dark setae (pale setae). Auricles ca 0.33 of segment's heig in lateral view, enlarged basally and inflated in upper portion; internal surface with numerous medially directed denticles, partially visible in lateral view. $\mathrm{Sl}-3$ with long yellowish setae concentrated on pale spol.

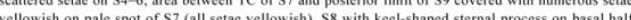

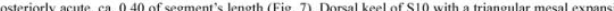
on rectangular base, in lateral view specially projected on middle of segment (Figs. 12: 13c). Cerci (Figs. 13a c; 14) conical, horn-shaped, slightly longer than segments $9+10$ in lateral view, covered with elongal

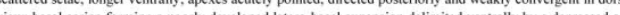

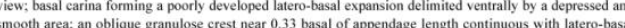
expansion, positioned ventrally, resembling a tubercle in lateral view. Epiproct inflated, with numerous sets. ventrally; apex obtuse curved upwards; lateral borders flattened close to base; length ca 0.66 of cercus

(13)
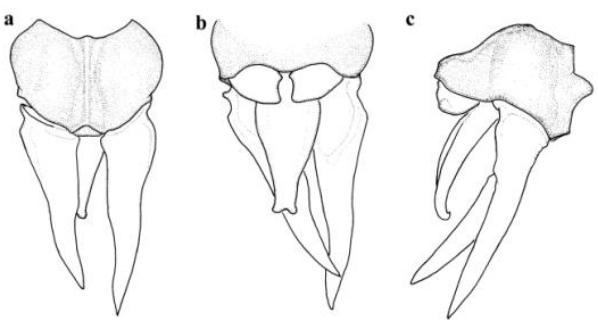

FIGURE 13. Male caudal app
ventral view; (c) lateral view.

Genital fosea Anterior lomina furrowed longitudinally, with inflated lateral portions bearing scatter setae. A weakly distinct simple laminar projection with inflated portions projected intero-posteriorly. posterior hamules globose, with intermal and external lobes poorly defined; apically with ventral keel raise a forming a mipple-tike apex, apexes of pair converging in ventral view; internar and apex surfaces with length of posterior field of $\mathrm{S} 2$ in lateral view; pex rounded, nipple-like, converving ventrally, dist thendes (a) clerite (p-ps): dorso-distal portion of $\mathrm{V} 3$ with a pair of strong proximal horms (ph); $\mathrm{V} 4$ with a strong distoventral sclerotized plate followed by ventral membranes and two distal long flagella (d-fl); sclerotized plate

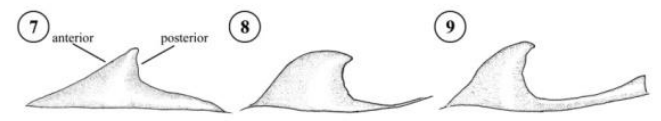

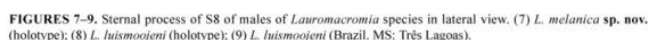
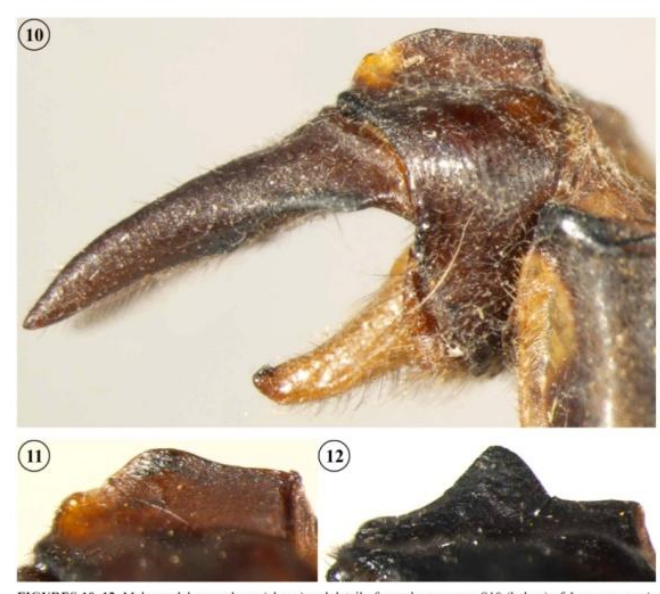

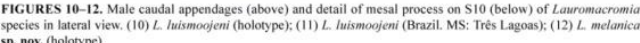

Abdomen. Cylindrical; S7-10 expanded Ground color black, lighter on S1 and basal half of S2; ventral border of S1-8 with a discontinuous pale yellowish stripe, on S3 wider basally; on S7-8 very narrowed at transversal small spot at postero-lateral border, $\mathbf{S 2}$ with four pairs of following spots, II the most $\mathbf{S 1}$ with a second half, not reaching superior limit of auricle; 2) a lateral just above auricle, elongated downwards,

50 - Zootura 2425 C 2010 Magenolia Press

PNTO \& CARYALO

projected distally into approximate parallel blades with membranes and flagella inserted at their tips, ventrally the sclerite is connected forming a ring-like process around inflatable membranes and laterally into two

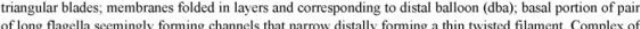
tructures of $\mathrm{V} 4$ probably movable dorsally, with membrone unfolded into a distinct balloon when complectely structures of $V 4$ probably movable dersally, 1 ,
inflated, as observed in $L$ husmoojent (Fig. 16)
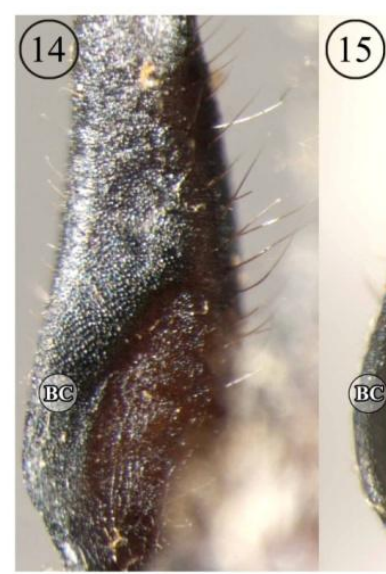

FIGURES 14-15. Detail of leff cercus of males of Laurromacromia species in vetural view. (14) $L$ melanica sp. nov.

Measurements (holotype / paratype; in mm). Total length (incl. caudal appendages) $51.9 / 50.2$,

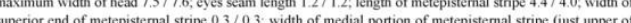
spiracle) $0.6 / 0.6$; width of inferior end of metepisternal stripe $0.1 / 0.3$; length of $\mathrm{left} \mathrm{Fw} 33.2 / 32.7$.

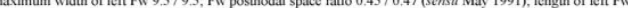
pt 2.5/2.5; length of left Hw 32.2/30.3, maximum widh of left $\mathrm{Hw}$ 10.7/ 10.2; length of left Hw pt 24/2.2. $346 / 338$. 38/35, length of epiproct $24 / 2$ Female and larva unknown.

52. Zootuxa 2425 O2010 Magnolia Press 
(16)

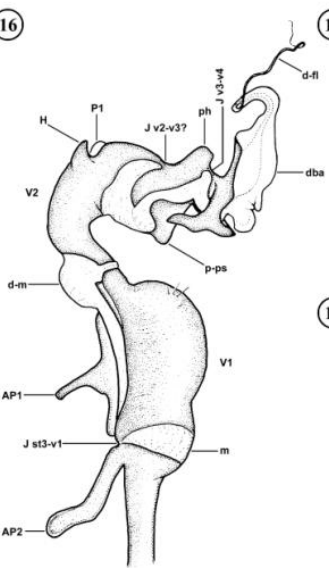

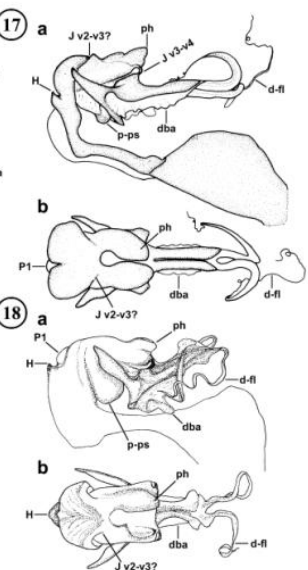

FIGURES 16-18. Vesica spermalis of Lauromacromia species; (16) L. luismoojenh (Brazil. MS: Tres Lapoas), partially

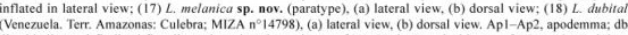

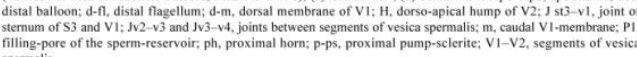

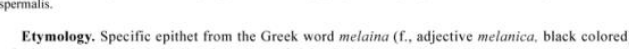
referring to almost entirely black color pattern of abdominal segments $\mathrm{S} 4-10$. The name was written on on

Remarks. Holotype with abdomen broken between S5-6, posterior fragment (S6-10) separated into glassine envelope, right cercus partially detached; detached portions of right Fw discoidal field broken, and in
separate glassine envelope. Paratype with some parts of exoskeleton crushed, and sternum of $\mathrm{S}$ removed vesica spermalis spearated.

The types of $L$, melanica were within a cellophane envelope containing a card printed with same card was pasted the following handwritten field collection data: "Conceiça da Barra, E. Santo, Sitio de Jos

We examined an adult male of $L$. huismoojeni (in MZSP) from Trés Lagoas municipality, Mato Grosso do Sul State, Brazil which we compared with the holotype of $L$. huismoojeni and both agree in all aspects excep for ils smaller size (e.g. length of Fw $3.0 \mathrm{ss} .3 .1 \mathrm{~mm}$ in Machado (2002), confirms it as unique for this species. We identified two larvac as probable $L$ d dubithlis from Brazil, one F-1 stadium from Manaus municipality, Amazonas State, and an early stadium from Barcaren municipality, Para State (both in DZRJ). The F-1 larva agrees in all aspects with the possible larva described and assigned to L. dubitalis by Fleck (2002), whose identity was later confirmed by emergence of both sex

\section{Identification key for males of Lauromacromia}

This key is based on males, but in some cases should allow identification of females according to color pattern. Due to fewness of specimens coupled with possible underestimation of intraspecific variation and
probable discovery of new species, this key should be used with caution.

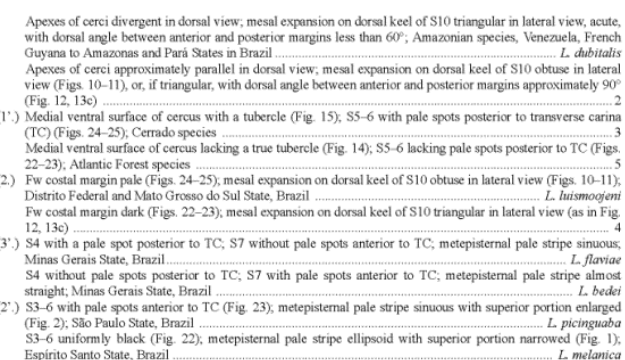

Cladistic analysis

Characters List. Forty-three extemal morphological characters of adult males were selected for the analysis
of which 17 were informative when all characters states were unordered and 19 when characters up to three states whe ordered. The character fir metrics, i.e. number of steps, consistency and retention indexes, a provided only based on the tree generated with all characters unordered (Fitch optimization) and full coding

1. Number of crossveins in the space between oblique vein and origin of IR2. Steps $=1, \mathrm{ci}=1, \mathrm{r}=1$. (0) two
bridge crossveins located before the RP1-2 fork; (1) one bridge crossvein under RP1-2 fork or at RP2. bridge crossveins located before the RP1-2 fork; (1) one bridge crossvein under RP1- 2 fork or at RP2.
2. Level of maximum extension of the anal loop. Steps $=1, \mathrm{ci}=1, \mathrm{r}=-$, (0) reaching the distal level of . Level of maximume extension of the anal loop. Steps $=1, \mathrm{c}=1, \mathrm{i}=,(0)$ reaching the distal level of
triangle, with undefined Cuspl (without midrib); (1) reaching approximately the level of RP-midfork, with triangle, with undefined Cuspl
defined Cuspl (midrib present)

NEW BRAZILAN LULTOMACROMU
Campista (Mata) Elias col. 1 a 6.XII.1969". Two other notations handwritten by Dr. Newton Dias dos Santos, according to Dr Janira M. Costa (pers. comm.), state "Neocordulia Lizmooieni i, penis extraido". After our description was completed, we studied the vesica spermalis of the paratype specimen in the MNRJ. Unlike

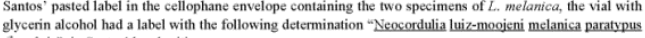

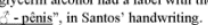

Taxonomic discussion

The VS must be used for aceurate specific identification for some New World libelluloid genera (e.g. Erythrodiplax Brauer, 1868). However, the structures of VS probably provides few reliable characters to distinguish among species of Lauromacroma, as also scems be frue for hic acshind gcnera Gynacantha in evolutionary understanding of VS of Anisopteres, there has been no comprechensive work on "Cordulididae" nd therefore the primary homology (sensu De Pinna 1991) among genera are not fully understood. Conflicting interpretations of homology coupled with different terminologies (Miller 1991 and Pfau 2005) have also significantly hampered comparative studies.

. Costa, 1995, one wovides valuable taxonomic information for Neocontulutia, diffor morphological types. Although this organ (cf. May 1991). Concerning to Lauromacromia, Machado (2002, 2005b) did not describe the VS for species to described. We observed title difference in morphology of the VS in $L$, melanica, L. dubitalis and $L$. huismoogeni (Figs. 16-18). Based on label data (see under remarks), Santos examined the VS of the paratype Ied him to consider the specimens we describe as new as conspecific with his $L$. luismoogeni. We could not find the VS of the holotype of $L$. luismoojeni and believe it lost precluding any further study. A detailed comparative study of the VS of all species of the genus specially based in fresh specimens may determine Lauromacromia comprises three well-defined species groups based on the caudal appendages: (1)
(1)

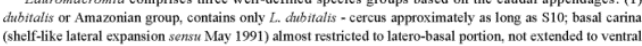
surface; apex of cerci divergent in dorsal view; (2) hismoojeni or Cerrado group (Machado 2002, 2005a),

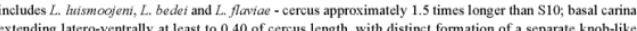
process (tubercle) on the ventral suffece; apex of cersus bluntly pointed; (3) picinguaba or Altantic Forest group, includes $L$. melanica and $L$, picinguaba - cercus approximately 2 times or longer than S1O; basal carina extending latero-ventrally but restricted to 0.33 basal of cercus, with a oblique granul ose crest connected with

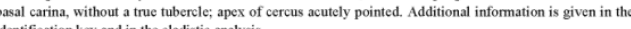

Lauromacromia melantica can only be confused with $L$. picinguaba, however they are easily distinguished by color pattern of thorax and abdomen. The pale spots anterior of TC in $L$. picinguaba are present on S3-6
and posterior to TC in S7 (Fig. 23), while in $L$. melanica only posterior to TC on S7, these being small and rounded (Fig. 22); the metepisternal pale stripe is smaller in L. melanica and not enlarged on its superior portion (Fig. I), as in $L$ picinguaba (Figs. $2 ; 22$ ). The shape of the mesal expansion on donsal keel of $S 10$ is obscuring this structure (cf. Carvalho et al. 2004: Fig. 6). Postmortem distortion also occurred in the stemite of S8, rendering the sternal process not completely visible. Howcver, Carvalho et al. (2004: 5) observed in the melanica (Fig. 7).

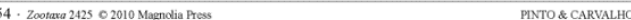

3. Color of costal margin of the wing (CA\&CP\&SCA). Steps $=2, \mathrm{ci}=0.50$, $\mathrm{ri}=0$. (0) brown to black (Figs, 22-23); (1) yellowish (Figs. 24-25).
Number of cell rows on Fw discoidal field. Steps $=1, \mathrm{ci}=1, \mathrm{r}=-$. , (0) one near to costal nodus level; (1) 4. Number of cell rows on Fw discoidal field. Steps $=1, \mathrm{ci}=1, \mathrm{r}=-,(0)$ one near to costal nodus level; (1)
two near to costal nodus level.
5. Shape of the distal portion of Fw discoidal field. Steps $=1, \mathrm{ci}=1, \mathrm{ri}=-(0)$ widened $(\mathrm{MA}$ and MP

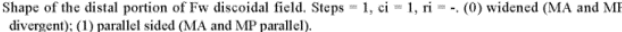

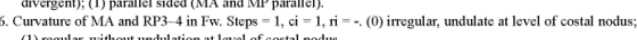
7) regular, without undulation at level of costal nodus.
7. Color pattern of dorsal surface of antealar sinus. Steps $=1, \mathrm{ci}=1, \mathrm{r}=1$. (0) brown to black in major area (Figs. 1-2); (1) completely yellowish (Figs. 3-4). 8. Color pattern of mesepisternum. Steps $=1, \mathrm{ci}=1, \mathrm{ri}=-.,(0)$ uniformly colored (Figs. 1-4; 22-25); (1)

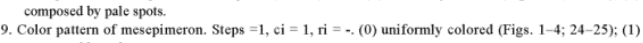
composed by pale spots.
10. Color pattem of metepisternum. Steps $=1, \mathrm{ci}=1, \mathrm{r}=1$. (0) uniformly colored; (1) with two discontinuous pale spots; (2) with a continuous pale stripe (Figs. $1-4 ;$; 22-25).
11. Inclusion of spiracle by the pale arca (stripe) of metepistermum. Steps -3 , ci -0.67 , ri -0.50 . (0) none; (1) partial; (2) complete (Figs. 1-4; 22-25)

12. Shape of dorsal portion of the metepisternal pale spot in comparison with midhcight length. Steps $=3$, $\mathrm{ci}=$

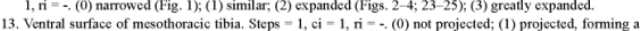

14. Ventral margins of S1. Steps $=1, \mathrm{ci}=1, \mathrm{ri}=-$. (0) projected into a denticulate process; (1) rounded, not
(S.) projected

Posterior margin of anterior lamina. Steps $=2, \mathrm{ci}=1, \mathrm{ri}=\boldsymbol{-}$, (0) weakly expanded; (1) expanded, forming one lamina (laminar projection sensu von Ellenrieder \& Garrison 2005); (2) expanded but lacking a distinct laminar-projection.
16. Ventral surface of $\mathrm{S2}$. Steps $=1, \mathrm{ci}=1, \mathrm{ri}=-$, (0) almost straight, not expanded in a genital lobe; (1)

Steps $=1, \mathrm{ci}=1, \mathrm{ri}=-,(0)$ subquadrangular, (1) subtriangular (Figs. 22-25).

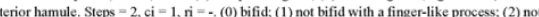
bifid with a nipple-like process.
. Height of genital lobe relative to postcrior hamule. Steps $=1, \mathrm{ci}=1, \mathrm{r}=. .,(0)$ higher; (1) approximately subequal.

20. Internal surface of auricles. Steps $=1, \mathrm{ci}=1, \mathrm{r}=\cdot$, , (0) smooth, without denticles; (1) with numerous

21. Color pattern of dorso-lateral area anterior to TC on S3 - . Steps $=2, \mathrm{ci}=0.50, \mathrm{r}=0.0$. (0) uniform, without a pale spot (Fig. 22); (1) with a pale spot (Figs. 23-25,

22. Color pattem of area anterior to TC on $\mathrm{S} 5-6$. Steps $-3, \mathrm{ci}=0.33, \mathrm{r}=0$. (0) uniform, without pale spots (Fiigs. 22); (1) with a pale spot (Figs. 232-25).

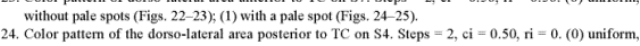
without pale spots (Figs. 22-25); (1) with a pale spot.

. Color pattem of the (orso-lateral area postcrior to TC on S5-6. Steps $=2$, ci $=0.50$, ri $=0.67$. (0) uniform, carina on S7. Steps $=1$, ci $=1, r i=-,(0)$ uniform, without pale spots; (1) with a pale spot (Figs. 22-25).
27. Color pattem of the dorso-lateral area on S8. Steps $=3, \mathrm{ci}=0.33, \mathrm{ri}=0.33$. (0) uniform, without a pale spot (Figs. 22); (1) with a pale spot (Figs. 23-25).

56. Zootara 2425 O 2010 Magndia Press 
28. Size of dorso-lateral pale spot on S8. Steps $=3$, ci $=1$, ri $=-$. (0) small, reduced a minute rounded anterior
spot; (1) small, reduced an elongated anterior spot (Figs. 23). (2) large, occupying at least 0.25 of the 29. Surface of sternum of $\mathbf{S 8}$. Steps $=1$, ci $=1, \mathrm{ri}=$. ( () projected, with basal process (Figs. 7-9; 22; 24-25); (1) smooth, without proceses

process of S8. Steps $=1, \mathrm{ci}=1, \mathrm{r}=\cdots,(0)$ apex two-pointed, biconical; $(1)$ 31. Shape of the sternal process of $S 8$, in lateral view. Steps $=1, \mathrm{ci}=1, \mathrm{r}=1$. (0) curved posteriorly, with

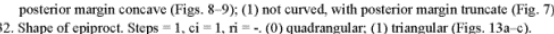

32. Shape of epiproct. Steps $=1, \mathrm{c} i=1, \mathrm{r}=-,(0)$ quadrangular; (1) triangular (Figs. 13a-c). restricted to extreme basal area; (1) elongate only laterally; (2) elongate latero-ventrally (Figs. 13a-c; 14 15 ).

34. Level of posterior reaching of ventral elongation of basal carina of cercus. Steps $=1, \mathrm{ci}=1, \mathrm{ri}=1$. (0) less than 0.33 of cercus total length, without $a$,

35. Internal surface of cercus. Steps $-1, \mathrm{ci}-1, \mathrm{ri}-\cdots$, (0) without a process (Figs, 13b-c; 14-15); (1) with

broad process (medial tooth sensu May 1991 )

36. Ventral-subbasal surface of cercus. Steps $=1, \mathrm{ci}=1, \mathrm{ri}=-$. (0) without a tooth-like process (Figs. 13b14-15); (1) with a ventrobasal tooth (sensu May 199.

38. Shape of cercus apex in dorsal view. Steps $=2 \mathrm{ci}=1, \mathrm{ri}=1$, (0) blunt; (1) (1) (Figs. 13a-c). acuminatc, acutely pointed (Figs. 13a-c).

39. Apexes of cerci. Steps $=2, \mathrm{ci}=1, \mathrm{r}=1$. (0) convergent; (1) divergent; (2) approximately parallel. Cercus length versus $S 10$ maximum length in lateral view (cercus $S 10$ length ratio). Steps $=2, \mathrm{ci}=1, \mathrm{r}=$

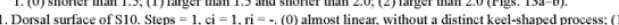
irregular, with a distinct keel-shaped process.
Shape of $\mathrm{mesal}$ expansion on dorsal keel of $\mathrm{S} 10$ in lateral vicw. Steps $=3, \mathrm{ci}=1, \mathrm{n}=-,(0)$ approximately

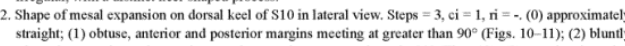
straight; (1) obtuse, anterior and posterior margins mecting at grater
triangular, anterior and posterior margins meeting at approximately $90^{\circ}($ Figs. 12) (3) acutely triangul anterior and posterior margins mecting at less than $60^{\circ}$.
3. Disposition of setae on cercus apex. Steps $=1$, ic $=1$, ri $=-,(0)$ regularly distributed; (1) concentrated to

form a tuft of prominent, long setac.

Results and discussion. The parsimony analysis with all characters states unordered (first analysis generated only one MPT, with 66 steps of length, $\mathrm{CI}=0.69$ and $\mathrm{RI}=0.62$ (Fig. 19). The 19). The hypothesis on monophyly of Lauromacromia is supported by eleven character states, however the branch showed low values of $b$ (1) and $b s$ ( $(50)$ (Fig. 19, node A). This unexpected low branch stability migh partially be explained by the effect of non-applicables states codificed for one or both of outgroups (Appendis

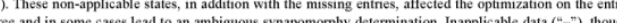
distinct from missing data ("?"), are computationally treated as the same and introduce severe difficultis under parsimony criterion resulting in a decrease of resolution of the MPT or loss of significance to $b s$ (c.

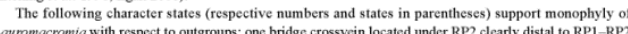
fork (ch. 1, state 1): metepisternal pale stripe partially enclosing spiracle (chill, state 1) but with a 列

all "Corduliidae" species. The most remarkable character state is the presence of a tubercle on the middle of cercus which difers from the other spectes within the genus. We consider his character as non-comparable

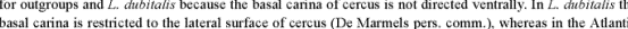
and Cerrado groups it is directed ventrally and surounds a distinct concave area. The tubercle of the Cerrato species apparently is an isolated posterior part of the ventral extension of basal carina, since the surface of both show characteristic micro-punctures (Fig. 15). Besides, the Atlantic group shows a process-lit projection connected with the carina that looks tike a tubercle in lateral view (Figs. 13c; 14). The sister-grou

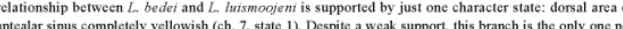
collapsed in the Bootstrap majority rule consensus with 60 of $b s$.

The analysis with the characters of up to three states ordered (second analysis) generated only one MPT with 68 slcps of lenght, $\mathrm{Cl}=0.70$. ACCTRAN and DELTRAN are presented in Figs. 20a-b. In this hypothesis the monophyly of
Lauromacromia is supported by twelve characters under ACCTRAN and eleven under DELTRAN (Figs. 20a-b, nodo A), similar to those of the first analysis, however with highervalues of branch stabilitit $(b=6$ and $b s=86)$. These values approximate the expected for a branch with several character state transformations.
This can have occurred due to the increasing the number of informative characters and corresponding This can have occurred due to the increasing the number of informative characters and corresponding
reduction of the influence of missing entrics on the analysis. The basal polytorny observed in the unordered

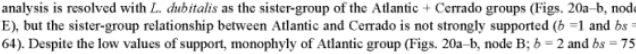
64). Despite the low values of support, monophyly of Atlantic group (Figs. 20a-b, node $\mathrm{B} ; b=2$ and $b s=75$
and Cerrado group (Figs. $20 \mathrm{a}-\mathrm{b}$, node $\mathrm{C} ; b=2$ and $b s=62$ ) endorses the hypothesis obtained with all characters unordered. The same was presented in relation to the monophyly of $L$, bedei $+L$. huismoojent, which was also supported by low values (Figs. $20 \mathrm{a}-\mathrm{b}$, node $\mathrm{D} ; \mathrm{b}=3$ and $b=79$ ). Though the linear transformation applied to characters in the second analysis (ordered) is feasible, the result should be
considered an alternative hypothesis to the one obtained from unordered analysis, and likely more robus considered an alternative hypothesis to the one
results will await discovery of females and larvac.

The phylogenetic relationships of $L$ auromacinia to other genera of Gomphomacrominae are not clest Adults share morphological features mainly with Gomphomacromia and Neocordulia in the New World, but the larva does not resemble either of these two genera (cf. Fleck 2002; Fleck \& Legrand 2006; Carvalho et $\mathrm{c}$ 203a. of $L$ dite not have a true phylogenetic signal, since these genera probably are not closely related. Based mainly larval morphology, Fleck \& Legrand (2006) proposed Lautromacromia as a sister-group of Idomacromia Nesocorddilia. These authors rejected the hypothesis of a sister-group relationship between Lauromacromia life-styles. They also suggested a close relationship between Neocondulia and the European Oxygastra Sclys
1870 . However the Fleck-Legrand hypothesis was not generated using an explicit congruence test of characters and caution should be used in interpreting their result. The character polarization was determined mori hypothesis of relationship. This aspect was extensively discussed under the context of primary and secondary
homology by De Pinna (1991: 372). Despite the use of methodological constraints the Fleck-Legran hypothesis yiclds important insights and partially agrees with the classification presented by Fraser (1957)
who considered Laurom acromi

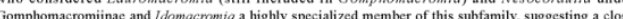
relationship among these genera. A recent molecular phylogenetic study with an extensive sample Libelluloidea (Ware et at. 2007) revealed Gomphomacrominae as paraphyletic with respect to "Corduliidace sensu stricto, but unfortunately no species of Lauromacromia, Now
were included, therefore their placements waiting to be asesesed hitsmoojent; posterior mangin of anterior lamina weakly expanded (ch. 15, state 1); genital lobe subtriangular
(ch. 17, 1); posterior hanule not bifid and with a nipple-like process (ch. 18, state 2); apex of the stemal

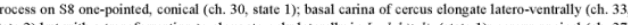

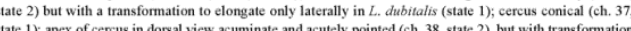

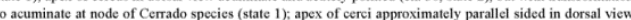
(ch. 39, state 2), but with transformation to divergent in $L$. dubitalis (state 1); mesal process on keel of S10 triangular with anterior and posterior margins forming an angle of approximately $90^{\circ}$ in lateral view (ch. 42 We We consider charactess states $1.1,17.1,18.2,30.1$ and 33.2 most relevant in our analy ses and probably character states, though optimized on the tree as unique for the genus, have been considered as shared with other Neotropical "Corduliidae" or previously overtooked. The presence of just one bridge crossvein ( $L$. Iutsmoogent holotype has two bridge crossveins in left Fw) distally to RP1-RP2 division (ch. 1, state 1) is

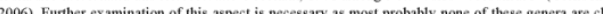
related to Lauromacromia but are probably "Cordulidae" sensus stricto (Fraser 1957; Warc et al. 2007). The triangular shape of genital lobe (ch. 17, state 1) in Paracordulia Martin, 1907 is superficially the same as in Lauromacromia but in Paracorduliti it is thin, strongly directed posteriorly and covered with scattered setac (Garrison et al. 2006); in Lauromacromia it is robust with lateral surface distinctly convex, weakly directed
posteriorly, and their internal surfaces are covered with rows of strong setas. The posterior hamule in but its presence in Old World genera is unknown. We consider the shape of the apex of stermal process of S8 (ch. 30, state 1) unique to Latromacromita, although Garrison ef al. (2006) assumed it to be shared with the subgenus Neccondulia. The apex of $\$ 8$ process in Latromacromia is one-pointed (conical), while in subgenus
Neocorduliti it is two-pointed (biconical), as indicated by May (1991). Machado (2005) stated that $N$.

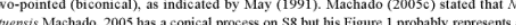
condition distinct from that found in Lauromacromia. The distinet basal carina of Lauromacromia forms a lateral basal expansion which encloses a concave central area and seems to be a unique feature of this genus (ch. 33, state 2). The basal carina has been destribed for att the species of Lauromacromia under different names, i.e. lateral keel-like expansion (Fraser 1939; Gejijkes 1970), external lateral margin thick (Santos
1967), shelf-like lateral expansion (May 1991), lateral carina (Machado 2002, 2005b) and latero-basal expansion (Carvalho et al. 2004). The surface of basal carina is micro-punctuate and differs from the

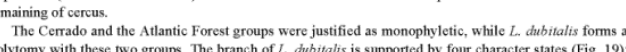
polytomy with these two groups. The branch of $L$, chubitalis is supported by four character states (Fig. 19):

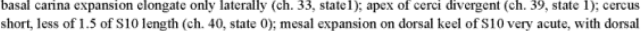

angle between anterior and posterior mangins less than $60^{\circ}$ (ch. 42 , state 3$)$.
The Allantic forest group $(L$. melataica $+L$. picinguaba) monophyly showed no significant values of $b$ and bs (Fig. 19, node B) and is supported by three character states of which only one (cercus more than 2 times of
$\mathrm{S10}$, ch. 40 , state 2 ) is unambiguously optimized. The character state dorso-lateral pale spot sall and S10, ch. 40 , state 2 ) is unambiguously optimized. Whe character state dorso-lateral pale spot small and
clongated on anterior of $\mathrm{S} 8$ (ch. 28 , state 1 ) is present only in $L$. picinguaba resulting in different optimizations under ACCTRAN and DELTRAN. Only the latter criterion (DELTRAN) should be accepted as a possible transformation since the dorso-lateral spot on $\mathrm{S} 8$ is absent in $L$. melanica.

The monophyly of Cerrado species group (L. bedei $+L$. flaviae $+L$. huismoojeni is supported by threc character states: sternal process of 58 strongly curved with the posterior margin concave (ch. 31 , state 0$)$, (ch. 34, state 1), cercus apex acuminate but not sharply acute (ch. 38, state 1) (Fig. 19, node C). The two first
character states provide the strongest evidence of monophyly for this group, and possibly are unique among

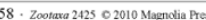

PINTO \& CARYALHO

(19)

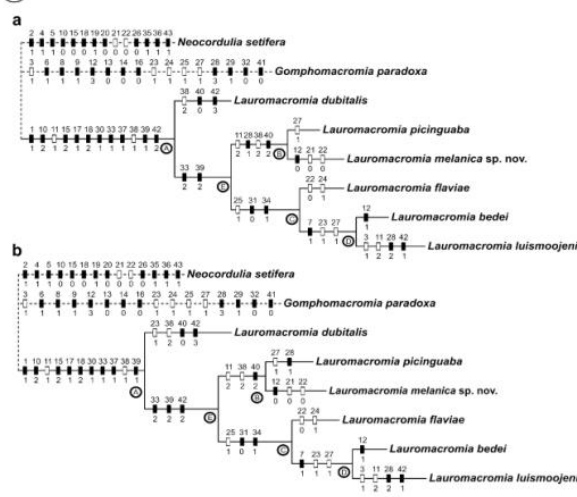

FIGURES 19-20. Most-parsimonious cladograms depicting phylogenetic relationship between Lauromacromia species.
(19) cladogram obtained from characters unordered and with equal weight $(66$ steps., $\mathrm{Cl}=0.69$ and $\mathrm{RI}=0.62)$. (20)

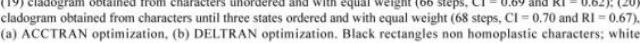
rectangles, characters with homoplastic transformation; partially black rectangle, unique character stare with different

60 - Zootaxa 2425 O 2010 Magnolia Press 


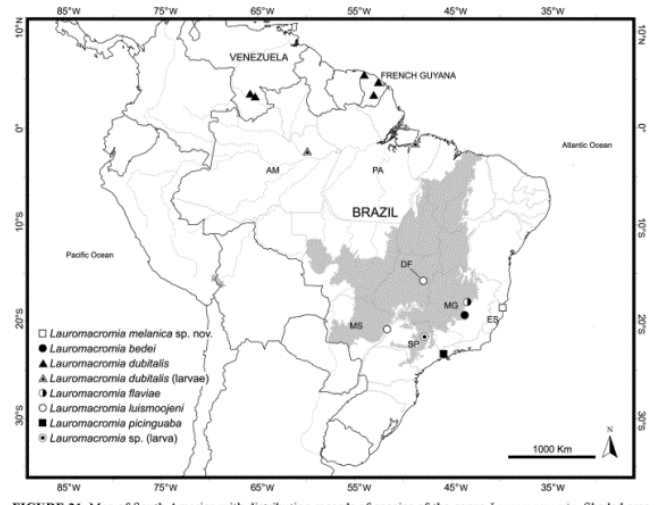

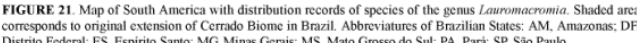

\section{Biogeography}

Comments on the Neotropical dragonnly biota. The Neotropical Odonata fauna is one the most diverse of the World with more than 1600 species (Garrison et al. 2006; Kalkman et al. 2008). However, this number
should be revised since current checklists present all South America as a unique biotic unity overlooking the composite nature of this continent. Temperate southem South America and the Andean mountain chain fron northem of Argentina to Colombia and Venezuela should not be considered as part of the Neotropical region
since they Amorim \& Tozoni 1994: Amorim \& Pires 1996; Morrone \& Urtubey 1997: Humpries \& Parenti 1999. Katinas et al. 1999; Morrone 2001, 2002, 2004a-b, 2006). Morrone (2006) proposed that South America should be composed of three major biogeographical units (arcas of endemism): Neotropical region, Sout American transition zone and Andean region. Remarkably the dragonfly fauna occurring in the Andean regio related with those of the tropical portion of South America such as (Allopetalia Selys, 1873 and most of Rhionaeschna Fôrster, 1909), Austropetaliidac (Hypopetalia MeLachlan, 1870 and Phyllopetalia Selys, 1858), Gomphidae (Neogomphus Selys, 1858), Libellulidac (some species of Sympetrum Newman, 1833). Petaluridac (Phenes Rambur, 1842) and Neopetalididae (Neopetal

NEW BRAZILIAN LAUROMACROVU

Vontrax 2425 o 2010 Magnolia Press - 61

p.62) wams against an unrestricted adoption of a DD category: "It is important to recognize that taxa that ar poorly known can often be assigned a threat catcgory on the basis of background information conceming the deterioration of their habiat and or other causal factors, thereffore the liberal use of Data Deficicnt is species (Cerrado and Atlantic groups) could be included under some level of threat, according to the fou known records and in respect the rapid deforestation in their areas of occurrence. Excluding $L$ dubitialis, the species are distributed in two of the five richest and most threatened areas of South America (hotspots, Myer et al. 2000). The Cerrado biome corresponds to $22 \%$ of total arca of Brazil and have undergone acceleral artificial pastures (Klink \& Machado 2005) The two records of $L$. huismoogenti are date from $1960^{\circ}$ 's and the of $L$. flaviae from 1970 's, onlv $L$. bedei was collected in the current decade. Priority areas for Cerrad conservation on the basis of several biological-social criteria were recently suggested, and included the occurrence areas of Lauromacromia Cerrado group (cf. Cavalcanti \& Joly 2002). In addition, the Atlant their original area (Morrellato \& Haddad 2000)
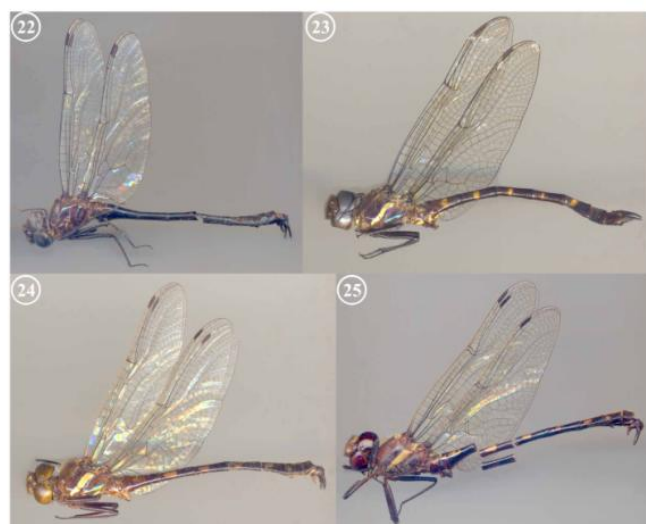

(25)

FIGURES 22-25. Adult males of Lauromacromia species in lateral vicw. (22) $L$ melanica sp. nov. (holoty pe); (23) $L$ Considering the progressive deterioration of their habitat and limited amount of individuals in collections extensive collecting expeditions to determine the range of distribution of Lauromacromia species and their
ccological requircments must be undertaken. These actions should be made as prionity efforts for enabling the NEW BRAZILIN LUCROMACROML
Coenagrionidae (Andinagrion Bulla, 1973, Mesamphiagrion Kennedy, 1920 and Oreiallagma von Ellenrieder
\& Garrison, 2008) (Muzón 1997; De Marmels 2000, 2001; von Ellenrieder 2003; Garrison et aL. 2006; Grehan 2006; von Elicnnieder \& Muzon 2006, von Ellennicder \& Ganison 2008). Athough the region IT a d on biotic elements (vidence of genealogical hierarch hy), thecir delimitation is not static and must represent as

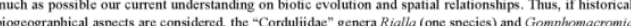
(four species) should be excluded from the Neotropical dragonfly fauna, since they present coincident distributions with the Andean region or at maximum with the South America transition zone. Therefore among the forty species listed by Carvalho et al. (2008) and with recent descriptions of the new species the "Corlulindac", Neotropical Lauromacromia biogegraphy. Based on the 14 known adult specimens of Lauromacromia and the
reported occurrence of few larvae of $L$. dubititalis (Fleck 2002; Araujo \& Beserra 2007 ) and of one unidentified species from São Paulo State in Brazil (Ferreira-Peruquetti \& Fonseca-Gessner 2003), the genus are Unfortunately the scancity of diestibuto Neorropics: Anlantic Forst, Cerrado and Amazon Forest (Fig. 21).

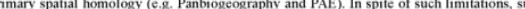
hypotheses of relationship of Lauromacromia species on the map of their distribution allow comparisons with existing hypotheses of interrelationships among the Nectropical subregions. Morrone (2006) partititioncd the Nectropical region into four subregions: Amazonian, Caribbean, Chacoan and Paraná, which are subdivided to Varzea and Pará provinces; $L_{-}$melanica and $L$. picingunabe are restricted to Brazilian Attantic Forest province in Parana subregion and $L$, bedect, $L$. luismoojeni and $L$. flavize are recorded from Cerrado province
in Chacoan subregion. Nihei \& Carvalho (2007), using Brooks Parsimony Analysis performed with $P$ Plietina in Chacoan subregion. Nihei \& Carvalho (2007), using Brooks Parsimony Analysis performed with Polietina
Schnabl \& Dziedzicki (Diptera: Muscidae), hypothesized that the Chacoan subregion is closely related to Schnabl \& Dziedzicki (Diptera: Muscidae), hypothesized that the Chacoan subregion is closety related to
Parana subregion, and that the Amazonian subregion comprises a paraphyletic area, basal to the two formers. This pattern is congruent with our cladogram, and the possible cladogenetic events identified for Lauromacromia notably correspond to the major South America vicariant events as proposed by Amorim \&
Pires (1996) and revised and updated by Nihei \& Carvallo (2004). The spparation of the continent between a orthwestern and a Southwestern portions, along Amazonas, Madeira and Mamoré rivers in the Late Cretaceous, could have occasioned the first cladogenetic event with isolation of $L$. cibititalis lineage; the

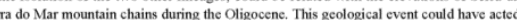
is an efficient geographic barrier resulting in a split in Lauromacromia components from the Cerrado and Atlantic groups, as hypothesized for freshwater fishes (Ingenito \& Buckup 2007).

Nevertheless, the scenario proposed above to Lauromacromia is somewhat speculative, and requires further studics applying methods of Historical Biogegoraphy for finding a general pattem to corroborate it.
Further, the identity of the sister-group of the genus should help provide a feasible hypothesis on spatial cvolution and infering their causal processes.

Ecology and conservation

Lauromacromia could be classified as forest-dependent dragonflies, breeding at sites near or within of forcsts. Although the Cerrado is composed mainly by savanna-like vegetation nor by forest in its strict sense (of.

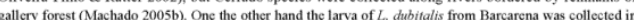

an open area (cf. Pinto \& Carvalho 2009).
Machado (2005b) discussed Lauromacromia conservation and proposed including Cerrado group in IUCN category Data Deficient (DD) based on limited information. Species in this category are not targeted
for conservation action although their needs might be very great (IUCN 2008 p.7). However, IUCN (2008

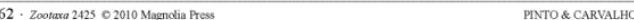

evaluation with some degree of precision of the status of these species. Therefore, just increasing the available Information on their biology and assessing their threat category will promote the preservation of their habitats

Lauromacromia cf. dubititalis. (2 larvac). BRAZIL. Amazonas State: Manaus, PDBFF ZF3, Km 21, F[azenda]

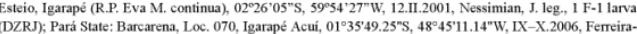
Jr, N \& Nessimian, J. leg., 1 carly stadium larva (DZRJ).

Lauromacromia lusismoojent. (2 3). BRAZIL. Distrito Federal: Brasilia, Rio [São] Bartolomeu 6.XI. 1963, Santos, N.D;; Machado, J.P.; Borges, C. \& Moojen, L. leg, holotype đ' 'MNRI no 775); Mato Grosso do Sul State: Très Lagoas [boundary with Castilho municipality in São Paulo Statec], X.1964[?], 1 ?
(MZSP).

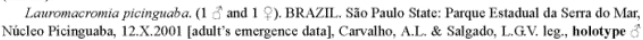
e 9 (DZRJ).

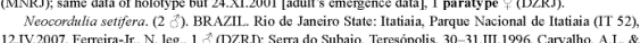

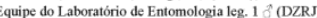

Acknowledgements

We are in debt with all curators of the collections studied. We especially thank: Dr. Angelo B. M. Machado (UFMG, Brazil) for reprints, valuable information about the specimens deposited in his collection and critical revision of the manuscript, Dr. Jurg De Marmels (MIZA, Venezucta) for reprints, information and onginal copiene (MNRJ, Brazil) for information on collecting labels and for kindly permitting the study of material deposited in MNRJ; Dr. Hans K. Pfau (Aarbergen, Germany) for corrections on vesica spermalis terminology; Dr.

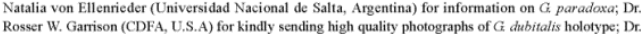

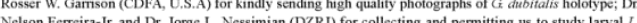
Aubbitalis : Paula Parise Pinto for facilities in São Paulo city during our visit to MZSP. Thanks are due Dr. Jessica L. Ware and another anonymous reviewer for the useful suggestions in the final version of the manuscript. This study was partially financed by Brazilian government agencies: Coordenação do Cherfeiçoamento de Pessoal de Nivel Superior (CAPES, fellowship to first author) and Fundaąăo Carlos 2004 and E-26171.281/2006).

References

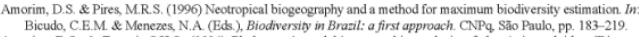

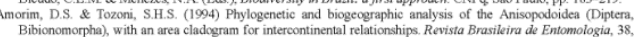

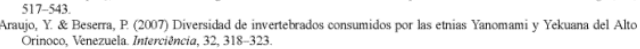

64- Zootaxa 2425 O 2010 Magndia Press $\quad$ PINTO \& CARVALHO 


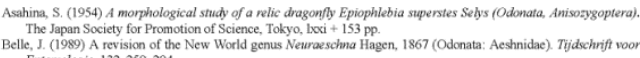
Entomologie, 132, $259-294$
Bremer, K. (1994) Branch support and tree stability Cladistics, 10, 295-304

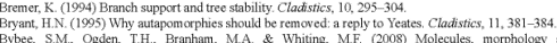

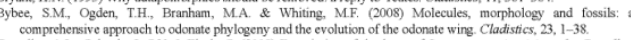

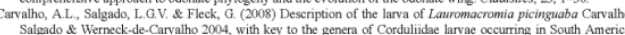

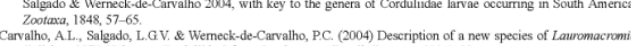
do region. In : Oliverira, P.S.

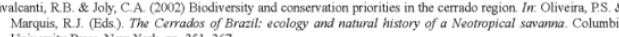
University Press, New York, pp. 351-367.
Crisci IV C

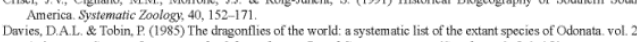

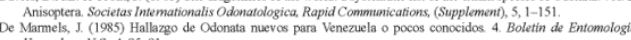
De Marmelas J. (2000) The larva of Allopetalia pussulosa Selys, 1873 (Anisoptera: Aeshnidae), with notes on aeshnoid

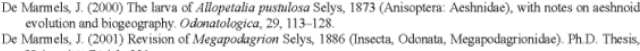

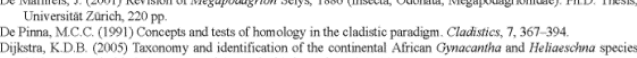

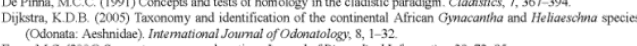

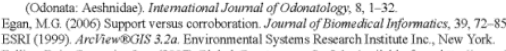

alling Rain Genomics Inc. (2007) Global Gazetert verşo 2.1 . Available from htpp://www fallingraincom (accessed July 2007) [Copyright 1996-2000
Farris, J. (1970) Methods for Comput

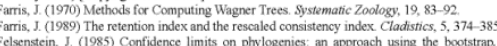

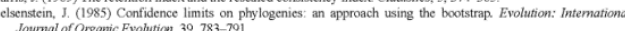

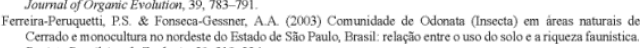

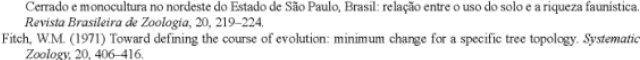
Zoology, 20,406-416.
Fleck, G (2002) Une larve dodonate remarquable de la Guvane francaise, probablement Lauromacromita dubitialis

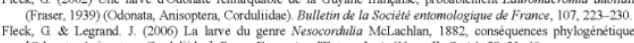

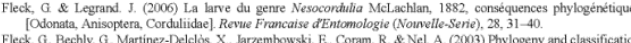

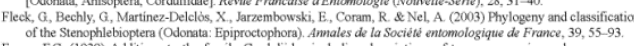

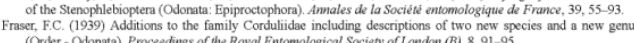

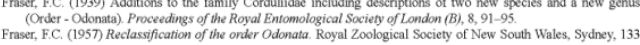
Garrison, R.W, von Ellenrieder, N. \& Louton, J.A. (2000) Dragonfly genera of the New World an illustrated and

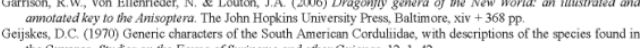

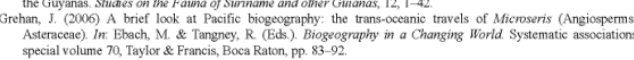

NEW BRAZZLIANLAUROMACROMU

Zootaxa 2425 O 2010 Magndia Press $\cdot 6$

Nixon, K.C. (2002) Winclada version 1.00.08. Publisheb by the author, Ithaca, New York, USA. (Nixon, K. C. 1999-

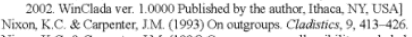

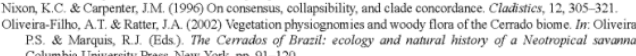

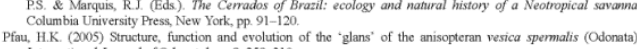

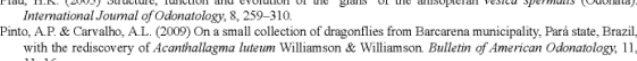
with the rediscovery of Acanthallagma luteum Williamson \& Williamson. Bulletin of American Odonatology. 11 ,
$11-16$

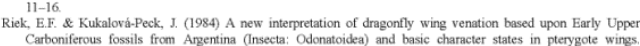

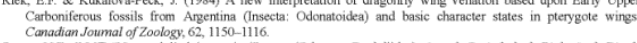

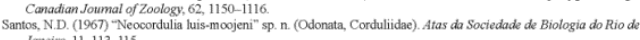
Janeiro, 11, 113-115.
Slowinski, J. B. (1993) "Unordered" versus "Ordered" characters Systematic Biology, 42, 155-165

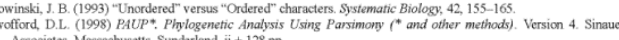
Associates, Massachusetts Sunderland ii 128 pp.
Swofford, DW. \& Maddison, W.P. (1987) Reconstructing ancestral character states under Wagner parsimony

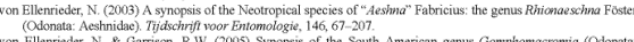
von Ellenrieder, N. \& Garrison, R.W. (2005) Synopsis of the South American genus Gomphomacromia (Odonat.

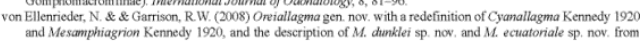

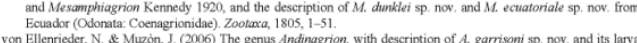

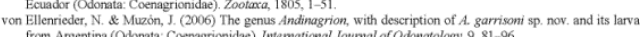

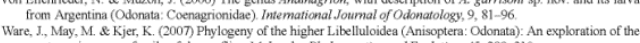

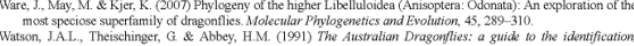

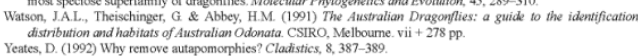

Humphries, CJ. \& Parenti, L. R. (1999) Cladistic biogeography second edition: interpreting pattems of plant and animal

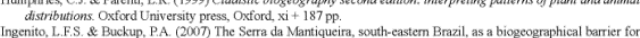

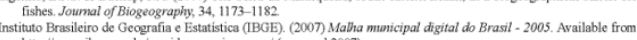

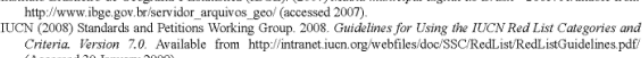
(Aarzembowsksi, E.A. \& N Nel, A. (1996) New fossil dmgonflies from the Lower Cretaceous of SE England and the

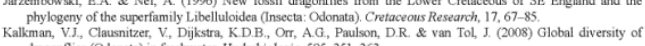

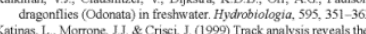

Joumal of Botany, $47,111-130$.

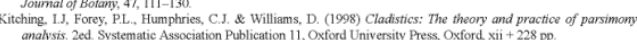
Klink, CA. \& Machado, RB. (2005) Conservation of the Brazilian Cerrado. Conservation Biology, 19, 707-71. Machado, ABM (2002) Descrption of Lauromacromia flaviae spec. nov,, with notes on the holotype of $L$. huismogien

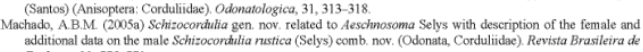

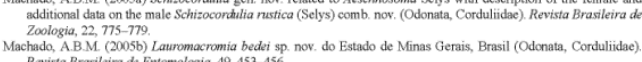

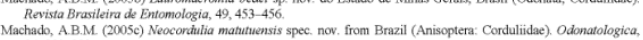
Machado, AB.M. \& Costa, IM. (1995) Navicordulia gen. nov, a new genus of Neotropical Corduliidae, with

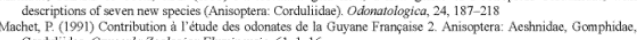

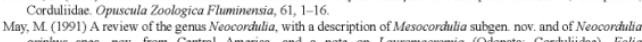

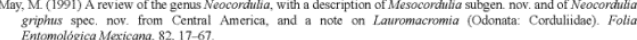
Miller, PL., (1991) The structure and function of the genitalia in the Libellulidae. Zoological Joumal of the Linn

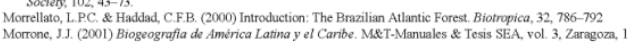

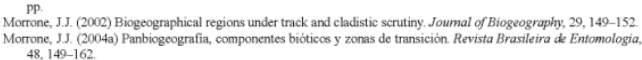
Morrone, J.J. (2004b) La zona de transición sudamericanac caracterización y relevancia evolutiva. Acta Entomologgica

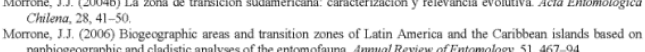
Morrone, JJ. \& U Utubey, E. (1997) Historical biogegegraphy of the northern Andes: a cladisticic analysis based on five

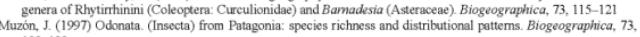
$123-133$
Mvers, N, Mittermeier, R.A. Mittemeier, C.; Fonseca, GAB. \& Kentand, J. (2000) Biodiversity hospots for Neecham, J.G., Westrall R, M, M.J. \& May, M.L. (2000) Dragonflies of North America. Scientific Publishers Florida

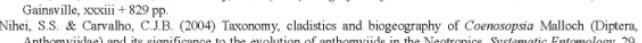

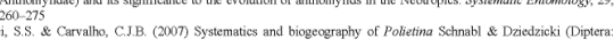
Nithei, S.S. \& Carvalho, CJ.B. (2007) Systematics and biogegraphy of Potietina Schnabl \& Dziedzicki (Diptera:
Muscidae): Neotropical areas relationships and Amazonia as composite area Systematic Entomology 32, 477-501.

$66 \cdot$ Zootaxa 2425 O 2010 Magndia Press $\quad$ PNTO \& CARVALHO

Appendix 1 . Data matrix for eight terminal taxa and 43 characters used in the cladistic analysis. Ingroup taxa
with bold font. Characters states with inapplicable data "- and unknown data " "?"; Taxa with more than one with bold font. Characters states with inapplicable dax

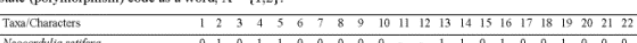

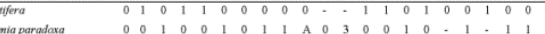

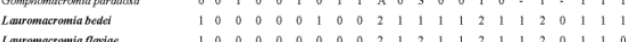

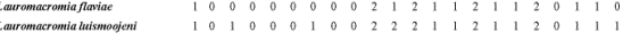

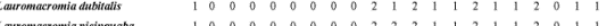

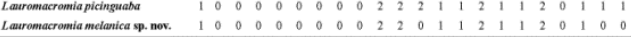
contimed

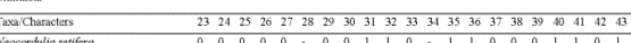

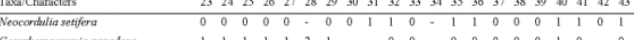

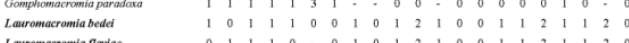

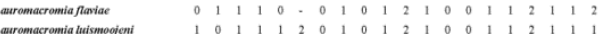
Laurromacromia adutatals Lauromacromia picinguaba
Laurromacromia melanica 
3. ReVISTA BRASILEIRA DE ENTOMOLOGIA [ISSN 0085-5626]- 2010

Navicordulia aemulatrix sp. nov, (Odonata, Corduliidae) from northeastern Santa Catarina State, Brazi

Ángelo Parise Pinto ${ }^{\text {ta }} \&$ Carlos José Einicker Lamas'

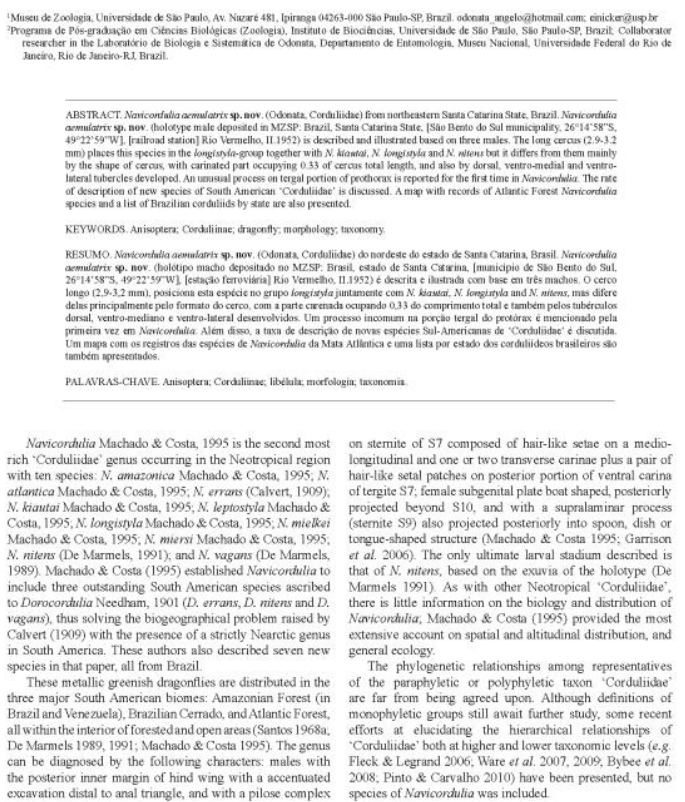

610

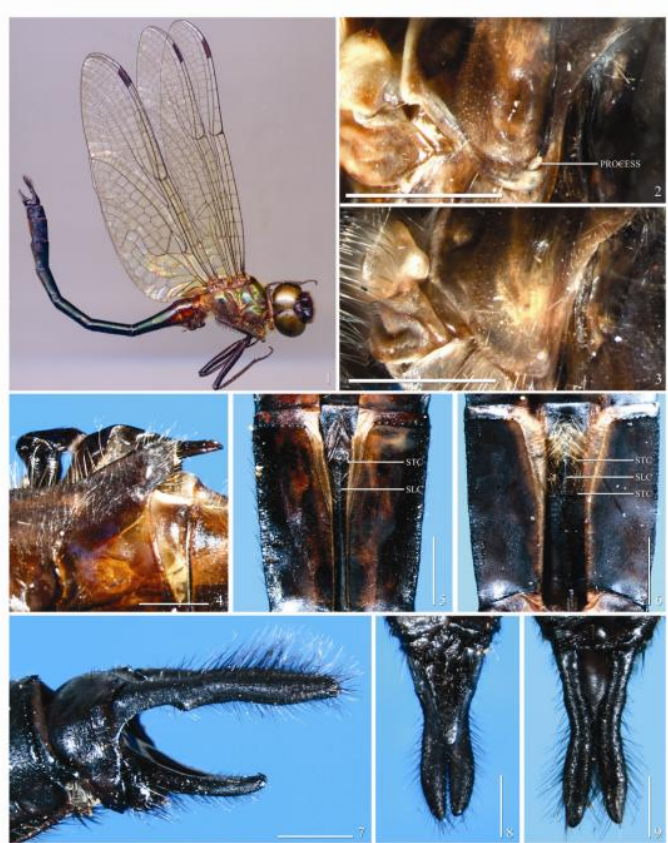

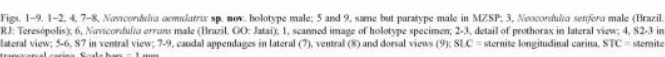
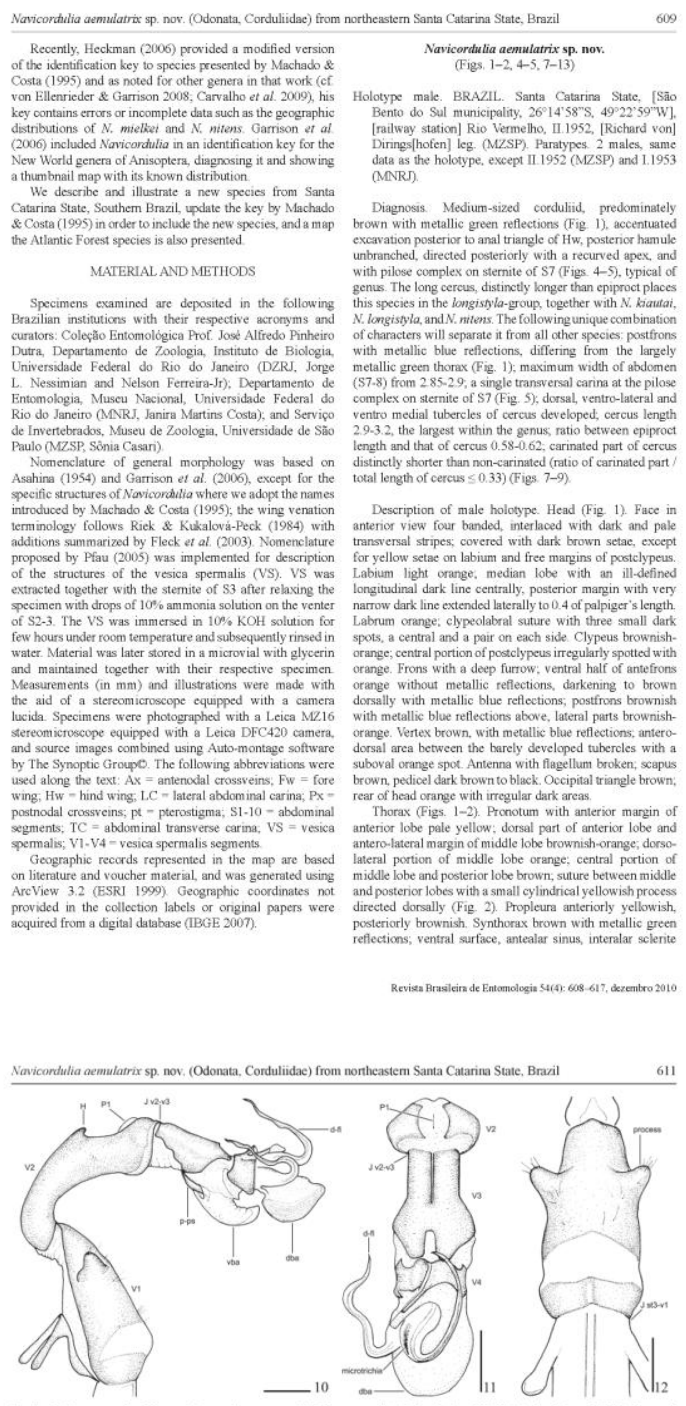

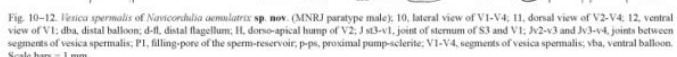

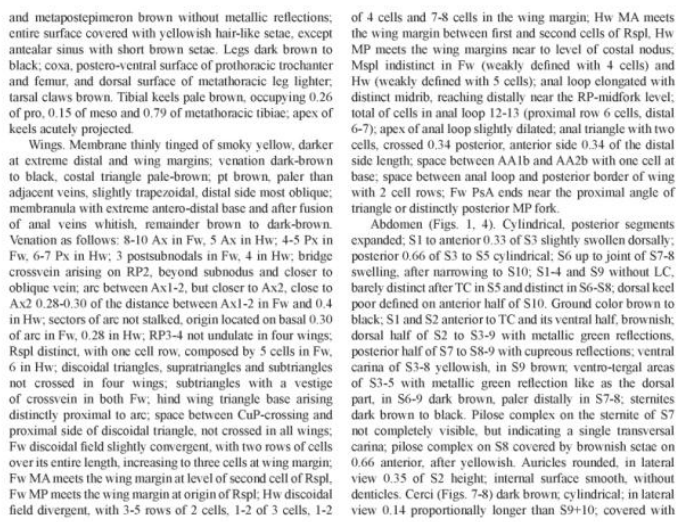



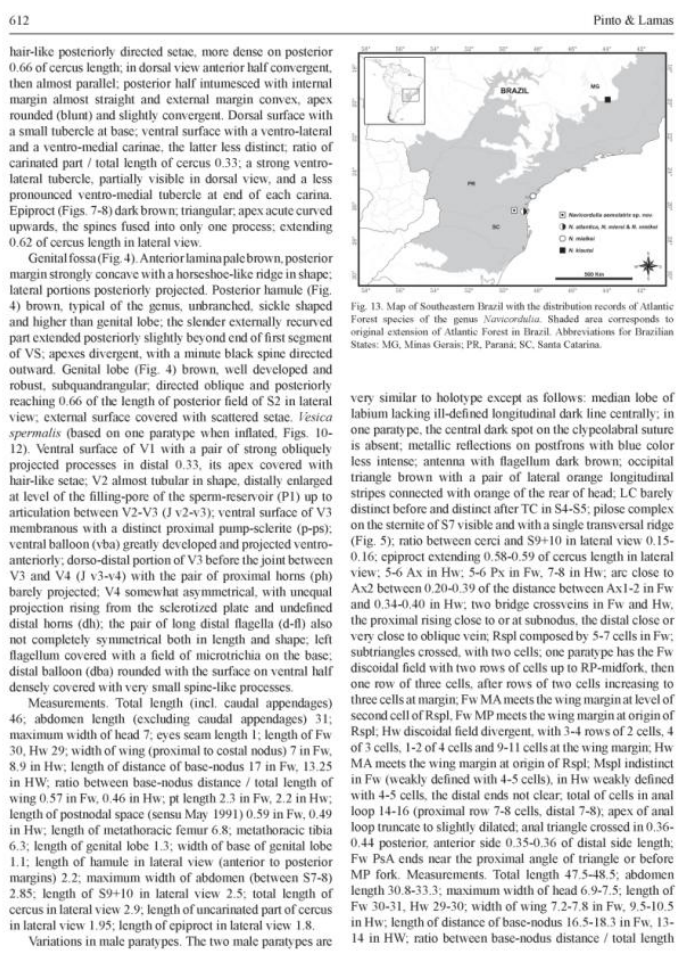

(1)

614

Pinto \& Lamas

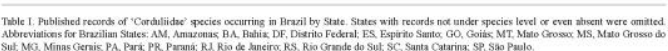

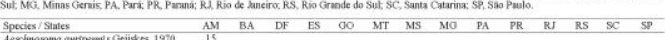

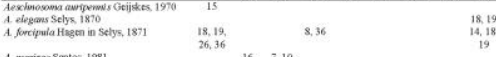

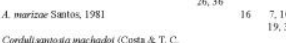

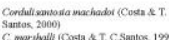

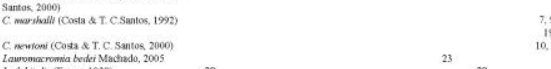

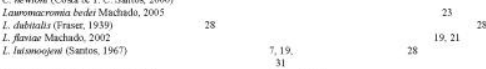

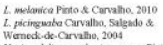

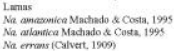

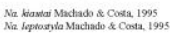

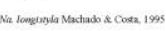

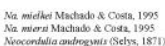

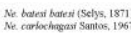

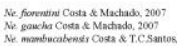

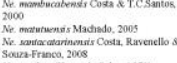

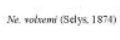

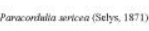

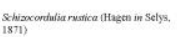

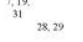

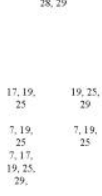

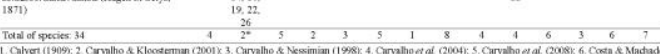

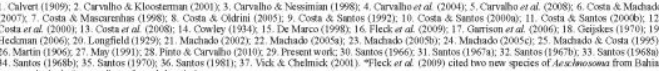

Navicordhtia aemulaturix sp. nov. (Odonata Cordulididec) from northeastern Santa Catarina Statc, Brazil

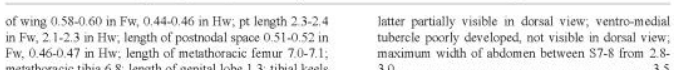

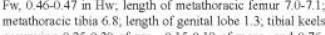

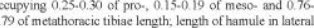
view 2, maximum widh of abdomen $2.85-29$; length of
So+10 in lateral view 25.27 ;

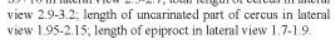
Emaology. The Latan word aemulatrixix (f, cmulate, to try
to equal or surpass) is a reference to intermediate features observed in the new species 'imitating' those of $N$. kantatas Remariss. The holoype is in a very good state of preservation, except the small area with a drop of glue unititing The head arac a procheracicic leg are detached with all parts in a small cellophane envelope and the stemum of $\mathrm{S} 3$ removed laterally with the pin passing close to metathoracic spinacte
To guarratee its preservation the pin was removed and the DIscussion

Based on the size of male caudal appendages, Machado \&.
Costa (1995) divided Naviconnihlia in tivo groups: longissylagroup (cercus length $2.5-2.9 \mathrm{~mm}$ ) including $N$. kiautai, $N$.

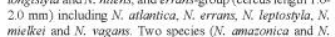

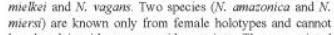
miersi) are known only from female holotypes and cannot
be placeci in either group with certainty The unresticted
adoption of this charracter as the unique enterion for the establishmento fr grouss in the ger

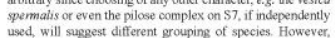

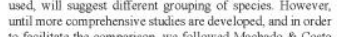
unth more comprechensive stulutits are developed, and in order
to facilitate the comparison, we followed Machado \& Costa
(1995) (1995) in adopting this division distinguished from the Venerzelan $N$. nituens by th its reduced carinated portion occupying 0.33 of cercus length in $N$. ca. 0.66. The new species will key out betreen N. katatat
and N. Longistla in Machado \& Costa (1995: 197) and a

3. Dorso-bassl tubercle poorly developed and the ventro-
lateral tulurcele vestigial to atsent; ventro-medial abdomen between S7-8 from 23-2.4. Cerrado species

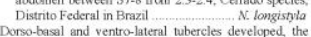
Cisudal appendages with carinated part as long as the
non-earinated (natio of carinated part/ total lenght of

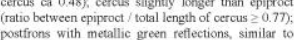
postrfons with metallic green reflections, similar to

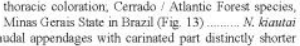
Caudal appendages with carinated part distinctly shorter
than non-carinated (rntio of carinated part total lengeth of cercus $\leq 0.33)$; cercus distinctly longer than cppiproct
of (maximum ratio between epiproct / total length of

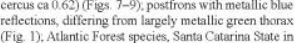

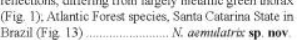

Aconspicuous cylindrical ycllowish process on the tergal
Nution of prothorax, placed on the suture between middele posterior lobes, was observed in the specimens of $N$

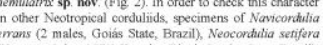
errans (2 males, Goias State, Brazil), Neocordatiat setffiera
(Hagen in Selys, 1871) (2 males, Riode Janeiro State, Brazil),

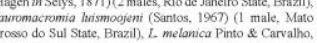

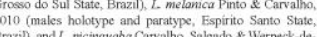
Brazilh, and $L$ picinguaba Carvalho, Salgado \& Werneck-de-

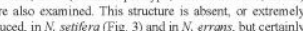
absent in $L$ tursmoojern, $L$ melanica and $L$, picinguaba

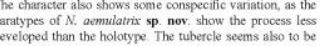
developed than the holotype The tubercle seems also to be

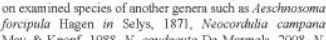
May \& K Kopt, 1988, N. cundacuta De Marmels, 2008, N.

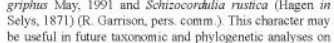
be sefulu in future taxonomic and phylogenetic analyses on
Cordulidace

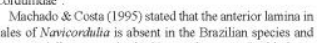

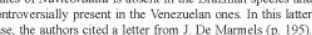
true, the absence of anterior lamina in males of Brazilian

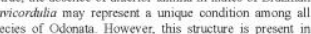

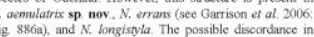

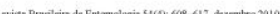

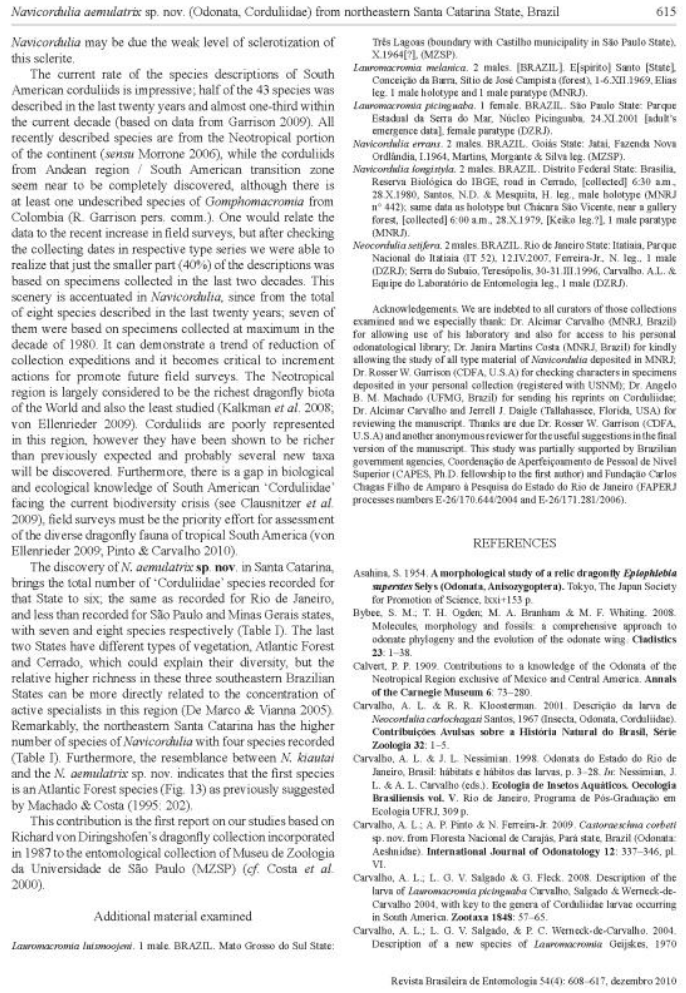



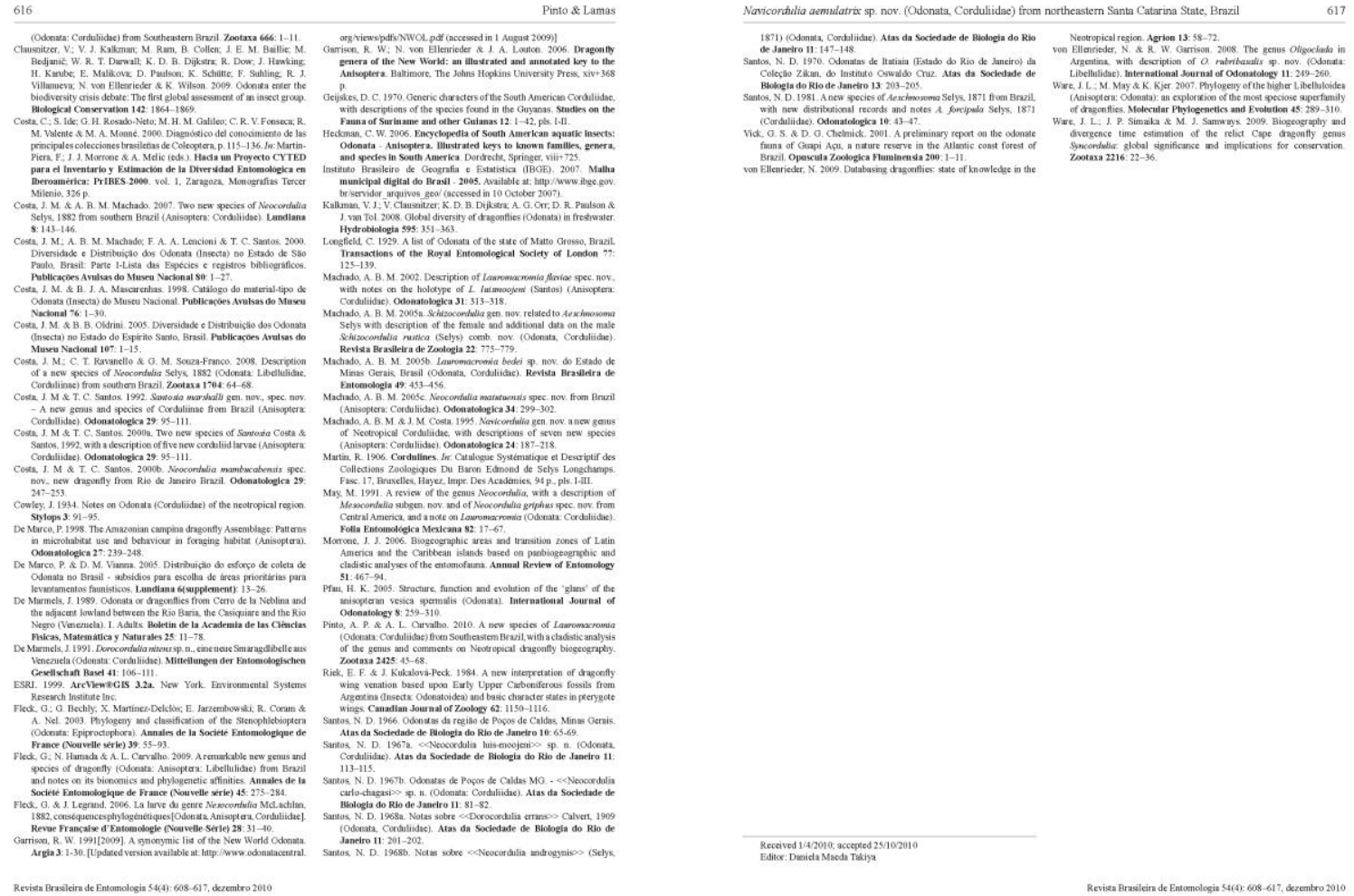

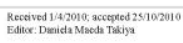


ISSN 1061-8503

\section{ARgIA}

The News Journal of the Dragonfly Society of the Americas

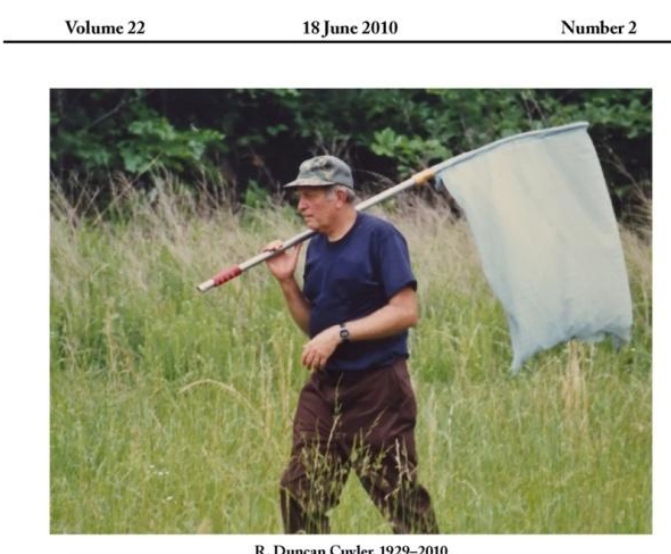

Published by the Dragonfly Society of the Americas

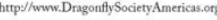

A Sertanejo's Trip: Occurrence of Orthemis sulphurata Hagen in Northeastern
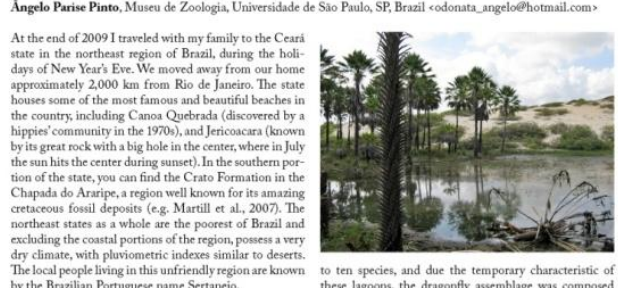

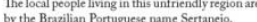

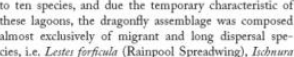

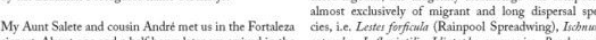

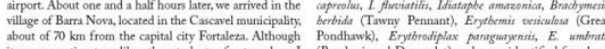

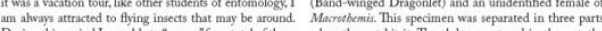

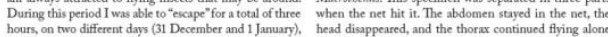

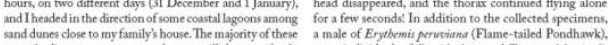
water bodices
during perio
with the abse with the absence of emergent aquatic plants, and the $s$ termin around them is covered with
palm trees called "Buritis" (Fig. 1).

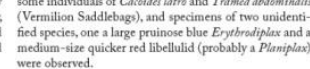

On my first day hunting dragonfies, I was accompanied
by Andre who helped me searnh for the red ones. We were

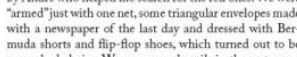

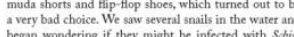
began wondering if they might be infected with Ssits-

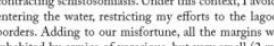

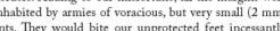
ants. They would bite our unprotected feet incessanth
Thus, I was able to collect just 19 specimens belongits 12
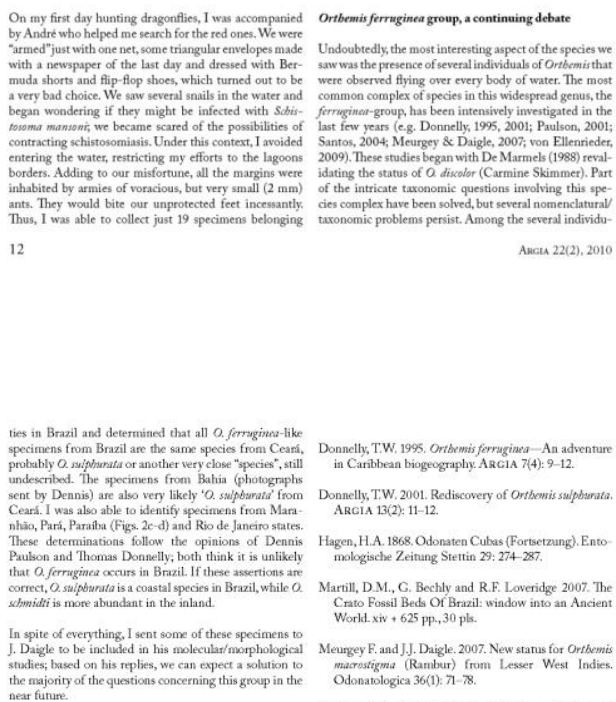

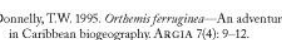

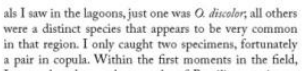

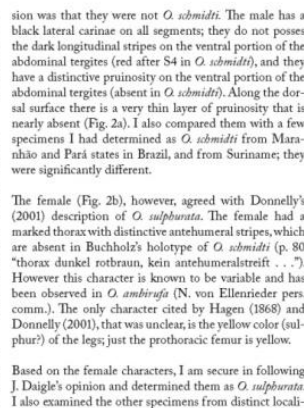

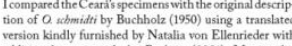
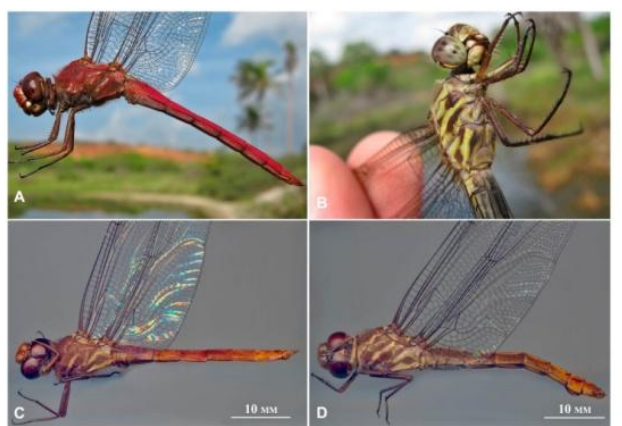

Acknowledgements

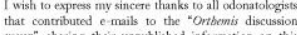

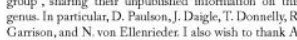

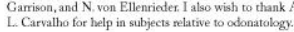

Literature cited

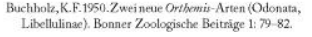

De Marmels, J. 1988. Odonata del Estalo de Tíchira.
Revista Cientific Unet 2(1): 91-111.

Donnelly, T.W.2001. Rediscovery of Orthomis supphinat

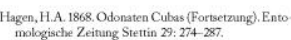
Marrill, DM., G. Bechly and R.F. Loveridge 2007. The World xivi 622 pp. 30 pris.

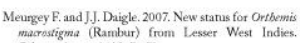
Ciding Paulson, D.R. 2001. Orthemis xhbu
Species, ARGIA 13(3): 24-25.

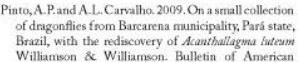
Williamson \& Williamoon. Bulletin of Americat
Odonatology $11.11-16$.

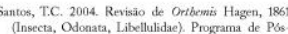

Coming Soon: Damselfly Genera of the New World: An Illustrated and Annotated Key to the Zygoptera, by Rosser W. Garrison, Natalia von Ellenrieder, and Jerry A. Louton

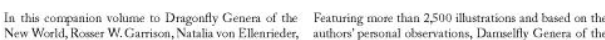

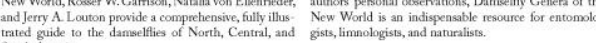

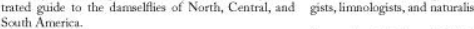

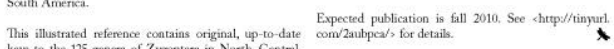
and South Americic; descriptive tert for each genus; dis

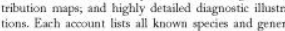

synonyms, information on the status of chassification, and

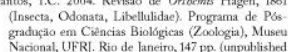




\section{International Journal of Odonatology [ISSN 1388-7890] - 2011}

\author{
International Journal of Odonatology
Vol. 14, No 4, Decemher 2011, 291-303

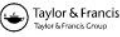

Oligoclada mortis sp. nov. from Rondônia State, Brazil, and distributional records of other species of the genus

$$
\text { (Odonata: Libellulidae) }
$$

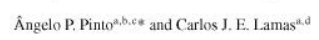

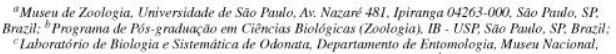

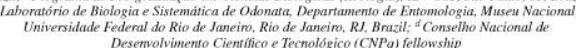

(Received 22 Jaly 2011; foral version neceived 3 October 2011)

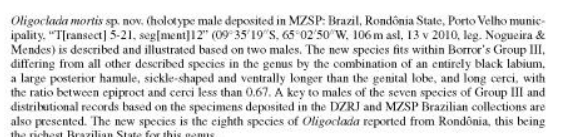

also presented. The new species is thic at

Keywords: Dragonnty: Libellulidde: Oligociada; new species; taxononny: Rondónia State; Amazonia
Fovest

\section{Introduction}

Oligoclada Karsch, 1890 comprises a group of small, bluish libellulids, mainly distributed in South America, with its grealest richness in the Amazonian region (Borror, 1931, with additions). Indeed, just two species have been recorded outside the continent, 1.e. O. umbricota Borror., 1931 and $O$. heliophila Borror, 1931 in Panama (Borror 1931) Due io the uni faragua (Daigle, 2002). with black and whitish-blue pruinosity of male adults, species are virtually undistinguishable in ifrom other genera with similar species such as Ervthrodiplax Braner. 1868 (cf. Santos, 1945b).

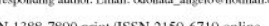

ISSN 1388-7890 print/ISSN $2159-6719$ online
O2011 Worldwide Dragonfly Association

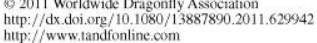
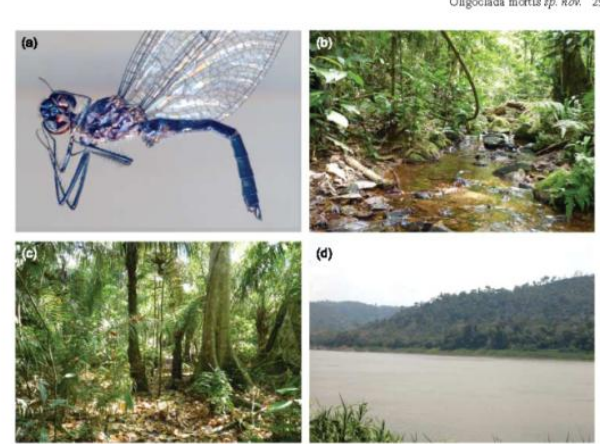

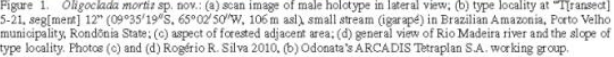

$\mathrm{KOH}$ solution for few hours at room temperature and subsequently rinsed in water. Generally, VS inflates after this process probably due to osmotic pressures (cf. Santos, 1945 a), but unfortunately this was not achieved with the only specimen examined, which precludes accurate identification of its structures. Material was later stored in a microvial with glycerin and stored with the specimen. The following abtreviations were used in the text: $\mathrm{AX}=$ antenodal crossveins; $\mathrm{FW}=$ forewing;

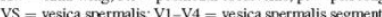

Oligoclada mortis sp. nov.

(Figures 1a, 2a-k)

Eymology

From the Latin mors (f. genitive mortis), personification of death, in reference to the sickle shape of posterior hamule recalling the tool used by the mythological entity to reap the life of the living Specimens studied

Holotype o": Brazil, Rondônia State, Porto Velho municipality, "T[ransect] 5-21, seg[ment]12" $\left(09^{\circ} 35^{\prime} 19^{\prime} \mathrm{S}, 65^{\circ} 02^{\prime} 50^{\prime} \mathrm{W}, 106 \mathrm{~m}\right.$ asl), 13 v 2010, leg. Nogueira \& Mendes (MZSP); $10^{\circ}$ paratype: same data as holotype but "Abuna area, T[ransect] 10-P2 seg[ment] 4" (c.09935 $43.70^{\prime \prime}$,
$65^{\circ} 20^{\circ} 55.70^{\prime} \mathrm{W}, 108 \mathrm{~m}$ asl), $17 \mathrm{v} 2010$, leg. Nogueira \& Mendes (MZSP). The specimens
292 A.P. Pinto and CJ.E. Lamas

Borror's (1931) revision was a milestone in the taxonomy of the genus, with his clear illusrrations, diagnoses and keys, an aspect repeatedly highlighted in recent works (Garrison et al. of the currently 24 described species (von Ellenrieder \& Garrison, 2008). After 1931 nine new species were described, one from Ecuador (Rehn, 2003), two each from Argentina (Fraser, 1947) von Ellenrieder \& Garrison, 2008) and Brazil (Santos, 1945b, 1951), and four from Venezuel. (De Marmels, 1989, 1992, 2008). Furthermore Podothemis nemesis Ris, 1909 was transferred to bur, 1942), and $O$, risi Geijskes, 1984 was proposed as a new name for $O$ abbreviata sens Borror (Geijskes, 1984). Finally, a new subspecies, Otigoclada abbreviata limnophila Machado \& Machado, 1993 was described (Machado \& Machado, 1993). These changes render Borror' key out-of-date, making it necessary to compare specimens with primary descriptions for secure

Recently Heckman (2006) presented an updated version of Borror's key containing 22 species In spite of containing a higher number of species than in Borror's work, this key was entirely com-
piled from the literature, and as was also observed for other genera (e.g. Carvalhoet al. 2009; Pinto \& Lamas, 2010), accumulated several imprecisions and thus cannot guarantee secure identificitions. This is exemplified by the incomprehensible confusion between $O$. abbreviata and $O$. risi (c. Heckman, 2006, p. 24, 107, 302-304). On the other hand, the three Argentinean species were accu-
rately revised, diagnosed and included in a key of their own by von Ellenrieder \& Garrison (2008) Oligoclada species have been generally recognized as inhabitants of lotic habitats (e. . B Borror 1931; Machado \& Machado, 1993). However, descriptions of ultimate larval stadia (Fleck, 2003; Souza et al., 2002) and notes on biology in taxonomic descriptive studies of adults (De Marmels 1989; Machado, 1954; Rehn, 2003, Santos, 1951; von Ellenrieder \& Garrison, 2008) challenge hodies were associated with river systens. Thus the breeding sites are probably varioble amorg he species, with a trend to lentic environments During recent expeditions for an environmental impact assessment required for installation of hydroelectric power station under construction on the Rio Madeira, Rondonia State, in Braziliaa Amazonia, we identified a striking new species or Oilgoclada, which is deserribed, illustrated an

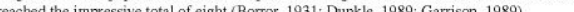

\section{Material and methods}

Specimens studied are deposited in Museu de Zoologia, Universidade de São Paulo (MZSP), São Paulo, and Coleçäo Entomológica Prof. José Alfredo Pinheiro Dutra, Departamento de Zoologis Brazil

Descriptions, illustrations, and measurements were made with the aid of a steresscopic microscope equipped with a camera lucida. For measurements greater than $10 \mathrm{~mm}$ a manual calipe

rized by Fleck et al. (2003). For description of the structures of (1984) with additions summanomenclature proposed by Miller thegr, whichis essentisty the son (1922) and Bortor (1931), was adopted, in preference to Pfau's (2005) terminology in order to facilitate comparisons among the species, since all descriptions of Oligoclada employed the Kennedy-Bortor systen. The $\mathrm{S}$ was extracted, together with sternitie 3 , after relaxing the
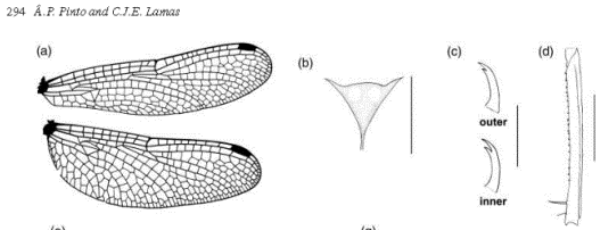

(e)

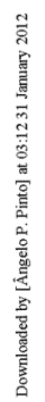
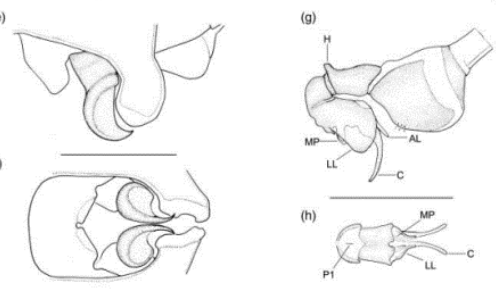

(h)
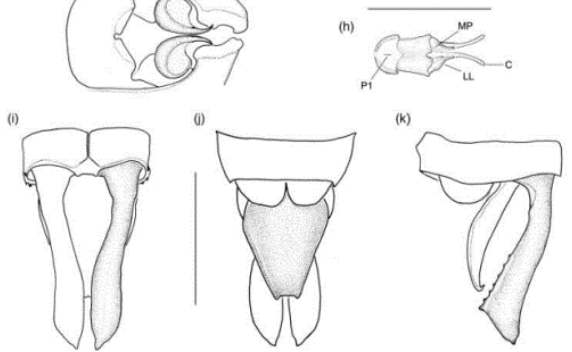

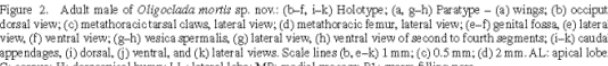

were collected under IBAMA 02001.006797/2008-30 and CGFAP 260/2010 licenses. Paratype with the left genital lobe lost and apex of right posterior hanmule broken. Lefl pair of win 
Male holotype

Head. Labium shining black. Labrum ivory, a narrow black spot at center of ventral margin harrowing laterally; base of mandibles ivory, irregularly spotted with brown to black. Clypeus reflections. Frons smashed, precluding precise messurement of width of ivory stripe on anterons. Antennae dark brown to black. Occipital triangle blackish brown with pair of ill-defined founded orange spots on each side (Figure $2 \mathrm{~b}$ ); rear of head black. Postfrons with wide-shallow or margin of occipital triangle slightly convex without any

Thorax. Prothorax black, except for brown spot lateral to middle lobe, narrowed dorsally; margin of posterior lobe with long, white, hair-like setae. Synthorax (Figure 1a) brown to black, irregularly covered with whitish-blue pruinosity; mesepisternum black dorsally, lightening to dark brown
towards mesepimeron; metapleura brown with irregular dark areas, without distinct pattern of pale towards mesepimeron; metapleura brown with irregular dark areas, without distinct pattern of pale
and dark areas. Legs black, covered with whitish-blue pruinosity on ventral surface; ventral surface f prot followed distally by one spine, 6.2 times longer than proximal ones (Figure $2 \mathrm{dit}$; anteroventral surface of metathoracic tibia with 12 spines, longer than intervening spaces; metathoracie pretarsal
claws with distinct acute supplementary inferior tooth at $c .0 .75$ (outer claw) and 0.66 (inner claw) of their length (Figure $2 \mathrm{c}$ ).

Wings. Membrane hyaline; venation black; pt pale brown, contrasting with black of surrounding veins, rectangular; membranula small, anterodistal base whitish, remainder brown to dark brown.
Venation as follows: $9-10 \mathrm{Ax}$ in $\mathrm{Fw}$ (distal one incomplete), $7 \mathrm{Ax}$ in $\mathrm{Hw}$; 7-9 Px in $\mathrm{Fw}, 8 \mathrm{Px}$ in $\mathrm{Hw}$; 7 postsubnodals in $\mathrm{Fw}, 7-8$ in $\mathrm{Hw}$; one bridge crossvein arising proximal to $\mathrm{RP} 2$ in all wings; arc
between $\mathrm{Axl} 1$ and 2 , closer to $\mathrm{Ax} 2$; 8 ectors of arc (MA+RP) stalked, their common origin located $c .0 .30$ distance from posterior to anterior end of arc in all wings; Rspl with one cell row, composed
of 5 cells in $\mathrm{Fw}, 4$ in $\mathrm{Hw}$; discoidal triangles, supratriangles and subtriangles not crossed in four wings; Hw triangle base arising obliquely to arc; space between CuP-crossing and proximal side of discoidal triangle not crossed in $\mathrm{Fw}$, with an additional crossvein in both $\mathrm{Hw}$; $\mathrm{Fw}$ discoidal field with two rows of cells up to level of nodus, increasing to $6-7$ cells at wing margin; Hw discoidal
field divergent, with 4 rows of one cell followed by 1-3 double cells, then broadening to 9-10 cells towards wing margin; Mspl indistinct in all wings; anal loop elongated with distinct midrib. with well-developed toe, foot-shaped, reaching distally to level of RP-midfork; total cells in anal rows posterior to anal loop ( 2 cell rows at triangle level).

Abdomen. Almost black, covered with whitish-blue pruinosity on $\mathrm{S} 1-4$ and ventral portions of S5-8; S2-3 paler, brownish orange with black carinas; dorsal center of $\mathrm{S} 4-7$ with ill-defined brownish-orange stripe, not reaching anterior and posterior margins of respective segment; vencarina of S4 barely distinguishable, suture-like in shape. Secondary genitalia: anterior surface of anterior lamina without spines, in ventral view (Figure $2 f$ ) with posterior margin concave, abruptly
accertuated medially, in lateral view lower than posterior hamule and genital lobe (Figure 2e); pos-
terior hamule unbranched, sickle-shaped, distinctly higher than genital lobe, apex acute, directed terior hamule unbranched, sickle-shaped, distinctly higher than genital lobe, apex acute, directed
posterodorsally in lateral view (Figure 2e) and outwards with apex diverging from opposite hamule posterodorsallly in lateral view (Figure 2e) and outwards with apex diverging from opposite hamule
in ventral view (Figure 20 , inner surface between base and apex of hook seermingly membranous; angle of curvature formed by the hamular ridge distinctly obtuse and of about $70^{\circ} ;$ ridge strongly
pronounced at base and gradually disappearing toward apex in lateral view (Figure $2 \mathrm{e}$; genital

Oligoclada mortis sp. nov. 297

indistinct, typical of the genus. The combination of uncrossed triangles, discoidal field beginning with two rows of cells in $\mathrm{Fw}$, foot-shaped anal loop, anal field with 2-3 three rows of cells (Figure 2a), transverse carina on $\mathrm{S}$ barely indicated, tarsal claws with a definite tooth on 0.66 of lateral lobes and medial process (Figure $2 \mathrm{~g}-\mathrm{h}$ ), separate $O$. mortis sp. nov, from all species

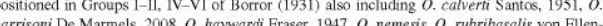
fieder and Garrison, 2008 and $O$. teretidentis Rehn, 2003 not considered in Borror's revision. Within Group III, in which we also include $O$. amphinome Ris, 1919, O c crocogaster Borror, 1931, O. borrori Santos, 1945, O. leucotaenia De Marmels, 1989 (see discussion), O. hypophane De Marmels, 1989 and $O$. waikinimae De Marmels, 1992 , the new species can easily be distin-
guished from all other species by following unique combination of characters: labium entirely
black, posterior hamule sickle-shaped, more than two times as long as anterior lamina and 1.6 times as long as genital lobe, proportionally the largest observed in the genus; hamular basal
length 0.33 of its total length; ventral edge of genital lobe rounded (Figure 2e); epiproct $\leq 0.66$
total length of cercus, ending posteriorly anterior to the last spine of cercus (Figure $2 \mathrm{k}$ ): venter of total length of cercus, ending posteriorly anterior to the last spine of cercus (Figure $2 \mathrm{k}$ ); venter of
$57-9$ almost black with a small indistinct brownish rounded spot on tergite of $S 9$; cercus widest $\$ 7-9$ almost black with a small indistinct brownish rounded spot on tergite of 59 ; cercus widest
at $c 0.66$ posterior of its length; ventral set of $6-7$ teeth arranged in ridge-like process; apexes of cerci convergent in dorsal view (Figure $2 \mathrm{i}-\mathrm{k}$ ).

\section{Biological and ecological data}

Rondônia State, especially the region of its capital Porto Velho, with its eight recorded species presents the highest richness of Oligoclada among the nine Brazilian States covered by the number of species of this genus. The huge Brazilin Amazonin is very poorly investigoted, with no extensive and systematic collecting expeditions, thus several areas are virtually terra incognita. Furthermore the few existing collections are understudied.

The gently sloping locality where the holotype of $O$. mortis was collected (Figure 1d) harbors a small partially shaded stream (igarapé) of second order with abundant leaf litter, and with its Veighboring areas include forest with partiolly open canopy ferms and young pan in the undersory, superior strata with trees and lianas (Figure 1c). Without identification of its larva, it is impossible to characterize this species as lotic or lentic, since the breeding site could be lentic, for example a stagnant portion of the igarape, in spite of the latter being running water. The paratype Theocted in a similar environment, alberit with denser vegetation.

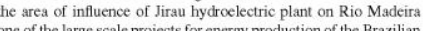
government in Amazonia

\section{Discussion}

Borror's (1931) division of Oligoclada into six 'natural' groups based on VS (penis) morphology is practical, in spite of his conflicting nomenclature. Differently from his work on Erythrodiplax (Borror, 1942), the distinction of lobes of fourth segment is unclear, especially between inner
lobes (internal lobes sensu Borror) and the apical lobe (posterior lobe sensu Borror). In some lobes (internal lobes sensu Borror) and the apical lobe (posterior lobe sensu Borror). In some
species he identified the most dorsal lobe as the apical lobe with inner lobes located immediately ventral to it (e.g. O. crocogaster), while in others species the most dorsal lobe was identified as
296 A.P. Pinto and CJE. Lames

lobe rounded with anterior and posterior margins similar, 1.25 longer than wide (Figure $2 \mathrm{e}$ ). For VS description see paratype. Cerci (Figure 2i-k) black, in lateral view regularly smoothly curved, slightly constricted at anterior 0.2 to 0.3 , then gradually expanding posteriorly; apex tapering
into a thumb-like process directed obliquely dorsad; posterior margin obliquely truncated; ventral margin with row of 6-7 spines on a ridge-like process from anterior 0.46 to posterior $0.79 \mathrm{~d}$

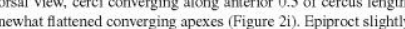
bens slightly diverging with somewhat flattened converg
bifid at tip, extending to 0.64 length of cerci (Figure 2j).

Measurements. Total length (including caudal appendages) 26.5; abdomen length (excluding caudal appendages) 15.5 ; head maximum width 4.2; Fw length 20; Hw length 19; Hw width 6.6 metathoracic tibia 6.3 ; length of genital lobe 0.5 ; width of base of genital lobe 0.4 ; length hamule in lateral view 0.8 ; length of anterior view 1.3; total length of cercus in lateral view 1.4; length of epiproct in lateral view 0.9 .

Variation in the paratype

Head. Base of mandibles ivory. Pair of rounded orange spots on occipital triangle clearly defined. Thorax. Prothorax black. Synthorax brown to black, pruinose areas more extensive; anteroventral surface of metafemora armed with 19 short spines followed distally by one longer distal onc
(apex broken in both legs); anteroventral surface of metathoracic tibia with 12-13 long spines tarsal supplementary inferior tooth at $c .0 .75$ of their length in both claws. Wing (Figure 2a) vena tion as follows: $8 \mathrm{Ax}$ in $\mathrm{Hw}$; 9-10 $\mathrm{Px}$ in Fw (distal $\mathrm{Ax}$ on right wing not reaching the costal margin), 8 Px in Hw; 6-7 postsubnodals in Fw, 6-7 in Hw; Rspl with one cell row, composed
of $4-5$ cells in Fw; space between CuP-crossing and proximal side of discoidal triangle with an additional crossvein only in left $\mathrm{Hw}$; $\mathrm{Hw}$ discoidal field with $4-5$ rows of one cell; total of cells in anal loop 15-16 (proximal row 7 cells, distal 8-9),

Abdomen. Dorsal center of $\mathrm{S5}-7$ each with ill-defined brownish-orange stripe, not reaching
anterior and posterior margins of segments; ventrotergal portion of $\$ 9$ with large brownish rounded spot on posterior half; cerci black with intermal posterior surface brown. Secondary genitalia
VS with pair of very long, filiform cornua extending distinctly beyond apex of subtriangular lateral lobes and ventrally beyond hood (Figure $2 \mathrm{~g}$ ); medial process with ventrally directed lobe, strongly sclerotized intermally and surrounded by membranous (probably inflatable) structures
(Figure 2g-h); apex of apical lobe tongue-shaped, covered by minute spines (Figure 2g); inner lobes not discernible.

Measurements. Total length (including caudal appendages) 25.3; abdomen length (excluding caudal appendages) 15.3 ; head maximum width 4.1 ; Fw length 20.9; Hw length $19.5 ; \mathrm{Hw}$ widt 6.3 (proximal to costal nodus); pt $1.7-1.8$ in $\mathrm{HW}$; length of metathoracic femur 5.8 ; metathoracic
tibia 6.1 ; length of $59+10$ in lateral view 1.4 . Female and larva. Unknown.

Diagnosis

Small-sized libellulid, predominately blackish brown covered with whitish-blue pruinosity 298 A.P. Pinto and CJE. Lames

not provide an explanation, at least in detail, for calling the dorsal lobe sometimes the apical lobe and at other times the inner lobe. This inconsistency renders comparison complex and unreliable, since identification of lobes is ambiguous and consequently errors of interpretation could be
common. The problem was highlighted by Santos ( 1945 a, p. 3) who studied VS structures under full inflation and considered the single most dorsal lobe, labeled as the inner lobe in some species by Borror (1931, pl. VD), as actually the apical lobe. Santos

segment. However, in Miller's $(1991)$ system it is positioned in the third segment. Indeed a distinct borderline, due to different levels of sclerotization, is observed between the large proximal part of $\mathrm{V} 2$ which ends in the dorsoapical hump (the point at which the ligula engages to VS, named
as dorsodistal peg in Miller's terminology) and a small distal portion largely in contact with V3 as dorsodistal peg in Mitler's terminology) and a small distal portion largely in contact with V VS of Libellulidae species represent a great challenge for proposition of a general system. In Oligoclada a comprehensive study must be undertaken for unambiguous correspondence in the distal lobes among all species.

In spite of these problems, based on morphology of its $\mathrm{VS}$ (observed only in the decompressed state) $O$. mortis can be placed in Group III together with $O$. amphinome, $O$. crocogaster, $O$. borrori, by the presence of a pair of filiform comua, much longer than inner lobes, extending considerably beyond the apex of lateral lobes; lateral lobes usually triangular, not narrowed basally; and medial process 0.33 as long as cornua or less. In Borror's (1931) work just two species (i.e. O. crocogaster and $O$. amphinome) were included in this group, thus we provide a key to males of the seven species
currently involved.

De Marmels $(1989$, p. 51 ) considered $O$. leucotaenia related to $O$. crocogaster and $O$. amphinome, both species of Group III. In spite of structural characters indicating a correct placement,
the author did not describe the VS and the only illustration provided for this organ (p. 77) depicts the cornua as apparently absent. The probable absence of this structure was later validated by De Marmels (1992, p. 45) "En O. leucotaenia (serie tipo) ... el pene carece de comua". We provi-
sionally keep O. leucotaenia in Group III of Borror (1931), following De Marmels" (1989, 1992)
opinion, but probably the groun should be reevaluated since this species does not show the main opinion, but probater tor group should be reckaluated since this species does not show the maln ses of the genus should be undertaken in order to identify the relationships among species and test
the validity of Borrors's groups. Furthermore, Heckman (2006, p. 299) questioned the validity of this species without presenting any reasons supporting his opinion. Based on the description and

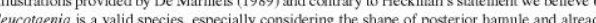
cited absence of a long cornua in VS. The sickle shape of the posterior hamules of $O$. mortis shows great similarity to $O$. stenopterd
Borror, 1931 and especially to the Venezuelan $O$. garrisoni, although both species belong to Group Borror, 1931 and especially to the Venezuelan $O$. garrisoni, although both species belong to Group
II. In addition to the larger hamule and distinct morphology of the caudal appendages of $O$. mortis. II. In addition to the larger hamule and distinct morphology of the caudal appendages of $O$. mortis,
these two species differ from $O$. mortis in presenting a less developed anal loop, without a distinct developed, being either absent $(O$. parrisoni $)$ or only as long as lateral lobes $(O$ stemoptera $)$.

Key to males of Borror (1931) species Group III of Oligoclada

This key was based on information available in the literature and examination of specimens of 


\section{8

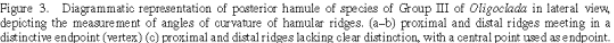

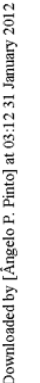

groups listed in the appendix. Therefore the key should be used with caution, and for correct
determination illustrations from Santos, 1945b) must be consulted. The angle of curvature of hamular ridges corresponds to the angle formed between posterior apexes of harmule and intersection of the proximal and distal extreme in $O$. leucotaenia (De Marmels, 1989, figure 207) and $O$. mortis (Figures $2 \mathrm{e}$, 3c) there is no clear distinction bet ween proximal and distal ridges and a central point was used as endpoint 2011) observed specimens in the Rosser W Garrison collection with features distinct from those by us

1. Cornua of VS greatly developed in along filiform structure, extending distally considerably heyond apex of lateral lobes, markedly curved, ventrally surpassing the margin of the
hood (except 0 . leucotaenia); eight or more Ax in Fw; discoidal triangles one-celled; subtriangles one-celled (rarely two-celled in one Fw), discoidal field beginning with two rows of cells in Fw, foot-shaped anal loop, anal fied with two or three rows of cells; tarsal claws with definite tooth at $0.66-0.75$ of its length (Group III)

1.' Character combinations differing from those above. of palp width and prolonged over the anterior margin; labrum entirely black; costal side of

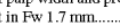
VS with long flififormcornua; labium with black spot covering less than 0.33 of palp width and not prolonged over anterior margin, or labium entirely black; labrum whitish yellow

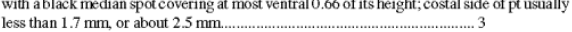

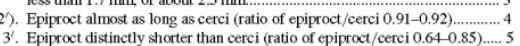

3'. Epiproct distinctly shorter than cerci (ratio of epiproct/ /cerci $0.64-0.85) \ldots . .5$
4(3). Anal loop composed of $17-20$ cells; posterior hamule as high as genital lobe; hamula . Anal loop composed of 17-20 cells; posterior hamule as high as genital lobe; hamular
proximal ridge meets distal one almost in an acute point, forming angle of curvature of
less than $35^{\circ}(34) ;$; cerci constricted at posterior 0.66 , with $4-6$ ventral spines located along posterior $0.6-0.75$ of cercus; length of costal side of pt in Fw $1.5 \mathrm{~mm}$............. idges (Figure 3a-c). In O. amphinome and $O$. crocogaster the proximal and distal ridges meet for determination of its angle of curvature (Figure 3c). Dr. N. von Ellenrieder (NvE; pers. comm,

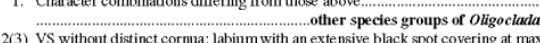

300 A.P. Pinto and CJE. Lamas

4. Anal loop composed of 13-14 cells [NvE, one specimen from Bolivar State, Venezuela
with $16-18$ cellst; posits cells]; posterior hamule slightly higher than genital lobe; hamular proximal ridge meets distal one in regular rounded curve, forming angle of curvature of more than
$35^{\circ}(40)$; cerci regularly curved with. 5 ventral spines located along posterior $0.5-0.66$ of cercus: length of costal side of $\mathrm{pt}$ in Fw $1.2 \mathrm{~mm}$ [ same specimen from Bolivar has pt in FW cercus: length of costal side of pt in Fw $1.2 \mathrm{~mm}$ [same specimen from Bolivar
with $1.7 \mathrm{~mm}] . \ldots . \ldots . .$.

$5(3)$. Length of costal side of pt in Fw c.2.5 mm; apex of wings with a brownish spot; anal loop composed usually of 13-16 cells; anterior lamina as long as 0.66 of genital lobe in lateral ………………............ . borrori 5. Length of costal side of pt in Fw at most $1.8 \mathrm{~mm}$; apex of wings hyaline; anal loop composed anterior larina at least 0.72 sang as genitol lobe in biteral view

c.

$6(5)$. Labium entirely black; venter of $57-9$ almost black with an ill-defined pale spot on posterior 0.5 of S9; posterior hamule distinctly higher than genital lobe; hamular ridge semicircular, forming anangle of curvature ofc.7\%, ventral margin of genitalloberounded, ratio between view; cercus with 6-7 ventral spines on a ridge-ilke process -

6. Labium with a black spot covering at most 0.33 of palp width; venter of $\$ 7-9$ reddis orange to red; posterior hamule no longer than genital lobe; hamular proximal and distal ridges forming angle of curvature less than $50^{\circ}$; ventral margin of genital lobe somewh of cerci parallel to slightly divergent in dorsal view; cercus with 46 ventral sines nexes

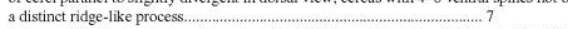

$7\left(6^{6}\right)$. Labrum with black spot covering ventral $0.25-0.5$; hamular proximal ridge meeting distal one in acute point (less acute in Pará specimens), forming angle of curvature of at most $28^{\circ}$;
cornua of VS greatly developed, extending distally considerably beyond apex of medial

process; lateral lobes distinctly rounded................................. 0 crocogaster
7. Labrum whitish yellow without black spots;

regular rounded curve, forming angle of curvature more than $30^{\circ}$ (35); cornua of VS less developed extending distally approximately level of apex of medial process, lateral lobe developed extending distaly approximately level of apex of medial process
subtriangular....... O. waikinima

Acknowledgements

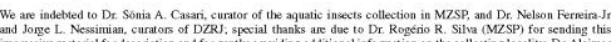

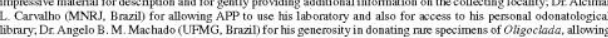

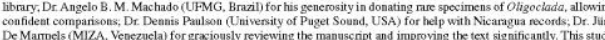

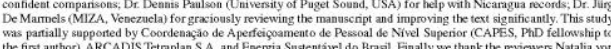

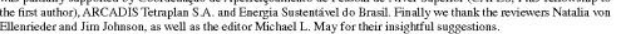

References

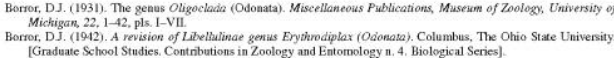

302 A.P. Pinto and CJE. Lame

Appendix. List of Oligoclada held in MZSP and DZRJ Brazilian collections

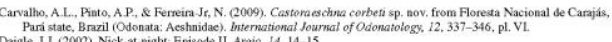

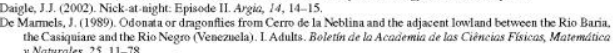

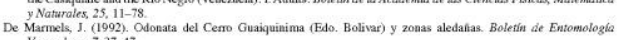

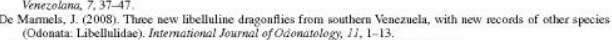

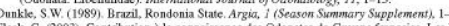

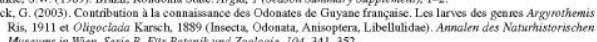

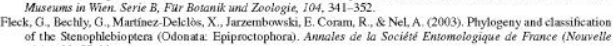

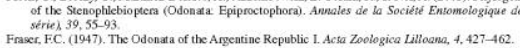

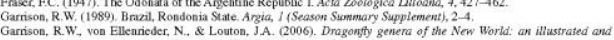

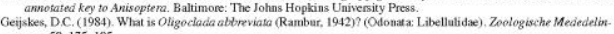

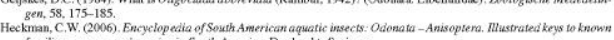

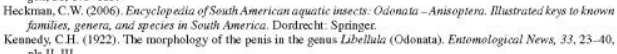

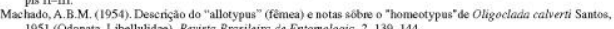

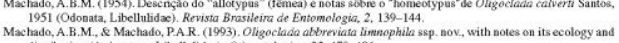

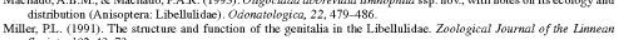

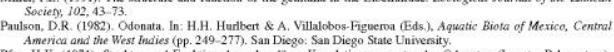

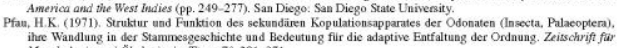

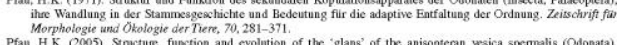

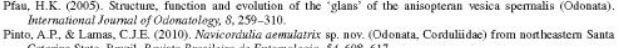

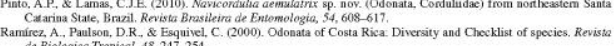

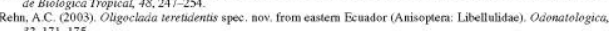

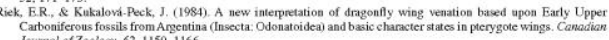

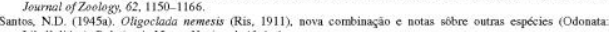

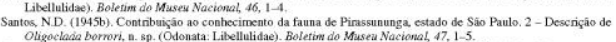

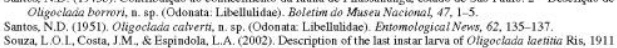

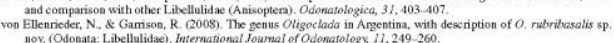

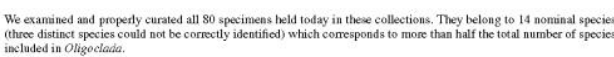

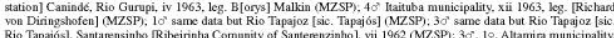

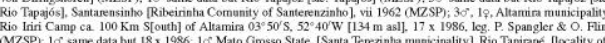

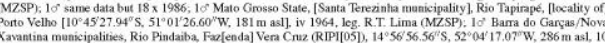

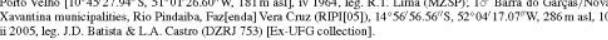
O. amphinome Ris, 1919. ISURINAMEF) 10' [Para District), Powrakka, $12 \times 1962, \mathrm{~kg}$, G. [D.C. Gejijkes?]
(MZSP).

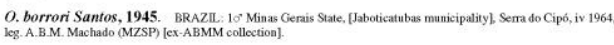

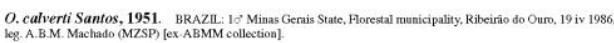

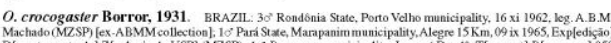

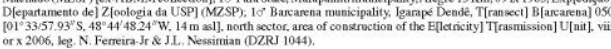

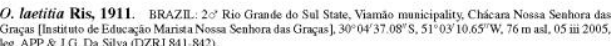

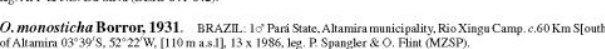

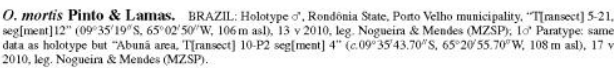
O. nemesis Ris, 1909. BRAZII: 10? Minas Gerais State, SAo Joato del Rei municipality, xii 1956, leg. A.B.M.
Machado (MZSP) [E-ABMM collection]

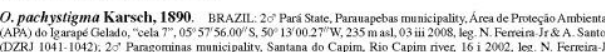

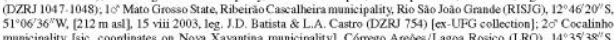

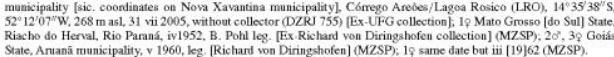

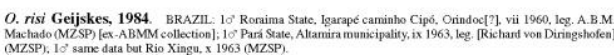

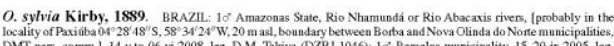

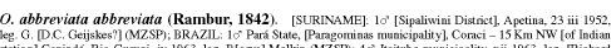


Oligoclada mortis sp. nov. 303

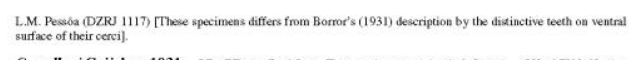

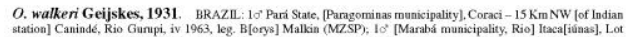

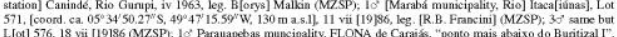

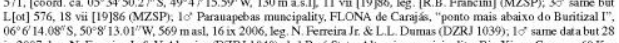

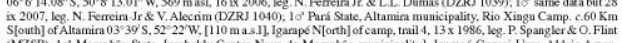

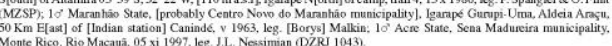
Monte Rico, Riø Macauas, 05 xi 1997, leg, J.L. Nessimian (D2RU 1043).

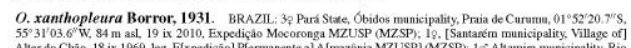

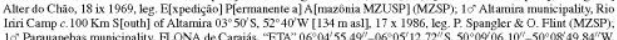

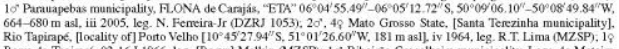

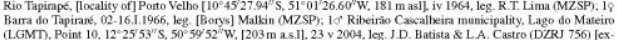

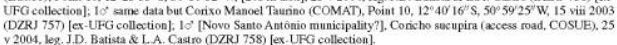
V2004, leg. J.D. Batista \& L.A. Casaro (D2R) 758) [ex UFG collection]

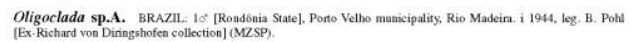

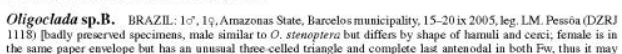
correspond to another specicss!

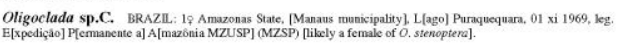


ISSN 1061-8503

\section{ARGIA}

The News Journal of the Dragonfly Society of the Americas

Volume 23 17 March 2011

Number 1

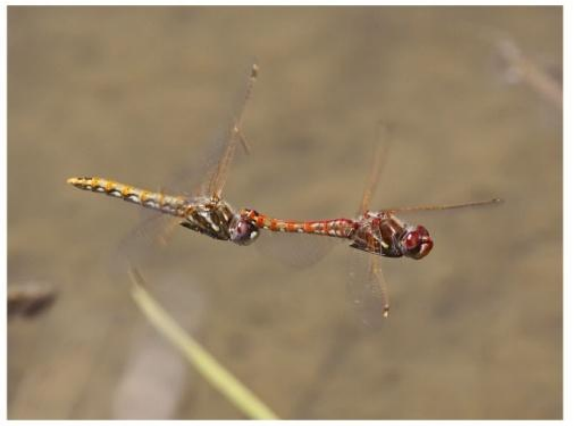

Published by the Dragonfly Society of the Americas

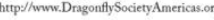

$\underset{\text { ArGiA }}{\text { In This lssu }}$

In This Issue...

2011 DSA Southeast Regional Mecting in Clayton, Geongia, by Giff Beaton and Marion Dobbs o

It's bection Time

CalOder/DSA Califormia Dragonfly Blitz, by Kathy Biggss

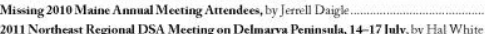

Syoziro Asalina: 1913-2010, by T.W. Donnelfy

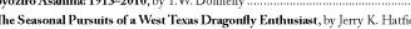

A Call for Papere for BAO.

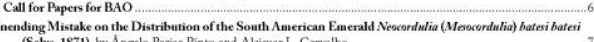

1937-2010: Odonata Associated with the Muddy River Watershed in Clark County, Nevadu, by Bruce Lund and Alan Myru

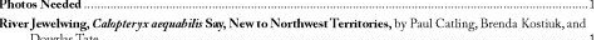

Dragonflise of Ives Road Fen Preserve, by Burton C.Cebulki and Chelsey J. Cebult

Wetland Mititigation Sites Can Provide Excellent Odonate Hahtat, by $\mathrm{C}$. DSA is on Faceboot

Announcing Daumselfies of Teass: A Field Guide, Bry John Abb

Annoencing Book on the Odonata of the Delmarra Peninsalla, by Hal Whitc
Unending Mistake on the Distribution of the South American Emerald Neocordulia (Mesocordulia) batesi batesi (Selys, 1871)

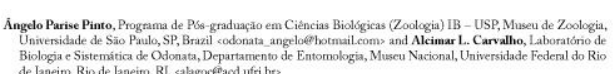

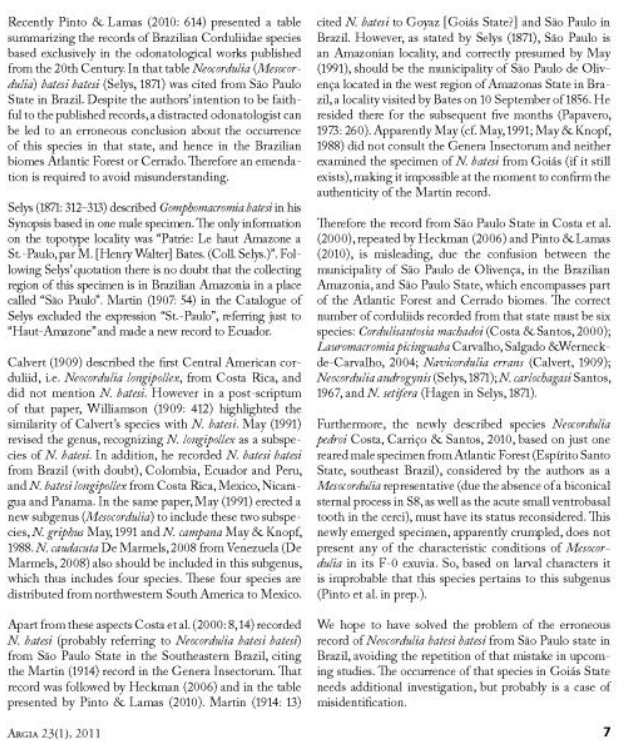

Acknowledgements

We wish to express our sincere thanks to Dt. Jesical
Ware (at least for her attempt and M. Sc. Daniclle Anjis

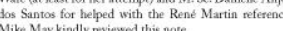

Literature Cited

Calvert P.P. 1909. The irst Central American corduline

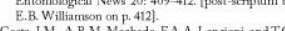

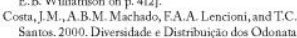

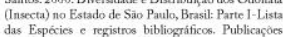

Avulusas do Museu Nacional 80: 1-27.

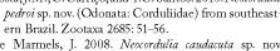

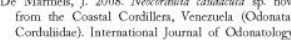

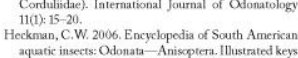

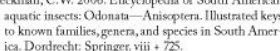

May, M. 1991. A review of the genus Necerrdalia, with a

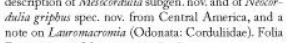
Entromolkgica Mexicana 82: 17-6.

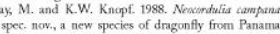

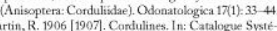

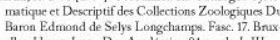

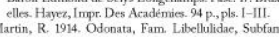

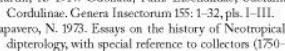
dipterology, with special referencec to collectors (1150-
1905). Vol. III Sio Panlo: Musue de Zoologia Univer-

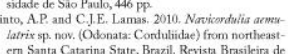

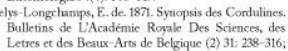

937-2010: Odonata Associated with the Muddy River Watershed in Clark County, Nevada

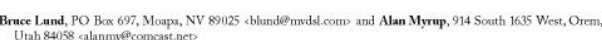

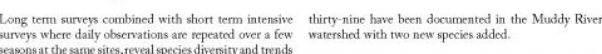

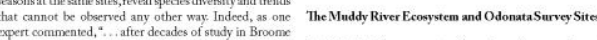

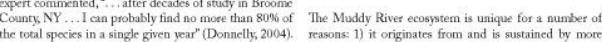

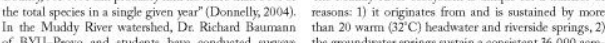

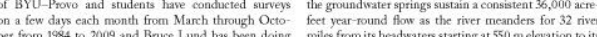
dalysurtees in all months, but mainly from May thrugh

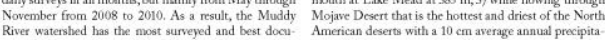

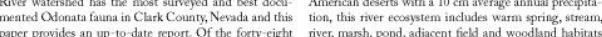

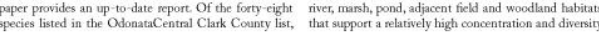

8 
0.7. Neotropical Entomology [ISSN 1519-566X] - 2011

\begin{tabular}{|c|}
\hline 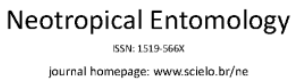 \\
\hline
\end{tabular}

SYSTEMATICS, MORPHOLOGY AND PHYSIOLOGY

Description of the Female of Navicordulia aemulatrix Pinto \& Lamas and

AP PINTO ${ }^{12}$, CIE LAMAS

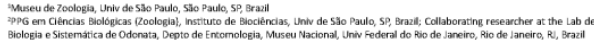

Kenwords
Anisoptera, Cordullinae, drag onfly,
merphology, trachory

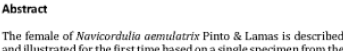

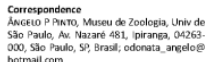

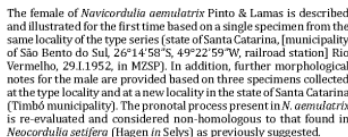

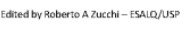

Receciod 17 Mar 2011 and accepped 30 Jut

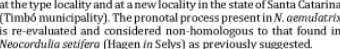

Introduction

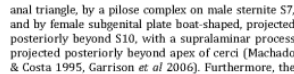

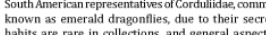

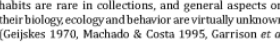

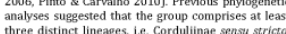
three distinct lineages, i.e. Cordullinae sensu strictci
GSt-group (Gomphomacrominae, syntremistinae an

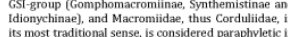

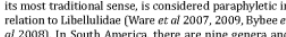
al 2008 ). In South America, there are nine genera and
44 species of cordulids reeconized, with 11 species

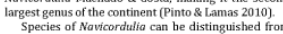

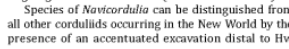

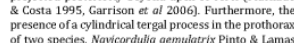

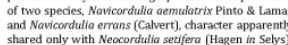
Navicordulfia aemulaterix was recently describe
based on three males. The specimens were collected in the locality of a deactivated railway station named
kio Vermelho in the municipality of Säo Bento do Sul atte of Santa Catarina southern Brazil (Pinto \& Lam

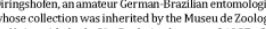
Wisiversidade de SAo Paulo in the year of 1987 after 698 Nestop Enomol ano

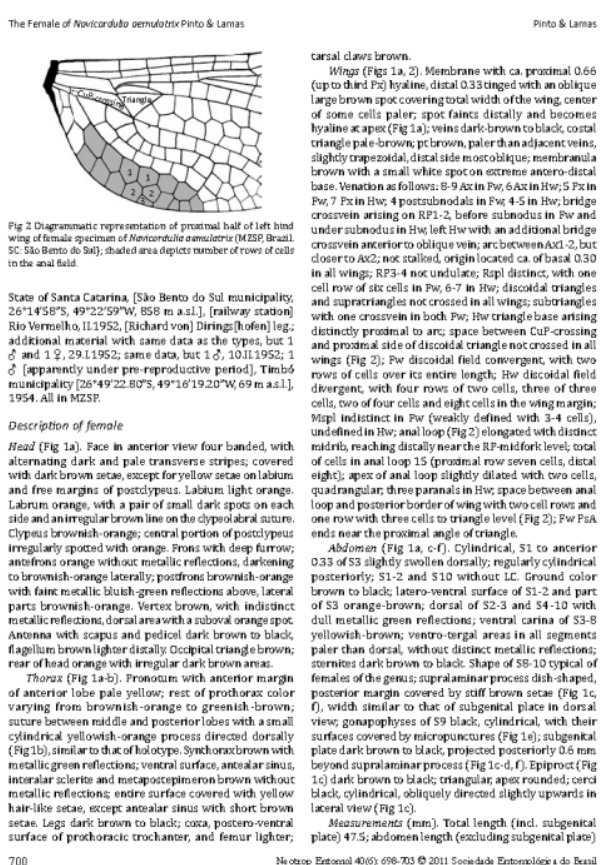

Prnto \& Lamas

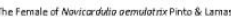

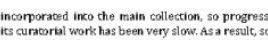

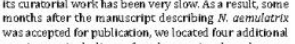

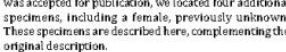

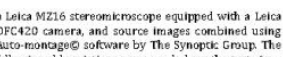

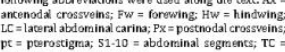

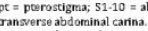

Specimens exannined are deposited in che Musseu

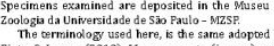

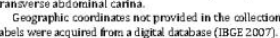

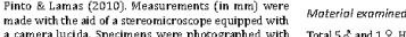

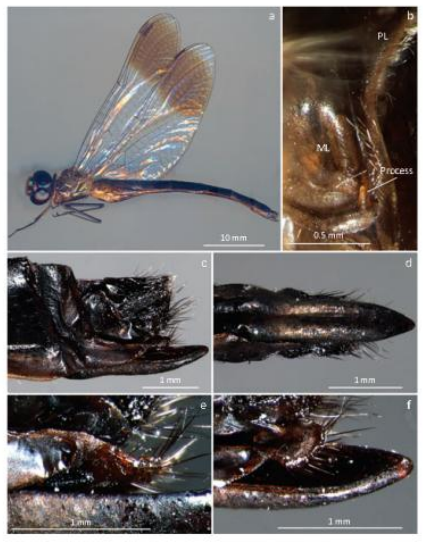

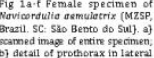

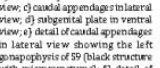

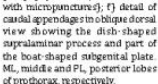

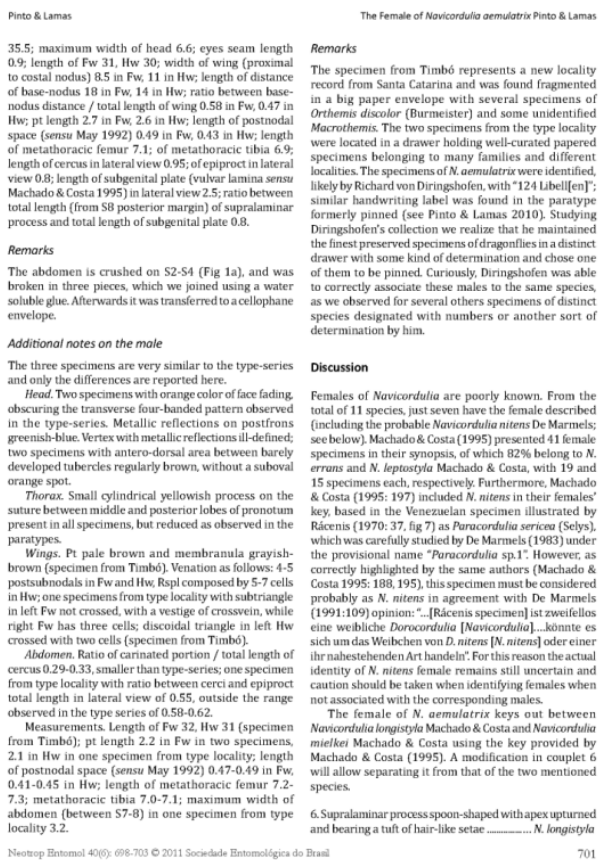




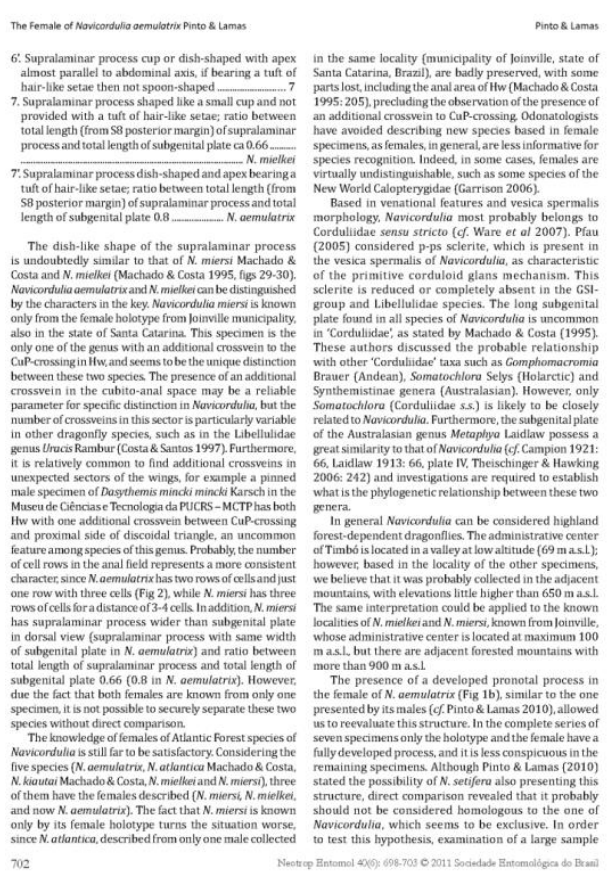

Pmos oums

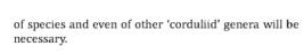

Acknowledgments

We thank Sónia A. Casarir (MZSP curator of Aquatic
Insects collection). Dr. Alcimar L C Carvalho (MNR)

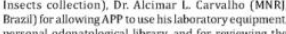

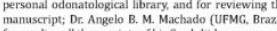

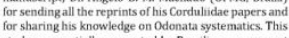

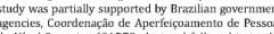

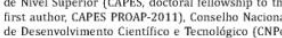

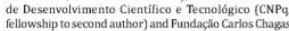

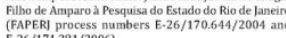

References

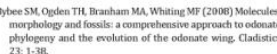

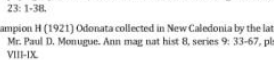

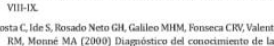

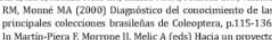

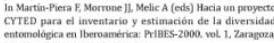

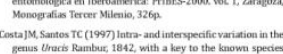

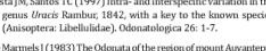

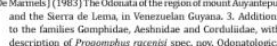

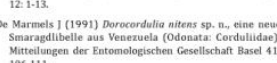

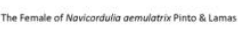

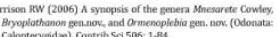

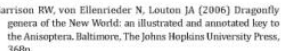

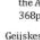

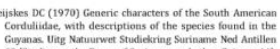
sit)

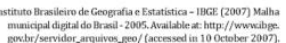

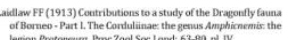

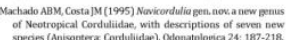

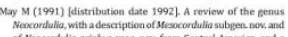

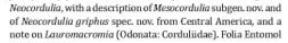

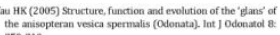

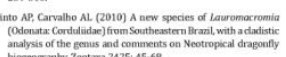

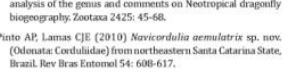

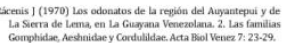

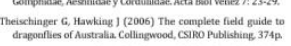

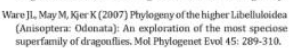

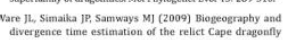

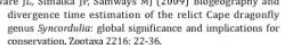




\section{Bulletin of Zoological Nomenclature [ISSN 0007-5167] - 2012}

Case 3584

Erythemis Hagen, 1861: proposed precedence over Lepthemis Hagen,

Angclo Parise Pinto

Programa de Pós-Graduação em Ciências Biológicas (Zoologia) IB - USP

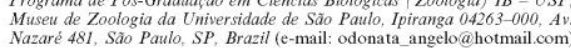
Rosser W. Garrison

California Department of Food \& Agriculture, 3294 Meadowview Road (c-mail: rosser-garrison $a$ cdfa.ca.gov)

Dennis R. Paulson

Slater Museum of Natural History, University of Puget Sound, Tacoma

Thomas W. Donnelly

2091 Partridge Lame, Binghamton NY 13903, U.S.A.

(e-mail: tdonelly@binghamton.edu)

Michael L. May

Rutgers University, New Brunswick, NJ 08901, U.S.A.

Abstract. The purpose of this application, under Articles 23.9.3 and 81.1 of the Code, is to conserve the widespread usage of the generic name Erythemis Hagen, 1861 for a group of common dragonties from the New World over the simulaneously First Reviser action (Article 24.2), whenever these names are considered to be synonyms. This proposal seeks to achieve the least change in the nomenclature of the species currently placed in these two genera, in strict accordance with Principle 4 of the Code.

Keywords. Nomenclature; taxonomy; Insecta; Odonata; LBEELLLIDAE; Erythemis; Lepthemis, Erythemis perwiana; Mesothemis, dragonflies; New World.

1. Hagen (1861), in a work dealing with North American species, established three genera for the reception of several new and previously described species of New World dragonflies. The first, Lepthemis (p. 160) included three species, Libelluta
vesiculosa Fabricius, 1775 , Libellula haematogastra Burmeister, 1839 and Libellula Hagen, 1861, Libellula bicolor Hoffmannsegg in Erichson, 1848 and Erythemis

Bulletin of Zoologial Nomenchature 6922) Jume 2012

(excluding nomina nuda and those that do not satisfy the provisions of Article 67.2), even when appearing on different pages, should be considered as names originally
included under provisions of the Article 6721 , and all are eligible for type species fixation. This validates Kirby's (1889, p. 305 ) act fixing Libellula peruvima Ramb 1842 as type species of the nominal genus Erythemis Hagen, 1861 . Kirby very likely
followed Hagen's advice that Libellula peruviana was the same species as $L$. bicolor Hoffimannsegg in Erichson, 1848, and chose it as the type specice

4. Kirby (1890, p. 40), followed by Calvert (1906, p. 30), considered Libellula
bicotor a junior synonym of Libellula peruviana. Calvert (1906, p. 30-31) established synonymy between Erythemis and Mesothemis and chose Erythemis as senic synonym based on page priority. Since Calvert (1906), Mesothemis as a genus-grou name was rarely used, with most citations up to 1940 referring to its type species p. 50: Ahrens, 1938, p. 14; Ferguson, 1942, p. 148). After 1940, Mesothemis has been listed as a junior 8synonym consistently except for two eoological studies where it was
cited as a valid genus (Polcyn, 1994, p. 443), and a subgenus (Harrison \& Lighton, 1998, p. 1739

5. The number of names included under Lepthemis has fluctuated from the original eight (Hagen, 1861, pp. 160-162, 316), to five (Hagen, 1877, pp. 73-74), then to 11 Calvert (1907, p. 3239), foll these last two works simply listed species-group names. entire family, reduced this number to one, its type species $L$. vesiculosa, and this was the only name associated with the genus from 1907 to $195 \%$.

6. The number of names included under Erythemis has fluctuated from the origina ork again simply listed species-group names. Williamson (1923, pp. 8-10), in his review of the genus, reduced this number to nine, a number which remained stabl
until 1957 ?

7. Lepthemis Hagen, 1861 and Erythemis Hagen, 1861 were considered valid genera
until Kennedy's (1923, p. 20) evaluation of members of these two genera. He suggested that Erythemis and Lepthemis (and the Old World Rhodothemis Ris, 1909 ) could be congeneric based on vesica spermalis (penis) morphology, but he did not
formally synonymise them . The writer would be inclined to call the whole serices of five or six groups Lepthemis and would consider the individual groups as
ond subgenera...' and '...The comprehensive genus would have to be Lepthemis becaus of the [page] priority in the use of that name by Hagen...) 8. Rácenis (1958, p. 217 [footnoted], following Kennedy's noncommittal opinion cited above, and acting as the First Reviser, formally synonymised Erythemis an opinión, Lepthenis Hagen, 1861 y Erythemis Hagen, 1861 son congenéricos merecen solamente el status de subgéneros. Para emplear el nombre Lepthemis par este genero, vease tambien las opimiones de Kennedy (1923)' 'In my opinion. Lepthemis ingen opinions of Kennedy (1923)!?

9. Gloyd (1980, p. 104) discussed the dual use of the generic names Lepthemis (with one species) and Erythemis (with 11 [sic!] species), noting that ....page priority is no
Bulletin of Zoological Nomenclature 692) Jume 2012

93

longipes Hagen, 1861. The third, Mesothemis (p. 170) included Libellula simplicicollis Say, 1840, Mesothemis collocata Hagen, 1861, Mesothemis corrupta Hagen, 1861,
Mesothemis illota Hagen, 1861, Libellula attala Selys in Sagra, 1857, Libellyla nithra Selys in Sagra, 1857 and Libellula longipermis Burmeister, 1839 as valid species. Ho also listed Libellula acuta Say, 1840 as a synonym of Lepthemis vesiculosa (p. 161 ), Libelluta caerulans Rambur, 1842 and Libellula maculiventris Rambur, 1842 a synonyms of Libellula simplicicollis (p. 170), Libellula ammulata Rambur, 1842 (partim, nec Libellula amulata Palisot de Beauvois, 1807) as a synonym of Libelluw truncatula Rambur, 1842 as synonyms of Libellula longipennis (p. 173). 2. In that same work Hagen (1861), in his 'List of South American Neuroptera'
(pp. 316-318), included fifteen more species in these three genera. Under the nominal genus Lepthemis (p. 316) five more species were cited, two already described species. Libellula cardinalis Erichson, 1848 and Libellula attemuata Erichson, 1848, and he introduced the following new species-group names: Lepthemis picta Hagen, 1861,
Lepthemis extensa Hagen, 1861 and Lepthemis cultriformis Hagen, 1861, all of them us nomina nuda since they do not sat sisy the provisions of Artice 12 of the Code. For Erythemis (pp. 317-318) he included two more species-group names: Libellula perwiana Rambur, 1842 and Libellula rubriventris Blanchard, 1845, and added Erythemis lavata Hagen, 1861 (a nomen nudum). Finally for Mesothemis (p. 318) te included seven more
plebejar, 1842, Libellula comata Burmeister, 1839, Libellula communis Rambur, 1842, Libelluta distinguenda Rambur, 1842 and Libellula abbreviat Rambur, 1842, and again introduced a nomen nudum, Mesothemis giva Hagen,
1861. All of these species-grour names listed by Hagen (1861, pp. 160-173, 316-318 1861. All of these species-group names listed by Hagen (1861, pp. 160-173, 316-318
encompass originally included nominal species (Article 67.2.1), rendering each of the encompass originally included nominal species (Article 67.2.1), rendering each of the

hree genera.
3. Kirby (1889), by subsequent designation, fixed Libellula vesiculosa Fabricius,
1775 as type species for Lepthemis Hagen, 1861 (p. 302), Libellula simplicicollis Say 1840 as type species for Lepthemis Hagen, 1861 (p. 302), Libellula simplicicollis Say, Rambur, 1842 as type species for Erythemis Hagen, 1861 (p. 305). Although it can be argued that Libellula peruviama was not a name originally included in the nomin genus Erythemis, which would render Kirby's type fixation invalid under Artic
67.25 of the Code, Hagen (1861 Erichson, 1848, p. 583), suggested synonymy with Libellula pervviana Rambur, 1842 ('Is it different of Libellula perwiama Rambur?') although he (Selys, 1850, p. 398 carlier had considered both as synonyms ('Dans le Voyage de Schomburgk au Brés et a la Guyane, M. Erichson a decrit sous le nom de Lib. bicolor la Lib. pennviana, M. Hagen... In the Voyage of Schomburgk in Brazil and Guyana, Mr Erichso addition, Hagen (1861, p. 318) included in his List of South American Neuroptera Libellula penuviana in Erythemis, a species for which he had previously (p. 169) and
again (p. 318) sugested synonymy with Libellula bicolor Hoffmannsegg in Erichson, again (p. 318) suggested synonymy with Libellula bicolor Hoffmannsegg in Erichson,
1848 ('Perhaps $E$. bicolor'). Even though Libellula perwitiana Rambur, 1842 was

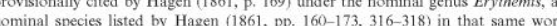

Bullecin of Zoological Nonendarture 69(2) June 2012
longer considered adamant in the choice of a name' genera are eventually proven to be congeneric, then retaining the name Erythemis would evoke less change.' She cautioned against a synonymy pending a thorough 10. Usage of either name during the last 50 years (1960-2011) shows an inconsistency of use for the ten species presently constituting these two genera. Only
six citations, Lutz \& Pittman (1970, pp. 280-281, 283), Paulson (1977, p. 180; 1982 six citations, Lutz \& Pittman (1970, pp. 280-281, 283), Paulson (1977, p. 180; 1982 ,
p. 266), Sherk (1977, p. 394; 1978, p. 62), and Fleck (2004, pp. 53-54) followed p. 266), Sherk (1977, p. 394; 1978, p. 62), and Fleck (2004, pp. 53-54) followed
Rácenis (1958, 1959) in using Lepthemis as senior synonym for all ten species; 25 citations consider Erythemis and Lepthemis as valid genera; and over 120 citations by at least 65 different authors consider Erythemis a senior synonym (full list of citations available from the authors). Current usage of Erythemis as senior synonym is overwhelmingly predominant in the literature. One common species from the Eastern
United States, Erythemis simplicicollis, has been the subject of studies in age United States, Erythemis simplicicollis, has been the subject of studies in age
maturation (McVey, 1985), behavior (Belle \& Whitcomb, 1961; Currie, 1963; Edwards, 1987; Sanborn, 1996), sexual selection and sperm competition (McVey Smittle, 1984; Waage, 1986; McVey, 1988), physiology and parasitology (May, 1976,
1979; McVey, 1984; Harrison et al., 1994; Painter et al., 1996; Locklin \& Vodopich, 2010), taxonomy (Donnelly, 2004a); it appeared in numerous illustrated odonate fiel guides and faunal lists (Dunkle, 1989; Abbott, 2001, 2005, 2006; Curry, 2001; Nikula
et al., 2002, 2003: Legler et al., 2003; Manolis, 2003; Mead, 2003: Biggs, 2004 et al, 2002, 2003; Legler et al., 2003; Manolis, 2003; Mead, 2003; Biggs, 2004 ; Silsby, 2001: Corbet, 2004: Triplehorn \& Johnson, 2005; Evans, 2007). There are also numerous taxonomic references, checklists, handbooks and textbooks where species placed under Erythemis, Lepthemis and Mesothemis have been included all together under Erythemis in South America (Rodrigues-Capitulo, 1992; Costa \& Pujol-Luz, Ellenrieder \& Muzón, 2008): Central America Measey, 1994: Boomsma \& Dunkle, 1996; Ramirez, Paulson \& Esquivel, 2000; Förster, 2001); North America (GonzilezSoriano \& Novelo-Gutiérrez, 1996; Dunkle, 2000; Needham et al., 2000; Donnelly, 2004b; Paulson, 2009), or the whole of the New World (Davies \& Tobin, 198 Garnis 1 . for publiction (Pinto \& Caryallho, in prep) shows a ll 10 specin the final stage Erythemis and Lepthemis to be congeneric, necessitating the choice of eithe Lepthemis or Erythemis as senior synonym. Setting aside the senior synonym Lepthemis in favor of the almost universally used Erythemis would cause the leas change in nomenclature and would promote stability for this group of dragonflice, some of which have been the subject of grudies in behavior and serual selection. Applying the rule of First Reviser (Article 24.2.1 of the Code) would not promote

12. The International Commission on Zoological Nomenclature is accordingly
stabity of nonclature (Principle 4 of Cole. asked

to use its plenary power to rule that the generic name Erythemis Hagen, 1861
be given precedence over Lepthemis Hagen, 1861, whenever the two are considered to be synonyms; 
(2) to place on the Official List of Generic Names in Zoology the name Erythemis Hagen, 1861 (gender: feminine), type species by subsequent designation by
Kirby (1889) Libellula peruviana Rambur, 1842 , with the endorsement that it
is to be given precedence over Lepthemis Hagen, 1861, whenever these two names are considered synonyms;

(3) to place on the Official List of Generic Names in Zoology the name Lepthemis Hagen, 1861 (gender: feminine), type species by subsequent designation by
Kirby (1889) Libellula vesiculosa Fabricius, 1775 , with the endorsement that it is not to be given priority over Erythemis Hagen, 1861, whenever these two names are considered synonym

(4) to place on the Official List of Specific Names in Zoology the following names: perviama Rambur, 1842, as published in the binomen Libellula perviama. 1848, specific name of the type species of Erythemis Hagen, 1861:

(b) vesiculosa Fabricius, 1775 , as published in the binomen Fibellula losa, specific name of the type species of Lepthemis Hagen, 1861 .

\section{Acknowledgement}

We thank Alcimar L. Carvalho (Musen Nacional, Rio de Jameiro), Jürg De Marmels (Universidad Central de Venezuela, Maracay), Jan van Tol (Naturalis, Leiden), and
Natalia von Ellenrieder (California Department of Food \& Agriculture, Sacramento) for advice and help with this application, and the two Commissioners who reviewed the application.

\section{References}

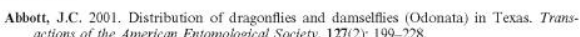

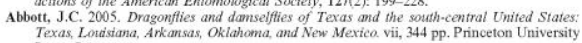
Press, Princeton.
Abbott, J.C. 2006. Dragonfities and damselffies (Odonata) of Texas, vol. I. vii, $320 \mathrm{pp}$. Odonata Survey of Texas Austin.
Ahrens, C. 1938. A list of dragonflies (Odonata) taken in southern Alaska. Entomotogical News, 49:225-227.
Arnett, R. H. 2000 . American insects, A hand book of the insets of Americanorth of Mexico. Ed. 2. xvii, 1003 pp. CRC Press, Boca Raton.
Beaton, G. 2007 . Dragonffies \& damselffies of Georgia and the Sotutheast. ix, 355 pp. The University of Georgia Press, Athens.
Behrstock, R.A. 2008. Dragonfies \& damselffies of the Southwest. 80 pp. Rio Nuevo Publishers, Bell, R. \& \& Whitcomb, W.H. 1961. Enythemis simplicicolilis (Say), a dragonfly predator of the Bollworm Moth. The Florida Ditomologist, 44(2): $95-97$.
Belle, J. 1978. Dragonfly records from Highlands County, Florida, United States. Notulae

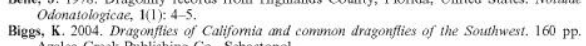
Boomsma, T. \& Dunkle, S.W. 1996. Odonata of Belize, Odonatotogica, 25(1): 17-29. Brauer, F. 1868. Verzecichniß der bis jetzt bekannten Neuropteren im Sinne Linne's. Verhand-

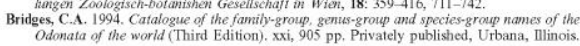

Gloyd L.K. 1980. The status of the generic names Erythemis, Lepthemis, and Mesothemis
(Anisoptera: Libellulidae). Notulae Odonatologicicae, 16): 103-104.

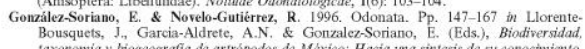

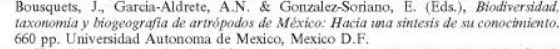

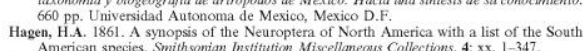

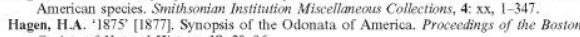
Soctety of Natural History, 18: $20-96$.
Harrison, J.F. \& L Lighton, J.R.B. 1998. Oxygen-sensitive fight metabolism in the dragontly

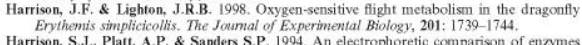

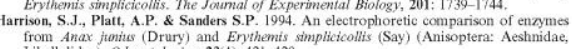
from Anax tatits (Drury) and Erythemis
Libellulidae, Odonatologica, 23(4): $421-429$.

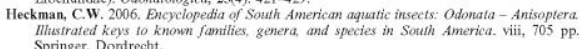
Entomological News, 44: 40 ,

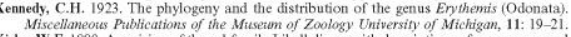

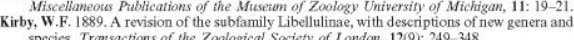
species. Transactions of the Zoological Society of London, 12 19:249-348.
Kirby, W.F. 1890. A synonymic catalogute of Neuroptera Odonata, or dragonffies, with an appendix of fossit species, ix, 202 pp. Gurney \& Jackson, London.
Legler, K., Legler, D. \& Westover, D. 2003. Color guide to dragonfties of Wisconsin. Ed. 4.0.68 pp. Amberwing publishing, Sark Cit.
Locklin, J.L. \& Vodopich, D. 2010 Fugs

at a constructed wetiand: a fitness cost for females? (Anisoptera: Libellulidae). Odonato logica, 39(4):319-331.
Lutz, P.E. \& P Pitman, A.R. 1970. Some ecological factors influencing a community of adult

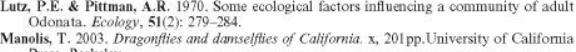
Press, Berkeley.

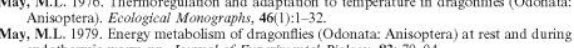

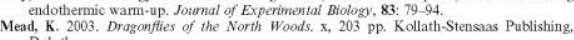
Measey, G.J.J. 1994. Some Odonata from Belize, Central America. Notulae Odonatologicae,
4.3. 40.46 McVey, M.E. 1984. Egg release nates with temperature and body size in libellulid dragonflies

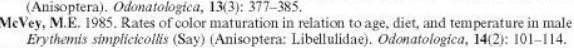
MeVey, M.E. 1988. The opportunity for sexual selection in a territorial dragonfly, Erythemi timplicicollis. Pp. 44.58 in Cutton-Brock, T.H. (Ed.), Reproductive successs studies of
individual variation in contrasting breeding systems, ix, 548 pp. University Chicapo Press

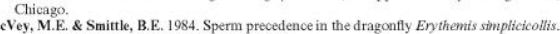
Jourmal of Insect Physiotogy, 30(8): $619-628$.
Needham, J.G. \& Heywood, H.B. 1929 . A handbook of dragonffies of North America

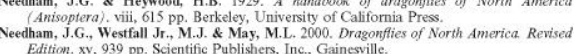

Bulletin of Zoological Nomenclature 69(2) June 2012

Burmeister, H. 1839. Handhuch der Entomologie, v. 2, part 2. Pp. 757-1050. Enslin, Berlin.
Calvert, P.P. 1906. Nomenclature of certain North American Odonata. Entomological News Calvert, P.P. 1907. Odonata. Pp. 17-420. In: Godman, F.D. \& Salvin, O. (Eds.), Biologia London.
Crralho, A.L. \& Pujol-Luz, J.R. 1992. On the odonate fauna of llha Grande and some othe cosstal islands of the State of Rio de Janeiro, Brazil. Notulae Odonatologicae, $3(10)$
$157-159$. Carvalho, A.L. \& Nessimian, J.L. 1998. Odonata do Estado do Rio de Janeiro, Brasil: hábitat

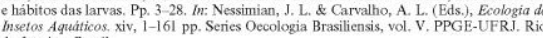

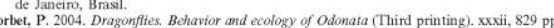
Comstock Publishing Associates, Ithaca,
Costa, J.M., Machado, A.B.M., Lencioni, F.A.A. \& Santos, T.C. 2000. Diversidade o

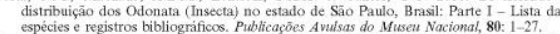
Costa, J.M. \& Pujol-Luz, J.R. 1993. Descricisio da larva de Erythemis mithroides (Brauer)
notas sobre as larvas conhecidas do genero (Odonata, Libellulidae). Revista Brasilera

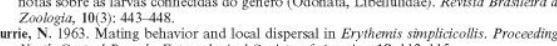
North Central Branch, Entomological Society of America, 18: 112-115.

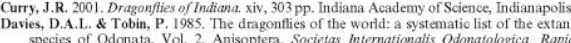

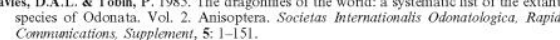

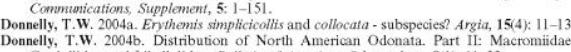

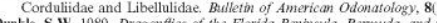
Scientific Publishers, Gainessille.
Dunkle, S.w. 2000. Dragonffies throtght brocculars vii, 266 pp. Oxford University Press Edwards, G.B. 1987. Predation by adult Enythemis simplicicollitis (Say) on spiders (Anisoptera)

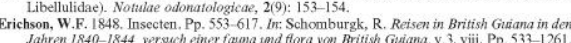

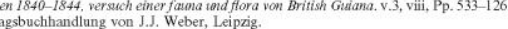
A.E. 2007. Feld gudde to insects and spiders of North America. 497 pp. Sterling

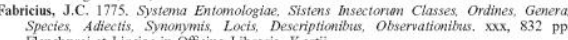
Ferguson, A. 1942. Scattered records of Texas and Louisiana Odonata with additional notes on
the Odonata of Dallas County. Field and Laboraton, 10 (2): 145-149.

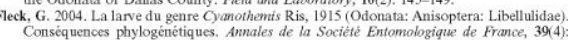

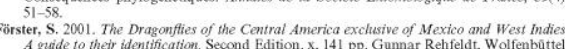
Germany. 1991 . Synonymic list of New World Odonata. Argia, 3(2): 1-30.
Garison, R.W.
Garrison, R.W., wo Ellenrieder, N. \& Louton, J.A. 2006. Dragonfty genera of the New World an ilhustrated and annotated key to Anisoptera. xiv, 368 pp. The Johns Hopkins University
Press, Baltimore.
Bulletin of Zoological Nomenclature 69(2) June 2012

Nikula, B., Sones, J., Stokes, D. \& Stokes, I. 2002. Stokes beginner's guide to dragonffites an

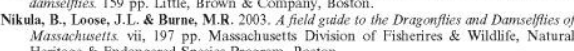
Heritage \& Endangered Species Program, Boston.
Heg6, Effects of repeated applications

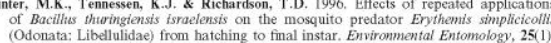
184-191.
ulson, D.R. 1977. Odonata. Pp. 170-184 in Hurlbert, S.H. (Ed.), Biota Acuatica de

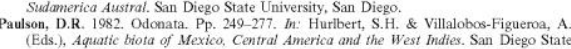

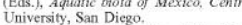
Paulson, D.R. 2009. Dragonffies of the West. 535 pp. Princeton University Press, Princeton.
Pinto, AP. 200 .

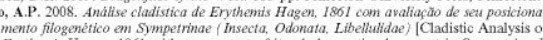
Eyythemis Hagen, 1861 with assessment of its phylogenetic placement in Sympetrina xiv, 144 pp. URRJ / MN, Rio de Janeiro. [Dissertation presented in the post-graduate
program in Biological Sciences (Zoology/UPRJ, as requirement for degree of Master o Sciencel.

Pinto, A.P. \& Carrallo, A.L. in preparation]. A morphological cladistic analysis of Enythemis
Hagen, 1861 and the sionificance of . conce test of characters for homology statements of wing venation in Anisoptera (Odonata).
Polcyn D. D. 1994. Thermoregulation during summer actity in Mojave Desert dragonflies

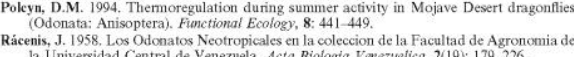
Rácenis, J. 1958. Los Odonatos Neotropicales en la coleccion de la Facultad de Agronomia
la Universidad Central de Venezuela Acta Biofogia Venezteflica, 2(19): $1799-226$ Rambur, P. 1842. Histoire naturelle des insectes. Netroppteres. i- $\mathrm{i}$-xvii, 534 pp. Librair Encyclopédique de Roret, Paris.
Ramirez, A., Paulson, D.R. \& Esquivel, C. 2000. Odonata of Costa Rica: diversity and checklis

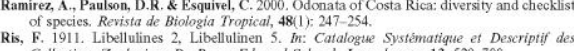

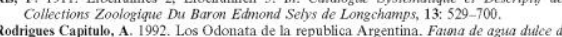
la Repabilica, Argentina, $34(1) 1-191$. anborn, A.F. 1996. The cicada Diceroprocta delicata (Homoptera: Cicadidac) as prey for the
dragonfly Enythemis simplicicollitis (Anisoptera: Libellulidae), Florida Entomologist, 79(1):

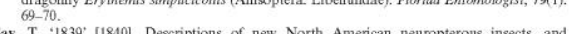
Say, T. '1839' [1840]. Descriptions of new North American neuropterous insects, and
observations on some already deseribed. Jotamal of the Academy of Natural Sciences of

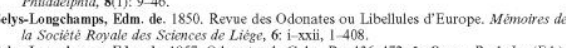

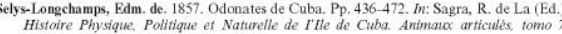
35.473. Arthus Bertrand Editeur, Paris. Sherk, T.E. 1977. Devdoppent of the compound eyes of dragonflies (Odonata). L. Larval
compound eves. Joumal of Experimental Zooloyy, 201(3): 391-416 Sherk, T.E. 1978. Development of the compound eyes of dragonflies (odonata). III. Adul

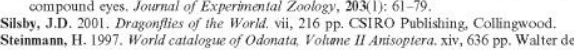




$$
100 \text { Bulletin of Zoologial Nomenclature 69(2) June } 2012
$$

Triplehorn, C.A. \& Johnson, N.F. 2005. Borror and Delong's introdiction to the study of insect.

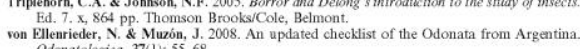
Waage, J.K. 1986 . Sperm displacement by two libellulid dragonflies with disparate copulation

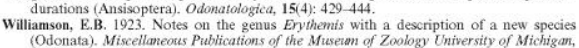
(Odonata)
11: $1-18$.

Acknowledgement of receipt of this application was published in BZN 69: 83 .

Comments on this case are invited for publication (subject to editing) in the Budlethin; they
should be sent to the Executive Secretary, LCCZ.N., do Natural History Museum, Cromwell Road, London SW7 SBD, U.K. (e-mail, ican@ntm.ac.uk). 


\section{Deutsche Entomologische Zeitschrift [ISSN 1860-1324] - 2012}
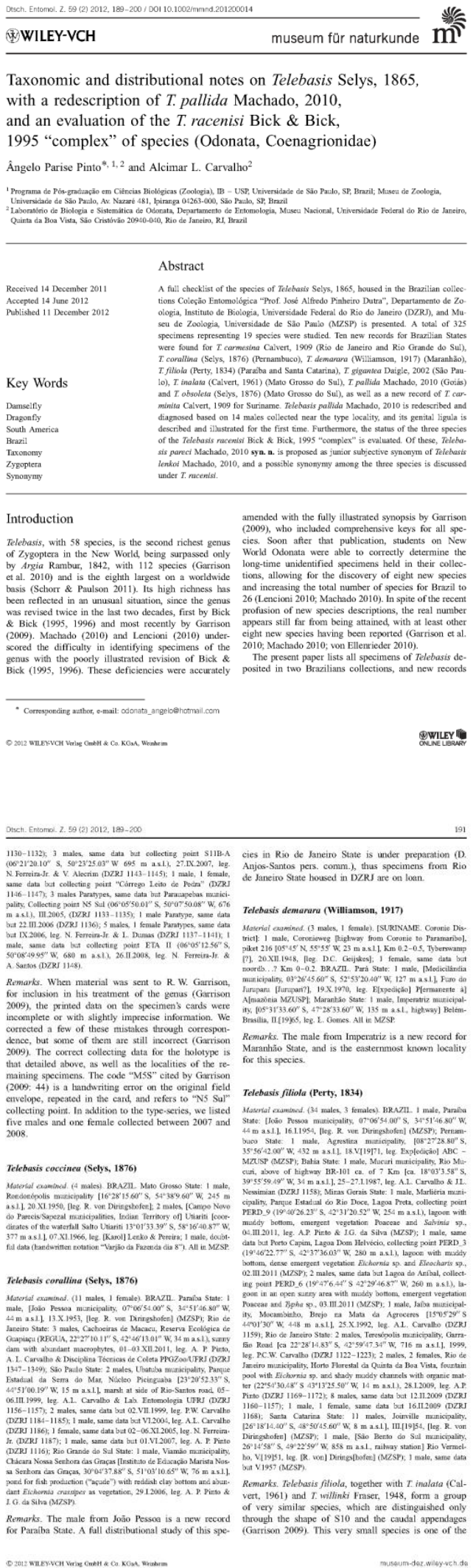
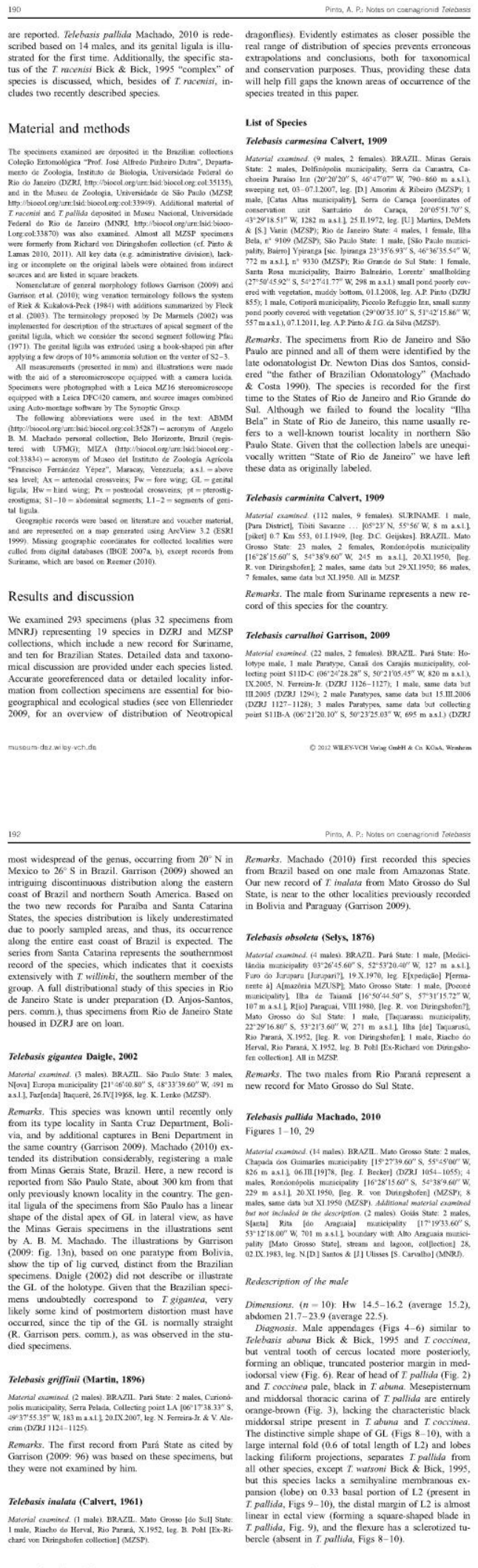


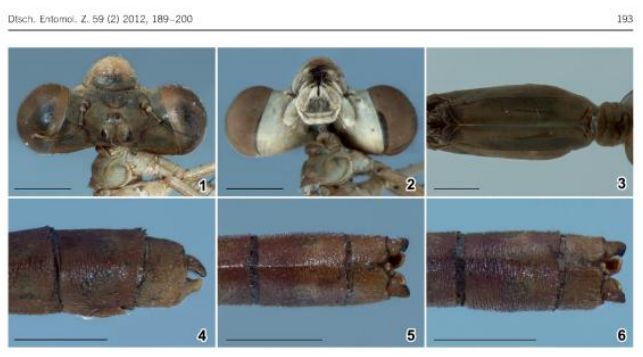

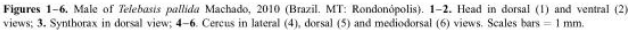

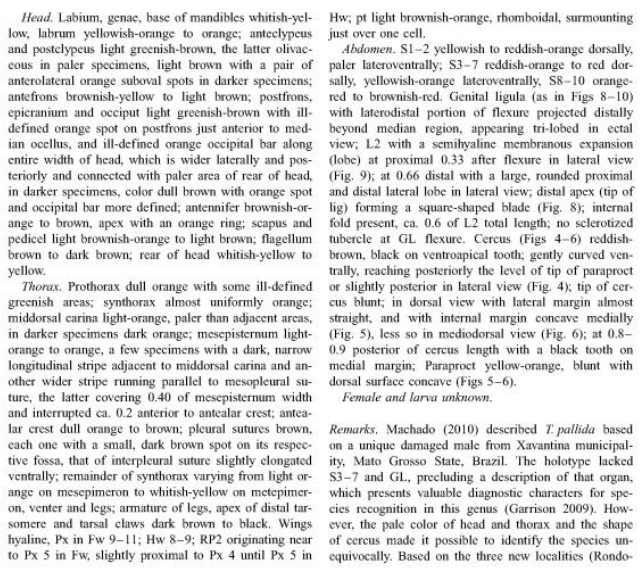

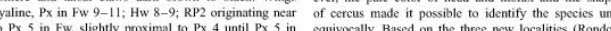
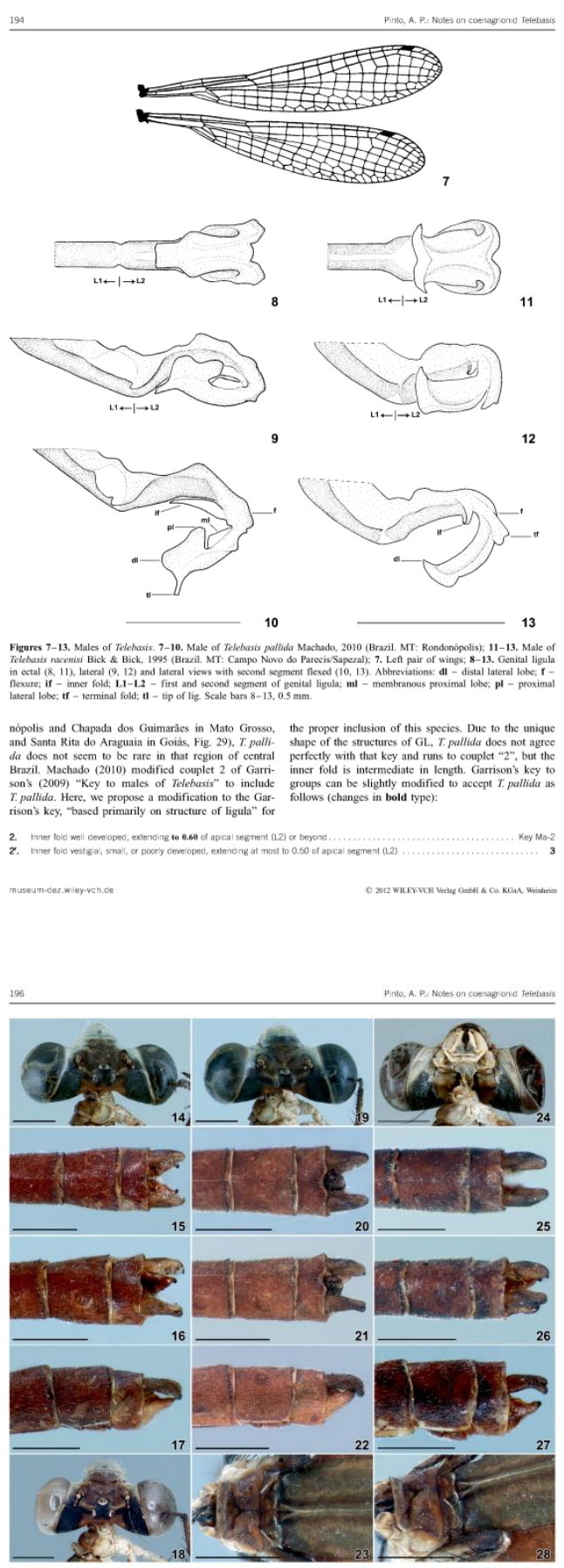

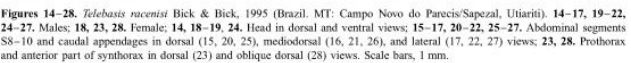

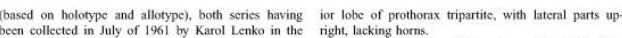

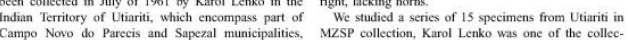

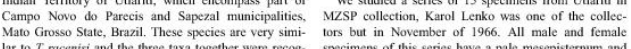

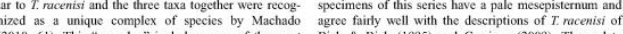

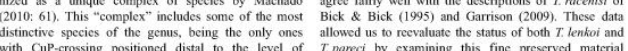

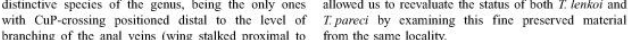

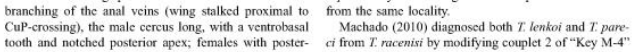

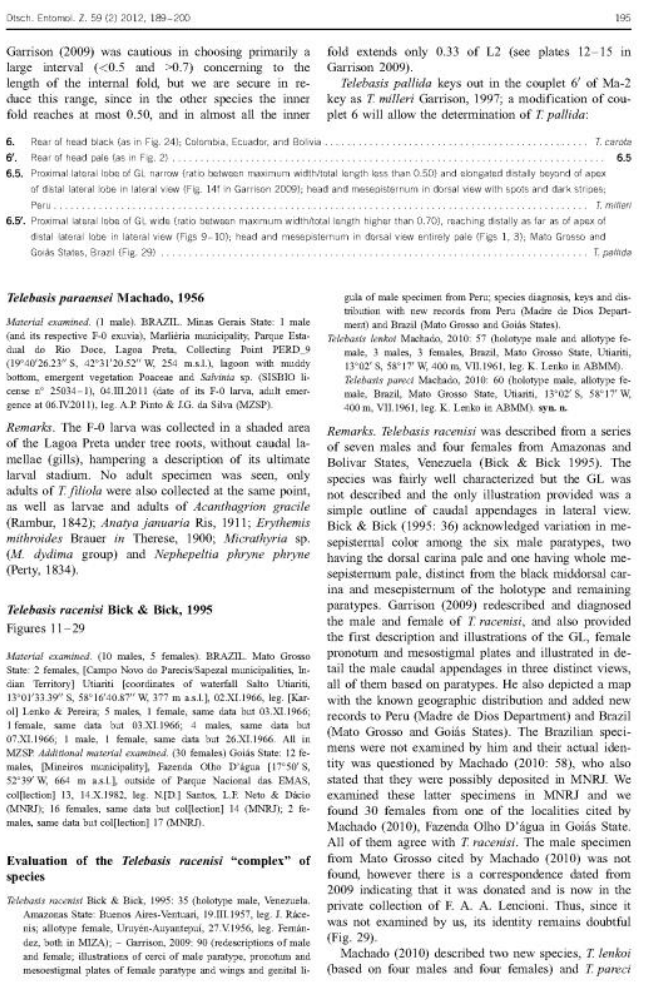




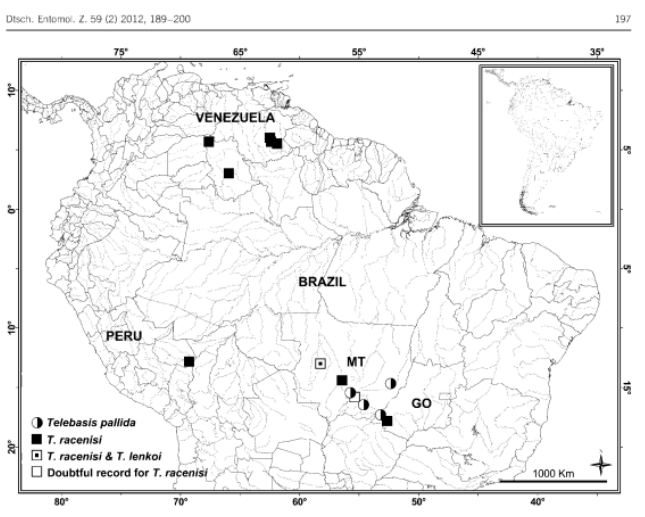

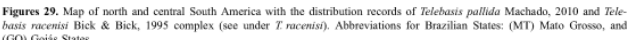

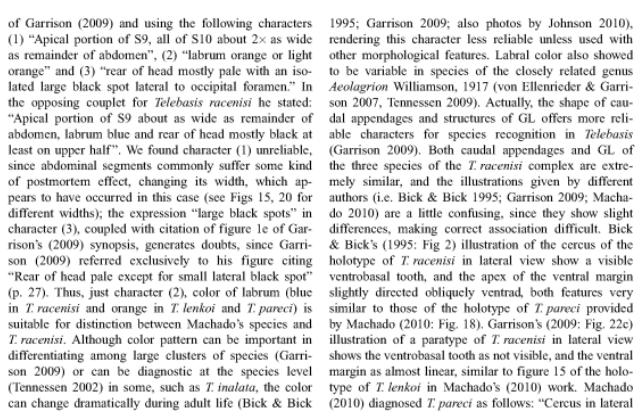

los

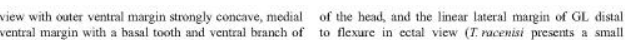

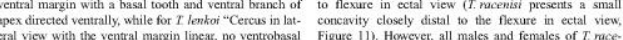

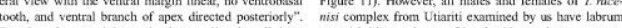

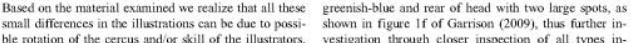

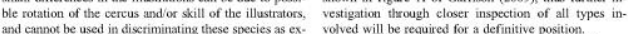

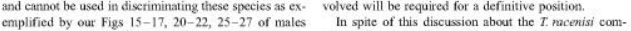

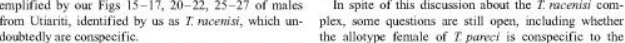

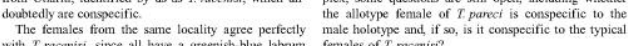

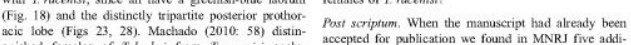

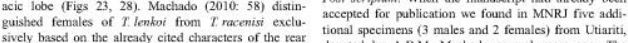

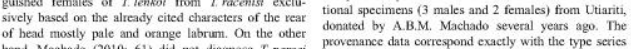

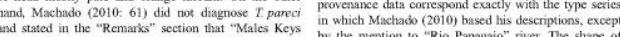
to M.4 and femates so T.5.

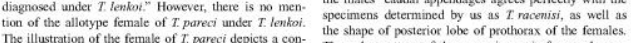

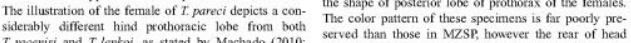

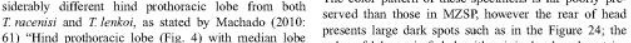

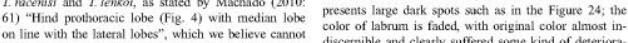

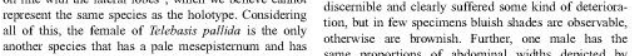

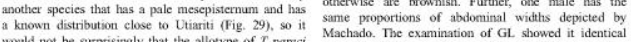

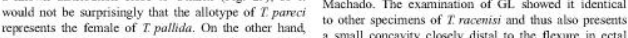

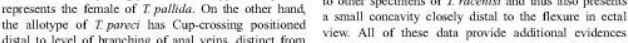

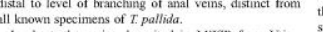

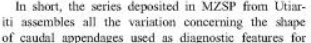

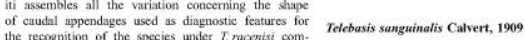

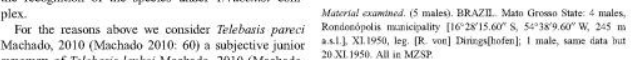

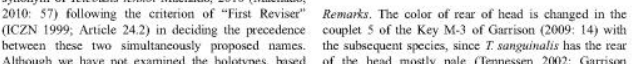

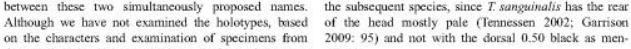

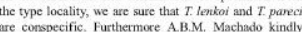

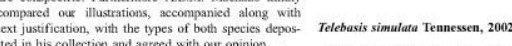

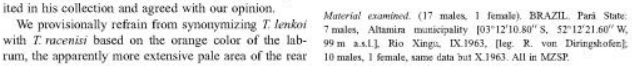

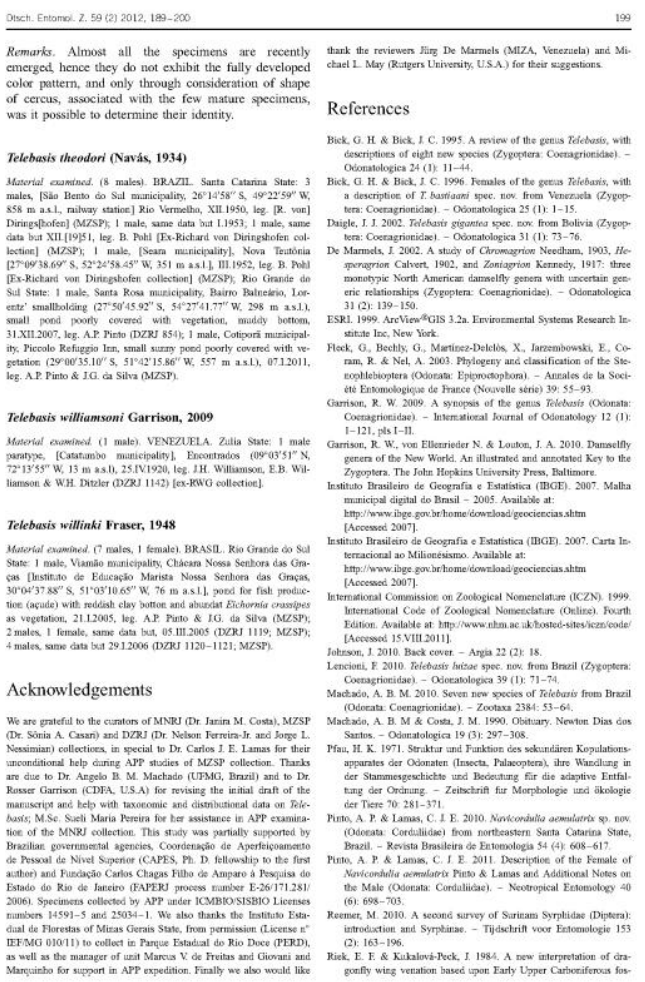

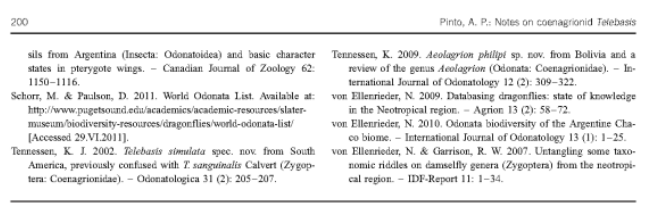

